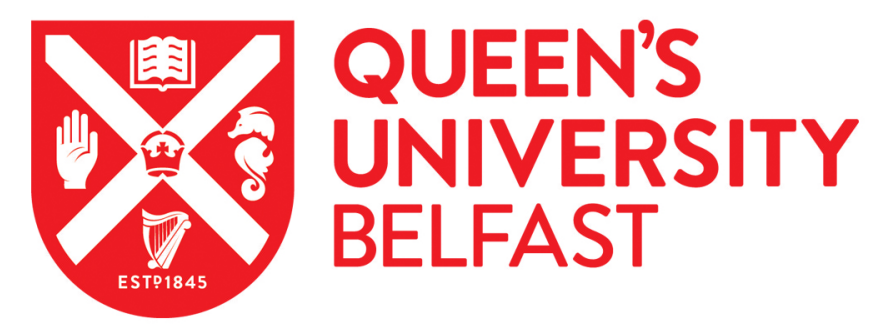

\title{
Speed of Sound and Ultrasound Absorption in Ionic Liquids
}

Dzida, M., Zorębski, E., Zorębski, M., Żarska, M., Geppert-Rybczyńska, M., Chorą̇ewski, M., Jacquemin, J., \& Cibulka, I. (2017). Speed of Sound and Ultrasound Absorption in lonic Liquids. Chemical Reviews, 117(5), 3883-3929. https://doi.org/10.1021/acs.chemrev.5b00733

\section{Published in:}

Chemical Reviews

\section{Document Version:}

Peer reviewed version

Queen's University Belfast - Research Portal:

Link to publication record in Queen's University Belfast Research Portal

\section{Publisher rights}

(C) 2017 American Chemical Society after peer review and technical editing by the publisher.

This work is made available online in accordance with the publisher's policies. Please refer to any applicable terms of use of the publisher.

\section{General rights}

Copyright for the publications made accessible via the Queen's University Belfast Research Portal is retained by the author(s) and / or other copyright owners and it is a condition of accessing these publications that users recognise and abide by the legal requirements associated with these rights.

Take down policy

The Research Portal is Queen's institutional repository that provides access to Queen's research output. Every effort has been made to ensure that content in the Research Portal does not infringe any person's rights, or applicable UK laws. If you discover content in the Research Portal that you believe breaches copyright or violates any law, please contact openaccess@qub.ac.uk. 


\section{Speed of sound and ultrasound absorption in ionic liquids}

Marzena Dzida ${ }^{1 *}$, Edward Zorębski ${ }^{1}$, Michał Zorębski ${ }^{1}$, Monika Żarska ${ }^{1}$, Monika Geppert-

Rybczyńska ${ }^{1}$, Mirosław Chorążewski ${ }^{1}$, Johan Jacquemin ${ }^{2,3}$ and Ivan Cibulka ${ }^{4}$

${ }^{1}$ University of Silesia, Institute of Chemistry, Szkolna 9, 40-006 Katowice, Poland

${ }^{2}$ School of Chemistry and Chemical Engineering/QUILL, Queen's University Belfast, Belfast

BT9 5AG, United Kingdom

${ }^{3}$ Université François Rabelais, Laboratoire PCM2E, Parc de Grandmont 37200 Tours, France

${ }^{4}$ University of Chemistry and Technology, Department of Physical Chemistry, Technická 5, 166

28 Prague, Czech Republic

*E-mail: mhd@ich.us.edu.pl 


\section{ABSTRACT}

A complete review of the literature data on the speed of sound and ultrasound absorption in pure ionic liquids (ILs) is presented. Apart of the analysis of data published to date, the significance of the speed of sound in ILs is regarded. An analysis of experimental methods described in the literature to determine the speed of sound in ILs as a function of temperature and pressure is reported and the relevance of ultrasound absorption in acoustic investigations is discussed. A careful attention was paid to highlight possible artifacts, side phenomena related to the absorption and relaxation present in such measurements. Then, an overview of existing data is depicted to describe the temperature and pressure dependences on the speed of sound in ILs, as well as, the impact of impurities in ILs on this property. A relation between ions structure and speeds of sound is presented by highlighting existing correlation and evaluative methods described in the literature. Importantly, a critical analysis of speeds of sound in ILs vs. those in classical molecular solvents is commented to compare these two classes of compounds. The last part presents the importance of acoustic investigations for chemical engineering design and possible industrial applications of ILs. 


\section{CONTENTS}

1 Introduction

2 Experimental methods and data treatment

2.1 Speed of sound measurements

2.2 Relationship between speed of sound and ultrasound absorption

2.2.1 Ultrasound absorption measurements

2.2.2 Effect of ultrasound absorption on speed of sound measurements

2.3 Overview of existing data for ionic liquids

2.4 Data treatment

3 Speed of sound in ionic liquids

3.1 Temperature and pressure effects

3.2 Effect of impurities on speed of sound measurements

3.3 Effect of ion structure on the speed of sound in ionic liquids

3.4 Critical analysis of the speed of sound in ionic liquids vs. classical molecular solvents

4 Calculation of volumetric properties and thermodynamic formalism

$5 \quad$ Existing correlations and evaluative methods

5.1 Empirical models 


\subsection{Theoretical models}

\section{Outlook}

\section{ABBREVIATIONS}

\section{ACKNOWLEDGMENT}

\section{SUPPORTING INFORMATION}

\section{REFERENCES}

\section{Introduction}

This review focuses on the speed of sound and ultrasound absorption in ionic liquids (ILs), which are substances that: (i) are composed of ions, and (ii) their melting points lie in below 373 K. Thus, in a formal sense, ILs can be treated as subset of molten salts. These materials are generally considered to be a novel, diverse and an extremely attractive class of chemical compounds with unique and tunable properties; hence, research on them is progressing very quickly. These "designer" compounds gained rapidly the curiosity and the interest of many research groups from both academia and industry especially due to their very low volatility. Subgroups of this ionic liquid class of compounds that are based on aprotic and protic ILs can be distinguished. Measurements of the speed of sound in pure ILs have been undertaken either to 
study the nature of the molecular interactions, structure and packing effects or to obtain the key thermodynamic properties of ILs for applications in chemical and industrial processes. Nevertheless, research into the speed of sound is relatively new, with the first articles on the subject published in $2004^{1,2}$, while the first IL was discovered in $1888 .^{3}$ However, 164 papers that are related to the speed of sound in ILs have been published over the following decade (2004 2014). To our knowledge, only one comprehensive, up-to-date review concerning the speed of sound in ILs has been published by Wu et al., ${ }^{4}$ whose review describes a correlation between the speed of sound and thermal conductivity of ILs. Among available ILs databases, only the Ionic Liquids Database - ILThermo (v2.0) (NIST Standard Reference Database \#147) is related to the speed of sound; this database was updated on August 7, 2015. ${ }^{5}$ Nowadays, an increasing amount of research groups is focusing their efforts on the data collection and understanding of this emerging, unique and crucial property field.

The speed of sound, sound velocity, and ultrasonic velocity are frequently used terms that describe the speed at which an ultrasound wave propagates in a liquid. In this work, the term "speed of sound", $u$, refers to propagation of ultrasonic waves at low frequencies $f$ (i.e., as independent on frequency at low-frequency limit, $\lim u(f \rightarrow 0))$. In other cases, the term ultrasound velocity is used. Liquids also absorb sound waves, which provides information on the relaxation time, structural arrangements in the liquids, and bulk viscosity. Moreover, the dispersion of the ultrasound velocity provides a method of studying relaxation phenomena connected with the energy exchange mechanisms at a molecular level in liquid systems by direct measurements or indirectly by measuring the absorption of ultrasonic waves.

Most of the problems that should be solved in each speed of sound experiment are dictated by side phenomena that must be identified and controlled. ${ }^{6}$ The correctness of measurements of the 
speed of sound depends, not only on the purity and viscosity of the liquid, but also on the frequencies of the ultrasound waves that propagate through a liquid. In other words, care must always be exercised when deciding whether the measured speed of sound is indeed the thermodynamic quantity to be used to calculate relevant derived properties. Particular attention should be paid to avoid ultrasound velocity dispersion from relaxation effects, which occurs because the relaxation frequency not only lies well within the usual frequency range of ultrasonic measurements but also depends on experimental conditions, such as the temperature and pressure ranges within which the measurement is recorded. With the exception of liquids that show rotational isomerisms, ${ }^{7,8}$ the ultrasound velocity dispersion in classical organic liquids occurs usually at frequencies above the ultrasonic range that is generally used in experiments. Thus, the speed of sound that is determined with available equipment is mostly the thermodynamic speed. However, some ILs exhibit dispersive effects at relatively low frequency range. Thus, the speed of sound measured with available equipment is a non-thermodynamic speed and cannot be used subsequently for determining relevant derived quantities. For non-dissipative and homogenous liquid systems, the speed of sound at frequencies where the liquid does not exhibit any dispersion can be regarded as a purely thermodynamic property that is related to the density and isentropic compressibility by the Newton-Laplace equation (see Section 4). Furthermore, the measurement of the speed of sound is the only direct way to determine the isentropic compressibility, which then provides the further access to related thermodynamic properties of the liquid phase (both at ambient and high pressures). The prior knowledge of the isentropic compressibility provides then an indirect, the most accurate and convenient means of calculating the isothermal compressibility of liquid. Additionally the isochoric heat capacity data are generally obtained indirectly from the experimentally determined speed of sound, isobaric heat capacity, and isobaric expansibility. Speed of sound measurements, because of their simplicity and accuracy, are a broadly used 
technique in the investigation of liquids and are essential in construction and for the validation of fundamental equations of state. ${ }^{9-11}$ The usability and practical aspects of speed of sound measurements for the characterization of liquids can be found in the Povey’s monograph. ${ }^{6}$ While the speed of sound is connected with thermodynamic properties of the liquids, the absorption of ultrasound waves probes the energy dissipation caused by various irreversible processes taking place in liquids during ultrasound wave propagation. Furthermore, it is the only way to determine the volume viscosity of the liquids. Absorption measurements can also contribute significantly to improve the knowledge of the microscopic and macroscopic properties of ILs. This is, in fact, very important as ILs are strongly dissipative, much more than classical molecular solvents. The first article devoted on ultrasound absorption has been published in 2006, ${ }^{12}$ however such measurements are only occasional, to date. Herein, this review focuses on four main aspects. First, this review highlights and describes a number of technical and procedural problems, artifacts, and side phenomena (i.e., absorption, relaxation) that arise from measurements of the speed of sound in ILs. Second, this paper describes a critical overview of experimental speed of sound (and absorption) data to assist readers to extract correct information regarding the speed of sound in ILs from the available literature and to prevent the above mentioned errors. Third, this paper highlights correlation and predictive methods that are applied to the speed of sound in ILs. The last aspect concerns the effect of the structure of ions on the speed of sound in ILs. Speed of sound measurements have been used to describe and understand the nature of molecular interactions in ILs.

\section{Experimental methods and data treatment}

\subsection{Speed of sound measurements}


As mentioned in the Introduction, speed of sound measurements in pure ILs were first reported in 2004. ${ }^{1,2}$ These reports came relatively late in the modern history of these compounds. Only single data points at $298.15 \mathrm{~K}$ were reported in the abovementioned papers. More systematic acoustic investigations started in 2005 and covered a broader range of temperatures from $298.15 \mathrm{~K}$ to $318.15 \mathrm{~K}^{13}$ and pressures from $0.1 \mathrm{MPa}$ to approximately $151 \mathrm{MPa}{ }^{14,15}$ The increasing interest in speed of sound measurements in ILs over the following decade produced 142 papers that reported experimental speed of sound $u$, and/or ultrasound velocity $u(f)$ values in pure ILs from various measuring methods and apparatuses.

In these 142 papers, the apparatuses based on transient grating, pulse-echo-overlap or singaround methods were underused, whereas the most popular was the time of flight $(76.6 \%$ of the data) technique because of its application in commercially available apparatuses from the AntonPaar DSA series. The second most frequently used measuring method $(13.5 \%)$ is the interferometric method, which is also not surprising because such apparatuses are commercially available as well (Ultrasonic Interferometers from Mittal Enterprises). A general summary of the popularity of all the methods that are used for both speed of sound and ultrasound velocity measurements in ILs is shown in Figure 1. 


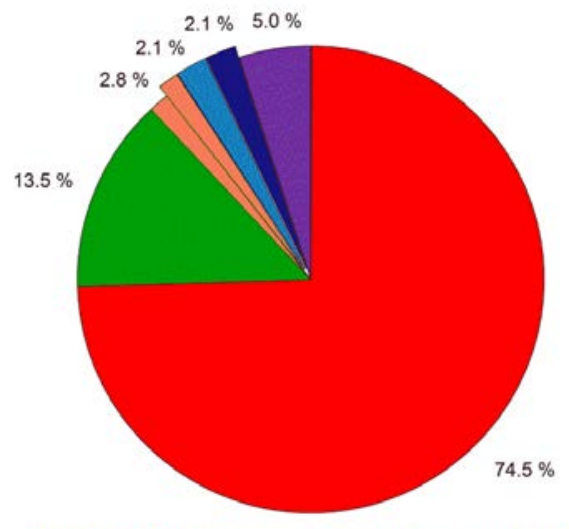

Anton Paar DSA, interferometers, transient grating, sing around pulse-echo-overlap, time of flight (other measuring sets)

Figure 1. Methods described in the literature for speed of sound and ultrasound velocity measurements in ILs. Parts put forward-non-commercially available measuring sets

Generally, the classification of the methods that are used for speed of sound measurements is not uniform and depends on assumed criteria. However, all the methods can be divided into two categories: (i) acoustic methods and (ii) optic methods. Acoustic methods that are based on a constant acoustic path length include the time of flight technique, pulse-echo-overlap, and singaround methods, and those that are based on a variable path length are represented here by ultrasonic interferometers. The other type of method is the transient grating method, which can be classified as an optic method because the presence of an acoustic wave is preceded by the creation of laser-induced gratings in a sample. Another two classifications cover methods that are based on (i) pulse and continuous wave techniques and (ii) single and dual transducer techniques. The time of flight technique, pulse-echo-overlap, and sing-around methods use relatively short burst pulses to determine the speed of sound, while ultrasonic interferometers work with 
continuous waves. Although broadband stimulation is generally possible, a tone burst stimulation from one to several tens of periods generally provides better results.

Also other classification of measuring sets exists, i.e., for group and phase velocity determination. The phase velocity $u_{f}=\lambda \cdot f$ is related to the group velocity $u_{g}$ as follows:

$u_{g}=u_{f}-\lambda \cdot \frac{d u_{f}}{d \lambda}$

where $\lambda$ is the wavelength and $f$ is the frequency of acoustic waves. $u_{g}$ corresponds to the propagation velocity of the energy through the sample, and $u_{f}$ is the propagation velocity of a given phase of a sinusoidal wave. The group velocity is equal to the phase velocity only if

$\frac{d u_{f}}{d \lambda}=0$; hence, correct measurements of speed of sound with apparatuses that are intended for group velocity investigations can be collected only in a non-dispersive region.

As shown in Table 1, typical representatives of such apparatuses are sing-around and time of flight meters, whereas interferometers belong to phase speed meters. When some conditions regarding the width of acoustic pulses (at least a dozen periods) and spectral purity of the wave are fulfilled, we may also include the echo- pulse-overlap and transient grating methods to phase velocity measurements methods.

Constructing an acoustic cell is very important for any ultrasonic measurements. This cell should be made of chemically resistant material, and its dimensions should provide good propagation conditions for acoustic waves. For acoustics investigations, similarly as for investigations other physicochemical properties of ILs, the most favorable is equipment that uses as small a volume of the sample as possible (for economic reasons); however, this approach may 
produce serious errors. For instance, when the diameter of the acoustic cell is too small, undesirable side-walls reflections and interferences of ultrasonic waves may appear. Similarly, an excessively small distance between transducers can cause entry in the near field with complex diffraction patterns. However, because ILs are rather moderate or highly absorbing substances for ultrasonic waves, the acoustic path should be short enough to avoid situations where acoustic pulses fade. One of the smallest acoustic cells that have been applied for the speed of sound measurements in ILs had a volume of $0.8 \mathrm{~cm}^{3}$ and an emitter-receiver distance of $9 \mathrm{~mm} .{ }^{16}$ On the other hand, the longest acoustic path, $50 \mathrm{~mm}$, was used in a sing-around measuring cell. ${ }^{25}$ The most frequently used apparatuses to measure the speed of sound in ILs are the coupled density and sound analyzers DSA series (see Figure 1), which have an acoustic flow cell with $5 \mathrm{~mm}$ length. 
Table 1. Methods and Instruments Used for Speed of Sound Measurements in ILs

\begin{tabular}{|c|c|c|c|c|c|c|c|}
\hline Method & Apparatus & $\begin{array}{l}\text { Acoustic } \\
\text { path }\end{array}$ & $\begin{array}{l}\text { Sample } \\
\text { volume }\end{array}$ & Uncertainty & $\begin{array}{c}\text { Main advantages and } \\
\text { disadvantages }\end{array}$ & Velocity & Remarks \\
\hline \multirow[t]{3}{*}{ Time of flight } & DSA series & constant & са. $3 \mathrm{~mL}$ & $\pm 0.5 \mathrm{~m} \cdot \mathrm{s}^{-1 c}$ & $\begin{array}{l}\text { (:) combined density and } \\
\text { speed of sound } \\
\text { measurements }\end{array}$ & group & $\begin{array}{l}\text { Only for non-dispersive } \\
\text { samples }\end{array}$ \\
\hline & $\begin{array}{l}\text { Home-made } \\
\text { sets }^{14-17}\end{array}$ & constant & $\begin{array}{l}0.8-\text { ca. } 10 \\
\mathrm{~mL}\end{array}$ & $\begin{array}{l} \pm 0.05 \%,^{17} \\
\pm 0.2 \%{ }^{14-16}\end{array}$ & $\begin{array}{l}\text { c) easy to use in } \\
\text { comparison with other } \\
\text { home-made sets }\end{array}$ & group & $\begin{array}{l}\text { Only for non-dispersive } \\
\text { samples; suitable for the } \\
\text { use also under high } \\
\text { pressures }\end{array}$ \\
\hline & $\begin{array}{l}\text { Home-made } \\
\text { set }^{18}\end{array}$ & constant $^{a}$ & са. $7 \mathrm{~mL}$ & $\pm(10-40) \mathrm{m} \cdot \mathrm{s}^{-1}$ & $\begin{array}{l}\text { (:) combined } \\
\text { measurements of the } \\
\text { speed of sound and } \\
\text { ultrasound absorption }\end{array}$ & group & Accuracy can be improved \\
\hline Interferometric & $\begin{array}{l}\text { Mittal } \\
\text { Enterprises } \\
\text { series }\end{array}$ & variable & ca. $10 \mathrm{~mL}$ & $\pm(0.02-0.2) \%$ & $\begin{array}{l}: \text { sophisticated high- } \\
\text { precision mechanical } \\
\text { system; } \\
\text {;) direct method }\end{array}$ & phase & $\begin{array}{l}\text { Measurements with } \\
\text { continuous wave; high } \\
\text { absorbing samples cause } \\
\text { uncertainty increase }\end{array}$ \\
\hline $\begin{array}{l}\text { Transient } \\
\text { grating }\end{array}$ & $\begin{array}{l}\text { Home-made } \\
\text { sets }^{12,19-24}\end{array}$ & constant $^{b}$ & $\leq 10 \mathrm{~mL}$ & $\pm(0.5-2) \%$ & $\begin{array}{l}: \text { complicated } \\
\text { calibration; } \\
: 0 \text { necessity of an } \\
\text { absorbing dye for a } \\
\text { transparent medium }\end{array}$ & phase $^{\mathrm{c}}$ & $\begin{array}{l}\text { Optic method; suitable for } \\
\text { measurements at high } \\
\text { frequencies of the acoustic } \\
\text { waves; not recommended } \\
\text { for high quality results at } \\
\text { low frequencies }\end{array}$ \\
\hline \multirow{2}{*}{ Sing-around } & $\begin{array}{l}\text { Home-made } \\
\text { set }^{25,26}\end{array}$ & \multirow{2}{*}{ constant } & & & $\begin{array}{l}\text { (:) high precision; } \\
\text { (:) easy automation }\end{array}$ & group & $\begin{array}{l}\text { Only for non-dispersive } \\
\text { samples; better for relative }\end{array}$ \\
\hline & $\begin{array}{l}\text { NuSonic } \\
\text { Analyzer }^{27,28}\end{array}$ & & non available & $\pm 0.02 \%$ & & & $\begin{array}{l}\text { (differential) than absolute } \\
\text { measurements }\end{array}$ \\
\hline $\begin{array}{l}\text { Pulse-echo- } \\
\text { overlap }\end{array}$ & $\begin{array}{l}\text { Home-made } \\
\text { set }^{29,30}\end{array}$ & constant & са. $10 \mathrm{~mL}$ & $\pm 0.5 \mathrm{~m} \cdot \mathrm{s}^{-1}$ & $\begin{array}{l}\text { :) high versatility } \\
\text { :) application in the } \\
\text { laboratory praxis } \\
\text { relatively complicated }\end{array}$ & phase $^{d}$ & $\begin{array}{l}\text { Suitable for the use also } \\
\text { under high pressures }\end{array}$ \\
\hline
\end{tabular}


As stated by some authors, ${ }^{31,32}$ this specific sandwiched sound speed cell geometry requires the implementation of a very rigorous cleaning procedure, much more rigorous than what has been suggested by the manufacturer. This general suggestion is especially important in the case of ILs because of the sensibility of their physicochemical properties.

Apart from the transient grating method, ultrasonic investigations are conducted by using transducers, usually piezoceramic discs or x-cut quartz crystals that operate at various frequencies from $0.5 \mathrm{MHz}^{16}$ to $11.3 \mathrm{MHz}^{18}$ (3 $\mathrm{MHz}$ in DSA apparatuses as well as mostly $2 \mathrm{MHz}$ or $4 \mathrm{MHz}$ in interferometers). These transducers are very often covered with a protective layer, which improves their durability but can create wave distortion and diminish the achieved accuracy of the measurements. Generally, there are three versions of measuring cells: (i) with a single emitting-receiving transducer and an acoustic reflector, ${ }^{29,33}$ (ii) with two separate transducers, ${ }^{25}$ and (iii) with a single transducer and two oppositely placed reflectors. ${ }^{17}$ The parallelism of the acoustic surfaces is generally an essential condition for performing correct measurements and must be preserved over the entire range of the reflector's movement in devices with a variable acoustic path length. The above problem is obviously more important when the wavelength becomes shorter (e.g., in water at $298 \mathrm{~K}$ and $1 \mathrm{MHz}, \lambda=1.5 \mathrm{~mm}$; at $4 \mathrm{MHz}, \lambda=0.375 \mathrm{~mm}$ ). One should pay attention to the possibility of the dispersion of the sound velocity interconnected with the choice of measurement frequency as the dispersion in some ILs may occur at relatively low lowerfrequencies, around a few $\mathrm{MHz} .^{34}$

With the exception of ultrasonic interferometers, where only testing prior to the measurements is necessary, ${ }^{35,36}$ calibration with standards of well-known speed of sound values must be made. Several liquids with different speed values should be used to achieve high precision. The closer the speed of sound values in the standard and measured liquid, the better the 
results that can be achieved. Unfortunately, very few standards exist in practice. The most popular is the redistilled water, ${ }^{37,38}$ which is also suitable for high-pressure measurements. ${ }^{39}$ Measurements from the transient grating method are often preceded by calibration and tests with entire sets of molecular liquids. ${ }^{20}$

In the time of flight technique, a piezoceramic transducer emits a burst pulse to the sample, and a counter is simultaneously triggered. After passing through the cell, the acoustic signal arrives at the receiver, where it is amplified and switches off the counter. The counter directly measures the time of flight that the acoustic pulse needed to cross the transmitter-receiver distance. To determine the speed of sound, the length of the acoustic path must have been obtained earlier from the calibration procedure. Sometimes, one can use multiple reflected echoes $^{40}$ or a pair of signals that are reflected from two identical reflectors ${ }^{41}$ instead of transmitted and first travelling pulses to increase the accuracy of the measurements. In these cases, the delay times from the electronic trigger circuits for both arriving signals cancel out. The time of flight method is easy to use, the calibration is relative simple and quick, and the amount of the sample that needed for the measurement is relatively small. However, this method provides the group velocity. Makino et al. ${ }^{18}$ used a measuring set that enabled simultaneous measurements of the speed of sound by using the time of flight method and measurements of ultrasound absorption.

The remaining measuring sets, which operate according to pulse techniques with a constant path length, were only reported in a few papers. Two variants have been recognized: (i) the singaround method ${ }^{25-28}$ and (ii) the pulse-echo-overlap method. ${ }^{29,30}$ In the sing-around method, a short acoustic pulse from a transmitting transducer crosses the sample and is received by a receiving transducer. After amplification, the signal re-excites the transmitter and the procedure 
is then repeated. The repetition frequency of such closed loop is measured and used to determination of the speed of sound. The main advantage of an apparatus that functions according to the principle of the sing-around method is its high precision $\left(\right.$ e.g., $3 \cdot 10^{-5} \mathrm{~m} \cdot \mathrm{s}^{-1},{ }^{25}$ which is generally up to $10^{-6} \mathrm{~m} \cdot \mathrm{s}^{-1}{ }^{40}$ ) and its simple operation. However, the calibration procedure is rather complicated and requires the use of some other standards in addition to water. $^{38}$ In pulse-echo-overlap apparatuses, a single transmitting-receiving piezoceramic transducer is used. ${ }^{29,30}$ The emitted burst signal (long enough so that its frequency is well defined and short enough to avoid interference because of multiple reflections within the sample) is reflected from a specially formed reflector and returns to the transmitter, where one part is received and the other is reflected again. This process is repeated, producing a series of echoes. Adjusting the frequency of the pulse signal synchronizes the oscilloscope; thus, overlapping two echoes on its screen is possible. The obtained frequency is proportional to the speed of sound. The accuracy of $u$ that can be achieved by means of this method is relatively high because this method measures the speed of sound discriminating wave phases; however, the subjective conditions of overlapping echoes may be disadvantageous. The calibration procedure is also rather simple and the reported uncertainty under high pressure is $\pm 1.0 \mathrm{~m} \cdot \mathrm{s}^{-1} \cdot{ }^{29}$ More detailed descriptions of these apparatuses, measuring cells, and characteristics can be found elsewhere. $^{37,39,42,43}$

In interferometric method (swept-distance interferometry), which is the second most frequently used method for measuring ILs, a continuous sinusoidal wave with a stable and known frequency excites an x-cut quartz crystal transducer, which emits acoustic wave. This wave is reflected from an acoustic mirror and for a certain distance reflector-transducer (which equals the entire multiple of the wavelength), a standing wave is formed. One may determine the 
wavelength and then the phase speed of sound by shifting the reflector in the direction of the wave propagation. ${ }^{33}$ Generally, the major sources of errors are caused by the diffraction of acoustic waves, acoustic streaming, local sample heating by acoustic waves (particularly near the transducer), and the lack of parallelism between the transducer and reflector. ${ }^{7}$

The last, but most sophisticated method for measurements in ILs, is the transient grating spectroscopy, ${ }^{12,19-24}$ which is classified as an optic method. The principle of this method is described in detail by Eichler et al. ${ }^{44}$ and is based on the formation of gratings in an electric laser field in weakly absorbing samples. The absorbed thermal energy and electrostriction cause local changes in the density and refractive index. These changes generate counter-propagating acoustic waves; their superposition produces a standing wave with a wavelength that is equal to the fringe spacing. ${ }^{12,20}$ Two lasers are usually involved in the experimental setup: the first produces a grating and the second sends a continuous-wave beam with a high temporal resolution. The calculation of the speed of sound requires knowledge of the distance between the nodes and antinodes (fringe spacing) and the acoustic wave frequency (or oscillation period). This experiment can simultaneously determine the speed of sound (or ultrasound velocity), thermal diffusivity and ultrasound absorption of the liquids. However, it should be noted that the frequencies of the acoustic waves were evidently higher (e.g., from $6.9 \mathrm{MHz}$ to $13.1 \mathrm{GHz},{ }^{22} 13.4$ MHz -18 MHz, ${ }^{12}$ or $15.3 \mathrm{GHz}^{19}$ ) than for "classical” acoustic methods. At present, the transient grating technique can be treated as an interesting possibility in the field of acoustic investigations of ILs in the low-frequency region (from a few to several tens of megahertz) compared to routine work. However, this method is very usable for studies in the gigahertz range.

The uncertainty of speed of sound measurements depends on the method and on the factors that are considered for its determination. In consequence, declared uncertainties varies significantly 
(see Table 1). Experience and results survey suggest that, excluding transient gratings, an uncertainty of $\pm 0.5 \mathrm{~m} \cdot \mathrm{s}^{-1}$ is generally attainable. In all cases, however, temperature control is very important, but it is primary importance when water is used as standard for calibration because of the opposite signs of the temperature coefficient of the speed of sound for water and ILs (positive up to $347 \mathrm{~K}$ and then negative). Widegren and Magee ${ }^{31}$ examined in details uncertainty in the case of $\left[\mathrm{C}_{6} \mathrm{C}_{1} \mathrm{im}\right]\left[\mathrm{NTf}_{2}\right]$ achieved with the DSA apparatus. These authors reported that differences between measured and reference values never exceeded $\pm 0.5 \mathrm{~m} \cdot \mathrm{s}^{-1}$ (in accordance with the manufacturer's declaration), while a change in the mass fraction of water in the $\left[\mathrm{C}_{6} \mathrm{C}_{1} \mathrm{im}\right]\left[\mathrm{NTf}_{2}\right]$ sample of $8.6 \cdot 10^{-4}$ produced an uncertainty of $\pm 0.7 \mathrm{~m} \cdot \mathrm{s}^{-1}$. Thus, the combined expanded uncertainty $(k=2)$ in their work amounted to $\pm 1.7 \mathrm{~m} \cdot \mathrm{s}^{-1}$, which is recommended by the IUPAC. ${ }^{45}$ A very detailed description of the importance of sample purity, advanced calibration, adjustment, and operation of DSA 5000 measuring sets, including rigorous uncertainty estimation, was performed by Fortin et al. ${ }^{32}$

Summing up, each above discussed method has specific advantages and disadvantages. If readers are interested in speed of sound measurements, they should take into account the time of flight method and apparatus with relatively short constant acoustic path length (low volume) and low measuring frequency (optimal 1-3 MHz). A good choice is, for example, the DSA series apparatus, based on which the density could be also obtained simultaneously. However, if the sample exibits a high absorption behavior, the measured values cannot be treated as proper speed of sound data, because any instrumentation based on the time of flight or the sing-around method is only appropriated when the distinction between the two definitions of the velocity is not significant (in other words, in non-dispersive regions). Unfortunately, ILs show moderate or high absorption (as any dissipative sample) connected with the velocity dispersion, creating some 
issues relayed to thermodynamic formalism (particularly at lower temperatures). Thus, one should be careful not to measure the speed of sound in the dispersive area, or alternative experimental method (the phase methods) should be used instead of. For measurements under high pressures, the best solution seems to be the pulse-echo-overlap method because of its high versatility. If readers want to investigate the velocity in a higher frequencies range (up to gigahertz), the best option remains the transient grating method. For the detection of small changes in the speed of sound (absolute values are less important), one should think about the use of sing-around apparatus. If readers are interested to get more detail and general description of the measuring methods for liquids, they can see the review of Kaatze et al. ${ }^{46}$

\subsection{Relationship between speed of sound and ultrasound absorption}

Contrary to non-dissipative liquids, ultrasound wave propagation in dissipative liquids is connected to a number of mechanisms (discussed in detail in Section 2.2.2) by which the acoustic energy is dissipated and the wave is weakened. Thus, an ultrasound velocity dispersion phenomenon that is interconnected with ultrasound absorption from relaxation effects occurs. In addition to ultrasound absorption, scattering in heterogeneous liquid systems can weaken ultrasound waves. However, scattering is outside the scope of this review.

Unfortunately, direct measurements of the dispersion of ultrasound velocity by means of measurements of ultrasound velocity as a function of frequency are very difficult and very sophisticated techniques are needed. However, recent progress in this matter (especially relating to acoustic waves generated and detected optically) allows for a determination of the dispersion curves over large temperature and frequency ranges (up to several hundreds of $\mathrm{GHz}$ ). ${ }^{47}$ More problematic are opaque and strongly dissipative liquids, where ultrasound velocity measurements are extremely difficult (heavy oils are a good example). ${ }^{48}$ Only a few impressive examples of so- 
called ultrasound broadband acoustic velocimetry (or ultrasound velocity spectrometry) exist in the literature because of high demands on the uncertainty for such measurements. ${ }^{49-51}$ Alternative include ultrasound absorption measurements and the indirect estimation of the dispersion because a functional relationship exists between $\alpha \cdot f^{-2}$ data and $u(f) .^{52,53}$

For ILs, such investigations are well-founded and desirable because many ILs under defined conditions can undoubtedly be classified as dissipative or even strongly dissipative liquids because of their high and very high viscosities (the viscosity values of most ILs are 2-3 orders of magnitude larger than typical molecular organic solvents). To our knowledge, the dispersion of ultrasound velocity has only been directly studied on a limited scale in some ILs with the transient grating method. ${ }^{19,22}$

\subsubsection{Ultrasound absorption measurements}

Unfortunately, as mentioned in Introduction, the measurements of ultrasound absorption in liquids are rather occasional, especially compared to typical measurements of the speed of sound at fixed, low-limit frequencies. The main reasons for such a state include more sophisticated setups and measurement procedures and a lack of commercially available broadband setups at moderate prices for ultrasound absorption measurements. This general rule is especially true in the case of ILs. To our knowledge, available literature data on the ultrasound absorption of ILs are very limited. Apart from data that we have reported, ${ }^{25,34,54}$ only two research groups have reported data that were obtained by means of a direct method. ${ }^{18,55}$ Moreover, experimental results have also been reported by Frez et al. ${ }^{12}$ and Kozlov et al. ${ }^{20}$, who used the transient grating method. Thus, only a very limited number of methods have been used for ILs. These methods are briefly described below.

No universal experimental method exists that covers the available frequency range from a few 
hundred kilohertz to several thousands of megahertz ${ }^{56}$ or more, even up to several dozen of gigahertz, ${ }^{47}$ and provides reliable results in the entire frequency range.

In the lower frequency band, which is typically below a few megahertz, a resonator method is used in which the sample is contained in a cylindrically shaped cavity cell. This relative method with a constant path length has only been used once for $\mathrm{ILs}^{55}$ for measurements in $\left[\mathrm{N}_{2000}\right]\left[\mathrm{NO}_{3}\right]$ at frequencies below $15 \mathrm{MHz}$. Because resonator measurements yield an absorption coefficient of the sample relative to a reference liquid, an appropriate reference liquid (with a speed of sound and density as close as possible to those of the sample) must be used. In the abovementioned study, methanol-water mixtures were used as a reference liquid. The authors declared an error in the absorption data that was below $5 \%$.

One of the most popular methods for ILs (and also all liquids) is still the standard pulse method, which uses a variable path length that covers the middle frequency range, mostly from ca. $5 \mathrm{MHz}-10 \mathrm{MHz}$ to ca. $300 \mathrm{MHz}-400 \mathrm{MHz} .^{18,25,34,54}$ This absolute measurement method can be used to measure the absorption coefficient, $\alpha$, by using the first travelling acoustic pulse and by varying the sample thickness; these $\alpha$ values are directly obtained from the slope of a straight line (amplitude change vs. sample thickness). This feature is a great advantage over cavity resonator methods, for which calibration measurements are needed because of instrumental losses (cavity resonator methods are, however, very useful for lower frequencies - mostly below $5 \mathrm{MHz}$ ). The measurements (mostly within a frequency range from a few to several hundred megahertz) can be executed for chosen series of discrete frequencies by using one, two, or more sets of broadband ultrasonic heads (mostly $\mathrm{LiNbO}_{3}$ transducers) at atmospheric pressure. This type setup has been used by some researchers to study $\left[\mathrm{C}_{2} \mathrm{C}_{1} \mathrm{im}\right]\left[\mathrm{NTf}_{2}\right],{ }^{25}\left[\mathrm{C}_{8} \mathrm{C}_{1} \mathrm{im}\right]\left[\mathrm{NTf}_{2}\right],{ }^{25}\left[\mathrm{C}_{2} \mathrm{C}_{1} \mathrm{im}\right]_{2}\left[\mathrm{Co}(\mathrm{NCS})_{4}\right]^{54}$ and $\left[\mathrm{C}_{4} \mathrm{C}_{1} \mathrm{im}\right]_{2}\left[\mathrm{Co}(\mathrm{NCS})_{4}\right]^{54}$ at 293.15 and $298.15 \mathrm{~K}$. Investigations continued for 
$\left[\mathrm{C}_{n} \mathrm{C}_{1} \mathrm{im}\right]\left[\mathrm{NTf}_{2}\right]$ with $n$ from 3 to 6 , mainly in the temperature range from $293.15 \mathrm{~K}$ to 323.15 $\mathrm{K} .{ }^{34}$ In all cases, the uncertainty of the $\alpha \cdot f^{-2}$ data was estimated to be $\pm 2.5 \%$. The setup details can be found elsewhere. ${ }^{57}$ Makino et al. also used this method, for measurements of $\left[\mathrm{C}_{4} \mathrm{C}_{1} \mathrm{im}\right]\left[\mathrm{PF}_{6}\right],\left[\mathrm{C}_{6} \mathrm{C}_{1} \mathrm{im}\right]\left[\mathrm{PF}_{6}\right],\left[\mathrm{C}_{8} \mathrm{C}_{1} \mathrm{im}\right]\left[\mathrm{PF}_{6}\right]$, and $\left[\mathrm{C}_{4} \mathrm{C}_{1} \mathrm{im}\right]\left[\mathrm{NTf}_{2}\right] .{ }^{18}$ The temperatures ranged from $293 \mathrm{~K}$ up to $393 \mathrm{~K}$, but only three discrete frequencies of $11.3 \mathrm{MHz}, 34.9 \mathrm{MHz}$, and 57.7 $\mathrm{MHz}$ were used. However, the authors recorded uncertainties that greatly differed, i.e., from a few percent to fifty percent. ${ }^{18}$ Generally, measurements in this middle frequency range are less complicated and more accurate than those for both lower and higher frequencies because of much more favorable acoustic conditions.

Another more sophisticated method of ultrasound absorption determination that has been used to study ILs is the transient grating method (described briefly in Section 2.1). To our knowledge, in the case of ILs, this method was probably used for the first time by Frez et al. ${ }^{12}$ Frez et al. studied seven ILs $\left(\left[\mathrm{C}_{4} \mathrm{C}_{1} \mathrm{im}\right]\left[\mathrm{BF}_{4}\right],\left[\mathrm{C}_{4} \mathrm{C}_{1} \mathrm{im}\right]\left[\mathrm{PF}_{6}\right]\right.$, and $\left[\mathrm{C}_{n} \mathrm{C}_{1}\right.$ im] $]\left[\mathrm{NTf}_{2}\right]$ with $n=$ 2,4,5,6,8) at $296.85 \mathrm{~K}$ and at acoustic frequencies (13-17) MHz. Unfortunately, the declared uncertainties of the results were relatively high, up to $\pm 27 \%$. In turn, Kozlov et al. ${ }^{20}$ investigated four ILs at $301 \mathrm{~K}$ with the same $\left[\mathrm{C}_{2} \mathrm{C}_{1} \mathrm{im}\right]^{+}$cation, i.e., $\left[\mathrm{C}_{2} \mathrm{C}_{1} \mathrm{im}\right]\left[\mathrm{NTf}_{2}\right],\left[\mathrm{C}_{2} \mathrm{C}_{1} \mathrm{im}\right]\left[\mathrm{N}(\mathrm{CN})_{2}\right]$, $\left[\mathrm{C}_{2} \mathrm{C}_{1} \mathrm{im}\right]\left[\mathrm{C}(\mathrm{CN})_{3}\right]$, and $\left[\mathrm{C}_{2} \mathrm{C}_{1} \mathrm{im}\right]\left[\mathrm{C}_{1} \mathrm{SO}_{3}\right]$, at acoustic frequencies of $36.5 \mathrm{MHz}, 52.6 \mathrm{MHz}, 47.6$ $\mathrm{MHz}$, and $52.1 \mathrm{MHz}$, respectively. Generally, this method is based on the analysis of temporal profiles of laser beam signals in the electrical field of weakly absorbing samples. Calculating the ultrasound absorption from raw data requires fitting with several adjustable parameters, ${ }^{20,58}$ which makes this method substantially more complicated and can be a source of potentially high uncertainty. Thus, the transient grating method can be treated as an interesting possibility in the field of ultrasound absorption measurements, maybe as a required supplementary method at high 
frequencies (near or above $1 \mathrm{GHz}$ ). Some real progress can be observed by comparing the older results by Frez et al. ${ }^{12}$ and those by Kozlov et al. ${ }^{20}$ These improvements are related to Kozlov et al.'s improved calibration and calculation procedure. Thus, the results that were reported by Kozlov et al. ${ }^{20}$ for the $\left[\mathrm{C}_{2} \mathrm{C}_{1} \mathrm{im}\right]\left[\mathrm{NTf}_{2}\right]$ show much better accordance with the values that were obtained by the standard pulse method ${ }^{25}$ (relative percent deviation of $-32 \%$ ) compared with the older results of Frez et al. ${ }^{12}$ In this later case, the values are remarkably larger (one order), which has also been noticed in the past in relation to $\left[\mathrm{C}_{4} \mathrm{C}_{1} \mathrm{im}\right]\left[\mathrm{NTf}_{2}\right]{ }^{18}$

Summing up, a very good choice for ultrasound absorption measurements in ILs is the standard pulse method with variable path length. Its advantages and power is hard to overestimate, however, the method is time-consuming and great care must be kept to avoid of moisture absorption by sample during measurements. Simultaneously, a broadening of the frequency range both towards lower frequencies $(<10 \mathrm{MHz})$ and towards higher frequencies (up to $\mathrm{GHz}$ range) by application of the other methods ${ }^{47,56}$ used to date only for molecular liquids is very important and urgent task.

\subsubsection{Effect of ultrasound absorption on speed of sound measurements}

Because ultrasound absorption is related to energy dissipation, and this latter results in characteristic ultrasound absorption spectra, an analysis of such spectra yields valuable information regarding the thermodynamic and kinetic parameters of the particular system, which are often difficult to obtain through other methods. Thus, ultrasound absorption can be a significant and integral source of information regarding the molecular structure of the liquid and the physical and chemical processes that occur in the liquid phase at an almost ideal thermal equilibrium, especially when investigations are made over two or more orders of magnitude of frequencies (see recent concise reviews for molecular liquids and their non-aqueous and aqueous 
solutions ${ }^{59,60}$ ). Moreover, the knowledge of ultrasound absorption is necessary in some methods to determine the acoustic nonlinearity parameter, ${ }^{61,62}$ which is a basic measurement of the nonlinearity of a medium.

Most often the ultrasound absorption coefficients $\alpha$ per squared frequency $f$, i.e., the quotients $\alpha \cdot f^{-2}$, are plotted against $\log f$, and the following approximation function is used:

$\alpha \cdot f^{-2}=\sum_{i=1}^{n} A_{i} \cdot\left(1+\left(\frac{f}{f_{\text {rel, }, i}}\right)^{2}\right)^{-1}+B$,

where $A_{i}$ is the relaxation amplitude and $f_{\mathrm{rel}, i}$ is the relaxation frequency of the discrete single Debye relaxation process. In many cases, one single Debye relaxation process $(n=1)$ is satisfied, but spectra with two, three, or four discrete single Debye relaxation processes have been reported .$^{53,63} \mathrm{~B}$ represents the sum of the classical part of the absorption and the contributions from possible processes with relaxation frequencies that are considerably higher than $f_{\text {rel, }, i}$

A number of mechanisms of acoustic energy dissipation exist. The so-called classical part of the absorption is connected with the static shear viscosity and heat conduction. However, energy dissipation that is caused by a finite coefficient of heat conduction $\Lambda$ can be neglected here because $\alpha_{\mathrm{K}}$ (calculated according to Kirchhoff) is very small for most liquids, including ILs, compared to the value that is calculated only from the viscous term $\alpha_{\mathrm{S}}$ (i.e., $\alpha_{\mathrm{K}}<<\alpha_{\mathrm{S}}$ ). Liquid metals, however, are an exception. Therefore, a classical absorption coefficient per squared frequency $\alpha_{\mathrm{cl}} \cdot f^{-2}$ can be calculated only from the so-called Stokes formula: 
$\alpha_{c l} \cdot f^{-2}=8 \cdot \pi^{2} \cdot \eta_{s} \cdot\left(3 \cdot \rho \cdot u^{3}\right)^{-1}$,

where $\eta_{\mathrm{s}}$ is the static shear (Newtonian) viscosity (i.e., the shear viscosity with a shear rate $\approx 0$; in other words, for $2 \cdot \pi \cdot f \rightarrow 0$ ) and $\rho$ is the density.

Thermal and structural relaxation processes may be present in addition to classical absorption. Such relaxation processes are responsible not only for absorption but also for the dispersion of the ultrasound velocity, ${ }^{7}$ because the latter is associated with any acoustic absorption of relaxational origin. In such cases, the experimental ultrasound velocity is higher than the speed of sound in the Newton-Laplace equation, i.e., higher than the low-frequency limit of the ultrasound velocity $\lim u(f)$ for $f \rightarrow 0$. For longitudinal waves, both the low- and high-frequency limits of the ultrasound velocity are finite. The latter produces the "solid" speed of ultrasound $u_{\infty}(\lim u(f)$ for $f \rightarrow \infty)$ ), contrary to the "liquid" isentropic speed of sound $u$ (lim $u(f)$ for $f \rightarrow 0)$ ).

At low frequencies and small absorption, i.e., when dissipative processes can be neglected, the speed of sound can be treated as a thermodynamic equilibrium property according to the NewtonLaplace equation. However, the effect of ultrasound absorption on the speed of sound must be considered in the presence of the abovementioned dissipation processes that are caused by relaxation effects, especially for highly absorbing samples and at higher frequencies. In other words, as mentioned in the Introduction, care must always be taken when the speed of sound is treated as a thermodynamic quantity. This approach is especially important when measurements are provided in relatively low temperatures and under elevated pressures because both the temperature and pressure shift the relaxation regions. For molecular liquids, increasing the pressure can both decrease and increase the relaxation frequency, although the relaxation frequency can also remain constant. ${ }^{64-66}$ These differences are related to fundamentally different relaxation mechanisms that exist in various classes of molecular liquids, e.g., in associated and 
non-associated liquids. Current ultrasound absorption results (at atmospheric pressure) for a very limited number ILs have shown that their behavior is similar to molecular associated liquids, i.e., small ratios of experimental to classical absorption and negative temperature absorption coefficient $\left(\mathrm{d}\left(\alpha \cdot f^{2}\right) / \mathrm{d} T\right)$ are observed (Table 2 summarized the existing data). Thus, the behavior of ILs under elevated pressures should be also similar to that of molecular associated liquids. In other words, the relaxation regions shift towards lower frequencies with increasing pressure. Thus, the measured speed of sound cannot be regarded as a pure thermodynamic equilibrium property in some cases. Therefore, investigations of ultrasound absorption are very useful and interesting in connection to pressure-temperature studies of thermodynamic properties with acoustic methods (an indirect route to obtain all the relevant thermodynamic properties of a single fluid phase) because such studies must be performed outside of the relaxation regions.,67,68

Table 2. Ultrasound Absorption Coefficients $\alpha$, Ratios of $\alpha / \alpha_{\mathrm{cl}}$ and Temperature Absorption Coefficients $\mathrm{d}\left(\alpha \cdot f^{-2}\right) / \mathrm{d} T$ for Various ILs at Different Temperatures $T$ in the NonRelaxation Region

\begin{tabular}{|c|c|c|c|c|}
\hline$T / \mathrm{K}$ & $10^{15} \cdot \alpha \cdot f^{-2} / \mathrm{s}^{2} \cdot \mathrm{m}^{-1}$ & $\alpha / \alpha_{\mathrm{cl}}$ & $\mathrm{d}\left(\alpha \cdot f^{2}\right) / \mathrm{d} T$ & refs \\
\hline \multicolumn{5}{|c|}{$\left[\mathrm{C}_{2} \mathrm{C}_{1} \mathrm{im}\right]\left[\mathrm{NTf}_{2}\right]$} \\
\hline 293.15 & 565 & 1.655 & negative & 25 \\
\hline 298.15 & 483 & 1.639 & negative & \\
\hline 301 & $294^{a}$ & $1^{b}$ & $\mathrm{n} / \mathrm{a}^{c}$ & 20 \\
\hline \multicolumn{5}{|c|}{$\left[\mathrm{C}_{3} \mathrm{C}_{1} \mathrm{im}\right]\left[\mathrm{NTf}_{2}\right]$} \\
\hline 293.15 & 862.1 & 1.641 & negative & 34 \\
\hline 298.15 & 717.9 & 1.654 & negative & \\
\hline 303.15 & 605.9 & 1.661 & negative & \\
\hline 313.15 & 454.6 & 1.692 & negative & \\
\hline
\end{tabular}




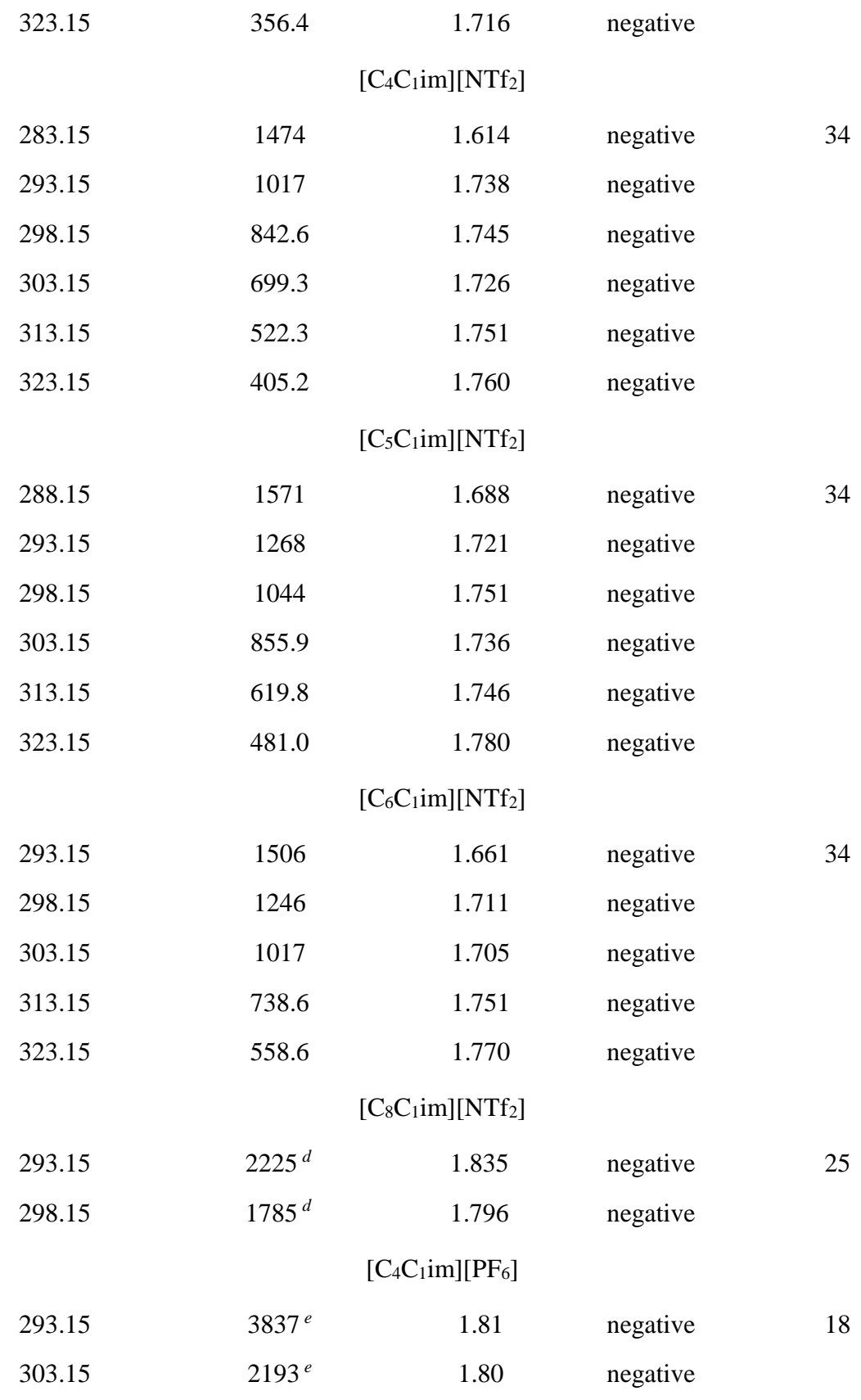




\begin{tabular}{|c|c|c|c|c|}
\hline 313.15 & $1410^{e}$ & 1.85 & negative & \\
\hline 323.15 & $963^{e}$ & 1.90 & negative & \\
\hline \multicolumn{5}{|c|}{$\left[\mathrm{C}_{6} \mathrm{C}_{1} \mathrm{im}\right]\left[\mathrm{PF}_{6}\right]$} \\
\hline 293.15 & $6578^{e}$ & 1.43 & negative & 18 \\
\hline 303.15 & $4777^{e}$ & 1.92 & negative & \\
\hline 313.15 & $2976^{e}$ & 2.07 & negative & \\
\hline 323.15 & $1958^{e}$ & 2.14 & negative & \\
\hline \multicolumn{5}{|c|}{$\left[\mathrm{C}_{8} \mathrm{C}_{1} \mathrm{im}\right]\left[\mathrm{PF}_{6}\right]$} \\
\hline 293.15 & $9006^{e}$ & 1.23 & negative & 18 \\
\hline 303.15 & $6343^{e}$ & 1.64 & negative & \\
\hline 313.15 & $4621^{e}$ & 2.08 & negative & \\
\hline 323.15 & $3289^{e}$ & 2.44 & negative & \\
\hline \multicolumn{5}{|c|}{$\left[\mathrm{C}_{2} \mathrm{C}_{1} \mathrm{im}\right]\left[\mathrm{N}(\mathrm{CN})_{2}\right]$} \\
\hline 301 & $160^{f}$ & $2.0^{b}$ & $\mathrm{n} / \mathrm{a}^{c}$ & 20 \\
\hline \multicolumn{5}{|c|}{$\left[\mathrm{C}_{2} \mathrm{C}_{1} \mathrm{im}\right]\left[\mathrm{C}_{1} \mathrm{SO}_{3}\right]$} \\
\hline 301 & $827^{g}$ & $1.5^{b}$ & $\mathrm{n} / \mathrm{a}^{c}$ & 20 \\
\hline \multicolumn{5}{|c|}{$\left[\mathrm{C}_{2} \mathrm{C}_{1} \mathrm{im}\right]\left[\mathrm{C}(\mathrm{CN})_{3}\right]$} \\
\hline 301 & $132^{h}$ & $1.6^{b}$ & $\mathrm{n} / \mathrm{a}^{c}$ & 20 \\
\hline \multicolumn{5}{|c|}{$\left[\mathrm{C}_{2} \mathrm{C}_{1} \mathrm{im}\right]_{2}\left[\mathrm{Co}(\mathrm{NCS})_{4}\right]$} \\
\hline 293.15 & $1479^{i}$ & 1.57 & negative & 54 \\
\hline 298.15 & $1104^{i}$ & 1.57 & negative & \\
\hline \multicolumn{5}{|c|}{$\left[\mathrm{C}_{4} \mathrm{C}_{1} \mathrm{im}\right]_{2}\left[\mathrm{Co}(\mathrm{NCS})_{4}\right]$} \\
\hline 293.15 & $3267^{i}$ & 1.49 & negative & 54 \\
\hline 298.15 & $2370^{i}$ & 1.59 & negative & \\
\hline \multicolumn{5}{|c|}{$\left[\mathrm{N}_{2000}\right]\left[\mathrm{NO}_{3}\right]$} \\
\hline 313.15 & 195 & $\mathrm{n} / \mathrm{a}^{c}$ & $\mathrm{n} / \mathrm{a}^{c}$ & 55 \\
\hline
\end{tabular}


${ }^{a}$ at $36.5 \mathrm{MHz}^{b}$ estimated from one-point data of volume viscosity $\eta_{V}$ that were reported in the provided reference ${ }^{c}$ not available ${ }^{d}$ reported in ref. ${ }^{34}$ and recalculated data from Zorębski et al. ${ }^{25}{ }^{e}$ at $11.3 \mathrm{MHz}{ }^{f}$ at $52.6 \mathrm{MHz}^{g}$ at $52.1 \mathrm{MHz}{ }^{\mathrm{h}}$ at $47.6 \mathrm{MHz}{ }^{i}$ reported in ref. ${ }^{34}$ and recalculated data from Hensel-Bielowka et al. ${ }^{54}$

To our knowledge, the experimental data for all ILs that have been studied, in the investigated frequency range clearly do not show a constant $\alpha \cdot f^{-2}$ but instead exhibit $\mathrm{d}\left(\alpha \cdot f^{-2}\right) / \mathrm{d} f<0 . \cdot^{18,25,34,54}$ Moreover, in the investigated temperature range, always $\mathrm{d}\left(\alpha \cdot f^{-2}\right) / \mathrm{d} T<0$. Apart from the $\left[\mathrm{C}_{2} \mathrm{C}_{1} \mathrm{im}\right]\left[\mathrm{NTf}_{2}\right]$, where the observed ultrasound absorption spectra indicate relaxation frequencies above $300 \mathrm{MHz}$ (Figure 2), the relaxation frequencies of other studied ILs are evidently lower.

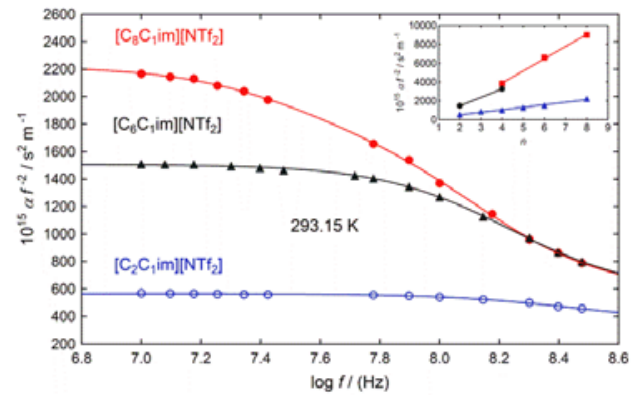

Figure 2. Semi-logarithmic plot of $\alpha \cdot f^{-2} v$ s. frequency for $\left[\mathrm{C}_{2} \mathrm{C}_{1} \mathrm{im}\right]\left[\mathrm{NTf}_{2}\right],\left[\mathrm{C}_{6} \mathrm{C}_{1} \mathrm{im}\right]\left[\mathrm{NTf} \mathrm{f}_{2}\right]$, and $\left[\mathrm{C}_{8} \mathrm{C}_{1} \mathrm{im}\right]\left[\mathrm{NTf}_{2}\right]$ at $293.15 \mathrm{~K} \cdot{ }^{25,34}$ For $\left[\mathrm{C}_{2} \mathrm{C}_{1} \mathrm{im}\right]\left[\mathrm{NTf}_{2}\right]$ and $\left[\mathrm{C}_{6} \mathrm{C}_{1} \mathrm{im}\right]\left[\mathrm{NTf}_{2}\right]$, a model with a single Debye term is used. For $\left[\mathrm{C}_{8} \mathrm{C}_{1} \mathrm{im}\right]\left[\mathrm{NTf}_{2}\right]$, a model with two single Debye terms is used. ${ }^{34}$ Inset shows $\alpha \cdot f^{-2}$ plotted vs. side carbon chain number $n$ in imidazolium cations at $293.15 \mathrm{~K}$ : blue filled triangle - $\left[\mathrm{C}_{n} \mathrm{C}_{1} \mathrm{im}\right]\left[\mathrm{NTf}_{2}\right](n=2,3,4,5,6,8)$; red filled squares - $\left[\mathrm{C}_{n} \mathrm{C}_{1} \mathrm{im}\right]\left[\mathrm{PF}_{6}\right](n=2,4,8)$; and black filled circles $-\left[\mathrm{C}_{n} \mathrm{C}_{1} \mathrm{im}\right]_{2}\left[\mathrm{Co}(\mathrm{NCS})_{4}\right](n=2,4) .{ }^{18,25,34}$ 
The carbon chain length in imidazolium cations appears to cause clear differences in the ultrasound absorption spectra of the studied ILs because both the relaxation region and the magnitude of $\alpha \cdot f^{-2}$ depend on the carbon chain length in the imidazolium cation. The magnitude of $\alpha \cdot f^{-2}$ clearly increases with increasing length of the side carbon chain in the imidazolium ring in the order $\left[\mathrm{C}_{2} \mathrm{C}_{1} \mathrm{im}\right]^{+}<\left[\mathrm{C}_{3} \mathrm{C}_{1} \mathrm{im}\right]^{+}<\left[\mathrm{C}_{4} \mathrm{C}_{1} \mathrm{im}\right]^{+}<\left[\mathrm{C}_{5} \mathrm{C}_{1} \mathrm{im}\right]^{+}<\left[\mathrm{C}_{6} \mathrm{C}_{1} \mathrm{im}\right]^{+}<\left[\mathrm{C}_{8} \mathrm{C}_{1} \mathrm{im}\right]^{+}$for the $\left[\mathrm{C}_{n} \mathrm{C}_{1} \mathrm{im}\right]\left[\mathrm{NTf}_{2}\right]$ series where $n=2,3,4,5,6$ or $8^{25,34}$ and in the order $\left[\mathrm{C}_{4} \mathrm{C}_{1} \mathrm{im}\right]^{+}<\left[\mathrm{C}_{6} \mathrm{C}_{1} \mathrm{im}\right]^{+}<\left[\mathrm{C}_{8} \mathrm{C}_{1} \mathrm{im}\right]^{+}$for $\left[\mathrm{C}_{n} \mathrm{C}_{1} \mathrm{im}\right]\left[\mathrm{PF}_{6}\right](n=4,6$ or 8$){ }^{18}$ A similar effect is observed for dicationic ILs, like the $\left[\mathrm{C}_{n} \mathrm{C}_{1} \mathrm{im}\right]_{2}\left[\mathrm{Co}(\mathrm{NCS})_{4}\right](n=2$ or 4$),{ }^{54}$ and the magnitude of $\alpha \cdot f^{-2}$ increases in the order $\left[\mathrm{C}_{2} \mathrm{C}_{1} \mathrm{im}\right]_{2}^{+}<\left[\mathrm{C}_{4} \mathrm{C}_{1} \mathrm{im}\right]^{+}$. Moreover, as the alkyl chain length increases, the relaxation regions shift towards lower frequencies in all cases. For the same imidazolium cation, the magnitude of $\alpha \cdot f^{-2}$ (below relaxation region) is clearly lower for the $\left[\mathrm{NTf}_{2}\right]^{-}$anion compared to the $\left[\mathrm{PF}_{6}\right]^{-}$anion (Figure 2, inset). In other words, $\left[\mathrm{C}_{n} \mathrm{C}_{1} \mathrm{im}^{-}\left[\mathrm{NTf}_{2}\right]\right.$ shows generally lower absorption than adequate $\left[\mathrm{C}_{n} \mathrm{C}_{1} \mathrm{im}\right]\left[\mathrm{PF}_{6}\right]$. The clear influence of anions structure is also visible from the data of Kozlov et al., ${ }^{20}$ where the magnitude of $\alpha \cdot f^{-2}$ increases in the order $\left[\mathrm{C}_{2} \mathrm{C}_{1} \mathrm{im}\right]\left[\mathrm{C}(\mathrm{CN})_{3}\right]<\left[\mathrm{C}_{2} \mathrm{C}_{1} \mathrm{im}\right]\left[\mathrm{N}(\mathrm{CN})_{2}\right]<\left[\mathrm{C}_{2} \mathrm{C}_{1} \mathrm{im}\right]\left[\mathrm{NTf}_{2}\right]<\left[\mathrm{C}_{2} \mathrm{C}_{1} \mathrm{im}\right]\left[\mathrm{C}_{1} \mathrm{SO}_{3}\right]$, and from the data set published by Frez et al., ${ }^{12}$ where ultrasound absorption increases in the order $\left[\mathrm{C}_{4} \mathrm{C}_{1} \mathrm{im}\right]\left[\mathrm{NTf}_{2}\right]<\left[\mathrm{C}_{4} \mathrm{C}_{1} \mathrm{im}\right]\left[\mathrm{BF}_{4}\right]<\left[\mathrm{C}_{4} \mathrm{C}_{1} \mathrm{im}\right]\left[\mathrm{PF}_{6}\right]$. However, on account of the great uncertainty, the influence of cations structure on the absorption could not be detected by Frez et al. ${ }^{12}$

Assuming that ILs can be treated as a mixture of polar and nonpolar domains, an equilibrium between these domains can be shifted by acoustic wave. Thus, various equilibria are reduced to one reaction, which can be described by the discrete relaxation time according to Eq. 2 (i.e., by a single Debye-type relaxation term). In principle, however, even the fact that the absorption data fit a single relaxation curve does not necessarily mean, indeed that a single relaxation process 
exists. Sometimes, resolving contributions to the absorption spectrum from two or more processes may be impossible (e.g., similar relaxation times), and the absorption data will have the appearance of a single relaxation curve. Only if the relaxation times that are associated with the two coupled processes differ sufficiently from each other the relaxation function would consist of two parts (or more). Although the spectra for ILs in many cases can be satisfactorily described with a single Debye-type exponential function of time, ${ }^{34}$ another model has been required for the $\left[\mathrm{C}_{n} \mathrm{C}_{1} \mathrm{im}\right]_{2}\left[\mathrm{Co}(\mathrm{NCS})_{4}\right]$ ( $n=2$ or 4 ) ILs, where the Cole-Cole function with the parameter $\beta$ $(0<\beta<1)$, which reflects the distribution of relaxation times (the smaller $\beta$ is, the wider the distribution), was used. ${ }^{54}$ If $\beta=1$, this model is reduced to the Debye model with a single relaxation term (Eq. 1). The results that were reported by Hensel-Bielowka et al. ${ }^{54}$ show that an increase in absorption is connected with the appearance of the distribution of relaxation times; however, this distribution of relaxation times was small. In other words, the higher the absorption, the poorer the fitting by the simple Debye model (see also, ${ }^{25}$ where visibly poorer fitting in the case of $\left[\mathrm{C}_{8} \mathrm{C}_{1} \mathrm{im}\right]\left[\mathrm{NTf}_{2}\right]$ compared to $\left[\mathrm{C}_{2} \mathrm{C}_{1} \mathrm{im}\right]\left[\mathrm{NTf}_{2}\right]$ can be observed). Revisiting the data that were reported for $\left[\mathrm{C}_{8} \mathrm{C}_{1} \mathrm{im}\right]\left[\mathrm{NTf}_{2}\right]^{25}$ and $\left[\mathrm{C}_{n} \mathrm{C}_{1} \mathrm{im}\right]_{2}\left[\mathrm{Co}(\mathrm{NCS})_{4}\right](n=2 \text { or } 4)^{54}$ by Zorębski et al. ${ }^{34}$ is sufficient to determine the use of a Debye model with two single relaxation terms.

Most probably assumed above domain structure is oversimplified because the dynamics of the of the domains structure of ILs investigated by Kofu et al. ${ }^{69}$ using the neutron spin echo spectroscopy (NSE) is more complicated. This technique is also able to investigate microscopic motions and results show that the relaxation mechanism is most probably more complicated, i.e., cannot be assigned solely to the domain dynamics. A comparison of the shear viscosity relaxation 
and NSE results implies that the shear viscosity relaxation cannot be explained solely nor by the domain or microscopic structures. ${ }^{70}$

The ultrasonic velocity is subject to considerable dispersion because of the relatively large ultrasonic absorption in many ILs. Fortunately, the frequency dependence of the ultrasonic velocity can be estimated from the ultrasound absorption data. ${ }^{34,52}$ Figures 3 and 4 show examples of the ultrasonic velocity dependence on frequency, which was estimated from the absorption data. ${ }^{34}$ From among the seven ILs for which the dispersion curves of ultrasonic velocities were estimated, $\left[\mathrm{C}_{4} \mathrm{C}_{1} i \mathrm{im}\right]_{2}\left[\mathrm{Co}(\mathrm{NCS})_{4}\right]$ shows ultrasonic velocity dependence on frequency as early as $7 \mathrm{MHz}$ at $293.15 \mathrm{~K}$ (Figure 4). Under the same conditions, [ $\left.\mathrm{C}_{6} \mathrm{C}_{1} \mathrm{im}\right]\left[\mathrm{NTf}_{2}\right]$ does not show this dependence until $28 \mathrm{MHz}$ (Figure 3). The frequency of the estimated ultrasound velocities for which the difference between these values and the experimentally determined speed of sound $\left(u_{f}-u\right)$ exceeded the expanded uncertainty of the experimental speed of sound, equal $\pm 1 \mathrm{~m} \cdot \mathrm{s}^{-1}\left(U_{u}=0.5 \mathrm{~m} \cdot \mathrm{s}^{-1}, k=2\right)$, indicates the dispersion beginning. ${ }^{34}$ Table 3 summarizes the dispersion values $u_{\infty} / u$ that were obtained both indirectly from absorption measurements and directly from the transient grating method.

Table 3. The Dispersion Values $u_{\infty} / u$ for ILs at Temperature 298.15 K

$\begin{array}{ccc}\text { ionic liquid } & u_{\infty} / u & \text { refs } \\ {\left[\mathrm{C}_{2} \mathrm{C}_{1} \mathrm{im}\right]\left[\mathrm{NTf}_{2}\right]} & 1.008^{b} & 34 \\ {\left[\mathrm{C}_{3} \mathrm{C}_{1} \mathrm{im}\right]\left[\mathrm{NTf}_{2}\right]} & 1.017^{b} & 34 \\ {\left[\mathrm{C}_{4} \mathrm{C}_{1} \mathrm{im}\right]\left[\mathrm{NTf}_{2}\right]} & 1.024^{b} & 34 \\ & 1.07^{a} & 19 \\ & 1.22^{a} & 22\end{array}$




$\begin{array}{ccc}{\left[\mathrm{C}_{5} \mathrm{C}_{1} \mathrm{im}\right]\left[\mathrm{NTf}_{2}\right]} & 1.031^{b} & 34 \\ {\left[\mathrm{C}_{6} \mathrm{C}_{1} \mathrm{im}\right]\left[\mathrm{NTf}_{2}\right]} & 1.033^{b} & 34 \\ {\left[\mathrm{C}_{8} \mathrm{C}_{1} \mathrm{im}\right]\left[\mathrm{NTf}_{2}\right]} & 1.034^{b} & 34 \\ {\left[\mathrm{~N}_{1113}\right]\left[\mathrm{NTf}_{2}\right]} & 1.26^{a} & 22 \\ {\left[\mathrm{C}_{4} \mathrm{C}_{1} \mathrm{im}\right]\left[\mathrm{BF}_{4}\right]} & 1.13^{a} & 19 \\ {\left[\mathrm{C}_{4}-2,3-\mathrm{dC} \mathrm{C}_{1} \mathrm{im}\right]\left[\mathrm{BF}_{4}\right]} & 1.14^{a} & 19 \\ {\left[\mathrm{C}_{4} \mathrm{C}_{1} \mathrm{im}\right]\left[\mathrm{PF}_{6}\right]} & 1.16^{a} & 19 \\ & 1.22^{a} & 22 \\ {\left[\mathrm{C}_{2} \mathrm{C}_{1} \mathrm{im}\right]_{2}\left[\mathrm{Co}(\mathrm{NCS})_{4}\right]} & 1.034^{b} & 34 \\ {\left[\mathrm{C}_{4} \mathrm{C}_{1} \mathrm{im}\right]_{2}\left[\mathrm{Co}(\mathrm{NCS})_{4}\right]} & 1.059^{b} & 34\end{array}$

${ }^{a}$ Obtained directly from measurements of the $u_{\infty}$ and $u .{ }^{b}$ Obtained indirectly by estimation from ultrasound absorption measurements.

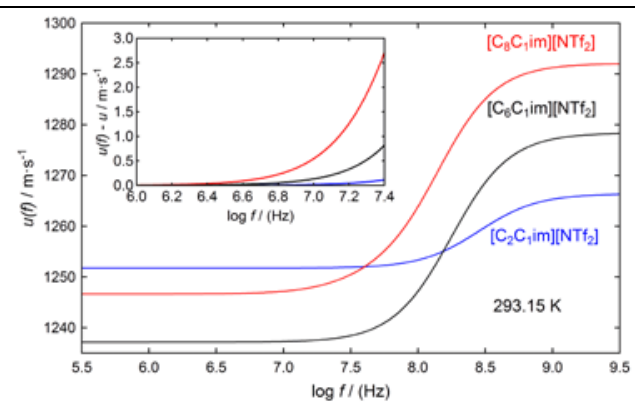

Figure 3. Semi-logarithmic plot of ultrasonic velocity vs. frequency for $\left[\mathrm{C}_{2} \mathrm{C}_{1} \mathrm{im}\right]\left[\mathrm{NTf}_{2}\right]$,

$\left[\mathrm{C}_{6} \mathrm{C}_{1} \mathrm{im}\right]\left[\mathrm{NTf}_{2}\right]$, and $\left[\mathrm{C}_{8} \mathrm{C}_{1} \mathrm{im}\right]\left[\mathrm{NTf}_{2}\right]$ at $293.15 \mathrm{~K}^{.34}$ The inset shows an adequate increase in $u(f)$ $-u$ in the low frequency range. 


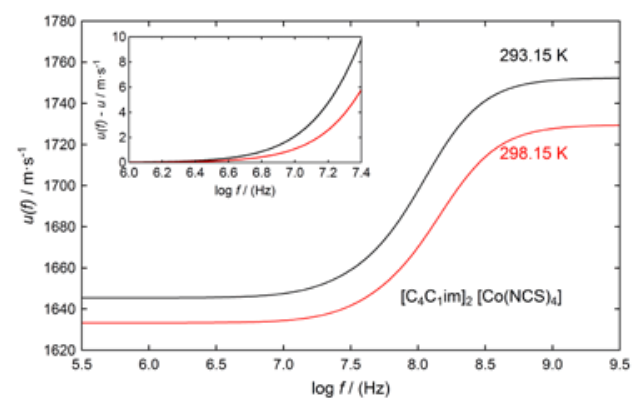

Figure 4. Semi-logarithmic plot of ultrasonic velocity vs. frequency for $\left[\mathrm{C}_{4} \mathrm{C}_{1} \mathrm{im}\right]_{2}\left[\mathrm{Co}(\mathrm{NCS})_{4}\right]$ at 293.15 K and 298.15 K. ${ }^{34}$ The inset shows an adequate increase in $u(f)-u$ in the low frequency range.

An indirect comparison of the ultrasound velocity dispersion reported by Fukuda et al. ${ }^{22}$ for $\left[\mathrm{C}_{4} \mathrm{C}_{1} \mathrm{im}\right]\left[\mathrm{NTf}_{2}\right]$ at $295.15 \mathrm{~K}$ with ultrasound absorption data for this $\mathrm{ILs}^{34}$ shows rather satisfactory agreement. According to Fukuda et al., ${ }^{22}$ the ultrasound velocities are constant below $260 \mathrm{MHz}$ within the experimental error, i.e., below $260 \mathrm{MHz}$, frequency dependence is not observed and the low-frequency limit of the ultrasound velocity (i.e., the speed of sound) is attained. According to the simple Debye model used to describe the ultrasound absorption data for $\left[\mathrm{C}_{4} \mathrm{C}_{1} \mathrm{im}\right]\left[\mathrm{NTf}_{2}\right]$ at $298.15 \mathrm{~K}$, the relaxation frequency is $289 \mathrm{MHz} .{ }^{34}$ Thus, the results that were obtained with different techniques are roughly consistent. Additionally, ultrasound velocity dispersion seems to be reproduced by the simple Debye model. ${ }^{22}$ A comparison of ultrasound velocity and dielectric relaxation, which was previously reported by Weingärtner et al. ${ }^{71}$, led Fukuda et al. $^{22}$ to conclude that structural relaxation (from the ultrasound velocity relaxation measurements) for $\left[\mathrm{C}_{4} \mathrm{C}_{1} \mathrm{im}\right]\left[\mathrm{NTf}_{2}\right]$ is much faster than reorientational relaxation (from dielectric relaxation measurements), i.e., showing that the relaxation is decoupled. On the contrary, 
structural and reorientational relaxation for $\left[\mathrm{C}_{4} \mathrm{C}_{1} \mathrm{im}\right]\left[\mathrm{PF}_{6}\right]$ are strongly coupled. These different behaviors are probably caused by the difference on the structure of these anions.

Recently reported studies of heterogenous nature of relaxation dynamics of $\left[\mathrm{C}_{2} \mathrm{C}_{1} \mathrm{im}\right]_{2}\left[\mathrm{Co}(\mathrm{NCS})_{4}\right]$, and $\left[\mathrm{C}_{4} \mathrm{C}_{1} \mathrm{im}\right]_{2}\left[\mathrm{Co}(\mathrm{NCS})_{4}\right]$ are also interesting. ${ }^{54}$ Combining ultrasound absorption spectroscopy with dielectric, rheological and calorimetric methods, the molecular dynamics in normal and supercooled liquid state as well as in a glassy state was studied in broad range over 12 decades. As results several phenomena were observed like non-Newtonian behiavior, lack of the dynamical crossover and decoupling between conductivity and structural relaxation times; Figure 5 shows that such decoupling between studied properties takes place. For both ILs, the results indicate that the dynamical heterogeneity and cooperativity play the same role in the molecular dynamics both in the vicinity of $T_{\mathrm{g}}$ and in the region up to $1.5-1.6 T_{\mathrm{g}}$. In other words, authors stated that even at temperatures typical for normal liquid state both ILs behave like supercooled liquids. ${ }^{54}$ 


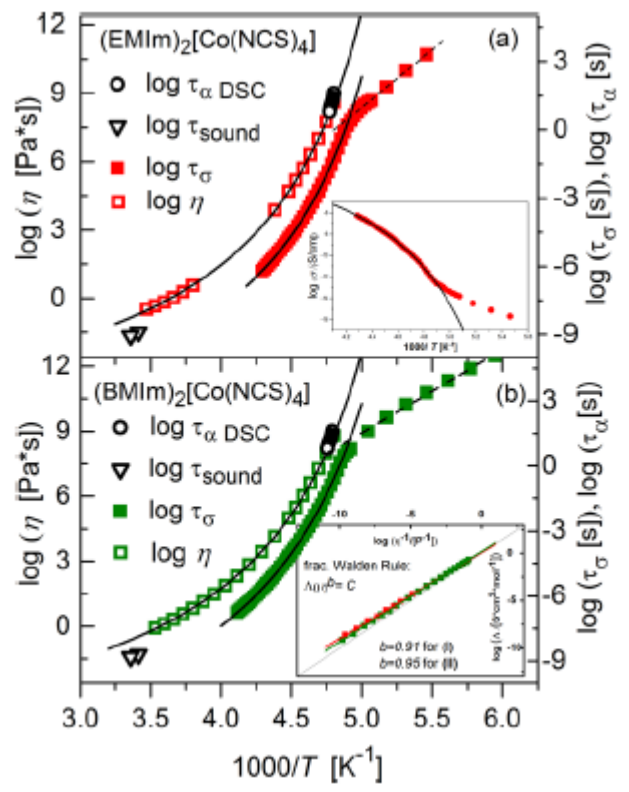

Figure 5. Relaxation map of (a) $\left(\mathrm{C}_{2} \mathrm{C}_{1} \mathrm{im}\right)_{2}\left[\mathrm{Co}(\mathrm{NCS})_{4}\right]$ and (b) $\left(\mathrm{C}_{4} \mathrm{C}_{1} \mathrm{im}\right)_{2}\left[\mathrm{Co}(\mathrm{NCS})_{4}\right]$.

Conductivity relaxation times $\tau_{\sigma}$ are compared with viscosity and structural relaxation times $\tau_{\alpha}$ from TMDSC. At the highest temperature limit, relaxation times $\tau_{\text {sound }}$ obtained from ultrasound absorption are added. Solid and dashed lines are Vogel-Fulcher-Tamman (VFT) and Arrhenius fits, respectively. Crossover point on $\tau_{\sigma}(T)$ dependence determines $T_{g}$. Upper inset: dcconductivity vs. inverse temperature with clearly visible crossover from the VFT to Arrhenius dependence. Lower inset: Walden plot. Reproduced with permission from ref ${ }^{54}$. Copyright 2015 American Chemical Society

For the most studied ILs, namely, $\left[\mathrm{C}_{6} \mathrm{C}_{1} \mathrm{im}\right]\left[\mathrm{NTf}_{2}\right],\left[\mathrm{C}_{8} \mathrm{C}_{1} \mathrm{im}\right]\left[\mathrm{NTf}_{2}\right],\left[\mathrm{C}_{n} \mathrm{C}_{1} \mathrm{im}\right]\left[\mathrm{PF}_{6}\right](n=4,6$ or 8), $\left[\mathrm{C}_{2} \mathrm{C}_{1} \mathrm{im}\right]_{2}\left[\mathrm{Co}(\mathrm{NCS})_{4}\right]$, and $\left.\left[\mathrm{C}_{4} \mathrm{C}_{1} \mathrm{im}\right]_{2}\left[\mathrm{Co}(\mathrm{NCS})_{4}\right]\right)$, an additional interesting feature at room temperature is observed, i.e., at some relatively low frequency (in the case of 
$\left[\mathrm{C}_{4} \mathrm{C}_{1} \mathrm{im}\right]_{2}\left[\mathrm{Co}(\mathrm{NCS})_{4}\right]$ even near $\left.20 \mathrm{MHz}-30 \mathrm{MHz}\right)$ the experimental values of $\alpha \cdot f^{-2}$ are smaller than those predicted by the classical theory (Eq. 3). ${ }^{25,54}$ In other words, a shear viscosity relaxation in the megahertz range is present, and the dependence of $\alpha \cdot f^{-2}$ on the frequency can also be attributed to the relaxation behavior of the shear viscosity. Thus, $\eta_{\mathrm{S}}$ must also decrease by increasing the frequency. This behavior was observed at room temperature probably first for

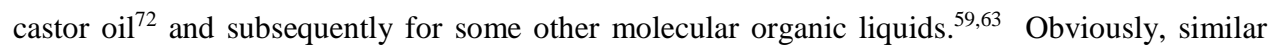
behavior has also been observed for other molecular liquids at lower temperatures. ${ }^{73}$ However, the separate determination of the shear viscosity behavior requires a separate study of shear ultrasound waves because ultrasonic relaxation as determined by means of a longitudinal wave is not a suitable tool to investigate the microscopic origin of shear viscosity (difficulties in the separation of the contributions of the volume and shear viscosities to the ultrasonic relaxation). Indirect conclusions regarding shear viscosity relaxation in ILs from ultrasound absorption measurements are consistent with the results of shear relaxation studies. ${ }^{70,74}$

Simultaneously, ultrasound absorption at low frequencies (i.e., at the frequencies in typical speed of sound measurements, for example, at $2 \mathrm{MHz}$ ) and at room temperature for most of the ILs reported in Table 2 is small enough for the correct use of the Newton-Laplace equation. In other words, $u$ may be still treated as a thermodynamic equilibrium property because the effects of absorption on the speed of sound are small and may be ignored (neglecting dissipative processes). This conclusion results from the fulfilled inequality $\alpha \cdot u \cdot(2 \cdot \pi \cdot f)^{-1}<<1$. For example, the $\alpha \cdot u \cdot(2 \cdot \pi \cdot f)^{-1}$ values lie in the range from $3.4 \cdot 10^{-4}$ (for $\left[\mathrm{C}_{3} \mathrm{C}_{1} \mathrm{im}\right]\left[\mathrm{NTf}_{2}\right]$ at $293.15 \mathrm{~K}$ ) to $5.9 \cdot 10^{-4}$ (for $\left[\mathrm{C}_{6} \mathrm{C}_{1} \mathrm{im}\right]\left[\mathrm{NTf}_{2}\right]$ at $293.15 \mathrm{~K}$ ). ${ }^{34}$ In some cases, however, the ultrasound absorption is not small enough for the correct use of the Newton-Laplace equation. Thus, $u$ may not be treated as a pure thermodynamic equilibrium property. For example, this situation applies to 
$\left[\mathrm{C}_{2} \mathrm{C}_{1} \mathrm{im}\right]_{2}\left[\mathrm{Co}(\mathrm{NCS})_{4}\right]$ and $\left[\mathrm{C}_{4} \mathrm{C}_{1} \mathrm{im}\right]_{2}\left[\mathrm{Co}(\mathrm{NCS})_{4}\right]$ because the $\alpha \cdot u \cdot(2 \cdot \pi \cdot f)^{-1}$ values changes from $2.8 \cdot 10^{-2}$ to $1 \cdot 10^{-2}$, respectively. A more extreme situation applies to $\left[\mathrm{C}_{n} \mathrm{C}_{1} \mathrm{im}\right]\left[\mathrm{PF}_{6}\right](n=4,6$ or 8$)$, where the $\alpha \cdot u \cdot(2 \cdot \pi \cdot f)^{-1}$ values roughly equal $5.7 \cdot 10^{-2}, 9.7 \cdot 10^{-2}$, and 0.13 , respectively. For comparison, in the case of typical molecular liquids (under similar experimental conditions), the the $\alpha \cdot u \cdot(2 \cdot \pi \cdot f)^{-1}$ values equals $3.8 \cdot 10^{-6}, 8.1 \cdot 10^{-5}$ and $1.52 \cdot 10^{-4}$ for water, 1,2-ethanediol and tetrachloride, respectively. ${ }^{34}$

One of the most urgent problems of ultrasonic investigations today is extending the number of absorption measurements for different classes of ILs at atmospheric pressure. Simultaneously, measurements under elevated pressures should be made to clarify better the relaxation processes, especially to verify the appropriate conditions to treat the speed of sound as a source of thermodynamic quantities.

Generally, because of the dissipative nature of many ILs, great care must be exercised for speed of sound investigations for ILs at lower temperatures and/or higher pressures. For instance, this approach is important for $\left[\mathrm{C}_{n} \mathrm{C}_{1} \mathrm{im}\right]\left[\mathrm{NTf}_{2}\right]$ homologues beginning from $\left[\mathrm{C}_{6} \mathrm{C}_{1} \mathrm{im}\right]\left[\mathrm{NTf}_{2}\right]^{34}$ and for $\left[\mathrm{C}_{n} \mathrm{C}_{1} \mathrm{im}\right]\left[\mathrm{PF}_{6}\right]$, beginning from $\left[\mathrm{C}_{4} \mathrm{C}_{1} \mathrm{im}\right]\left[\mathrm{PF}_{6}\right] .^{18}$

For $\left[\mathrm{C}_{n} \mathrm{C}_{1} \mathrm{im}\right]\left[\mathrm{PF}_{6}\right]$, clear dispersion symptoms are visible for $\left[\mathrm{C}_{6} \mathrm{C}_{1} \mathrm{im}\right]\left[\mathrm{PF}_{6}\right]$ and $\left[\mathrm{C}_{8} \mathrm{C}_{1} \mathrm{im}\right]\left[\mathrm{PF}_{6}\right]^{75,76}$ independently from the absorption measurements, i.e., from temperatures near $300 \mathrm{~K}$ at atmospheric pressure, one needs only analyzing the temperature dependence of the measured speed of sound. ${ }^{18,75}$ In both cases, this dependence increasingly deviates from linearity (much more evident for $\left[\mathrm{C}_{8} \mathrm{C}_{1} \mathrm{im}\right]\left[\mathrm{PF}_{6}\right]$ ) with decreasing temperature. ${ }^{18,75}$ In other words, the higher increase in the speed of sound with decreasing temperature (concave up curve) at the lower temperatures is observed, which is typical behavior in dispersion regions. ${ }^{7}$ Unfortunately, this problem is ignored and the values that are measured by commercial apparatuses are treated as 
thermodynamic values although such clear dispersion symptoms are visible. ${ }^{77}$ Understanding this behavior is difficult because of the existence of a dispersion region, especially for ILs that exhibit high viscosities and/or a rapid increase of viscosity with decreasing temperature (see Figure 8). Thus, high viscosity and large deviations from the linearity of the temperature dependence of the speed of sound can be used as an indirect prove of the existence of velocity dispersion. Therefore, using available instrumentation that was not designed for IL investigations and does not carefully consider the IL's properties can therefore constitute a seriously detrimental contribution to databases.

\subsection{Overview of existing data for ionic liquids}

An overview of existing of speed of sound data in ILs was performed by using Scopus. The search queries were "ionic liquid" together with "speed of sound”, "sound velocity”, "ultrasonic sound velocity”, “ultrasonic velocity”, “sound speeds”, “ultrasonic speed”, “speed of ultrasound" or "ultrasound velocity”. The obtained results were verified by a comparison with the Ionic Liquids Database - ILThermo (v2.0) (NIST Standard Reference Database \#147), which was updated on August 7, 2015. ${ }^{5}$ The database included papers in which experimental speed of sound data were reported for temperatures from $278.15 \mathrm{~K}$ to $393.15 \mathrm{~K}$ and pressures from 0.1 MPa to $200 \mathrm{MPa}$ (142 articles), a paper in which experimental data are presented only as a plot (1 article) and works where only calculated values of speed of sound are available (22 articles) published in the period 2004 - 2014 (Table S1). ${ }^{1,2,12-15,18-23,25-31,33,35,36,45,75-213}$ Table S1 lists 149 ILs (among them, 70\% are aprotic ILs and 30\% are protic ILs), which contain 79 cations and 32 anions, and 5 deep eutectic solvents and 1 Ammoeng 102, which contain acyclic ammonium salts with cations with oligoethylenglycol units of different chain lengths. 


\subsection{Data treatment}

Among the 149 ILs considered here for which speed of sound data are available in the literature, values from one source are available for 75 ILs, values from two sources are available for 24 ILs, values from three to five sources are available for 26 ILs, and more than five sources are available for 24 ILs.

A detailed analysis of literature data for five ILs, namely $\left[\mathrm{C}_{2} \mathrm{C}_{1} \mathrm{im}\right]\left[\mathrm{BF}_{4}\right],\left[\mathrm{C}_{4} \mathrm{C}_{1} \mathrm{im}\right]\left[\mathrm{BF}_{4}\right]$, $\left[\mathrm{C}_{4} \mathrm{C}_{1} \mathrm{im}\right]\left[\mathrm{PF}_{6}\right],\left[\mathrm{C}_{4} \mathrm{C}_{1} \mathrm{im}\right]\left[\mathrm{NTf}_{2}\right],\left[\mathrm{C}_{6} \mathrm{C}_{1} \mathrm{im}\right]\left[\mathrm{NTf}_{2}\right]$ was presented as examples in order to show real difficulties and problems with consistency of speed of sound data sets. For $\left[\mathrm{C}_{2} \mathrm{C}_{1} \mathrm{im}\right]\left[\mathrm{BF}_{4}\right]$ among twelve papers ${ }^{135-146}$, published up to 2014, in eleven there are identical data sets, in some cases differ in decimal places (i.e. one or two); only data reported by Sharma et al. ${ }^{146}$ are different, however they did not compare these results with their own data reported in other papers. Therefore, finally, the analysis of consistency of speed of sound data was presented for four ILs, i.e., $\left[\mathrm{C}_{6} \mathrm{C}_{1} \mathrm{im}\right]\left[\mathrm{NTf}_{2}\right]^{12,31,34,79,152}$ as a substance recommended by IUPAC, [C4 $\left.\mathrm{C}_{1} \mathrm{im}\right]\left[\mathrm{BF}_{4}\right]$, $\left[\mathrm{C}_{4} \mathrm{C}_{1} \mathrm{im}\right]\left[\mathrm{PF}_{6}\right]$ as well as for $\left[\mathrm{C}_{4} \mathrm{C}_{1} \mathrm{im}\right]\left[\mathrm{NTf}_{2}\right] .^{12,14,18,19,22,23,25,30,34}$ The purity of these ILs is compared in Table 4. Among those ILs, two were the most investigated in the literature: $\left[\mathrm{C}_{4} \mathrm{C}_{1} \mathrm{im}\right]\left[\mathrm{BF}_{4}\right]$ in 14 papers, $12,15,19,23,27,28,83,103,106,112,113,117-119$ and $\left[\mathrm{C}_{4} \mathrm{C}_{1} \mathrm{im}\right]\left[\mathrm{PF}_{6}\right]$ in 19 papers $^{12,13,15,18,19,21,22,27,33,75,87-89,105-110}$. However, for $\left[\mathrm{C}_{4} \mathrm{C}_{1} \mathrm{im}\right]\left[\mathrm{BF}_{4}\right]$, the identical speeds of sound data as obtained by Govinda et al. ${ }^{83}$ are reported by Kavitha et al. ${ }^{103}$ Garcia-Miaja et al. ${ }^{112,113}$ cited data published by Zafarani-Moattar and Shekaari. ${ }^{106}$ Additionally, Shekaari and ZafaraniMoattar ${ }^{117}$ wrongly reported speed of sound data for $\left[\mathrm{C}_{4} \mathrm{C}_{1} \mathrm{im}\right]\left[\mathrm{PF}_{6}\right]$ as those for $\left[\mathrm{C}_{4} \mathrm{C}_{1} \mathrm{im}\right]\left[\mathrm{BF}_{4}\right]$ $\left(\mathrm{see}^{13}\right)$. The experimental data are not available in paper by Singh and Kumar. ${ }^{28}$ For the [C4 $\left.\mathrm{C}_{1} \mathrm{im}\right]\left[\mathrm{PF}_{6}\right]$, Pereiro and Rodríguez ${ }^{87,88}$ reported two times the same values of speed of sound. 
Zafarani-Moattar and Shekaari reported three times the same speed of sound values for $\left[\mathrm{C}_{4} \mathrm{C}_{1} \mathrm{im}\right]\left[\mathrm{PF}_{6}\right]$ at $298.15 \mathrm{~K}^{13,105,106}$ In contrast to $\left[\mathrm{C}_{2} \mathrm{C}_{1} \mathrm{im}\right]\left[\mathrm{BF}_{4}\right],\left[\mathrm{C}_{4} \mathrm{C}_{1} \mathrm{im}\right]\left[\mathrm{BF}_{4}\right]$ and $\left[\mathrm{C}_{4} \mathrm{C}_{1} \mathrm{im}\right]\left[\mathrm{PF}_{6}\right]$, for $\left[\mathrm{C}_{4} \mathrm{C}_{1} \mathrm{im}\right]\left[\mathrm{NTf}_{2}\right]$ and $\left[\mathrm{C}_{6} \mathrm{C}_{1} \mathrm{im}\right]\left[\mathrm{NTf}_{2}\right]$, all data sets are original. The temperature dependence on speed of sound was described by a second-order polynomial as suggested by Chirico et al. ${ }^{42}$ Herein, only original data sets (i.e. if there are two or more identical data sets only first published was taken into consideration) were taken into account for comparison. The speeds of sound measured at $11.3 \mathrm{MHz}$ presented by Makino et al., ${ }^{18}$ measured at $30 \mathrm{MHz}$ reported by Demizu et al., ${ }^{23}$ and results for the lowest frequency from work by Fukuda et al. ${ }^{22}$ were included, while results for frequencies of order of $\mathrm{GHz}^{19}$ were excluded. In the first step all original data sets taken into consideration, data which differed more than \pm 10 $\mathrm{m} \cdot \mathrm{s}^{-1}$ from the second-order polynomial fit were excluded and new global fitting has been done. Relative deviations from the fit are presented in Figure 6. As a reference uncertainty, we assumed the combined expanded uncertainty $(k=2)$ equal $1.7 \mathrm{~m} \cdot \mathrm{s}^{-1}$ had estimated by Widegreen and Magee $^{31}$ for $\left[\mathrm{C}_{6} \mathrm{C}_{1} \mathrm{im}\right]\left[\mathrm{NTf}_{2}\right]$ and had recommended by IUPAC ${ }^{45}$.

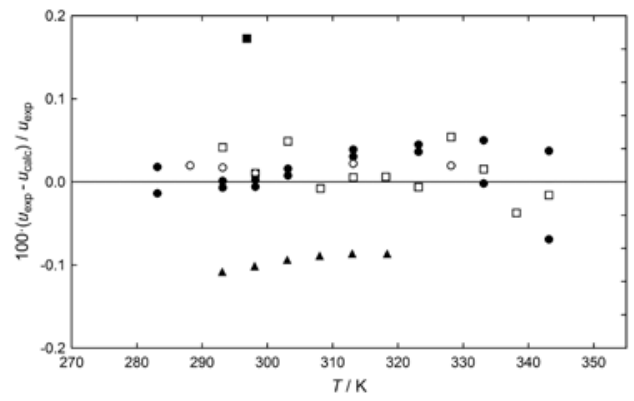

a) $\left[\mathrm{C}_{6} \mathrm{C}_{1} \mathrm{im}\right]\left[\mathrm{NTf}_{2}\right]$ open circle $^{152}$, open squares $^{79}$, filled circles $^{31}$, filled square $^{12}$, filled triangles ${ }^{34}$ 


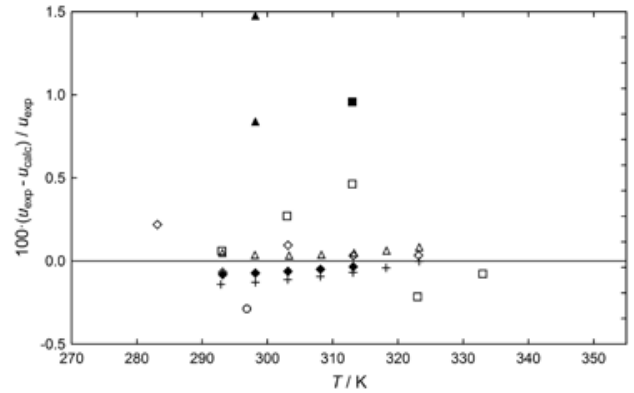

b) $\left[\mathrm{C}_{4} \mathrm{C}_{1} \mathrm{im}\right]\left[\mathrm{NTf}_{2}\right]$ open circle $^{12}$, open squares ${ }^{18}$, open diamonds ${ }^{14}$, open triangles ${ }^{25}$, filled diamonds ${ }^{30}$, filled squares ${ }^{23}$, filled triangles ${ }^{22}$, crosses $^{34}$

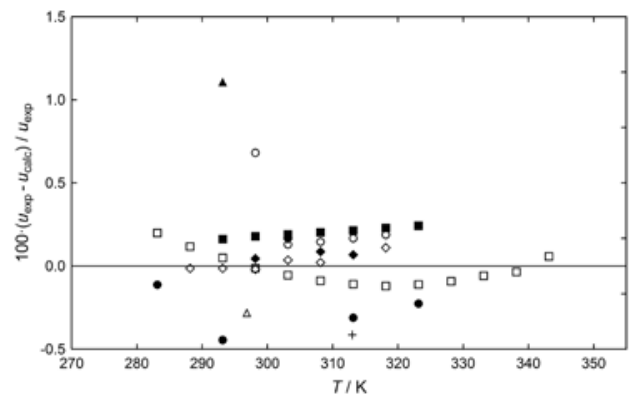

c) $\left[\mathrm{C}_{4} \mathrm{C}_{1} \mathrm{im}\right]\left[\mathrm{BF}_{4}\right]$ open circles ${ }^{106}$, open squares ${ }^{27}$, open diamonds ${ }^{118}$, open triangles ${ }^{12}$, filled circles $^{15}$, filled squares ${ }^{119}$, filled diamonds ${ }^{83}$, filled triangles ${ }^{112}$, crosses $^{23}$ 


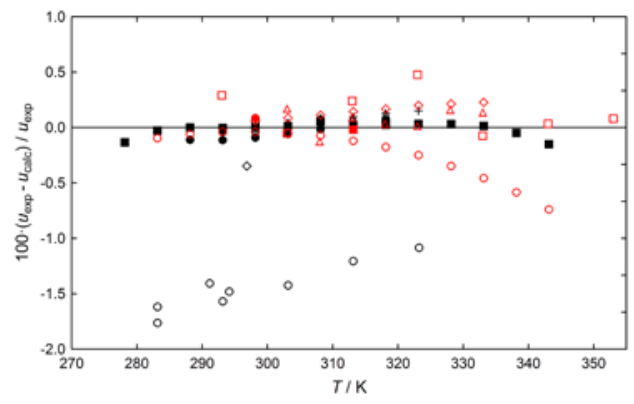

d) $\left[\mathrm{C}_{4} \mathrm{C}_{1} \mathrm{im}\right]\left[\mathrm{PF}_{6}\right]$ open black circles ${ }^{15}$, open black squares ${ }^{107}$, open black diamonds ${ }^{12}$, open black triangles ${ }^{13}$, filled black circles ${ }^{109}$, filled black squares ${ }^{75}$, filled black diamonds ${ }^{108}$, filled black triangles ${ }^{88}$, crosses $^{110}$, red circles $^{27}$, red squares ${ }^{18}$, red diamonds ${ }^{89}$, red triangles $^{33}$, filled red circles $^{22}$, filled red squares ${ }^{21}$

Figure 6. Relative differences between experimental speeds of sound and calculated by secondorder polynomial.

Most of the data for $\left[\mathrm{C}_{6} \mathrm{C}_{1} \mathrm{im}\right]\left[\mathrm{NTf}_{2}\right]$ in Figure 6 a are consistent and are within the range of the speed of sound uncertainty that was estimated for this IUPAC sample, specifically: \pm 1.7 $\mathrm{m} \cdot \mathrm{s}^{-1}$; the only exception is the speed of sound value from the transient grating method ${ }^{12}$, where authors measured speed of sound at $13.4 \mathrm{MHz}$ and declared an error of obtained result $\pm 11 \mathrm{~m} \cdot \mathrm{s}^{-1}$. The combined expanded uncertainties $(k=2)$ of data presented in Figure 6a are: $\pm 0.6 \mathrm{~m} \cdot \mathrm{s}^{-1},{ }^{152} 1.7$ $\mathrm{m} \cdot \mathrm{s}^{-1},{ }^{31} ; \pm 1 \mathrm{~m} \cdot \mathrm{s}^{-1}, 34$ and an uncertainty is $\pm 1 \mathrm{~m} \cdot \mathrm{s}^{-1} \cdot{ }^{79}$

The speeds of sound for $\left[\mathrm{C}_{4} \mathrm{C}_{1} \mathrm{im}\right]\left[\mathrm{NTf}_{2}\right]$ reported by Zorębski et al. ${ }^{25}$, Geppert-Rybczyńska and Sitarek $\mathrm{k}^{30}$, and Zorębski et al. ${ }^{34}$ (the combined expanded uncertainty $(k=2)$ equals $\pm 1 \mathrm{~m} \cdot \mathrm{s}^{-1}$, ${ }^{25,30,34}$ ) are within the assumed reference speed of sound uncertainty $\pm 1.7 \mathrm{~m} \cdot \mathrm{s}^{-1}$ over the whole temperature range (Figure 6b). Discrepancies higher than $+10 \mathrm{~m} \cdot \mathrm{s}^{-1}$ are observed for data reported by Fukuda et al. ${ }^{22}$ and by Demizu et al., ${ }^{23}$ both authors used transient grating method. The error deduced from work of Fukuda et al. is 2-3\%, while Demizu et al. declared error of \pm 
$0.5 \%$. The lower differences in the speed of sound values for $\left[\mathrm{C}_{4} \mathrm{C}_{1} \mathrm{im}\right]\left[\mathrm{NTf}_{2}\right]$, but also beyond of $\pm 1.7 \mathrm{~m} \cdot \mathrm{s}^{-1}$ were obtained from transient grating method by Frez et al. ${ }^{12}$ (speed of sound at 13.4 $\mathrm{MHz}$ ), for the speed of sound data at $283.15 \mathrm{~K}$ reported by Gomes de Azevedo et al., ${ }^{14}$ and by Makino et al., ${ }^{18}$ for which the uncertainties declared by the authors are $6 \mathrm{~m} \cdot \mathrm{s}^{-1}, \pm 0.2 \%$ and from $10 \mathrm{~m} \cdot \mathrm{s}^{-1}$ to $20 \mathrm{~m} \cdot \mathrm{s}^{-1}$, respectively.

For the $\left[\mathrm{C}_{4} \mathrm{C}_{1} \mathrm{im}\right]\left[\mathrm{BF}_{4}\right]$, observed discrepancies are more significant (Figure $6 \mathrm{c}$ ). The data reported by Pal and Kumar are within the quoted uncertainty range $\pm 1.7 \mathrm{~m} \cdot \mathrm{s}^{-1}$ for all temperatures, ${ }^{118}$ as well as results of Kumar except values at $283.15 \mathrm{~K}$ and $288.15 \mathrm{~K}^{27}$ and results of Govinda et al. except at $303.15 \mathrm{~K}^{83}$ and similarly Kavitha et al. ${ }^{103}$ The $u$ values obtained from the transient grating method, ${ }^{12,23}$ the data by Gomes de Azevedo et al., ${ }^{15}$ and the data from commercial apparatuses $^{106,119}$ are beyond $\pm 1.7 \mathrm{~m} \cdot \mathrm{s}^{-1}$. But results reported by Frez et al. ${ }^{12}$ (measured at $17 \mathrm{MHz}$ ), Demizu et al. ${ }^{23}$ are within the errors declared by authors. The two highest deviations are probably the result of editorial mistakes. First one is observed for speed of sound at $298.15 \mathrm{~K}$ reported by Zafarani-Moattar and Shekaari ${ }^{106}$, which is probably a result of wrongly typed values i.e. exchanged tens with units number. As a result of this mistake the second highest deviation is observed for value reported by Garcia-Miaja et al. ${ }^{112,113}$ based on the results of Zafarani-Moattar and Shekaari. ${ }^{106}$

The highest discrepancies of speed of sound were found for $\left[\mathrm{C}_{4} \mathrm{C}_{1} \mathrm{im}\right]\left[\mathrm{PF}_{6}\right]$ (Figure $6 \mathrm{~d}$ ). However the most data are consistent. The speeds of sound reported in ten papers ${ }^{13,21,22,87,88,105-109}$ are within the quoted uncertainty range $\pm 1.7 \mathrm{~m} \cdot \mathrm{s}^{-1}$ for all temperatures. For data reported in ${ }^{33,75}$ deviations are higher than $\pm 1.7 \mathrm{~m} \cdot \mathrm{s}^{-1}$ for extreme temperatures. Pereiro et al. ${ }^{75}$ reported precision of speed of sound measurements equal to $\pm 0.2 \mathrm{~m} \cdot \mathrm{s}^{-1}$. The combined expanded uncertainty $(k=2)$ for the data reported by Singh et al. ${ }^{33}$ is $\pm 0.06 \%$. For data presented by Chaudhary et al. ${ }^{110}$ similar 
deviation is observed for the highest temperature. They assumed the uncertainty of speed of sound measurements to be lower than $5 \cdot 10^{-2} \mathrm{~m} \cdot \mathrm{s}^{-1}$. For data reported by Makino et al., ${ }^{18}$ all deviations are lower than the declared uncertainty from $10 \mathrm{~m} \cdot \mathrm{s}^{-1}$ to $20 \mathrm{~m} \cdot \mathrm{s}^{-1}$ and for six temperatures even lower than $\pm 1.7 \mathrm{~m} \cdot \mathrm{s}^{-1}$. For speeds of sound reported $\mathrm{in}^{27,89}$ the deviations is higher than $\pm 1.7 \mathrm{~m} \cdot \mathrm{s}^{-1}$ for temperatures higher than $308.15 \mathrm{~K}$. The deviation $-5.0 \mathrm{~m} \cdot \mathrm{s}^{-1}$ is observed for speed of sound reported by Frez et al. ${ }^{12}$ (measured at $15.7 \mathrm{MHz}$ ); deviations higher than $14.8 \mathrm{~m} \cdot \mathrm{s}^{-1}$ are observed for data reported by Gomes de Azevedo et al. ${ }^{15}$

Analyses within homologous series may be helpful to indicate erroneous data. For example an analysis of data for the series of $\left[\mathrm{C}_{n} \mathrm{C}_{1} \mathrm{im}\right]\left[\mathrm{BF}_{4}\right] n=2,4,6,8$, revealed that the reported values for $\left[\mathrm{C}_{6} \mathrm{C}_{1} \mathrm{im}\right]\left[\mathrm{BF}_{4}\right]$ by Malek and $\operatorname{Ijardar}^{156,157}$ are systematically lower than correspond to the trends in this homologous series, specifically, deviations from the parabolic functions $u(n)$ are higher than $20 \mathrm{~m} \cdot \mathrm{s}^{-1}$. There is interesting underline that for the [ $\left.\mathrm{N}_{2200}\right][\mathrm{Ac}]$ observed discrepancies c.a. $20 \mathrm{~m} \cdot \mathrm{s}^{-1}$ come from the opposite temperature coefficients of $u$. Unfortunately existing data for the speed of sound in ILs are not as plentiful as would enable to perform extensive and deep analyses of various homologous series.

The analysis of the available speed of sound data under high pressure was discussed by Dzida et al. ${ }^{214}$ The speed of sound in $\left[\mathrm{C}_{3} \mathrm{C}_{1} \mathrm{im}\right]\left[\mathrm{NTf}_{2}\right]$ in the temperature range from $298.15 \mathrm{~K}$ to 338.15 $\mathrm{K}$ at pressures up to $200 \mathrm{MPa}$ and in $\left[\mathrm{C}_{5} \mathrm{C}_{1} \mathrm{im}\right]\left[\mathrm{NTf}_{2}\right]$ in the temperature range from 288.15 K to 338.15 K at pressures up to $200 \mathrm{MPa}$ have been reported by Esperança et al., ${ }^{17}$ while Gomes de Azevedo et al. ${ }^{14}$ have reported data of the speed of sound in $\left[\mathrm{C}_{4} \mathrm{C}_{1} \mathrm{im}\right]\left[\mathrm{NTf}_{2}\right]$ for temperatures from $283.15 \mathrm{~K}$ to $323 \mathrm{~K}$ at pressures up to $151 \mathrm{MPa}$. The speed of sound has also been measured in $\left[\mathrm{C}_{3} \mathrm{C}_{1}\right.$ im] $\left[\mathrm{NTf}_{2}\right]$ and $\left[\mathrm{C}_{5} \mathrm{C}_{1} \mathrm{im}\right]\left[\mathrm{NTf}_{2}\right]$ in the temperature range from $293 \mathrm{~K}$ to $318 \mathrm{~K}$, in $\left[\mathrm{C}_{4} \mathrm{C}_{1} \mathrm{im}\right]\left[\mathrm{NTf}_{2}\right]$ in the temperature range from $293 \mathrm{~K}$ to $323 \mathrm{~K}$ at pressures up to 101 
$\mathrm{MPa}$, and in $\left[\mathrm{C}_{6} \mathrm{C}_{1} \mathrm{im}\right]\left[\mathrm{NTf}_{2}\right]$ in the temperature range from $303 \mathrm{~K}$ to $323 \mathrm{~K}$ at pressures up to $101 \mathrm{MPa} .^{214}$ Dzida et al. ${ }^{214}$ selected temperature ranges by considering the relaxation processes. ${ }^{34}$ It should be noted that $\left[\mathrm{C}_{3} \mathrm{C}_{1} \mathrm{im}\right]\left[\mathrm{NTf}_{2}\right],\left[\mathrm{C}_{4} \mathrm{C}_{1} \mathrm{im}\right]\left[\mathrm{NTf}_{2}\right]$, and $\left[\mathrm{C}_{5} \mathrm{C}_{1} \mathrm{im}\right]\left[\mathrm{NTf}_{2}\right]$ have been studied under high pressure by three different laboratories, but all samples were synthesized and purified at the QUILL research Centre at Belfast. ${ }^{14,17,214}$ In case of $\left[\mathrm{C}_{3} \mathrm{C}_{1} \mathrm{im}\right]\left[\mathrm{NTf}_{2}\right]$ and $\left[\mathrm{C}_{5} \mathrm{C}_{1} \mathrm{im}\right]\left[\mathrm{NTf}_{2}\right]$, the differences observed between data sets published by Esperança et al. ${ }^{17}$ and by Dzida et al. ${ }^{214}$ increase systematically with increasing pressure, while in case of the $\left[\mathrm{C}_{4} \mathrm{C}_{1} \mathrm{im}\right]\left[\mathrm{NTf}_{2}\right]$ the observed differences between data sets published by Gomes de Azevedo et al. ${ }^{14}$ and by Dzida et al. ${ }^{214}$ are not regular. The maximum deviations are $-11.8 \mathrm{~m} \cdot \mathrm{s}^{-1}$ and $-12.1 \mathrm{~m} \cdot \mathrm{s}^{-1}$ at $101 \mathrm{MPa}$ for $\left[\mathrm{C}_{3} \mathrm{C}_{1} \mathrm{im}\right]\left[\mathrm{NTf}_{2}\right]$ and $\left[\mathrm{C}_{5} \mathrm{C}_{1} \mathrm{im}\right]\left[\mathrm{NTf}_{2}\right]$, respectively. The observed deviations have the same magnitude at a given pressure independently on temperature and IL and are higher than uncertainties declared by Esperança et al. (i.e. $0.05 \%)^{17}$ and by Dzida et al. (i.e., $\left.\pm 1 \mathrm{~m} \cdot \mathrm{s}^{-1}\right)^{214}$ These differences probably resulted from the reference liquids that were chosen for calibration and the method of calibration selected by each group. In the case of $\left[\mathrm{C}_{4} \mathrm{C}_{1} \mathrm{im}\right]\left[\mathrm{NTf}_{2}\right]$, the differences are lower than accuracy claimed by Gomes de Azevedo et al. (i.e., $\pm 0.2 \%$ ), ${ }^{14}$ but are higher than that reported by Dzida et al. (i.e., $\pm 1 \mathrm{~m} \cdot \mathrm{s}^{-1}$ ), as the maximum deviation observed between these two data sets is $-2.42 \mathrm{~m} \cdot \mathrm{s}^{-1}$ at $45.59 \mathrm{MPa}$ and $303.15 \mathrm{~K}$. The appropriate absolute average relative deviation $(A A R D)$ is reported in table 5 in paragraph 4.

Summing up above analysis, we noticed that the disagreement between the different available data sets is highly distressing as was noted by Nieto de Castro in case of other physicochemical properties. ${ }^{215}$ Besides the fact that the ILs are difficult objects of study, authors should pay more attention and should have more criticism in citation literature data in order to avoid duplication of mistakes or to avoid dissemination of unreliable data sets. Moreover, based 
on new experience gained in work with ILs, authors should also focus on new experimental data even for very popular ILs in order to obtain more reliable ones, not only reproduce old values.

\section{Speed of sound in ionic liquids}

\subsection{Temperature and pressure effects}

The speed of sound in ILs has been measured in the temperature range from $278.15 \mathrm{~K}$ to $393.15 \mathrm{~K}$ (see Table S1). In case of the $\left[\mathrm{C}_{4} \mathrm{C}_{1} \mathrm{im}\right]\left[\mathrm{NTf}_{2}\right]$, its speed of sound was estimated at temperature close to $T_{g}=181.15 \mathrm{~K} \cdot{ }^{216}$ The highest pressure condition reported in the literature for the speed of sound in IL was $200 \mathrm{MPa} .{ }^{17} \mathrm{Wu}$ et al. ${ }^{4}$ examined the effect of temperature on the speed of sound in ILs based on seven substances as an example. The authors showed an atypical $u(T)$ dependence for $\left[\mathrm{N}_{2200}\right][\mathrm{Ac}] .^{36}$ However, available data sets for $\left[\mathrm{N}_{2200}\right][\mathrm{Ac}]$ exhibited a negative temperature coefficient for the speed of sound $\left(-0.80 \mathrm{~m} \cdot \mathrm{s}^{-1} \cdot \mathrm{K}^{-1}\right)^{80}$ and a positive temperature coefficient for the speed of sound $\left(+0.80 \mathrm{~m} \cdot \mathrm{s}^{-1} \cdot \mathrm{K}^{-1}\right){ }^{36}$ opposite temperature dependences have not been verified (Figure 7). An unusual temperature dependence on the speed of sound was also observed for $\left[\mathrm{N}_{1110}\right]\left[\mathrm{H}_{2} \mathrm{PO}_{4}\right]{ }^{81,189}$ Additionally, Wu et al. ${ }^{4}$ noticed a „nonlinear” temperature dependence on the speed of sound in $\left[\mathrm{N} 2(\mathrm{OH}) \mathrm{C}_{2111}\right][\mathrm{Lact}]$ and $[\mathrm{N}$ $\left.\left(2(\mathrm{OH}) \mathrm{C}_{2}\right) 3_{1}\right]\left[\mathrm{C}_{1} \mathrm{SO}_{4}\right],{ }^{174}$ which has also been observed for $\left[\mathrm{C}_{8} \mathrm{C}_{1} \mathrm{im}\right][\mathrm{Cl}],{ }^{114,160}\left[\mathrm{P}_{4448}\right][\mathrm{Cl}],{ }^{77}$ $\left[\mathrm{GlyC}_{3}\right][\mathrm{LS}],{ }^{179} \quad\left[\mathrm{GluC}_{3}\right][\mathrm{LS}],{ }^{179} \quad\left[\mathrm{AlaC}_{4}\right][\mathrm{LS}],{ }^{179} \quad\left[\mathrm{ValC}_{4}\right][\mathrm{LS}],{ }^{179} \quad\left[\mathrm{~N}\left(2(\mathrm{OH}) \mathrm{C}_{2}\right) 2_{00}\right][\mathrm{O}],{ }^{78}$ $\left[\mathrm{N} 2(\mathrm{OH}) \mathrm{C}_{2000}\right]\left[\mathrm{C}_{4} \mathrm{COO}\right]^{171}$ and $\quad\left[\mathrm{N}\left(2(\mathrm{OH}) \mathrm{C}_{2}\right) 2_{00}\right]\left[\mathrm{C}_{4} \mathrm{COO}\right],{ }^{171} \quad\left[\mathrm{~N}\left(2(\mathrm{OH}) \mathrm{C}_{2}\right) 3_{0}\right]\left[\mathrm{C}_{4} \mathrm{COO}\right],{ }^{171}$ $\left[\mathrm{N} 2(\mathrm{OH}) \mathrm{C}_{2111}\right][\mathrm{Lact}],{ }^{174,175} \quad\left[\mathrm{~N}\left(2(\mathrm{OH}) \mathrm{C}_{2}\right) 3_{1}\right]\left[\mathrm{C}_{2} \mathrm{SO}_{4}\right],{ }^{174} \quad\left[\mathrm{C}_{2} \mathrm{C}_{1} \mathrm{im}\right][\mathrm{Lact}],{ }^{128} \quad\left[\mathrm{C}_{4} \mathrm{C}_{1} \mathrm{im}\right][\mathrm{Ac}],{ }^{100}$ $\left[\mathrm{P}_{i 3 i 3 i 31}\right][\mathrm{Tos}],{ }^{89}\left[\mathrm{~N}\left(2(\mathrm{OH}) \mathrm{C}_{2}\right) 2_{00}\right][\mathrm{O}],{ }^{78}\left[\mathrm{C}_{6} \mathrm{C}_{1} \mathrm{im}\right]\left[\mathrm{PF}_{6}\right],{ }^{18,75,76,87-89,154,155}$ and $\left[\mathrm{C}_{8} \mathrm{C}_{1} \mathrm{im}\right]\left[\mathrm{PF}_{6}\right] .{ }^{18,87-}$ ${ }^{89,154,163}$ According to the effects described in paragraph 2.2.2, the nonlinear dependence of $u(T)$ i.e., the high rate of $(\partial u / \partial T)_{p}$ at low temperature range could be interpreted as a result of 
absorption and/or relaxation phenomena. An increase of the nonlinearity of $u(T)$ with decreasing the temperature, together with a similar temperature effect on the viscosity (see Figure 8) could indicate that the absorption and/or relaxation effects probably occurred (as mentioned above, see paragraph 2.2.2). However, in many cases, the speed of sound is described by using a linear function of the temperature as claimed by $\mathrm{Wu}$ et al. ${ }^{4}$ in the case of the $\left[\mathrm{C}_{4} \mathrm{C}_{1} \mathrm{pyr}\right]\left[\mathrm{NTf}_{2}\right]$, [C 4 -3$\left.\mathrm{C}_{1} \mathrm{py}\right]\left[\mathrm{BF}_{4}\right],\left[\mathrm{P}_{4441}\right]\left[\mathrm{C}_{1} \mathrm{SO}_{4}\right]$. Wu et al. ${ }^{4}$ classified $u(T)$ for $\left[\mathrm{C}_{6} \mathrm{C}_{1} \mathrm{im}\right]\left[\mathrm{PF}_{6}\right]$ as a linear function, but according to the Figure 7, it appears that a nonlinear relationship may occur. A linear function was also used for $\left[\mathrm{C}_{4} \mathrm{C}_{1} \mathrm{im}\right]\left[\mathrm{N}(\mathrm{CN})_{2}\right],{ }^{79}\left[\mathrm{C}_{4}-4-\mathrm{C}_{1} \mathrm{py}\right]\left[\mathrm{BF}_{4}\right],{ }^{124}$ and $\left[\mathrm{AlaC}_{3}\right][\mathrm{LS}]^{179}$ (Figure 7). Quadratic equation is also frequently used to describe the temperature dependence on speed of sound data in ILs, such as for $\left[\mathrm{C}_{4} \mathrm{C}_{1} \mathrm{im}\right]\left[\mathrm{NTf}_{2}\right],{ }^{25}\left[\mathrm{C}_{1} \mathrm{py}\right]\left[\mathrm{C}_{1} \mathrm{SO}_{4}\right],{ }^{84}\left[\mathrm{C}_{2}-2-\mathrm{C}_{1} \mathrm{py}\right]\left[\mathrm{NTf}_{2}\right],{ }^{127}$ and $\left[\mathrm{N}_{1} 2(\mathrm{OH}) \mathrm{C}_{200}\right][\mathrm{HCOO}] .{ }^{182}$ In some cases, $u(T)$ described third-order polynomial equation, while this nonlinearity was not connected with absorption and/or relaxation effects. Widegreen and Magee described the temperature dependence on the speed of sound in the IUPAC sample $\left[\mathrm{C}_{6} \mathrm{C}_{1} \mathrm{im}\right]\left[\mathrm{NTf}_{2}\right]$ by using a third-order polynomial, ${ }^{31}$ while Chirico et al. described the same data set by using a quadratic function. ${ }^{45}$ In case of the $\left[\mathrm{N} 2(\mathrm{OH}) \mathrm{C}_{2000}\right][\mathrm{O}]$ an inflection point at $\sim 287 \mathrm{~K}$ was observed that could be explained as the formation of a new molecular structure in a new physical phase. ${ }^{78}$ This inflection also exists for the density and isentropic compressibility of $\left[\mathrm{N} 2(\mathrm{OH}) \mathrm{C}_{2000}\right][\mathrm{O}]$.

Aside from the three above mentioned data sets, the temperature coefficients of the speed of sound are negative and differ by one order of magnitude at most. At $303.15 \mathrm{~K}$ the values lie in the range from $-6.08 \mathrm{~m} \cdot \mathrm{s}^{-1} \cdot \mathrm{K}^{-1}$ to $-0.60 \mathrm{~m} \cdot \mathrm{s}^{-1} \cdot \mathrm{K}^{-1}$. The highest temperature dependence on the speed of sound in ILs was observed for $\left[\mathrm{P}_{4448}\right][\mathrm{Cl}],{ }^{77}$ whereas the lowest one is described for the $\left[\mathrm{N}_{2220}\right]\left[\mathrm{HSO}_{4}\right]$ (Figure 7). ${ }^{36}$ Low temperature coefficients of $-0.80 \mathrm{~m} \cdot \mathrm{s}^{-1} \cdot \mathrm{K}^{-1}$ can be attributed to 
three ILs, i.e., $\left[\mathrm{N}_{1110}\right]\left[\mathrm{HSO}_{4}\right]^{189}\left[\mathrm{C}_{2} \mathrm{C}_{1} \mathrm{im}\right][\mathrm{Cl}],{ }^{103}$ and $\left[\mathrm{N}_{2200}\right][\mathrm{Ac}]^{80}$ whereas the second highest value, $-6.00 \mathrm{~m} \cdot \mathrm{s}^{-1} \cdot \mathrm{K}^{-1}$, was observed for $\left[\mathrm{N}_{1110}\right][\mathrm{Ac}] .{ }^{189}$ All the remaining ILs show temperature coefficients from $-5.00 \mathrm{~m} \cdot \mathrm{s}^{-1} \cdot \mathrm{K}^{-1}$ to $-1.60 \mathrm{~m} \cdot \mathrm{s}^{-1} \cdot \mathrm{K}^{-1}$, which is similar to those observed for most molecular liquids. Moderate temperature coefficients range from $-3.60 \mathrm{~m} \cdot \mathrm{s}^{-1} \cdot \mathrm{K}^{-1}$ to $-2.05 \mathrm{~m} \cdot \mathrm{s}^{-1} \cdot \mathrm{K}^{-1}$ can be attributed to ILs with the $\left[\mathrm{NTf}_{2}\right]^{-}$anion, while the most similar range of temperature coefficients accurs for ILs with [TFO] $]^{-}$and $\left[\mathrm{PF}_{6}\right]^{-}$anions from $-2.20 \mathrm{~m} \cdot \mathrm{s}^{-1} \cdot \mathrm{K}^{-1}$ to $-2.88 \mathrm{~m} \cdot \mathrm{s}^{-1} \cdot \mathrm{K}^{-1}$.

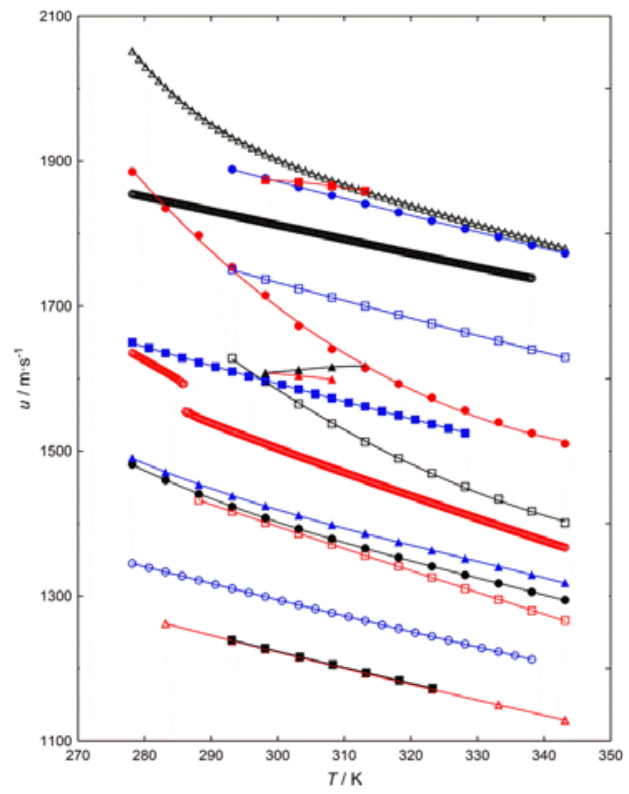

Figure 7. Temperature dependence of the speed of sound in various ILs: open black triangle $\left[\mathrm{N} 2(\mathrm{OH}) \mathrm{C}_{2111}\right][\mathrm{Lact}],{ }^{174}$ filled red squares - $\left[\mathrm{N}_{2220}\right]\left[\mathrm{HSO}_{4}\right],{ }^{36}$ filled blue circles -

$\left[\mathrm{C}_{1} \mathrm{py}\right]\left[\mathrm{C}_{1} \mathrm{SO}_{4}\right],{ }^{84}$ open black circles - $\left[\mathrm{N}_{1} 2(\mathrm{OH}) \mathrm{C} 2_{00}\right][\mathrm{HCOO}],{ }^{182}$ open blue squares -

$\left[\mathrm{C}_{4} \mathrm{C}_{1} \mathrm{im}\right]\left[\mathrm{N}(\mathrm{CN})_{2}\right],{ }^{79}$ filled red circles $-\left[\mathrm{C}_{8} \mathrm{C}_{1} \mathrm{im}\right][\mathrm{Cl}],{ }^{114}$ filled black triangles $-\left[\mathrm{N}_{2200}\right][\mathrm{Ac}]{ }^{36}$ 
filled red triangles - $\left[\mathrm{N}_{2200}\right][\mathrm{Ac}]{ }^{80}$ filled blues squares - $\left[\mathrm{C}_{4}-4-\mathrm{C}_{1} \mathrm{py}\right]\left[\mathrm{BF}_{4}\right],{ }^{124}$ open black squares $-\left[\mathrm{P}_{4448}\right][\mathrm{Cl}],{ }^{77}$ open red circles - $\left[\mathrm{N} 2(\mathrm{OH}) \mathrm{C}_{2000}\right][\mathrm{O}],{ }^{78}$ filled blue triangles - $\left[\mathrm{C}_{6} \mathrm{C}_{1} \mathrm{im}\right]\left[\mathrm{PF}_{6}\right],{ }^{75}$ filled black squares - $\left[\mathrm{C}_{8} \mathrm{C}_{1} \mathrm{im}\right]\left[\mathrm{PF}_{6}\right],{ }^{75}$ open red squares - $\left[\mathrm{AlaC}_{3}\right][\mathrm{LS}],{ }^{179}$ open blue circles - $\left[\mathrm{C}_{2}-\right.$ 2-C $\mathrm{C}_{1}$ py $]\left[\mathrm{NTf}_{2}\right],{ }^{127}$ filled black squares - $\left[\mathrm{C}_{4} \mathrm{C}_{1} \mathrm{im}\right]\left[\mathrm{NTf}_{2}\right],{ }^{25}$ open red triangle - $\left[\mathrm{C}_{6} \mathrm{C}_{1} \mathrm{im}\right]\left[\mathrm{NTf}_{2}\right] .{ }^{31}$

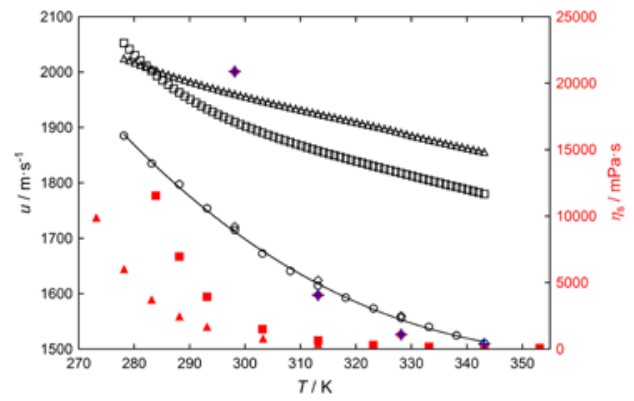

Figure 8. Temperature dependence of the speed of sound (open black symbols) and viscosity (filled red symbols): open black circles - $\left[\mathrm{C}_{8} \mathrm{C}_{1} \mathrm{im}\right][\mathrm{Cl}],{ }^{114}$ open black diamonds $\left[\mathrm{C}_{8} \mathrm{C}_{1} \mathrm{im}\right][\mathrm{Cl}],{ }^{160}$ filled red circles $-\left[\mathrm{C}_{8} \mathrm{C}_{1} \mathrm{im}\right][\mathrm{Cl}],{ }^{160}$ blue pluses $-\left[\mathrm{C}_{8} \mathrm{C}_{1} \mathrm{im}\right][\mathrm{Cl}],{ }^{217}$ squares$\left[\mathrm{N} 2(\mathrm{OH}) \mathrm{C}_{2111}\right][\mathrm{Lact}],{ }^{174}$ triangles - $\left[\mathrm{N}\left(2(\mathrm{OH}) \mathrm{C}_{2}\right) 3_{1}\right]\left[\mathrm{C}_{1} \mathrm{SO}_{4}\right] .{ }^{174}$

Only six publications were dedicated to the experimental speed of sound under high pressures,${ }^{14,15,17,29,214}$ which were obtained from direct measurements, and all other high pressure data had been estimated from the equation of state. ${ }^{196,199,200,207,218}$

The equation by Sun et al. ${ }^{219}$ was chosen by Dzida et al. ${ }^{29,214}$ to smooth out the speed of sound, pressure and temperature:

$p-p_{0}=\sum_{i=1}^{3} \sum_{j=0}^{2} a_{i j}\left(u-u_{0}\right)^{i} T^{j}$. 
Esperança et al. ${ }^{17}$ used the following equation:

$u=\left(a+b p+c p^{2}+d T+e T^{2}\right) /\left(1+f p+g p^{2}+h p^{3}+i T\right)$,

where $a, b, c, d, e, f, g, h$ and $i$ are fitting parameters. Gomes de Azevedo et al. ${ }^{14,15}$ also used the above equation but with pressure raised to the power of 2. Hence, an improperly described pressure-temperature behavior of the speed of sound is the main source of the errors in the relevant thermodynamic quantities.

In contrast to molecular liquids, ${ }^{63,220}$ the relationship $u(n, p)$ for $\left[\mathrm{C}_{n} \mathrm{C}_{1} \mathrm{im}\right]$ $\left[\mathrm{NTf}_{2}\right]^{14,15,17,29,214}$ is irregular. However the $u(p)$ and $(\partial u / \partial p)_{T}$ for all the studied ILs are typical, ${ }^{14,15,17,29,214,221}$ exhibiting no anomalies, and are similar to those of organic molecular liquids. An example for $\left[\mathrm{C}_{2} \mathrm{C}_{1} \mathrm{im}\right]\left[\mathrm{NTf}_{2}\right]$ is depicted in Figure 9.

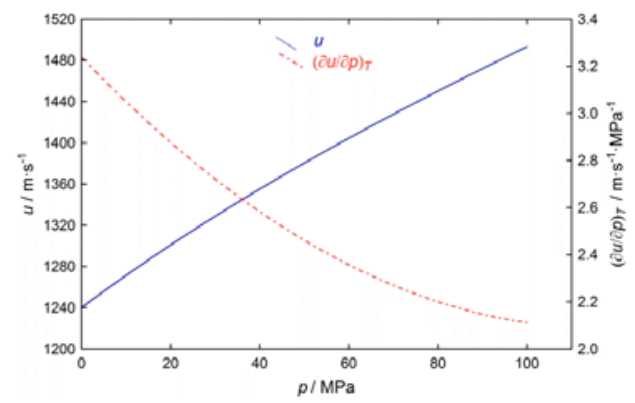

Figure 9. Dependence of the speed of sound $u$ (blue line) and the pressure derivative of the speed of sound $(\partial u / \partial p)_{T}$ (dashed red line) on pressure $p$ for $\left[\mathrm{C}_{2} \mathrm{C}_{1} \mathrm{im}\right]\left[\mathrm{NTf}_{2}\right]$ at temperature $298.15 \mathrm{~K}$. Lines are obtained from smoothing equation $u=u(p, T)$ reported by Dzida et al. ${ }^{29}$ and from derivation of this smoothing equation. ${ }^{221}$ Reproduced with permission from ref ${ }^{221}$. Copyright 2016 Polish Academy of Science. 
The knowledge of the pressure and temperature derivative of the speed of sound allows one to determine of the second-order nonlinearity parameter $B / A$ (the so-called Beyer nonlinearity parameter). However, to date, this parameter was only calculated for one IL namely the $\left[\mathrm{C}_{2} \mathrm{C}_{1} \mathrm{im}\right]\left[\mathrm{NTf}_{2}\right] .{ }^{221}$

\subsection{Effect of impurities on speed of sound measurements}

The impurities that are usually present in pure ILs after synthesis are water, organic solvents and halides (chlorides or bromides). ${ }^{222-224}$ Water, the other organic solvents and gases that are dissolved in ILs can be removed very effectively under high vacuum, whereas halides and metal content are usually removed by washing the IL with water. This process is obviously useless for water-miscible ILs, for which another solvent should be used to dissolve the IL but not the undesidered impurities. Unfortunately, this approach can cause some losses in the amount of the IL. Determining the water in the samples is currently a standard procedure before (and sometimes after) physicochemical measurements. The amount of water in the sample is usually estimated by the volumetric or coulometric Karl-Fisher titration procedure. ${ }^{26,127}$ Determining the halide content is not performed very often. ${ }^{15,27,31,92,164,168,222}$ Methods to determine the halide content were mentioned and/or described in only a few of the papers that were regarded in this

work; ${ }^{15,27,31,92,164,168}$ in other papers, ${ }^{25,26,79,166}$ the necessary data were given after a certificate of analysis provided by the supplier. The simplest process is a silver nitrate test (Volhard's method), which can show (when precipitation occurs) some traces of halide ions to the detection level. ${ }^{17,27}$ More sophisticated techniques, such as ionic chromatography, ${ }^{168}$ capillary electrophoresis, ${ }^{164}$ or halide-selective electrodes, ${ }^{15,31,92}$ are not very commonly used.

In many studies, the process of preparing ILs for measurement is described as purifying or drying in a vacuum system with stirring. The most typical conditions are very similar to those for 
samples of $\left[\mathrm{C}_{3} \mathrm{C}_{1} \mathrm{pyr}\right]\left[\mathrm{NTf}_{2}\right]$, where medium temperatures up to $343 \mathrm{~K}$ and pressures down to 0.2 Pa are applied for 24-48 hours or longer. ${ }^{75,95,159}$ This condition can be changed depending on the IL (hydrophobic or hydrophilic) and the amount of water, such as for $\left[\mathrm{C}_{4} \mathrm{C}_{1} \mathrm{im}\right][\mathrm{SCN}]$, for which the sample is dried under very low pressures of approximately $5 \cdot 10^{-3} \mathrm{~Pa}$ at $300 \mathrm{~K}$ for 5 hours, ${ }^{201}$ or for $\left[\mathrm{C}_{3} \mathrm{C}_{1} \mathrm{im}\right][\mathrm{Br}],{ }^{169}$ for which the drying time was reduced to 4 hours under $p \approx 700 \mathrm{~Pa}$ at $T=$ 333.15 K. The reported times of the drying process were sometimes evidently longer. ${ }^{100}$

The impact of water as an impurity on speed of sound data has been discussed in two papers; ${ }^{31,225}$ however, no information regarding the influence of halides nor metal content on the speed of sound exists in the literature. The results that were obtained by Widegren and Magee ${ }^{31}$ were used to establish $\left[\mathrm{C}_{6} \mathrm{C}_{1} \mathrm{im}\right]\left[\mathrm{NTf}_{2}\right]$ as the IUPAC standard for many thermodynamic, transport and phase-equilibria properties, including the speed of sound under atmospheric pressure. $^{45}$

Table 4 shows collected data that could be useful in an analysis of the influence of water and halides in pure ILs on the speed of sound. These factors were only considered for ILs for which at least two $u$ values were present in the literature. 
Table 4. The List of ILs for Analysis of Influence of Impurities on Speed of Sound ${ }^{a}$

\begin{tabular}{|c|c|c|c|c|c|c|c|c|}
\hline cation & anion & supplier & purity of IL & water (ppm) & $\begin{array}{l}\text { halides and } \\
\text { others (ppm) }\end{array}$ & $u / \mathrm{m} \cdot \mathrm{s}^{-1}$ & measurement method & references \\
\hline $\mathrm{C}_{4} \mathrm{C}_{1} \mathrm{im}$ & $\mathrm{NTf}_{2}$ & $\begin{array}{c}\text { synt. QUILL Centre, } \\
\text { Belfast }\end{array}$ & $99 \%$ & $<75$ & & 1227.61 (int.) & Time of flight & 14 \\
\hline $\mathrm{C}_{4} \mathrm{C}_{1} \mathrm{~mm}$ & $\mathrm{NTf}_{2}$ & Kanto Chemical Co. & n.s. & & & 1230 (int.) & Time of flight & 18 \\
\hline $\mathrm{C}_{4} \mathrm{C}_{1} \mathrm{im}$ & $\mathrm{NTf}_{2}$ & Iolitec & $>99 \mathrm{wt} \%$ & 70 & $<100$ & 1228.1 (int.) & Sing-around & 25 \\
\hline $\mathrm{C}_{4} \mathrm{C}_{1} \mathrm{~m}$ & $\mathrm{NTf}_{2}$ & Iolitec & > $99 \mathrm{wt} \%$ & 300 & $<100$ & 1226.7 & Pulse-echo overlap & 30 \\
\hline $\mathrm{C}_{4} \mathrm{C}_{1} \mathrm{im}$ & $\mathrm{NTf}_{2}$ & $\begin{array}{l}\text { synt. QUILL Centre, } \\
\text { Belfast }\end{array}$ & > 99.95 wt\% & 171 & $\begin{array}{l}<5 \text { (bromides) } \\
19 \text { (lithium) }\end{array}$ & 1226.02 (int.) & Pulse-echo overlap & 34 \\
\hline $\mathrm{C}_{4} \mathrm{C}_{1} \mathrm{im}$ & $\mathrm{Cl}$ & Sigma Chemical Co. & $>98 \%$ & & & 1868 & $\begin{array}{c}\text { Ultrasonic } \\
\text { interferometer }\end{array}$ & 102 \\
\hline $\mathrm{C}_{4} \mathrm{C}_{1} \mathrm{im}$ & $\mathrm{Cl}$ & Sigma-Aldrich & $99 \mathrm{wt} \%$ & $<75$ & & 1868 & $\begin{array}{c}\text { Ultrasonic } \\
\text { interferometer }\end{array}$ & 83 \\
\hline $\mathrm{C}_{4} \mathrm{C}_{1} \mathrm{im}$ & $\mathrm{Cl}$ & Sigma-Aldrich & 99 wt\% & $<100$ & & 1874 & $\begin{array}{c}\text { Ultrasonic } \\
\text { interferometer }\end{array}$ & 103 \\
\hline $\mathrm{C}_{4} \mathrm{C}_{1} \mathrm{im}$ & $\mathrm{N}(\mathrm{CN})_{2}$ & Iolitec & > $98 \mathrm{wt} \%$ & 1240 & $<700$ & 1738.53 (int.) & $\begin{array}{c}\text { Anton Paar DSA } \\
5000 \mathrm{M}\end{array}$ & 104 \\
\hline $\mathrm{C}_{4} \mathrm{C}_{1} \mathrm{~m}$ & $\mathrm{~N}(\mathrm{CN})_{2}$ & Iolitec & $98 \mathrm{wt} \%$ & $<851$ & & 1738.1 & $\begin{array}{c}\text { Anton Paar DSA } \\
5000 \mathrm{M}\end{array}$ & 85 \\
\hline $\mathrm{C}_{4} \mathrm{C}_{1} \mathrm{im}$ & $\mathrm{N}(\mathrm{CN})_{2}$ & Iolitec & $99 \mathrm{wt} \%$ & 1240 & $<700$ & 1737 & $\begin{array}{c}\text { Anton Paar DSA } \\
5000 \mathrm{M}\end{array}$ & 79 \\
\hline $\mathrm{C}_{4} \mathrm{C}_{1} \mathrm{im}$ & $\mathrm{PF}_{6}$ & $\begin{array}{c}\text { synt. QUILL Centre, } \\
\text { Belfast }\end{array}$ & n.s. & 75 & 2 & 1422.4 (int.) & Time of flight & 15 \\
\hline $\mathrm{C}_{4} \mathrm{C}_{1} \mathrm{im}$ & $\mathrm{PF}_{6}$ & Solvent Innovation & $\begin{array}{c}>98 \mathrm{wt} \%^{13,105} \\
\text { n. } \text { s }^{106}\end{array}$ & & & 1442.41 & $\begin{array}{c}\text { Anton Paar DSA } \\
5000\end{array}$ & $13,105,106$ \\
\hline $\mathrm{C}_{4} \mathrm{C}_{1} \mathrm{im}$ & $\mathrm{PF}_{6}$ & $\begin{array}{l}\text { Green Solutions } \\
\text { Chemicals S. L. }\end{array}$ & $>98 \mathrm{wt} \%$ & $<300$ & & 1443 & Anton Paar DSA 48 & 87,88 \\
\hline $\mathrm{C}_{4} \mathrm{C}_{1} \mathrm{im}$ & $\mathrm{PF}_{6}$ & synthesized & n.s. & $<300$ & & 1442.8 & $\begin{array}{c}\text { Anton Paar DSA } \\
5000\end{array}$ & 75 \\
\hline $\mathrm{C}_{4} \mathrm{C}_{1} \mathrm{im}$ & $\mathrm{PF}_{6}$ & Solvent Innovation & $98 \mathrm{wt} \%$ & 1 & & 1443.54 & $\begin{array}{c}\text { Anton Paar DSA } \\
5000\end{array}$ & 107 \\
\hline
\end{tabular}




\begin{tabular}{|c|c|c|c|c|c|c|c|c|}
\hline $\mathrm{C}_{4} \mathrm{C}_{1} \mathrm{im}$ & $\mathrm{PF}_{6}$ & Kanto Chemical Co. & n.s. & & & 1446 (int.) & Time of flight & 18 \\
\hline $\mathrm{C}_{4} \mathrm{C}_{1} \mathrm{im}$ & $\mathrm{PF}_{6}$ & Merck & $>98 \mathrm{wt} \%$ & $<200$ & $\begin{array}{c}<100 \\
\text { (chlorides) }\end{array}$ & 1442.2 & Sing-around & 27 \\
\hline $\mathrm{C}_{4} \mathrm{C}_{1} \mathrm{im}$ & $\mathrm{PF}_{6}$ & Fluka & > 98 mole\% & $<200$ & & 1442.9 & $\begin{array}{c}\text { Anton Paar DSA } \\
5000\end{array}$ & 108 \\
\hline $\mathrm{C}_{4} \mathrm{C}_{1} \mathrm{im}$ & $\mathrm{PF}_{6}$ & Merck-Schuchardt & > 98 mole $\%$ & $<100$ & & 1441.45 & $\begin{array}{c}\text { Anton Paar DSA } \\
5000\end{array}$ & 109 \\
\hline $\mathrm{C}_{4} \mathrm{C}_{1} \mathrm{im}$ & $\mathrm{PF}_{6}$ & Sigma-Aldrich & $\geq 97 \mathrm{wt} \%$ & & & 1442.64 & $\begin{array}{l}\text { Anton Paar DSA } \\
\quad 5000\end{array}$ & 110 \\
\hline $\mathrm{C}_{4} \mathrm{C}_{1} \mathrm{im}$ & $\mathrm{PF}_{6}$ & Sigma & $\geq 97$ wt $\%$ & $<1000$ & & 1443.6 & $\begin{array}{c}\text { Anton Paar DSA } \\
5000\end{array}$ & 89 \\
\hline $\mathrm{C}_{4} \mathrm{C}_{1} \mathrm{im}$ & $\mathrm{C}_{1} \mathrm{SO}_{4}$ & synthesized & n.s. & $<300$ & & 1658.4 & $\begin{array}{c}\text { Anton Paar DSA } \\
5000\end{array}$ & 111 \\
\hline $\mathrm{C}_{4} \mathrm{C}_{1} \mathrm{im}$ & $\mathrm{C}_{1} \mathrm{SO}_{4}$ & $\begin{array}{l}\text { Green Solutions } \\
\text { Chemicals S. L. }\end{array}$ & $>98 \mathrm{wt} \%$ & $<300$ & & 1658 & Anton Paar DSA 48 & 87 \\
\hline $\mathrm{C}_{4} \mathrm{C}_{1} \mathrm{im}$ & $\mathrm{C}_{1} \mathrm{SO}_{4}$ & Solvent Innovation & $>98$ mole $\%$ & $<200$ & & 1658 & $\begin{array}{c}\text { Anton Paar DSA } \\
5000\end{array}$ & 114 \\
\hline $\mathrm{C}_{4} \mathrm{C}_{1} \mathrm{im}$ & $\mathrm{C}_{1} \mathrm{SO}_{4}$ & Aldrich & $>97$ wt\% & & & 1654.61 & $\begin{array}{c}\text { Anton Paar DSA } \\
5000\end{array}$ & 115 \\
\hline $\mathrm{C}_{4} \mathrm{C}_{1} \mathrm{im}$ & $\mathrm{C}_{8} \mathrm{SO}_{4}$ & Fluka & $>95 \%$ & $<500$ & $\begin{array}{c}<1000 \\
\text { (chlorides) }\end{array}$ & 1472.9 & $\begin{array}{c}\text { Anton Paar DSA } \\
5000\end{array}$ & 116 \\
\hline $\mathrm{C}_{4} \mathrm{C}_{1} \mathrm{im}$ & $\mathrm{C}_{8} \mathrm{SO}_{4}$ & Solvent Innovation & > 98 mole\% & $<200$ & & 1484.7 & $\begin{array}{l}\text { Anton Paar DSA } \\
\quad 5000\end{array}$ & 114 \\
\hline $\mathrm{C}_{4} \mathrm{C}_{1} \mathrm{im}$ & $\mathrm{BF}_{4}$ & Solvent Innovation & $>98$ mole $\%$ & 75 & 100 & 1557.9 (int.) & Time of flight & 16 \\
\hline $\mathrm{C}_{4} \mathrm{C}_{1} \mathrm{im}$ & $\mathrm{BF}_{4}$ & Solvent Innovation & $>98$ wt\% & & & 1576.05 & $\begin{array}{l}\text { Anton Paar DSA } \\
\quad 5000\end{array}$ & 106 \\
\hline $\mathrm{C}_{4} \mathrm{C}_{1} \mathrm{im}$ & $\mathrm{BF}_{4}$ & Solvent Innovation & > 98 mole $\%$ & & & 1442.41 & $\begin{array}{c}\text { Anton Paar DSA } \\
5000\end{array}$ & 117 \\
\hline $\mathrm{C}_{4} \mathrm{C}_{1} \mathrm{im}$ & $\mathrm{BF}_{4}$ & Merck & $>98 \mathrm{wt} \%$ & $<200$ & $\begin{array}{c}<100 \\
\text { (chlorides) }\end{array}$ & 1565.1 & Sing-around & 27 \\
\hline $\mathrm{C}_{4} \mathrm{C}_{1} \mathrm{im}$ & $\mathrm{BF}_{4}$ & Merck-Schuchardt & $>98$ mole\% & $<100$ & & 1565 & $\begin{array}{c}\text { Anton Paar DSA } \\
5000\end{array}$ & 118 \\
\hline $\mathrm{C}_{4} \mathrm{C}_{1} \mathrm{im}$ & $\mathrm{BF}_{4}$ & Sigma-Aldrich & 99 wt\% & $<75^{83} ;<100^{103}$ & & 1566 & Ultrasonic & 83,103 \\
\hline
\end{tabular}




\begin{tabular}{|c|c|c|c|c|c|c|c|c|}
\hline $\mathrm{C}_{4} \mathrm{C}_{1} \mathrm{im}$ & $\mathrm{BF}_{4}$ & Sigma-Aldrich & $\geq 97 \%$ & & & 1568.1 & $\begin{array}{c}\text { interferometer } \\
\text { Anton Paar DSA } \\
5000\end{array}$ & 119 \\
\hline $\mathrm{C}_{4} \mathrm{C}_{1} \mathrm{im}$ & TFO & Merck & $99 \mathrm{wt} \%$ & & 500 & 1393 & Anton Paar DSA 48 & 2 \\
\hline $\mathrm{C}_{4} \mathrm{C}_{1} \mathrm{im}$ & TFO & Solvent Innovation & n.s. & $<130$ & $<550^{113}$ & 1392.1 & Anton Paar DSA 48 & 112,113 \\
\hline $\mathrm{C}_{4} \mathrm{C}_{1} \mathrm{im}$ & TFO & Solvent Innovation & $>98 \mathrm{wt} \%$ & $<500$ & & 1393.01 & $\begin{array}{c}\text { Anton Paar DSA } \\
5000\end{array}$ & 95 \\
\hline $\mathrm{C}_{4} \mathrm{C}_{1} \mathrm{im}$ & TFO & Iolitec & 99 wt\% & 170 & 50 & 1391 & $\begin{array}{c}\text { Anton Paar DSA } \\
5000 \mathrm{M}\end{array}$ & 79 \\
\hline $\mathrm{C}_{4} \mathrm{C}_{1} \mathrm{im}$ & TFO & Iolitec & 99 wt\% & $<602$ & & 1391.4 & $\begin{array}{c}\text { Anton Paar DSA } \\
5000 \mathrm{M}\end{array}$ & 85 \\
\hline $\mathrm{C}_{4} \mathrm{C}_{1} \mathrm{im}$ & TFO & Iolitec & $>99 \mathrm{wt} \%$ & 602 & & 1391.5 (int.) & $\begin{array}{c}\text { Anton Paar DSA } \\
5000\end{array}$ & 121 \\
\hline $\mathrm{C}_{4}-3-\mathrm{C}_{1} \mathrm{py}$ & $\mathrm{NTf}_{2}$ & Iolitec & $99 \mathrm{wt} \%$ & 90 & 10 & 1248 & $\begin{array}{c}\text { Anton Paar DSA } \\
5000\end{array}$ & 79 \\
\hline $\mathrm{C}_{4}-3-\mathrm{C}_{1} \mathrm{py}$ & $\mathrm{NTf}_{2}$ & Iolitec & $>98 \mathrm{wt} \%$ & 632 & & 1248.3 & $\begin{array}{l}\text { Anton Paar DSA } \\
5000\end{array}$ & 93 \\
\hline $\mathrm{C}_{4}-3-\mathrm{C}_{1} \mathrm{py}$ & $\mathrm{N}(\mathrm{CN})_{2}$ & Solvent Innovation & $98 \%$ & & & 1757.2 & $\begin{array}{c}\text { Anton Paar DSA } \\
48^{119} ; 5000^{94}\end{array}$ & 97,122 \\
\hline $\mathrm{C}_{4}-2-\mathrm{C}_{1} \mathrm{py}$ & $\mathrm{BF}_{4}$ & Iolitec & $99 \%$ & & & 1644.84 & $\begin{array}{c}\text { Anton Paar DSA } \\
5000\end{array}$ & 97, 98 \\
\hline $\mathrm{C}_{4}-3-\mathrm{C}_{1} \mathrm{py}$ & $\mathrm{BF}_{4}$ & Solvent Innovation & n.s. & $<130$ & $<550$ & 1587 & Anton Paar DSA 48 & 112 \\
\hline $\mathrm{C}_{4}-3-\mathrm{C}_{1} \mathrm{py}$ & $\mathrm{BF}_{4}$ & Solvent Innovation & $99 \%$ & & & 1583.8 & Anton Paar DSA 48 & 97,124 \\
\hline $\mathrm{C}_{4}-3-\mathrm{C}_{1} \mathrm{py}$ & $\mathrm{BF}_{4}$ & Iolitec & 99 wt\% & $<100$ & & 1586.05 (int.) & $\begin{array}{l}\text { Anton Paar DSA } \\
5000\end{array}$ & 123 \\
\hline $\mathrm{C}_{4}-4-\mathrm{C}_{1} \mathrm{py}$ & $\mathrm{BF}_{4}$ & Solvent Innovation & $99 \%$ & & & 1597 & Anton Paar DSA 48 & 97,112 \\
\hline $\mathrm{C}_{4}-4-\mathrm{C}_{1} \mathrm{py}$ & $\mathrm{BF}_{4}$ & Iolitec & 99 wt\% & $<100$ & & 1599.18 (int.) & $\begin{array}{c}\text { Anton Paar DSA } \\
5000\end{array}$ & 123 \\
\hline $\mathrm{C}_{4}-4-\mathrm{C}_{1} \mathrm{py}$ & $\mathrm{BF}_{4}$ & Sigma & $\geq 97 \mathrm{wt} \%$ & $<1000$ & & 1602.3 & $\begin{array}{c}\text { Anton Paar DSA } \\
5000\end{array}$ & 89 \\
\hline $\mathrm{C}_{4} \mathrm{C}_{1} \mathrm{pyr}$ & $\mathrm{N}(\mathrm{CN})_{2}$ & Iolitec & $>98 \mathrm{wt} \%$ & 1497 & & 1811.1 & $\begin{array}{c}\text { Anton Paar DSA } \\
5000 \mathrm{M}\end{array}$ & 85 \\
\hline $\mathrm{C}_{4} \mathrm{C}_{1} \mathrm{pyr}$ & $\mathrm{N}(\mathrm{CN})_{2}$ & Iolitec & $>98 \mathrm{wt} \%$ & $<1500$ & & 1810 & Anton Paar DSA & 94 \\
\hline
\end{tabular}


$5000 \mathrm{M}$

\begin{tabular}{|c|c|c|c|c|c|c|c|c|}
\hline $\mathrm{C}_{4} \mathrm{C}_{1} \mathrm{pyr}$ & $\mathrm{NTf}_{2}$ & Iolitec & 99 wt $\%$ & $60^{79} ; 55^{92}$ & $20^{79} ; 100^{92}$ & 1269 & $\begin{array}{c}\text { Anton Paar DSA } \\
5000\end{array}$ & 79,92 \\
\hline $\mathrm{C}_{4} \mathrm{C}_{1} \mathrm{pyr}$ & $\mathrm{NTf}_{2}$ & Iolitec & > 98 wt $\%$ & 525 & & 1269.3 & $\begin{array}{c}\text { Anton Paar DSA } \\
5000\end{array}$ & 93 \\
\hline $\mathrm{C}_{4} \mathrm{C}_{1} \mathrm{pyr}$ & $\mathrm{NTf}_{2}$ & Iolitec & 99 wt\% & $<100$ & $<100$ & 1269.73 (int.) & Sing-around & 26 \\
\hline $\mathrm{C}_{4} \mathrm{C}_{1} \mathrm{pyr}$ & TFO & Iolitec & $>99 \mathrm{wt} \%$ & $<500$ & & 1461.43 & $\begin{array}{c}\text { Anton Paar DSA } \\
5000 \mathrm{M}\end{array}$ & 95 \\
\hline $\mathrm{C}_{4} \mathrm{C}_{1} \mathrm{pyr}$ & TFO & Iolitec & > 99 wt $\%$ & 270 & $<100$ & 1461 & $\begin{array}{c}\text { Anton Paar DSA } \\
5000 \mathrm{M}\end{array}$ & 79 \\
\hline $\mathrm{C}_{4} \mathrm{C}_{1} \mathrm{pyr}$ & TFO & Iolitec & 99 wt\% & $<836$ & & 1460.1 & $\begin{array}{c}\text { Anton Paar DSA } \\
5000 \mathrm{M}\end{array}$ & 85 \\
\hline $\mathrm{C}_{4} \mathrm{Py}$ & $\mathrm{BF}_{4}$ & Iolitec & $99 \%$ & & & 1599.63 & $\begin{array}{c}\text { Anton Paar DSA } \\
5000\end{array}$ & 97 \\
\hline $\mathrm{C}_{4} \mathrm{Py}$ & $\mathrm{BF}_{4}$ & Iolitec & 99 wt\% & $<100$ & & 1599.70 (int.) & $\begin{array}{c}\text { Anton Paar DSA } \\
5000\end{array}$ & 125 \\
\hline $\mathrm{C}_{4} \mathrm{Py}$ & $\mathrm{BF}_{4}$ & Iolitec & $99 \%$ & $<500$ & & 1599.63 & $\begin{array}{c}\text { Anton Paar DSA } \\
5000\end{array}$ & 126 \\
\hline $\mathrm{C}_{4} \mathrm{Py}$ & TFO & Iolitec & $99 \%$ & $<500^{126}$ & & 1416.11 & $\begin{array}{c}\text { Anton Paar DSA } \\
5000\end{array}$ & 97,126 \\
\hline $\mathrm{N}_{2200}$ & Ac & synthesized & n.s. & & & 1609 & $\begin{array}{c}\text { Ultrasonic } \\
\text { interferometer }\end{array}$ & 35,90 \\
\hline $\mathrm{N}_{2200}$ & Ac & synthesized & $\begin{array}{c}\text { n.s. }{ }^{80} ; 99 \%^{178} \\
99 \text { wt } \%{ }^{36}\end{array}$ & $<70$ & & 1608 & $\begin{array}{l}\text { Ultrasonic } \\
\text { interferometer }\end{array}$ & $36,80,178$ \\
\hline $\mathrm{N}_{2200}$ & $\mathrm{HSO}_{4}$ & synthesized & 99 wt $\%^{36,178} ; n . s^{80}$ & $<70$ & & 1432 & $\begin{array}{c}\text { Ultrasonic } \\
\text { interferometer }\end{array}$ & $36,80,178$ \\
\hline $\mathrm{C}_{2} \cdot 2-\mathrm{C}_{2} \mathrm{Py}$ & $\mathrm{C}_{2} \mathrm{SO}_{4}$ & synthesized & n.s. & $<700$ & & 1745.6 & $\begin{array}{c}\text { Anton Paar DSA } \\
5000\end{array}$ & 84 \\
\hline $\mathrm{C}_{2} \cdot 2-\mathrm{C}_{2} \mathrm{Py}$ & $\mathrm{C}_{2} \mathrm{SO}_{4}$ & Iolitec & 99 wt\% & $<561$ & & 1745.2 & $\begin{array}{c}\text { Anton Paar DSA } \\
5000 \mathrm{M}\end{array}$ & 85 \\
\hline $\mathrm{C}_{1} \mathrm{C}_{1} \mathrm{im}$ & $\mathrm{C}_{1} \mathrm{SO}_{4}$ & synthesized & $\begin{array}{c}\text { n.s. }{ }^{86} \\
>98 \text { wt } \%{ }^{87,88}\end{array}$ & $<300$ & & 1813 & $\begin{array}{c}\text { Anton Paar DSA } \\
5000\end{array}$ & 86-88 \\
\hline $\mathrm{C}_{1} \mathrm{C}_{1} \mathrm{im}$ & $\mathrm{C}_{1} \mathrm{SO}_{4}$ & Sigma & $\geq 97 \mathrm{wt} \%$ & $<1000$ & & 1811.5 & Anton Paar DSA & 89 \\
\hline
\end{tabular}


5000

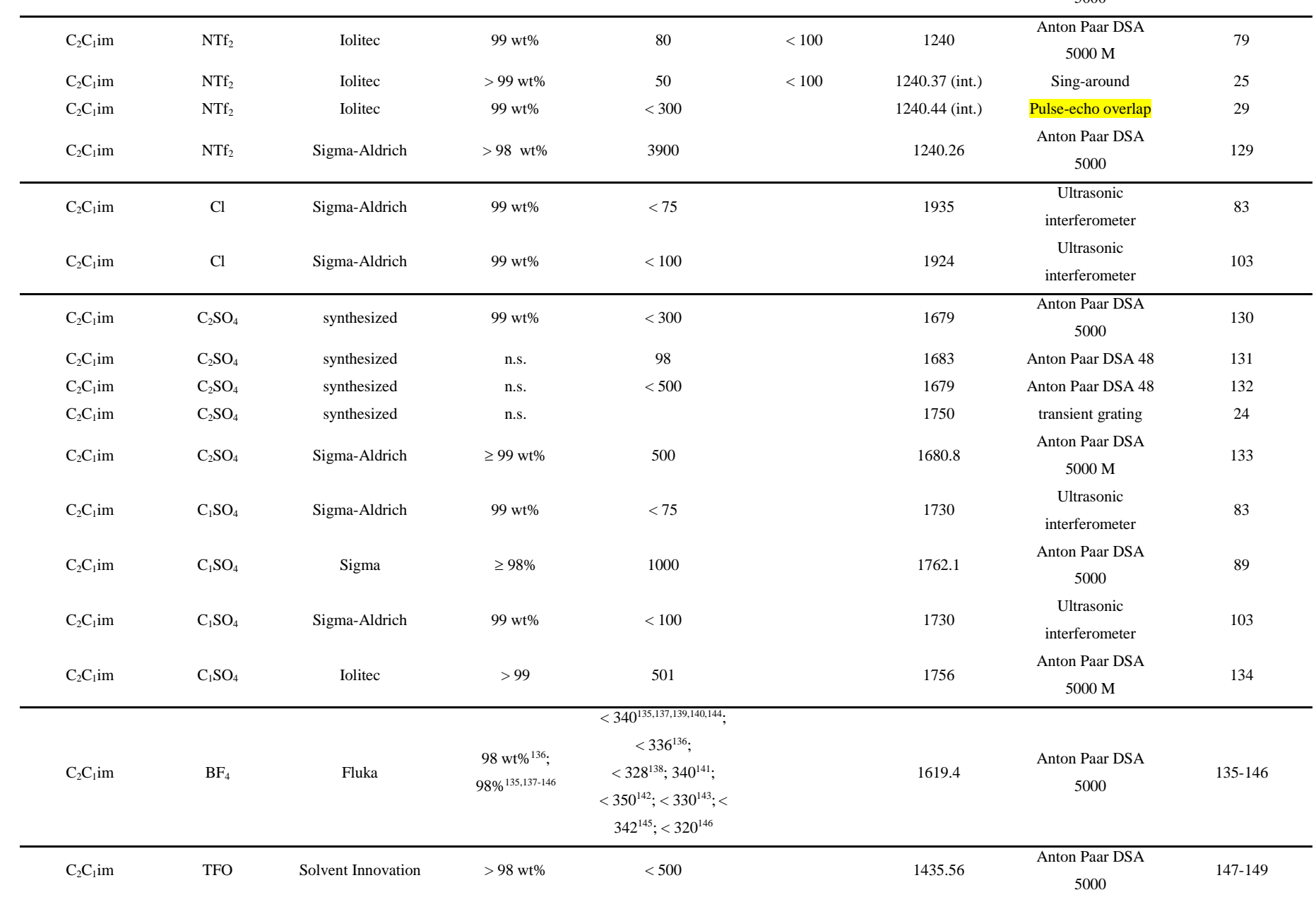




\begin{tabular}{|c|c|c|c|c|c|c|c|c|}
\hline $\mathrm{C}_{6} \mathrm{C}_{1} \mathrm{im}$ & $\mathrm{NTf}_{2}$ & synthesized & 99.76 mole\% & $\leq 10$ & $<10$ (bromides) & 1226.9 & $\begin{array}{c}\text { Anton Paar DSA } \\
5000\end{array}$ & 31 \\
\hline $\mathrm{C}_{6} \mathrm{C}_{1} \mathrm{im}$ & $\mathrm{NTf}_{2}$ & Iolitec & $\begin{array}{c}99 \mathrm{wt}^{2} \%^{79} ;>99 \\
\mathrm{wt} \%^{152}\end{array}$ & 70 & $<100$ & 1227 & $\begin{array}{c}\text { Anton Paar DSA } \\
5000 \mathrm{M}\end{array}$ & 79,152 \\
\hline $\mathrm{C}_{6} \mathrm{C}_{1} \mathrm{im}$ & $\mathrm{NTf}_{2}$ & $\begin{array}{c}\text { synt. QUILL Centre, } \\
\text { Belfast }\end{array}$ & $>99.95 \mathrm{wt} \%$ & 92 & $\begin{array}{l}<5 \text { (bromides) } \\
23 \text { (lithium) }\end{array}$ & 1225.64 & Pulse-echo overlap & 214 \\
\hline $\mathrm{C}_{6} \mathrm{C}_{1} \mathrm{im}$ & $\mathrm{Br}$ & synthesized & > $98 \mathrm{wt} \%$ & & & 1587.61 & $\begin{array}{c}\text { Anton Paar DSA } \\
5000\end{array}$ & 153 \\
\hline $\mathrm{C}_{6} \mathrm{C}_{1} \mathrm{im}$ & $\mathrm{Br}$ & synthesized & > $98 \mathrm{wt} \%$ & $<350$ & & 1587.53 & $\begin{array}{c}\text { Anton Paar DSA } \\
5000\end{array}$ & 76 \\
\hline $\mathrm{C}_{6} \mathrm{C}_{1} \mathrm{im}$ & $\mathrm{N}(\mathrm{CN})_{2}$ & Iolitec & $97 \mathrm{wt} \%$ & $<1242$ & & 1704.8 (int.) & $\begin{array}{c}\text { Anton Paar DSA } \\
5000 \mathrm{M}\end{array}$ & 85 \\
\hline $\mathrm{C}_{6} \mathrm{C}_{1} \mathrm{im}$ & $\mathrm{N}(\mathrm{CN})_{2}$ & Iolitec & $99 \mathrm{wt} \%$ & $<1350$ & & 1687 & $\begin{array}{c}\text { Anton Paar DSA } \\
5000 \mathrm{M}\end{array}$ & 79 \\
\hline $\mathrm{C}_{6} \mathrm{C}_{1} \mathrm{im}$ & $\mathrm{PF}_{6}$ & synthesized & n.s. & $<300$ & & 1424.2 & $\begin{array}{c}\text { Anton Paar DSA } \\
5000\end{array}$ & 75 \\
\hline $\mathrm{C}_{6} \mathrm{C}_{1} \mathrm{im}$ & $\mathrm{PF}_{6}$ & $\begin{array}{c}\text { Green Solutions } \\
\text { Chemicals S. L..77,8; } \\
\text { synthesized }^{154}\end{array}$ & $\begin{array}{c}>98 \text { wt } \%{ }^{87,88} \\
\text { n.s. }\end{array}$ & $<300^{87,88} ;<200^{154}$ & & 1424 & Anton Paar DSA 48 & $87,88,154$ \\
\hline $\mathrm{C}_{6} \mathrm{C}_{1} \mathrm{im}$ & $\mathrm{PF}_{6}$ & Kanto Chemical Co. & n.s. & & & 1432 (int.) & Time of flight & 18 \\
\hline $\mathrm{C}_{6} \mathrm{C}_{1} \mathrm{im}$ & $\mathrm{PF}_{6}$ & synthesized & > $98 \mathrm{wt} \%$ & $<350$ & & 1420.27 & $\begin{array}{c}\text { Anton Paar DSA } \\
5000\end{array}$ & 76 \\
\hline $\mathrm{C}_{6} \mathrm{C}_{1} \mathrm{im}$ & $\mathrm{PF}_{6}$ & synthesized & n.s. & 42 & & 1423.53 & $\begin{array}{c}\text { Anton Paar DSA } \\
5000\end{array}$ & 155 \\
\hline $\mathrm{C}_{6} \mathrm{C}_{1} \mathrm{im}$ & $\mathrm{PF}_{6}$ & Fluka & $\geq 97 \mathrm{wt} \%$ & $<1000$ & & 1424.4 & $\begin{array}{c}\text { Anton Paar DSA } \\
5000\end{array}$ & 89 \\
\hline$\overline{\mathrm{C}_{6} \mathrm{C}_{1} \mathrm{im}}$ & $\mathrm{BF}_{4}$ & Solvent Innovation & n.s. & $<130$ & $<550^{112}$ & 1519.5 & Anton Paar DSA 48 & 112,113 \\
\hline $\mathrm{C}_{6} \mathrm{C}_{1} \mathrm{im}$ & $\mathrm{BF}_{4}$ & synthesized & > $98 \mathrm{wt} \%$ & $<350$ & & 1420.27 & $\begin{array}{c}\text { Anton Paar DSA } \\
5000\end{array}$ & 76 \\
\hline $\mathrm{C}_{6} \mathrm{C}_{1} \mathrm{im}$ & $\mathrm{BF}_{4}$ & synthesized & $\begin{array}{c}>99 \text { wt } \%^{156} ; \\
\text { n.s. }{ }^{157}\end{array}$ & $<100^{157}$ & & 1496.7 & $\begin{array}{c}\text { Anton Paar DSA } \\
5000\end{array}$ & 157 \\
\hline $2(\mathrm{OH}) \mathrm{C}_{2111}$ & Lact & Aldrich & n.s. & 8100 & & 1910 & $\begin{array}{c}\text { Anton Paar DSA } \\
5000\end{array}$ & 174 \\
\hline
\end{tabular}




\begin{tabular}{|c|c|c|c|c|c|c|c|c|}
\hline $\mathrm{N} 2(\mathrm{OH}) \mathrm{C}_{2111}$ & Lact & Sigma-Aldrich & $\geq 95 \%$ & & & 1911.79 & $\begin{array}{l}\text { Anton Paar DSA } \\
5000\end{array}$ & 175 \\
\hline $\mathrm{C}_{8} \mathrm{C}_{1} \mathrm{im}$ & $\mathrm{Cl}$ & synthesized & n.s. & $<500^{160} ; 521^{161}$ & & 1721 & $\begin{array}{c}\text { Anton Paar DSA } \\
5000^{157} ; 48^{158}\end{array}$ & 160,161 \\
\hline $\mathrm{C}_{8} \mathrm{C}_{1} \mathrm{im}$ & $\mathrm{Cl}$ & Solvent Innovation & $\geq 97$ mole $\%$ & $<200$ & & 1715 & $\begin{array}{c}\text { Anton Paar DSA } \\
5000\end{array}$ & 114 \\
\hline $\mathrm{C}_{8} \mathrm{C}_{1} \mathrm{im}$ & $\mathrm{Cl}$ & Sigma & > 98 mole $\%$ & $<1000$ & & 1687.2 & $\begin{array}{c}\text { Anton Paar DSA } \\
5000\end{array}$ & 89 \\
\hline $\mathrm{C}_{8} \mathrm{C}_{1} \mathrm{im}$ & $\mathrm{PF}_{6}$ & synthesized & n.s. & $<300$ & & 1407.8 & $\begin{array}{c}\text { Anton Paar DSA } \\
5000\end{array}$ & 75 \\
\hline $\mathrm{C}_{8} \mathrm{C}_{1} \mathrm{im}$ & $\mathrm{PF}_{6}$ & $\begin{array}{c}\text { Green Solutions } \\
\text { Chemicals S. L. }{ }^{87,162} \text {; } \\
\text { synthesized }^{163}\end{array}$ & $>98 \mathrm{wt} \%$ & $<300^{87,162} ;<200^{163}$ & & 1408 & Anton Paar DSA 48 & $87,162,163$ \\
\hline $\mathrm{C}_{8} \mathrm{C}_{1} \mathrm{im}$ & $\mathrm{PF}_{6}$ & Kanto Chemical Co. & n.s. & & & 1438 (int.) & Time of flight & 18 \\
\hline $\mathrm{C}_{8} \mathrm{C}_{1} \mathrm{im}$ & $\mathrm{PF}_{6}$ & synthesized & n.s. & 81 & & 1388.15 & $\begin{array}{c}\text { Anton Paar DSA } \\
5000\end{array}$ & 155 \\
\hline $\mathrm{C}_{8} \mathrm{C}_{1} \mathrm{im}$ & $\mathrm{PF}_{6}$ & Sigma & $\geq 95 \mathrm{wt} \%$ & $<1000$ & & 1404.7 & $\begin{array}{c}\text { Anton Paar DSA } \\
5000\end{array}$ & 89 \\
\hline $\mathrm{C}_{8} \mathrm{C}_{1} \mathrm{im}$ & $\mathrm{BF}_{4}$ & synthesized & n.s. & 326 & 750 (bromides) & 1491 & Anton Paar DSA 48 & 131 \\
\hline $\mathrm{C}_{8} \mathrm{C}_{1} \mathrm{im}$ & $\mathrm{BF}_{4}$ & Merck & > 98 wt\% & $<200$ & $\begin{array}{l}<100 \\
\text { (chlorides) }\end{array}$ & 1482.2 & Sing-around & 27 \\
\hline $\mathrm{C}_{8} \mathrm{C}_{1} \mathrm{im}$ & $\mathrm{BF}_{4}$ & Solvent Innovation & > 99 wt\% & $<200$ & & no access & Sing-around & 28 \\
\hline $\mathrm{C}_{8} \mathrm{C}_{1} \mathrm{im}$ & $\mathrm{BF}_{4}$ & synthesized & $\begin{array}{c}>99 \text { wt } \%^{156} \\
\text { n.s. }{ }^{1.57}\end{array}$ & $<100^{157}$ & & 1481.1 & $\begin{array}{l}\text { Anton Paar DSA } \\
5000\end{array}$ & 156,157 \\
\hline $\mathrm{C}_{1} \mathrm{py}$ & $\mathrm{C}_{1} \mathrm{SO}_{4}$ & synthesized & n.s. & $<600$ & & 1876.4 & $\begin{array}{l}\text { Anton Paar DSA } \\
5000\end{array}$ & 84 \\
\hline $\mathrm{C}_{1} \mathrm{py}$ & $\mathrm{C}_{1} \mathrm{SO}_{4}$ & Iolitec & $99 \mathrm{wt} \%$ & $<475$ & & 1875.8 & $\begin{array}{c}\text { Anton Paar DSA } \\
5000 \mathrm{M}\end{array}$ & 85 \\
\hline $\mathrm{N}_{1888}$ & $\mathrm{NTf}_{2}$ & Fluka & > 99 wt\% & 400 & & 1260 & $\begin{array}{c}\text { Ultrasonic } \\
\text { interferometer }\end{array}$ & 82,180 \\
\hline $\mathrm{C}_{5} \mathrm{C}_{1} \mathrm{im}$ & $\mathrm{NTf}_{2}$ & $\begin{array}{c}\text { synt. QUILL Centre, } \\
\text { Belfast }\end{array}$ & n.s. & 150 & & 1230.69 (int.) & Pulse-echo overlap & 17 \\
\hline $\mathrm{C}_{5} \mathrm{C}_{1} \mathrm{im}$ & $\mathrm{NTf}_{2}$ & synt. QUILL Centre, & $>99.95$ wt \% & 194 & $<5$ (bromides) & 1226.33 (int.) & Pulse-echo overlap & 214 \\
\hline
\end{tabular}




\begin{tabular}{|c|c|c|c|c|c|c|c|c|}
\hline & & Belfast & & & 34 (lithium) & & & \\
\hline $\mathrm{C}_{3} \mathrm{C}_{1} \mathrm{im}$ & $\mathrm{NTf}_{2}$ & Iolitec & $>99$ wt $\%$ & 50 & 53 & 1232 & $\begin{array}{c}\text { Anton Paar DSA } \\
5000\end{array}$ & 168 \\
\hline $\mathrm{C}_{3} \mathrm{C}_{1} \mathrm{im}$ & $\mathrm{NTf}_{2}$ & $\begin{array}{c}\text { synt. QUILL Centre, } \\
\text { Belfast }\end{array}$ & $>99.95$ wt \% & 71 & $\begin{array}{l}<5 \text { (bromides) } \\
26 \text { (lithium) }\end{array}$ & 1230.33 & Pulse-echo overlap & 214 \\
\hline $\mathrm{C}_{3} \mathrm{C}_{1} \mathrm{im}$ & $\mathrm{Br}$ & synthesized & > $98 \mathrm{wt} \%$ & $<200^{169}$ & & 1672.04 & $\begin{array}{c}\text { Anton Paar DSA } \\
5000\end{array}$ & 153,169 \\
\hline $\mathrm{C}_{3} \mathrm{C}_{1} \mathrm{pyr}$ & $\mathrm{NTf}_{2}$ & Iolitec & > 99 wt\% & 431 & & 1270.6 & $\begin{array}{c}\text { Anton Paar DSA } \\
5000\end{array}$ & 159 \\
\hline $\mathrm{C}_{3} \mathrm{C}_{1} \mathrm{pyr}$ & $\mathrm{NTf}_{2}$ & Iolitec & $99 \mathrm{wt} \%$ & $<100$ & $<100$ & 1271.02 (int.) & Sing-around & 26 \\
\hline Сзру & $\mathrm{BF}_{4}$ & Iolitec & $>98 \%$ & $<500$ & $<5000$ & 1641.7 & $\begin{array}{c}\text { Anton Paar DSA } \\
5000\end{array}$ & 166 \\
\hline Сзру & $\mathrm{BF}_{4}$ & Iolitec & $98 \%$ & $<100$ & $<100$ & 1641.7 (int.) & $\begin{array}{c}\text { Anton Paar DSA } \\
5000\end{array}$ & 167 \\
\hline $\mathrm{N}_{4444}$ & $\mathrm{OH}$ & synthesized & $\begin{array}{c}99 \text { wt\% } \%^{83} ; 99 \%{ }^{185} ; \\
\text { n.s. }{ }^{186}\end{array}$ & $<70^{83}$ & & 1798 & $\begin{array}{c}\text { Ultrasonic } \\
\text { interferometer }\end{array}$ & $83,185,186$ \\
\hline $\mathrm{N}_{2222}$ & $\mathrm{OH}$ & synthesized & $\begin{array}{c}99 \text { wt } \%{ }^{83} ; 99 \%{ }^{185} ; \\
\text { n.s. }{ }^{187}\end{array}$ & $<70^{83}$ & & 1814 & $\begin{array}{c}\text { Ultrasonic } \\
\text { interferometer }\end{array}$ & $83,185,187$ \\
\hline $\mathrm{N}_{1111}$ & $\mathrm{OH}$ & synthesized & $\begin{array}{c}99 \text { wt\% } \%^{83} ; 99 \%{ }^{185} ; \\
\text { n.s. }{ }^{187}\end{array}$ & $<70$ & & 1828 & $\begin{array}{c}\text { Ultrasonic } \\
\text { interferometer }\end{array}$ & $83,185,186$ \\
\hline $\mathrm{N}_{3333}$ & $\mathrm{OH}$ & synthesized & $\begin{array}{c}99 \text { wt } \%^{83} \\
99 \%^{185} \text {; n.s. }{ }^{186,187}\end{array}$ & $<70^{83}$ & & 1801 & $\begin{array}{c}\text { Ultrasonic } \\
\text { interferometer }{ }^{44,182,184} \text {; } \\
\text { Anton Paar DSA } \\
5000^{183}\end{array}$ & $83,185-187$ \\
\hline $\mathrm{N}_{2220}$ & Ac & synthesized & $\begin{array}{c}\text { n.s. }{ }^{35,80,90} ; \\
99 \text { wt } \%^{36,83} ; \\
99 \%{ }^{178}\end{array}$ & $<70^{35,83,90,178}$ & & 1840 & $\begin{array}{c}\text { Ultrasonic } \\
\text { interferometer }\end{array}$ & $\begin{array}{c}35,36,80,83,90, \\
178\end{array}$ \\
\hline $\mathrm{N}_{2220}$ & $\mathrm{H}_{2} \mathrm{PO}_{4}$ & synthesized & n.s. ${ }^{35,90} ; 99 \%^{81,188}$ & $<70^{188}$ & & 1794 & $\begin{array}{c}\text { Ultrasonic } \\
\text { interferometer }\end{array}$ & $35,81,90,188$ \\
\hline $\mathrm{N}_{2220}$ & $\mathrm{HSO}_{4}$ & synthesized & $\begin{array}{c}\text { n.s. }{ }^{35,90 ;} \\
99 \text { wt\% } \%^{36,178,188}\end{array}$ & $<70^{188}$ & & 1874 & $\begin{array}{c}\text { Ultrasonic } \\
\text { interferometer }\end{array}$ & $\begin{array}{c}35,36,90,178, \\
188\end{array}$ \\
\hline $\mathrm{N}_{1110}$ & Ac & synthesized & $\begin{array}{c}99 \text { wt\% }{ }^{81,178,188 ;} ; \\
99 \%^{189}\end{array}$ & $<70$ & & 1544 & $\begin{array}{c}\text { Ultrasonic } \\
\text { interferometer }\end{array}$ & $81,178,189,190$ \\
\hline
\end{tabular}




\begin{tabular}{|c|c|c|c|c|c|c|c|}
\hline $\mathrm{N}_{1110}$ & $\mathrm{H}_{2} \mathrm{PO}_{4}$ & synthesized & $\begin{array}{l}99 \%^{81,189} ; \\
99 \text { wt\% }{ }^{190}\end{array}$ & & 1672 & $\begin{array}{c}\text { Ultrasonic } \\
\text { interferometer }\end{array}$ & $81,189,190$ \\
\hline $\mathrm{N}_{1110}$ & $\mathrm{HSO}_{4}$ & synthesized & $\begin{array}{l}99 \%^{81,189} ; \\
99 \%^{178,190}\end{array}$ & $<70^{178}$ & 1564 & $\begin{array}{c}\text { Ultrasonic } \\
\text { interferometer }\end{array}$ & $81,178,189,190$ \\
\hline
\end{tabular}


In some substances, the $u$ values are the same (or very close) despite the different profiles of the impurities (within the given uncertainty of the measurements), such as for [ $\left.\mathrm{C}_{4} \mathrm{C}_{1} \mathrm{im}\right][\mathrm{TFO}]$, $\left[\mathrm{C}_{4} \mathrm{C}_{1} \mathrm{pyr}\right][\mathrm{TFO}]$ and $\left[\mathrm{C}_{4} \mathrm{C}_{1} \mathrm{pyr}\right]\left[\mathrm{NTf}_{2}\right]$ (Table 4). A few other types of impurities are present in the sample in addition to water and halides; however, only the water content is usually reported. The observed discrepancies could also be attributed to the method that was used to record the $u$ measurements and the lack of agreement in the water determinations from the different methods. The handling of a sample can also explain the observed disagreements in the speed of sound values from different authors. However, this factor cannot be confirmed based on the descriptions in most of these studies.

If the speed of sound in pure ILs is lower than that in water, any addition of water may increase the $u$ values. Skowronek et al., ${ }^{225}$ who measured five different substances, found that any changes in the speed of sound are below the declared $u$ uncertainty of $\pm 0.5 \mathrm{~m} \cdot \mathrm{s}^{-1}$ up to a mass fraction of water of $2.0 \cdot 10^{-3}$. However, Widegren and Magee ${ }^{31}$ claimed that changes in the amount of water in the IUPAC sample $\left[\mathrm{C}_{6} \mathrm{C}_{1} \mathrm{im}\right]\left[\mathrm{NTf}_{2}\right]$ of $8.6 \cdot 10^{-4}$ will much more significantly change the speed of sound, specifically, $\pm 0.7 \mathrm{~m} \cdot \mathrm{s}^{-1}$.

Gonzalez et al., ${ }^{160}$ Singh and Kumar, ${ }^{114}$ and AlTuwaim et al. ${ }^{89}$ reported a temperature dependence of the speed of sound in $\left[\mathrm{C}_{8} \mathrm{C}_{1} \mathrm{im}\right][\mathrm{Cl}]$. The $u(T)$ that was reported by Singh and Kumar $^{114}$ is nonlinear and agrees with the data by Gonzalez et al., ${ }^{160}$ but differs from the linear dependence that was reported by AlTuwaim et al. ${ }^{89}$ (Figure 10). The nonlinear dependence of $u(T)$ and the temperature dependence on the viscosity indicate the existence of ultrasound relaxation in the investigated temperature range. At higher temperatures, the speed of sound in $\left[\mathrm{C}_{8} \mathrm{C}_{1} \mathrm{im}\right][\mathrm{Cl}]$ is lower than that in water; at lower temperatures, the speed of sound in $\left[\mathrm{C}_{8} \mathrm{C}_{1} \mathrm{im}\right][\mathrm{Cl}]$ becomes higher than that in water (it is connected with the different signs of the 
temperature coefficients of the speed of sound). AlTuwaim et al. ${ }^{89}$ reported higher water content than Gonzalez et al. ${ }^{160}$ and Singh and Kumar ${ }^{114}$. Moreover, the purity of sample that was studied by AlTuwaim et al. ${ }^{89}$ was lower than the sample that was investigated by Singh and Kumar ${ }^{114}$ (see table 4).

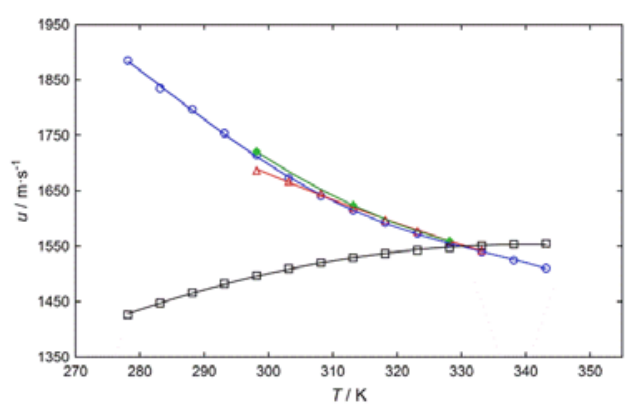

Figure 10. Comparison of the speed of sound in $\left[\mathrm{C}_{8} \mathrm{C}_{1} \mathrm{im}\right][\mathrm{Cl}]$ reported by filled green diamond Gonzalez et al., ${ }^{160}$ open blue circles - Singh and Kumar, ${ }^{114}$ and open red triangles - AlTuwaim et al. $^{89}$ with speed of sound in water - open black squares. ${ }^{226}$

Gonzalez et al. ${ }^{160}$ synthesized $\left[\mathrm{C}_{8} \mathrm{C}_{1} \mathrm{im}\right][\mathrm{Cl}]$ in their laboratory but authors did not report the purity of the sample. The higher amount of water in $\left[\mathrm{C}_{8} \mathrm{C}_{1} \mathrm{im}\right][\mathrm{Cl}]$ influenced the speed of sound differently depending on the temperature. At higher temperatures, the speed of sound values that were reported by AlTuwaim et al. ${ }^{89}$ and Gonzalez et al. ${ }^{160}$ are comparable but higher than those reported by Singh and Kumar. ${ }^{114}$ The effect of higher amounts of water in sample, which was studied by AlTuwaim et al., ${ }^{89}$ is more visible at lower $T$, where relaxation is more pronounced. Considerably lower speed of sound values were observed compared to the data reported by Gonzalez et al. ${ }^{160}$ and Singh and Kumar. ${ }^{114}$ Thus, water contamination or other impurities can change the speed of sound but could also probably give reason why relaxation phenomena were not observed in the sample investigated by AlTuwaim et al., ${ }^{89}$ hence the linear temperature 
dependence on the speed of sound in $\left[\mathrm{C}_{8} \mathrm{C}_{1} \mathrm{im}\right][\mathrm{Cl}]$. The performance of ultrasound absorption measurements is necessary to explain this effect.

\subsection{Effect of ion structure on the speed of sound in ionic liquids}

Analyses of the influence of an IL's constitution on the speed of sound have been already performed in literature.,12,79,89,91,99,211 In particular, view of the influence of the length of alkyl chains in cations on the speed of sound in different ILs has been evaluated over the past years. For instance, Frez et al. ${ }^{12}$ postulated no significant effect of the cation structure on the speed of sound of ILs. In contrast, Esperança et al. ${ }^{17}$ assumed that the speed of sound in $\left[\mathrm{C}_{n} \mathrm{C}_{1} \mathrm{im}\right]\left[\mathrm{NTf}_{2}\right]$ regularly decreasing from $\left[\mathrm{C}_{3} \mathrm{C}_{1} \mathrm{im}\right]\left[\mathrm{NTf}_{2}\right]$ to $\left[\mathrm{C}_{5} \mathrm{C}_{1} \mathrm{im}\right]\left[\mathrm{NTf}_{2}\right]$ with the addition of carbon atoms in the alkyl chains of imidazolium cations. In 2008, Gardas and Coutinho ${ }^{211}$ found an increase in the speed of sound with the elongation of the alkyl chains in imidazolium cations based on a modified Auerbach's equation. Wu et al. ${ }^{4}$ in their review paper analyzed the experimental speed of sound in four rows of substances, including $\left[\mathrm{C}_{n} \mathrm{C}_{1} \mathrm{im}\right]\left[\mathrm{BF}_{4}\right],\left[\mathrm{C}_{n} \mathrm{C}_{1} \mathrm{im}\right]\left[\mathrm{NTf}_{2}\right]$, and $\left[\mathrm{C}_{n}-3-\right.$ $\left.\mathrm{C}_{1} \mathrm{py}\right]\left[\mathrm{NTf}_{2}\right]$ at $293.15 \mathrm{~K}$ and $\left[\mathrm{N}_{n n n n}\right][\mathrm{OH}]$ at $298.15 \mathrm{~K}$. Generally, the speed of sound decreases with an increase of the alkyl chain length in the cation; the only irregularities were visible for the

$\left[\mathrm{C}_{n} \mathrm{C}_{1} \mathrm{im}\right]\left[\mathrm{NTf}_{2}\right]$ series (see Figures 11-16). ${ }^{4}$ The decrease in $u$ with the alkyl chain length in the cation was also reported for $\left[\mathrm{C}_{n} \mathrm{C}_{1} \mathrm{im}\right]\left[\mathrm{PF}_{6}\right],\left[\mathrm{C}_{n} \mathrm{C}_{1} \mathrm{im}\right][\mathrm{TFO}]$ and $\left[\mathrm{C}_{n} \mathrm{C}_{1} \mathrm{im}\right][\mathrm{Br}]$ (see Figures 11 and 14). A minimum value for $u(n)$ was noticed for $\left[\mathrm{C}_{n} \mathrm{C}_{1} \mathrm{im}\right]\left[\mathrm{NTf}_{2}\right],{ }^{4,34}$ but differences between the experimental data sets made it impossible to clearly establish the substance with the lowest $u$ value, as comparable speed of sound values have been observed in $\left[\mathrm{C}_{4} \mathrm{C}_{1} \mathrm{im}\right]\left[\mathrm{NTf}_{2}\right]$, $\left[\mathrm{C}_{5} \mathrm{C}_{1} \mathrm{im}\right]\left[\mathrm{NTf}_{2}\right]$, and $\left[\mathrm{C}_{6} \mathrm{C}_{1} \mathrm{im}\right]\left[\mathrm{NTf}_{2}\right]$, as presented in Figure 11. However, the minimum of $u(n)$ moves with pressure towards the IL with a lower number of carbon atoms in the alkyl chain attached to the cation ring (Figure 12). The $u(n)$ dependence for ILs cannot be investigated in a 
wider context because of the lack of suitable experimental data for longer homologues, such as for $\left[\mathrm{C}_{n}-3-\mathrm{C}_{1} \mathrm{py}\right]\left[\mathrm{NTf}_{2}\right]$ (Figure 11 ). However, changes in $u$ from $\left[\mathrm{C}_{3}-3-\mathrm{C}_{1} \mathrm{py}\right]\left[\mathrm{NTf}_{2}\right]$ to [C $4-3-$ $\left.\mathrm{C}_{1} \mathrm{py}\right]\left[\mathrm{NTf}_{2}\right]$ are significantly lower than changes in $u$ from $\left[\mathrm{C}_{2}-3-\mathrm{C}_{1} \mathrm{py}\right]\left[\mathrm{NTf}_{2}\right]$ to $\left[\mathrm{C}_{3}-3-\right.$ $\left.\mathrm{C}_{1} \mathrm{py}\right]\left[\mathrm{NTf}_{2}\right]$.

Nevertheless, the observed trends in $u(n)$ for the $\left[\mathrm{C}_{n} \mathrm{C}_{1}\right.$ im] $]\left[\mathrm{NTf}_{2}\right]$ series (Figure 11 ) may confirm the transition between globular and sponge-like solvent morphologies marks by the butyl side chain (Figure 17), ${ }^{227,228}$ as initially postulated by Canongia Lopez and Pádua. ${ }^{229}$ However, this mesoscopic effect has been also reported for several 1-alkyl-3-methylimidazolium-based ILs (see Figure 17), ${ }^{227,228}$ which did not present such $u(n)$ feature, even if their nanostructure seems to be clearly anion dependent. ${ }^{227,228}$ Alternatively, the observed minimum value for $u(n)$ shown in Figure 11 in the case of the $\left[\mathrm{C}_{n} \mathrm{C}_{1} \mathrm{im}\right]\left[\mathrm{NTf}_{2}\right]$ series could be related to the structure differences between selected anions, as the charge on the $\left[\mathrm{NTf}_{2}\right]^{-}$(a non-globular, relatively large anion with the possibility of internal rotations what is theoretically $y^{230}$ and experimentally ${ }^{231}$ proved) is more delocalized than $\left[\mathrm{BF}_{4}\right]^{-},\left[\mathrm{PF}_{6}\right]^{-},[\mathrm{Br}]^{-}$or $[\mathrm{OH}]^{-}$, which results in relatively weaker cation-anion Coulombic interactions reducing the likelihood of ion association in solution.

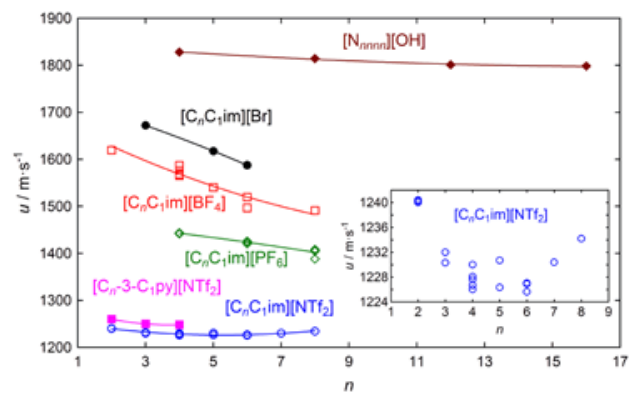

Figure 11. Influence of the chain length in the methylimidazolium, methylpyridynium and tetraalkylammonium cations on the speed of sound in ILs at $298.15 \mathrm{~K}$; Inset: Influence of the 
chain length in the $\left[\mathrm{C}_{n} \mathrm{C}_{1} \mathrm{im}\right]^{+}$cation in $\left[\mathrm{C}_{n} \mathrm{C}_{1} \mathrm{im}\right]\left[\mathrm{NTf}_{2}\right]$; points - experimental values (given in increasing order); lines are drawn as an aid; for homologues $\left[\mathrm{N}_{n n n n}\right][\mathrm{OH}]$ the number of all the methylene groups was counted according to the cation structure: open blue circles,

$\left[\mathrm{C}_{n} \mathrm{C}_{1} \mathrm{im}\right]\left[\mathrm{NTf}_{2}\right], n: 2^{25,29,34,79,129,168} ; 3^{34,168} ; 4^{14,18,25,30,34} ; 5^{17,34} ; 6^{31,34,79,152} ; 7^{34} ; 8^{25} ;$ red open squares, $\left[\mathrm{C}_{n} \mathrm{C}_{1} \mathrm{im}\right]\left[\mathrm{BF}_{4}\right], n: 2^{84,146}, 4^{27,83,106,118,119}, 5^{96}, 6^{76,112,156,164}$; green open diamonds, $\left[\mathrm{C}_{n} \mathrm{C}_{1} \mathrm{im}\right]\left[\mathrm{PF}_{6}\right], n: 4^{13,27,75,88,89,107-110}, 6^{75,76,88,89,155}, 8^{75,88,89,155}$; black filled circles, $\left[\mathrm{C}_{n} \mathrm{C}_{1} \mathrm{im}\right][\mathrm{Br}]$, $n: 3^{169} ; 5^{169} ; 6^{76,153}$; orange filled squares, [C $\left.\mathrm{C}_{n}-3-\mathrm{C}_{1} \mathrm{py}\right]\left[\mathrm{NTf}_{2}\right], n:(2,3,4){ }^{79}$; brown filled diamonds, [N $\left.\mathrm{N}_{n n n}\right][\mathrm{OH}], n:(1,2)^{83,185,187},(3,4)^{83,185-187}$.

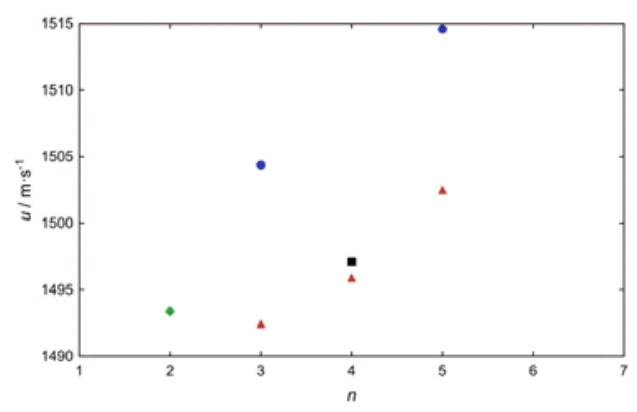

Figure 12. Influence of the chain length in the cation on the speed of sound in $\left[\mathrm{C}_{n} \mathrm{C}_{1} \mathrm{im}\right]\left[\mathrm{NTf}_{2}\right]$ at 100 MPa and $298.15 \mathrm{~K} ; n: 2$ : green diamond ${ }^{29}$; 3: blue circle $^{17}$, red triangle ${ }^{214} ;$ 4, black square ${ }^{14}$, red triangle ${ }^{214}$; 5: blue circle ${ }^{17}$, red triangle ${ }^{214}$.

The position of alkyl chains in pyridinium cations can also influence the speed of sound in ILs . ${ }^{79,127}$ This concept was observed for pyridinium ILs, whose $u$ is higher in cations with methyl groups in position "2" from the nitrogen atom (i.e., $\left[\mathrm{C}_{2}-2-\mathrm{C}_{1} \mathrm{py}\right]\left[\mathrm{NTf}_{2}\right]$ or $\left[\mathrm{C}_{3}-2-\mathrm{C}_{1} \mathrm{py}\right]\left[\mathrm{NTf}_{2}\right]$ ) compared to those in position "3" (i.e., $\left[\mathrm{C}_{2}-3-\mathrm{C}_{1} \mathrm{py}\right]\left[\mathrm{NTf}_{2}\right]$ or $\left.\left[\mathrm{C}_{3}-3-\mathrm{C}_{1} \mathrm{py}\right]\left[\mathrm{NTf}_{2}\right]\right)$. This difference 
is significant and amounts to 39.01 and $35.80 \mathrm{~m} \cdot \mathrm{s}^{-1}$, respectively. Another example of the influence of the position of substituents in cations is visible in Figure 13, where the $u$ for [ $\mathrm{C}_{4}$-2$\left.\mathrm{C}_{1} \mathrm{py}\right]\left[\mathrm{BF}_{4}\right],\left[\mathrm{C}_{4}-3-\mathrm{C}_{1} \mathrm{py}\right]\left[\mathrm{BF}_{4}\right]$, and $\left[\mathrm{C}_{4}-4-\mathrm{C}_{1} \mathrm{py}\right]\left[\mathrm{BF}_{4}\right]$ decreases in the sequence $\left[\mathrm{C}_{4}-2-\mathrm{C}_{1} \mathrm{py}\right]\left[\mathrm{BF}_{4}\right]$ $>\left[\mathrm{C}_{4}-4-\mathrm{C}_{1} \mathrm{py}\right]\left[\mathrm{BF}_{4}\right]>\left[\mathrm{C}_{4}-3-\mathrm{C}_{1} \mathrm{py}\right]\left[\mathrm{BF}_{4}\right]$.

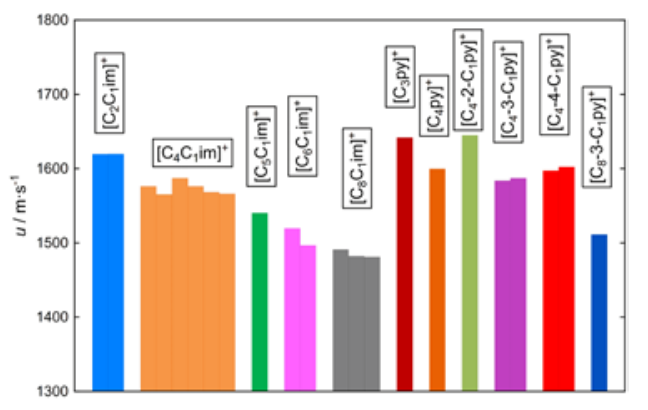

Figure 13. Influence of the length of the hydrocarbon chains and cation cores of tetrafluoroborate ILs on the speed of sound at $298.15 \mathrm{~K}$; $\left[\mathrm{C}_{2} \mathrm{C}_{1} \mathrm{im}\right]\left[\mathrm{BF}_{4}\right]^{144,146}$; $\left[\mathrm{C}_{4} \mathrm{C}_{1} \mathrm{im}\right]\left[\mathrm{BF}_{4}\right]^{27,103,106,112,118,119}$; $\left[\mathrm{C}_{5} \mathrm{C}_{1} \mathrm{im}\right]\left[\mathrm{BF}_{4}\right]^{35} ;\left[\mathrm{C}_{6} \mathrm{C}_{1} \mathrm{im}\right]\left[\mathrm{BF}_{4}\right]^{112,156} ;\left[\mathrm{C}_{8} \mathrm{C}_{1} \mathrm{im}\right]\left[\mathrm{BF}_{4}\right]^{27,156,164} ;\left[\mathrm{C}_{3} \mathrm{py}\right]\left[\mathrm{BF}_{4}\right]^{166} ;\left[\mathrm{C}_{4} \mathrm{py}\right]\left[\mathrm{BF}_{4}\right]^{97} ;$ $\left[\mathrm{C}_{4}-2-\mathrm{C}_{1} \mathrm{py}\right]\left[\mathrm{BF}_{4}\right]^{97} ;\left[\mathrm{C}_{4}-3-\mathrm{C}_{1} \mathrm{py}\right]\left[\mathrm{BF}_{4}\right]^{112,124} ;\left[\mathrm{C}_{4}-4-\mathrm{C}_{1} \mathrm{py}\right]\left[\mathrm{BF}_{4}\right]^{89,124} ;\left[\mathrm{C}_{8}-3-\mathrm{C}_{1} \mathrm{py}\right]\left[\mathrm{BF}_{4}\right]^{97}$.

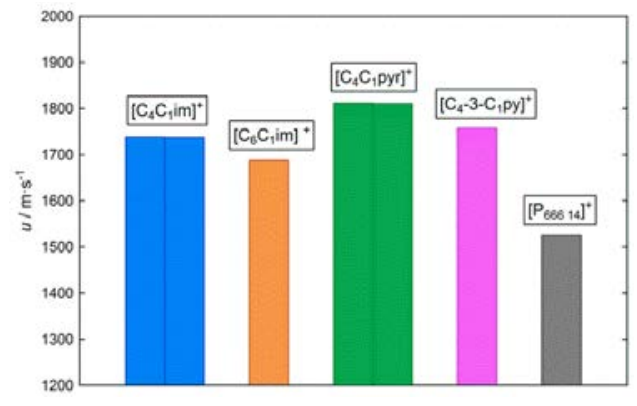


Figure 14. Influence of the length of the hydrocarbon chains and cation cores of dicyanamide ILs on the speed of sound at $298.15 \mathrm{~K}$; $\left[\mathrm{C}_{4} \mathrm{C}_{1} \mathrm{im}\right]\left[\mathrm{N}(\mathrm{CN})_{2}\right]^{79,85}$; $\left[\mathrm{C}_{6} \mathrm{C}_{1} \mathrm{im}\right]\left[\mathrm{N}(\mathrm{CN})_{2}\right]^{79}$; $\left[\mathrm{C}_{4} \mathrm{C}_{1} \mathrm{pyr}\right]\left[\mathrm{N}(\mathrm{CN})_{2}\right]^{85,94} ;\left[\mathrm{C}_{4}-3-\mathrm{C}_{1} \mathrm{py}\right]\left[\mathrm{N}(\mathrm{CN})_{2}\right]^{97} ;\left[\mathrm{P}_{66614}\right]\left[\mathrm{N}(\mathrm{CN})_{2}\right]^{92}$.

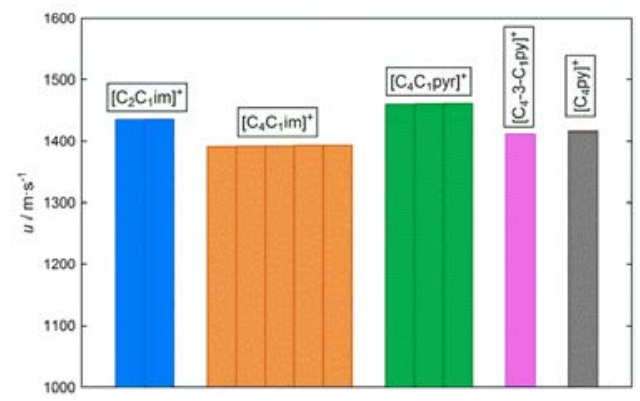

Figure 15. Influence of the length of the hydrocarbon chains and cation cores of trifluoromethanesulfonate ILs on the speed of sound at $298.15 \mathrm{~K}$; [C $\left.\mathrm{C}_{2} \mathrm{C}_{1} \mathrm{im}\right][\mathrm{TFO}]^{113,147}$; $\left[\mathrm{C}_{4} \mathrm{C}_{1} \mathrm{im}\right][\mathrm{TFO}]^{2,79,85,95,112} ;\left[\mathrm{C}_{4} \mathrm{C}_{1} \mathrm{pyr}\right][\mathrm{TFO}]^{79,85,95} ;\left[\mathrm{C}_{4}-3-\mathrm{C}_{1} \mathrm{py}\right][\mathrm{TFO}]^{85} ;\left[\mathrm{C}_{4} \mathrm{py}\right][\mathrm{TFO}]^{97}$.

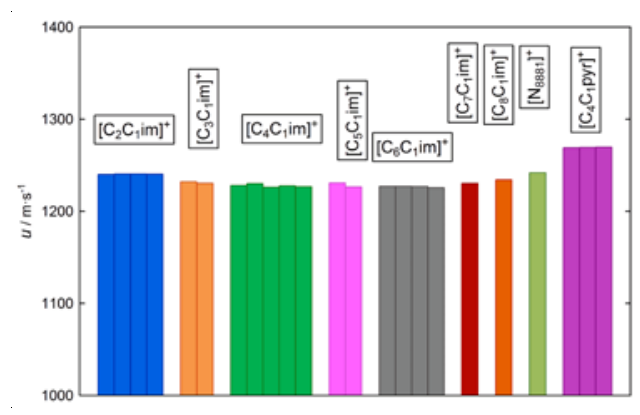

Figure 16. Influence of the length of the hydrocarbon chains and cation cores of bis(trifluoromethyl-sulfonyl)imide ILs on the speed of sound at $298.15 \mathrm{~K}$; $\left[\mathrm{C}_{2} \mathrm{C}_{1} \mathrm{im}\right]\left[\mathrm{NTf}_{2}\right]$ 25,29,79,129; $\left[\mathrm{C}_{3} \mathrm{C}_{1} \mathrm{im}\right]\left[\mathrm{NTf}_{2}\right]^{34,168} ;\left[\mathrm{C}_{4} \mathrm{C}_{1} \mathrm{im}\right]\left[\mathrm{NTf}_{2}\right]^{14,18,25,30,34} ;\left[\mathrm{C}_{5} \mathrm{C}_{1} \mathrm{im}\right]\left[\mathrm{NTf}_{2}\right]^{17,34}$; 


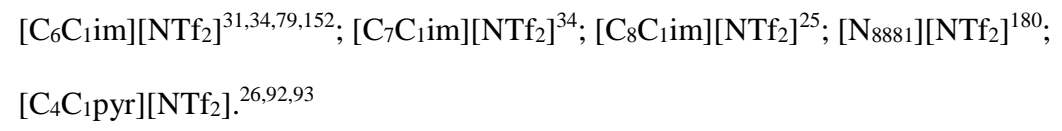

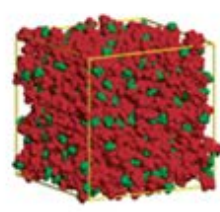

$\left[\mathrm{C}_{2} \mathrm{mim}\right]\left[\mathrm{PF}_{6}\right]$

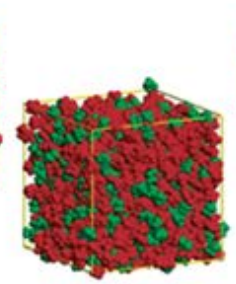

$\left[\mathrm{C}_{4} \operatorname{mim}\right]\left[\mathrm{PF}_{6}\right]$

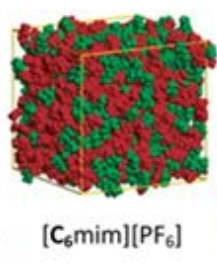

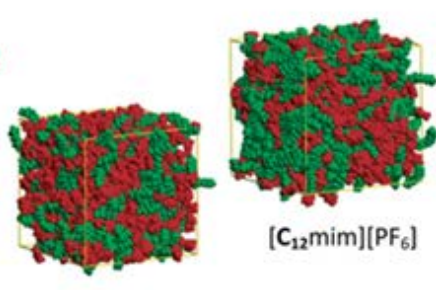

Sponge-like

\section{Globular}

Increasing alkyl chain length

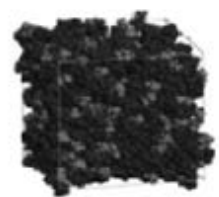

$\left[\mathbf{C}_{4} \mathrm{mim}\right]\left[\mathrm{NTf}_{2}\right]$

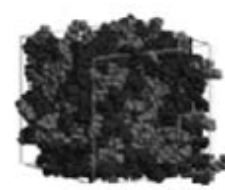

$\left[\mathrm{C}_{8} \mathrm{mim}\right]\left[\mathrm{NTf} \mathrm{f}_{2}\right]$

Figure 17. (upper part) Snapshots of the bulk structure of $\left[C_{n} \operatorname{mim}\right][P F 6]$ ILs for $n=2-12$. Each box shows 700 IL ion pairs at equilibrium with polar domains (red, anion + cation imidazolium ring) and nonpolar domains (green, cation alkyl chain) observed. Note the box dimensions are not the same length due to differences in ion size and box density. Reproduced with permission from ref ${ }^{227}$. Copyright 2015 American Chemical Society.; (bottom part) Snapshot of a configuration of $\left[\mathrm{C}_{4} \mathrm{mim}\right]\left[\mathrm{NTf}_{2}\right]$ and $\left[\mathrm{C}_{8} \mathrm{mim}\right]\left[\mathrm{NTf}_{2}\right]$ obtained from simulation where atoms belonging to the regions of high charge density (the imidazolium head groups of the cations and the entire anions) colored black, and atoms belonging to the regions of low charge density (the alkyl side chains of 
the cations) colored grey. Reproduced with permission from ref ${ }^{228}$. Copyright 2009 The Royal Society of Chemistry.

For ILs with the anions $\left.\left[\mathrm{N}(\mathrm{CN})_{2}\right]^{-},{ }_{\mathrm{TFO}}\right]^{-}$and $\left[\mathrm{NTf}_{2}\right]^{-}$, changes in the core of the cation, such as from imidazolium $\left(\left[\mathrm{C}_{4} \mathrm{C}_{1} \mathrm{im}\right]^{+}\right)$to pyrrolidinium $\left(\left[\mathrm{C}_{4} \mathrm{C}_{1} \mathrm{pyr}\right]^{+}\right)$, pyridinium $\left(\left[\mathrm{C}_{4}-3-\mathrm{C}_{1} \mathrm{py}\right]^{+}\right)$or alkylammonium $\left(\left[\mathrm{N}_{8881}\right]^{+}\right)$, increase the speed of sound (Figures $\left.14,15,16\right)$. At the same time, the $u$ in $\left[\mathrm{P}_{66614}\right]\left[\mathrm{N}(\mathrm{CN})_{2}\right]$ is much lower than that in other dicyanamide ILs, for which the cation is based on imidazolium, pyrrolidinium and pyridinium rings (see Figure 14). For $\left[\mathrm{N}(\mathrm{CN})_{2}\right]^{-}$and [TFO] $]^{-}$ILs, the speed of sound in pyrrolidinium-based ILs $\left[\mathrm{C}_{4} \mathrm{C}_{1} \mathrm{pyr}\right]^{+}$is higher than in

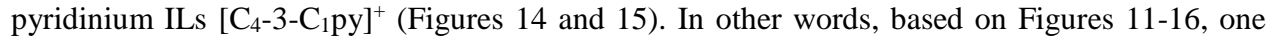
can be concluded that the speed of sound in ILs is strongly affected by the structure of the selected cation and its induced interactions with the anion.

The influence of IL anions on $u$ is, as for many physicochemical properties, more obvious and has been previously discussed ${ }^{79,89,211}$. The speed of sound has been claimed to increase with decreasing molar mass of the anion ${ }^{79}$ or molecular volume. ${ }^{211}$ According to the literature, changes in the speed of sound for imidazolium, pyrrolidinium and phosphonium can be ordered as follows: $\left[\mathrm{PF}_{6}\right]^{-<}<\left[\mathrm{BF}_{4}\right]^{-15},{ }^{15}\left[\mathrm{PF}_{6}\right]^{-}<\left[\mathrm{BF}_{4}\right]^{-}<\left[\mathrm{NTf}_{2}\right]^{-14},{ }^{14}$ and $\left[\mathrm{PF}_{6}\right]^{-}<\left[\mathrm{BF}_{4}\right]^{-}<\left[\mathrm{C}_{1} \mathrm{SO}_{4}\right]^{-}<[\mathrm{Cl}]^{-},\left[\mathrm{HSO}_{4}\right]^{-}$ $<[\mathrm{Tos}]^{-} .^{89}$ Some chosen examples with the common cations $\left[\mathrm{C}_{2} \mathrm{C}_{1} \mathrm{im}\right]^{+},\left[\mathrm{C}_{4} \mathrm{C}_{1} \mathrm{im}\right]^{+},\left[\mathrm{C}_{6} \mathrm{C}_{1} \mathrm{im}\right]^{+}$, $\left[\mathrm{C}_{8} \mathrm{C}_{1} \mathrm{im}\right]^{+},\left[\mathrm{C}_{4} \mathrm{C}_{1} \mathrm{pyr}\right]^{+}$and $\left[\mathrm{C}_{4}-3-\mathrm{C}_{1} \mathrm{py}\right]^{+}$are present in Figure 18. The speed of sound in ILs with anions, such as $\left[\mathrm{C}_{1} \mathrm{SO}_{4}\right]^{-},\left[\mathrm{C}_{2} \mathrm{SO}_{4}\right]^{-},\left[\mathrm{C}_{8} \mathrm{SO}_{4}\right]^{-},[\mathrm{Ac}]^{-},[\mathrm{Cl}]^{-}$and $[\mathrm{Br}]^{-}$, is higher than that in $\left[\mathrm{BF}_{4}\right]^{-}$, $\left[\mathrm{PF}_{6}\right]^{-}$, or $[\mathrm{TFO}]^{-}$. The lowest speed of sound is in ILs with $\left[\mathrm{NTf}_{2}\right]^{-}$, while the highest is in ILs with $[\mathrm{Cl}]^{-}$. In the first approximation, the speed of sound values in ILs with anions that contain fluorine are lower than those in ILs with comparable molar masses of anion (Figure 18). Moreover, $u$ decreases in the order $\left[\mathrm{N}(\mathrm{CN})_{2}\right]^{-}>\left[\mathrm{BF}_{4}\right]^{-}>\left[\mathrm{PF}_{6}\right]^{-}>[\mathrm{TFO}]^{-}$. According to the 
available literature data and as reported in Figure 18, one may assume that the speed of sound decreases with the molar mass of the IL anion (i.e. size of anion). Some obvious deviations can also be found; for example, the speed of sound in ILs with $\left[\mathrm{BF}_{4}\right]^{-},\left[\mathrm{PF}_{6}\right]^{-}$, or $[\mathrm{TFO}]^{-}$anions is somewhat lower than what is expected by assuming a linear decrease in the speed of sound with the molar mass of the anion.

Summing up, according to the Figure 18, it appears that the anion structure has a direct impact on the speed of sound in ILs. Generally, one can be observed that the speed of sound in ILs decreases by increasing the anion size. In other words, a decrease on the speeds of sounds in ILs as the function of the anion structure may be related to a decrease of the ion-ion interaction, which could be related to an increase of the cation-anion distances in solution, as observed by neutron diffraction and MD simulations (see Figure $19^{232}$ ).

As with many physicochemical properties, the speed of sound can be correlated with the structures of the ILs, their individual ions or sometimes their molar masses. ${ }^{4,79,89,91,99}$ The variation in the speed of sound with molar mass resembles that for density (and in some cases for surface tension), which is contrary to the trend for viscosity. ${ }^{79,89,233}$ However, as presented earlier, some discrepancies from any rule may occur. Additionally, acoustic relaxation processes are not always recognized but can be present in some ILs, which can undoubtedly influence the relationship between the speed of sound, structure and molar mass. 


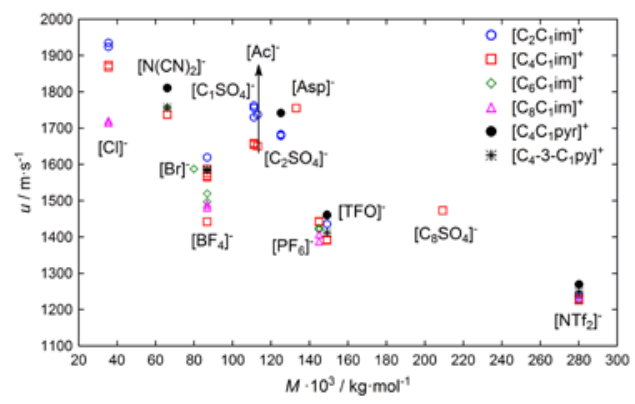

Figure 18. Speed of sound for various ILs vs. molar mass of anions at $298.15 \mathrm{~K}$; blue open circles, $\left[\mathrm{C}_{2} \mathrm{C}_{1} \mathrm{im}\right]^{+}$; red open squares: $\left[\mathrm{C}_{4} \mathrm{C}_{1} \mathrm{im}\right]^{+}$; green open diamonds: $\left[\mathrm{C}_{6} \mathrm{C}_{1} \mathrm{im}\right]^{+}$; magenta open triangles: $\left[\mathrm{C}_{8} \mathrm{C}_{1} \mathrm{im}\right]^{+}$; black filled circles: $\left[\mathrm{C}_{4} \mathrm{C}_{1} \mathrm{pyr}\right]^{+;}$stars: $\left.\left[\mathrm{C}_{4}-3-\mathrm{C}_{1} \mathrm{py}\right]^{+}\right)\left[\mathrm{C}_{2} \mathrm{C}_{1} \mathrm{im}\right]\left[\mathrm{NTf}_{2}\right]^{25,29,79}$, $\left[\mathrm{C}_{2} \mathrm{C}_{1} \mathrm{im}\right][\mathrm{TFO}]^{113,147},\left[\mathrm{C}_{2} \mathrm{C}_{1} \mathrm{im}\right]\left[\mathrm{C}_{2} \mathrm{SO}_{4}\right]^{130,132,133},\left[\mathrm{C}_{2} \mathrm{C}_{1} \mathrm{im}\right][\mathrm{Ac}]^{100},\left[\mathrm{C}_{2} \mathrm{C}_{1} \mathrm{im}\right]\left[\mathrm{C}_{1} \mathrm{SO}_{4}\right]^{83,89,103,134}$, $\left[\mathrm{C}_{2} \mathrm{C}_{1} \mathrm{im}\right]\left[\mathrm{BF}_{4}\right]^{135-141}, \quad\left[\mathrm{C}_{2} \mathrm{C}_{1} \mathrm{im}\right][\mathrm{Cl}]^{83,103} ; \quad\left[\mathrm{C}_{4} \mathrm{C}_{1} \mathrm{im}\right]\left[\mathrm{NTf}_{2}\right]^{18,25,30,34}, \quad\left[\mathrm{C}_{4} \mathrm{C}_{1} \mathrm{im}\right]\left[\mathrm{C}_{8} \mathrm{SO}_{4}\right]^{116}$, $\left[\mathrm{C}_{4} \mathrm{C}_{1} \mathrm{im}\right][\mathrm{TFO}]^{79,85,95,112}, \quad\left[\mathrm{C}_{4} \mathrm{C}_{1} \mathrm{im}\right]\left[\mathrm{PF}_{6}\right]^{13,27,75,88,89,107-110}, \quad\left[\mathrm{C}_{4} \mathrm{C}_{1} \mathrm{im}\right][\mathrm{Asp}]^{197}, \quad\left[\mathrm{C}_{4} \mathrm{C}_{1} \mathrm{im}\right][\mathrm{Ac}]^{100}$, $\left[\mathrm{C}_{4} \mathrm{C}_{1} \mathrm{im}\right]\left[\mathrm{C}_{1} \mathrm{SO}_{4}\right]^{83,87,115}, \quad\left[\mathrm{C}_{4} \mathrm{C}_{1} \mathrm{im}\right]\left[\mathrm{BF}_{4}\right]^{27,83,106,112,119}, \quad\left[\mathrm{C}_{4} \mathrm{C}_{1} \mathrm{im}\right]\left[\mathrm{N}(\mathrm{CN})_{2}\right]^{79,85}$, $\left[\mathrm{C}_{4} \mathrm{C}_{1} \mathrm{im}\right][\mathrm{Cl}]^{83,102,103} ; \quad\left[\mathrm{C}_{6} \mathrm{C}_{1} \mathrm{im}\right]\left[\mathrm{NTf}_{2}\right]^{31,34,79,152}, \quad\left[\mathrm{C}_{6} \mathrm{C}_{1} \mathrm{im}\right]\left[\mathrm{BF}_{4}\right]^{112,157}, \quad\left[\mathrm{C}_{6} \mathrm{C}_{1} \mathrm{im}\right][\mathrm{Br}]^{76,153}$, $\left[\mathrm{C}_{6} \mathrm{C}_{1} \mathrm{im}\right]\left[\mathrm{N}(\mathrm{CN})_{2}\right]^{97} ; \quad\left[\mathrm{C}_{8} \mathrm{C}_{1} \mathrm{im}\right]\left[\mathrm{NTf}_{2}\right]^{25}, \quad\left[\mathrm{C}_{8} \mathrm{C}_{1} \mathrm{im}\right]\left[\mathrm{PF}_{6}\right]^{75,88,155}, \quad\left[\mathrm{C}_{8} \mathrm{C}_{1} \mathrm{im}\right]\left[\mathrm{BF}_{4}\right]^{27,164}$, $\left[\mathrm{C}_{8} \mathrm{C}_{1} \mathrm{im}\right][\mathrm{Cl}]^{114,160} ; \quad\left[\mathrm{C}_{4} \mathrm{C}_{1} \mathrm{pyr}\right]\left[\mathrm{NTf}_{2}\right]^{26,79,92,93}, \quad\left[\mathrm{C}_{4} \mathrm{C}_{1} \mathrm{pyr}\right][\mathrm{TFO}]^{79,85,95}, \quad\left[\mathrm{C}_{4} \mathrm{C}_{1} \mathrm{pyr}\right]\left[\mathrm{C}_{1} \mathrm{SO}_{4}\right]^{91}$, $\left[\mathrm{C}_{4} \mathrm{C}_{1} \mathrm{pyr}\right]\left[\mathrm{N}(\mathrm{CN})_{2}\right]^{85,94} ; \quad\left[\mathrm{C}_{4}-3-\mathrm{C}_{1} \mathrm{py}\right]\left[\mathrm{NTf}_{2}\right]^{79,93}, \quad\left[\mathrm{C}_{4}-3-\mathrm{C}_{1} \mathrm{py}\right][\mathrm{TFO}]^{85}, \quad\left[\mathrm{C}_{4}-3-\mathrm{C}_{1} \mathrm{py}\right]\left[\mathrm{BF}_{4}\right]^{112,124}$, $\left[\mathrm{C}_{4}-3-\mathrm{C}_{1} \mathrm{py}\right]\left[\mathrm{N}(\mathrm{CN})_{2}\right]^{97}$. 


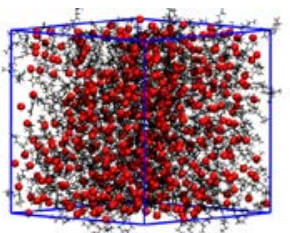

$[\mathrm{Hmim}][\mathrm{Cl}]$

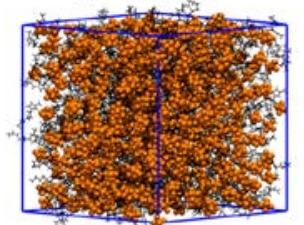

$[\mathrm{Hmim}]\left[\mathrm{PF}_{6}\right]$

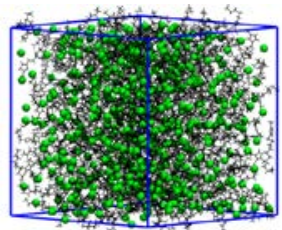

[Hmim][Br]

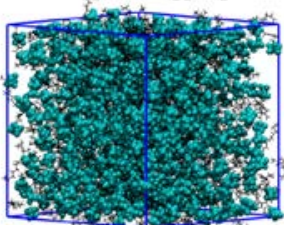

[Hmim][OTf]

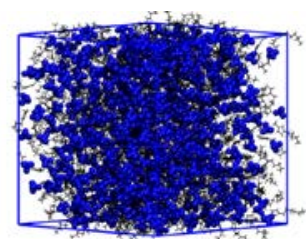

$[\mathrm{Hmim}]\left[\mathrm{BF}_{4}\right]$

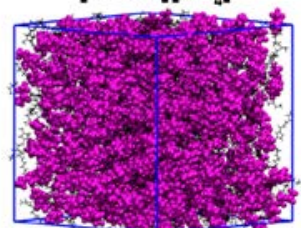

$[\mathrm{Hmin}]\left[\mathrm{NTf}_{2}\right]$

Figure 19. Final snapshot from a $5 \mathrm{~ns}$ equilibration at $\mathrm{T}=303 \mathrm{~K}$. Color scheme is as follows: black, $\left[\mathrm{C}_{6} \mathrm{C}_{1} \mathrm{im}\right]^{+}$cation; red, $[\mathrm{Cl}]^{-}$; green, $[\mathrm{Br}]^{-}$; blue, $\left[\mathrm{BF}_{4}\right]^{-}$; orange, $\left[\mathrm{PF}_{6}\right]^{-}$; cyan, $[\mathrm{OTf}]^{-}$; purple, $\left[\mathrm{NTf}_{2}\right]^{-}$. Reproduced with permission from ref ${ }^{232}$. Copyright 2015 American Chemical Society.

\subsection{Critical analysis of the speed of sound in ionic liquids vs. classical molecular solvents}

ILs are generally more complex than conventional organic molecular solvents. Thus, both their bulk and interfacial structures are different. Generally, ILs show structural diversity both in the nature of their ions and in the organization of their ions in the liquid phase. Presently, however, the nanoheterogeneity in ILs is generally well-established. ${ }^{234}$ ILs are generally much more viscous than molecular organic liquids, so somewhat different ultrasound velocity terms are present.

To our knowledge, the lowest and highest reported speed of sound values occurred in ILs at $298.15 \mathrm{~K}$ and an atmospheric pressure of $1225.64 \mathrm{~m} \cdot \mathrm{s}^{-1}$ in $\left[\mathrm{C}_{6} \mathrm{C}_{1} \mathrm{im}\right]\left[\mathrm{NTf}_{2}\right]^{34}$ and $2096 \mathrm{~m} \cdot \mathrm{s}^{-1}$ in [BenzC $\left.\mathrm{B}_{1}\right][\mathrm{Cl}],{ }^{35}$ respectively. The upper limit for the speed of sound in ILs is slightly higher than that observed in molecular liquids, but the lower limit is considerably different (Figure 20). For molecular organic liquids, the lowest speed of sound values, which are near $500 \mathrm{~m} \cdot \mathrm{s}^{-1}$, are 
observed for so-called perfluorocarbon liquids, such as some fully or partially fluorinated alcohols, alkanes, and ethers. ${ }^{235-237}$ Thus, the range of speed of sound values in measured ILs is clearly narrower compared to the range that is observed in molecular liquids under the same temperature and pressure conditions (Figure 20). Gomes de Azevedo et al. have also noticed that "speed of sound values of ILs are not too dissimilar from those typically found in conventional solvents, tending to fall in the high-value side of the range". ${ }^{15}$

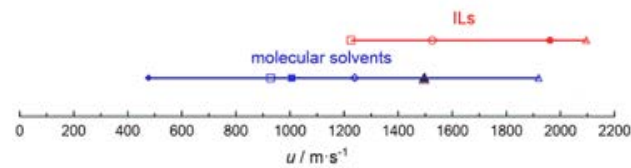

Figure 20. Speed of sound values for ILs (red line) and molecular organic liquids (blue line) and the speed of sound for water at a temperature of 298.15 K. For clarity, only selected and characteristic values are shown as symbols: red open square, $\left[\mathrm{C}_{6} \mathrm{C}_{1} \mathrm{im}\right]\left[\mathrm{NTf}_{2}\right]$; red filled triangle, [BenzC $\left.\mathrm{B}_{1} \mathrm{im}\right][\mathrm{Cl}]$; red open circle, $\left[\mathrm{P}_{66614}\right]\left[\mathrm{N}(\mathrm{CN})_{2}\right]$; red filled circle, $\left[\mathrm{N}\left(2(\mathrm{OH}) \mathrm{C}_{2}\right) 3_{1}\right]\left[\mathrm{C}_{1} \mathrm{SO}_{4}\right]$; blue filled diamond, $\mathrm{C}_{5} \mathrm{~F}_{12}$; blue open square, $\mathrm{CHBr}_{3}$; blue filled square, $\mathrm{C}_{5} \mathrm{H}_{12}$; blue open diamond, 1-butanol; blue open triangle, 1,2,3-propanetriol; and black filled triangle, water. ${ }^{235,236,238-241}$

As with impedance in electrical circuits, acoustic impedance matching or mismatching is a crucial problem in any ultrasonic experiment. Thus, the specific acoustic impedance $z$ $(z=\rho \cdot u)$, which is directly connected to the speed of sound in a medium, is very important, especially in practical applications. A specific acoustic impedance value describes the resistance of a medium to wave propagation and depends on the medium's properties and the type of wave that is propagating through it. Thus, the specific acoustic impedance that is acting in resistance to the wave propagation increases with increasing medium density and speed of sound. Recently, 
reported pressure-temperature values $z(p, T)$ for $\left[\mathrm{C}_{2} \mathrm{C}_{1} \mathrm{im}\right]\left[\mathrm{NTf}_{2}\right]$ are contained between $1.7934 \cdot 10^{6} \mathrm{~kg} \cdot \mathrm{m}^{-2} \cdot \mathrm{s}^{-1}$ and $2.4006 \cdot 10^{6} \mathrm{~kg} \cdot \mathrm{m}^{-2} \cdot \mathrm{s}^{-1}$ at $318.15 \mathrm{~K}$ and $0.1 \mathrm{MPa}$ and at $288.15 \mathrm{~K}$ and 100 MPa, respectively. ${ }^{221}$ Thus, the $z$ of $\left[\mathrm{C}_{2} \mathrm{C}_{1} \mathrm{im}\right]\left[\mathrm{NTf}_{2}\right]$ in this $(p, T)$ range changes by approximately $34 \%$. For the ILs that were analyzed in this review, the magnitude of $z$ at ambient pressure and 298.15 K ranges from $1.3717 \cdot 10^{6} \mathrm{~kg} \cdot \mathrm{m}^{-2} \cdot \mathrm{s}^{-1}$ for $\left[\mathrm{P}_{66614}\right]\left[\mathrm{N}(\mathrm{CN})_{2}\right]^{92}$ to $2.6352 \cdot 10^{6} \mathrm{~kg} \cdot \mathrm{m}^{-2} \cdot \mathrm{s}^{-1}$ for $\left[\mathrm{N}\left(2(\mathrm{OH}) \mathrm{C}_{2}\right) 3_{1}\right]\left[\mathrm{C}_{1} \mathrm{SO}_{4}\right] .{ }^{174}$ The $z$ values for the ILs spanned a narrower range compared to the $z$ values for the molecular liquids. In particular, the lower limit of $z$ for the ILs was evidently higher than those for organic molecular liquids (Figure 21).

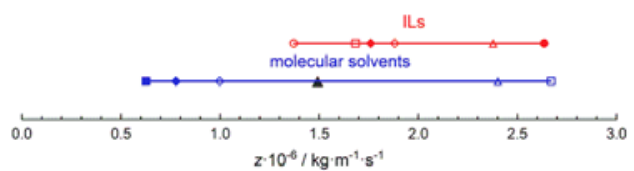

Figure 21. Specific acoustic impedance range for ILs (red line) and molecular organic liquids (blue line) and the specific acoustic impedance for water at a temperature of $298.15 \mathrm{~K}$. For clarity, only selected and characteristic values are shown as symbols: red open circle,

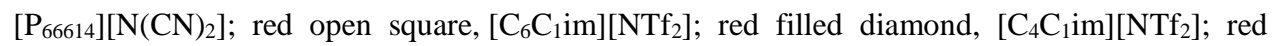
open diamond, $\left[\mathrm{C}_{2} \mathrm{C}_{1}\right.$ im] $\left[\mathrm{NTf}_{2}\right]$; red open triangle, $\left[\right.$ BenzC $\left.\mathrm{C}_{1} \mathrm{im}\right] \mathrm{Cl}$; red filled circle, $\left[\mathrm{N}\left(2(\mathrm{OH}) \mathrm{C}_{2}\right) 3_{1}\right]\left[\mathrm{C}_{1} \mathrm{SO}_{4}\right]$; blue open square, $\mathrm{CHBr}_{3}$; blue filled square, $\mathrm{C}_{5} \mathrm{H}_{12}$; blue filled diamond, $\mathrm{C}_{5} \mathrm{~F}_{12}$; blue open triangle, 1,2,3-propanetriol; blue open diamond, 1-butanol; and black filled triangle, water. ${ }^{35,92,174,235,239-241}$

Parthasarathy ${ }^{242-244}$ derived a few empirical rules that relate the speed of sound and chemical constitution of molecular liquids. These rules cannot be simply adapted to ILs because of the different chemical constitutions of ILs compared to molecular solvents. However, some regularities can be observed. According to Parthasarathy, substituting a chloride atom for a 
bromide atom decreases the speed of sound. This effect is also observed for $\left[\mathrm{C}_{n} \mathrm{C}_{1} \mathrm{im}\right][\mathrm{Br}]$ and $\left[\mathrm{C}_{n} \mathrm{C}_{1} \mathrm{im}\right][\mathrm{Cl}]$ (see paragraph 3.3, Figure 18). Lengthening the carbon chain of alkanes, 1alkanols, ketones and compounds that contain two bromide atoms, which are progressively separated, i.e., by adding - $\mathrm{CH}_{2}$ - groups, enhances the speed of sound. This relationship could then explain results reported by Gardas and Coutinho ${ }^{211}$ during earlier acoustic investigations. These authors predicted an increase in the speed of sound with elongated alkyl chains of imidazolium cations, which agrees with changes that were observed for molecular liquids. Increment of alkyl chains as substituents in IL cation rings (i.e., adding $-\mathrm{CH}_{2}$ - groups) creates the opposite effect, or the existence of a $u(n)$ minimum for $\left[\mathrm{C}_{n} \mathrm{C}_{1} \mathrm{im}\right]\left[\mathrm{NTf}_{2}\right]$ (see paragraph 3.3 and Figure 11). Chhotaray et al. ${ }^{177}$ analyzed the speed of sound in the investigated ILs ([BT][Ac], [CP][Ac], $\left.[\mathrm{BT}][\mathrm{HCOO}],[\mathrm{BT}]\left[\mathrm{C}_{5} \mathrm{COO}\right],[\mathrm{CP}][\mathrm{HCOO}],[\mathrm{CP}]\left[\mathrm{C}_{5} \mathrm{COO}\right]\right)$ and noticed that “...the addition of a carbon chain on either cation or anion produces the opposite trend over the speed of sound. While the increment of carbon chain length on the cationic side works in favour of speed of sound, the increment on the anionic side reduces the speed of sound in the ionic fluid.” Mainly, increments of carbon chains on both the cationic and anionic sides reduces the speed of sound in ILs, except for the abovementioned ILs that were examined by Chhotaray et al. ${ }^{177}$ and for $\left[\mathrm{N}_{2200}\right][\mathrm{Ac}]$ and $\left[\mathrm{N}_{2220}\right][\mathrm{Ac}] .^{36}$ In contrast to the last example, the speed of sound in $\left[\mathrm{C}_{2} \mathrm{C}_{1} \mathrm{im}\right][\mathrm{Ac}]$ is noticeably higher than that in $\left[\mathrm{C}_{4} \mathrm{C}_{1}\right.$ im $][\mathrm{Ac}] .{ }^{100}$ Parthasarathy found that the speed of sound in esters decreases with increasing length of the alcohol radical; for example, butyl acetate $\left(\mathrm{C}_{4} \mathrm{Ac}\right)<$ propyl acetate $\left(\mathrm{C}_{3} \mathrm{Ac}\right)<$ ethyl acetate $\left(\mathrm{C}_{2} \mathrm{Ac}\right)<$ methyl acetate $\left(\mathrm{C}_{1} \mathrm{Ac}\right){ }^{242}$

Accordingly to Parthasarathy's rules for molecular solvents, highly viscous liquids have greater speed of sound values. ${ }^{242}$ The opposite $u(\eta)$ behavior was observed for $\left[\mathrm{C}_{n} \mathrm{C}_{1} \mathrm{im}\right]\left[\mathrm{BF}_{4}\right]$ and $\left[\mathrm{C}_{n} \mathrm{C}_{1} \mathrm{im}\right]\left[\mathrm{PF}_{6}\right]$ and an irregular behavior of $u(n)$ for $\left[\mathrm{C}_{n} \mathrm{C}_{1} \mathrm{im}\right]\left[\mathrm{NTf}_{2}\right]$ (see Figure 11 ). 
Similarly to Parthasarathy, Rao ${ }^{245}$ observed that measurements of the speed of sound and density produce information that could be helpful in the structural analysis of liquids. Figure 22 presents the empirical ratio $K$ of two relative coefficients $u^{-1}(\partial u / \partial T)_{p}$ and $V^{-1}(\partial V / \partial T)_{p}$ for molten salts, molecular solvents, and ILs. The empirical values of $K$ for ILs are similar to those for molecular solvents and different than those for molten salts.

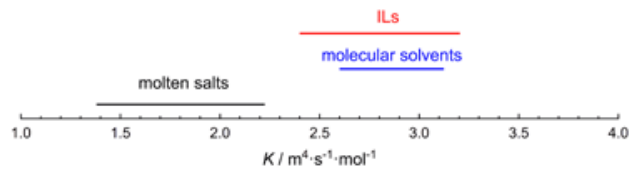

Figure 22. Absolute values of the empirical ratio $K$ for molten salts, ${ }^{246}$ organic molecular solvents, ${ }^{245,246}$ and ILs (calculated from ${ }^{25,75,79,109,118,119,136,156,168}$ ).

In turn, the Rao's constant $R$, sometimes called the molar speed of sound, from simply empirical rule as a product of $u^{1 / 3}$ and $V$. $R$ is independent of the temperature but depends on the nature of the liquid and is related to the repulsive exponent in the Lennard-Jones potential. ${ }^{247}$ Because Rao's constant is an additive quantity, its value for liquids can be determined from the contributions of the constituent groups. Figure 23 presents Rao's constant, $R$, plotted against the molar mass of homologous series of molecular organic solvents and ILs. All the presented series match the same slope, but the $R$ values for ILs are much larger than those for organic molecular solvents. Additionally, Rao's constant undergoes regular increments among the members of homologues series of liquids. This approach is justified even in complicated objects such as ILs. 


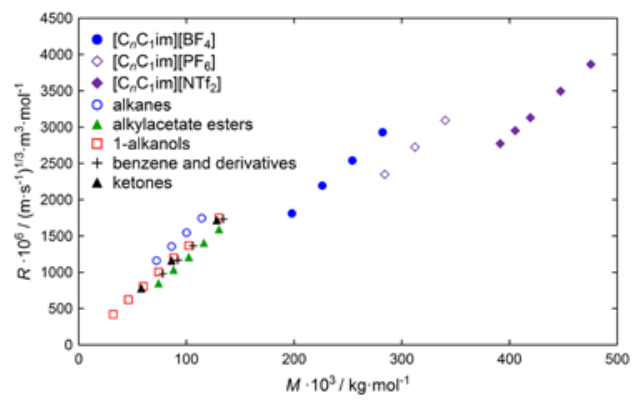

Figure 23. Rao's constant, $R$, for homologous series of molecular solvents and ILs as a function of the molar mass: black open triangles - ketones (acetone, diethylketone, 2-octanone) ${ }^{245}$; cross benzene and its derivatives (benzene, toluene, xylene, cymene) ${ }^{245}$; red open squares - 1 - alkanols (from methanol to 1-octanol) ${ }^{245}$; green filled triangles - esters (methylacetate, ethylacetate, propylacetate, butylacetate, amylacetate $)^{245}$; blue open circles - alkanes $(n=5-8)^{245}$; violet filled diamonds - $\left[\mathrm{C}_{n} \mathrm{C}_{1} \mathrm{im}\right]\left[\mathrm{NTf}_{2}\right](n: 2,3,4,6,8)$ (calculated from $\left.{ }^{25,79,168}\right)$; violet filled circles $\left[\mathrm{C}_{n} \mathrm{C}_{1} \mathrm{im}\right]\left[\mathrm{PF}_{6}\right](n: 4,6,8)$ (calculated from $\left.{ }^{75,109,155}\right)$; violet open diamonds - $\left[\mathrm{C}_{n} \mathrm{C}_{1} \mathrm{im}\right]\left[\mathrm{BF}_{4}\right](n$ : 2,4,6,8) (calculated from ${ }^{118,119,136,156}$ ).

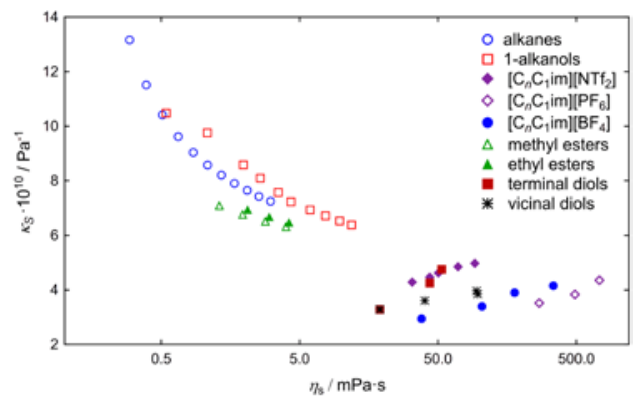

Figure 24. Isentropic compressibility vs. viscosity for chosen groups of molecular solvents and ILs: blue open circles: alkanes (density and speed of sound ${ }^{248}$, viscosity $-n$ : $(6,7,8,10,12,14)^{249}$, $\left.9^{250},(11,13,15)^{251}, 16^{252}\right)$; red open squares: 1 -alkanols (density and speed of sound ${ }^{253}$, viscosity 
- $\left.n:(1,2,6)^{254},(3,4,5,7-10)^{255}\right)$; green open triangles: methyl esters of fatty acids (methyl caprylate, methyl caprate, methyl laurate, methyl myristate - isentropic compressibility ${ }^{256}$, viscosity ${ }^{257}$ ); green filled triangles: ethyl esters of fatty acids (isentropic compressibility - ethyl caprate $^{258}$, (ethyl laurate, ethyl myristate) $)^{259}$, viscosity ${ }^{257}$ ); black stars: terminal diols (1,2etanediol $^{260}$, 1,3-propanediol - isentropic compressibility ${ }^{261}$, viscosity $^{262}, 1$,4-butanediol ${ }^{263}, 1,5-$ pentanediol - isentropic compressibility ${ }^{264}$, viscosity $\left.{ }^{265}\right)$; red filled squares: vicinal diols (1,2etanediol $^{260}$, 1,2-propanodiol ${ }^{261}$, 1,2-butanediol - isentropic compressibility ${ }^{266}$, viscosity ${ }^{262}$ ); violet filled diamonds: [ $\left.\mathrm{C}_{n} \mathrm{C}_{1} \mathrm{im}\right]\left[\mathrm{NTf}_{2}\right]\left(n: 2^{29,267}, 3^{168}, 4^{25,268} ; 8^{25,269}\right)$; blue filled circles: $\left[\mathrm{C}_{n} \mathrm{C}_{1} \mathrm{im}\right]\left[\mathrm{BF}_{4}\right]\left(n: 2^{270,271}, 4^{119,272}, 6^{157,273}, 8^{157,274}\right)$; violet opened diamonds: [ $\left.\mathrm{C}_{n} \mathrm{C}_{1} \mathrm{im}\right]\left[\mathrm{PF}_{6}\right](n$ : $\left.4^{75,275}, 6^{155,276}, 8^{155,274}\right)$.

As it was mentioned above ILs are generally much more (from 2 to 3 orders of magnitude) viscous than the almost all molecular organic liquids with exception of highly associated polyhydroxyl liquids. Figure 24 presents isentropic compressibility - quantity directly related to speed of sound, plotted against the viscosity of homologous series of molecular organic solvents and ILs. As seen, all presented series of ILs and $\alpha, \omega$-diols match the same slope. The values of viscosity for ILs and diols are much larger than ones for typical organic molecular solvents, while isentropic compressibility for ILs and diols are lower than ones for other organic molecular solvents (Figure 24).

\section{Calculation of volumetric properties and thermodynamic formalism}

General formalism concerning relationship between speed of sound and thermodynamic quantities based on conception of non-Gibbsian quantities was described in details by Reis et al. ${ }^{277}$ and Douhéret et al. ${ }^{278}$ As mentioned in Introduction and taking into consideration all 
requirements described in the paragraph 2.2.2, the Newton-Laplace equation is the fundament for the determination of the isentropic compressibility $\left(\kappa_{S} \equiv-V^{-1}(\partial V / \partial p)_{S}\right)$ within prior knowledge of the density and speed of sound:

$\kappa_{S} \equiv\left(\rho \cdot u^{2}\right)^{-1}$.

Therefore, beside speed of sound, experimental density was reported in almost all papers, except works where transient grating ${ }^{12,19,20,22,23}$ and some time of flight ${ }^{18}$ methods had been used. In the most cases (75\%) density was measured together with the speed of sound by means of Anton-Paar DSA series, as reported in Table S1. In 21\%, density was measured separately using Anton-Paar DMA series, high pressure Anton-Paar DMA series or pycnometer (see Table S1). However, generally density data of ILs have been determined using a wide range of experimental techniques based on direct methods such as volumetric (piezometer, pycnometer, dilatometer) or buoyancy methods (direct Archimedes techniques, desinsimeters with magnetic suspension coupling) and on indirect methods (vibrating tube densimeter, speed of sound). ${ }^{279,280}$

However, such data have been mainly reported for atmospheric pressure (more than 80 \% of the data described in the ILs NIST database comes from vibrating-tube densimeter). ${ }^{5}$ In other words, there is still a lack of accurate ILs density data over a wide range of pressure. This is clearly illustrated by the fact that the high-pressure density data have been determined for "only" 79 different ILs, while the density at atmospheric pressure of more than 400 different ILs has been reported in the literature, to date. ${ }^{5}$ This difference is related to the experimental difficulties associated with obtaining accurate measurements under high-pressure. Most of the density data for ILs as a function of temperature and pressure $(\approx 82 \%)$ have been measured by using indirect methods and principally the vibrating-tube densimeter that requires rather extensive calibration. 
The calibration at high pressures, similarly as at atmospheric pressure, should be made with reference liquids with densities close to those of the samples to obtain accurate data. ${ }^{279,281,282}$ Furthermore, in the case of viscous liquids such as ILs, a viscosity correction on the density must be applied. ${ }^{281,282,283}$

Non-viscosity dependent are direct methods, ${ }^{279}$ however, these methods are time consuming, e.g., an extensive calibration as in the case of dilatometer, ${ }^{284}$ and instrumentation is not fully commercialized. However, whatever the methods used, a special attention must be paid to determine accurate density data, which may be then combined with speeds of sound to further calculate related thermodynamic properties.

Isentropic compressibility of pure ILs at atmospheric pressure and at a given temperature or as a function of temperature, is request to gain a better understanding of inter- and intramolecular interactions including ions and substituent effects as well as for better and selective use in various chemical and industrial processes. ${ }^{13-15,17,20,21,23,25,26,29,30,33,36,76,78,80-83,85,87-}$ 90,93,94,96,102-104,107-110,115,117-121,123,125,127,129-144,147-152,154-157,159-164,167,168,170,171,173,175,177-180,182,185,187,189, 190,214 The isentropic compressibility multiplied by molar volume is shifted into molar isentropic compressibility, which has been reported in some papers concerning ILs investigations..$^{30,85,93,94,118,119,129,132,134,152,156,159,168}$ Note also that the isentropic compressibility is the reciprocal of the isentropic static bulk modulus, $K_{0},\left(\kappa_{S}=K_{0}{ }^{-1}\right)$.

Using abovementioned formalism concerning calculations thermodynamic properties on the basis of the speed of sound, ${ }^{278}$ the very realiable isothermal compressibility $\left(\kappa_{T} \equiv-V^{-1}(\partial V / \partial p)_{T}\right)$ values are calculated too. ${ }^{25}$ The isothermal compressibility is used as an input parameter in the ERAS model calculations ${ }^{112,113}$ and very often is obtained at atmospheric 
pressure as a reference isobar for high pressure calculations ${ }^{14,15}$ and also for computing isochoric heat capacity, ${ }^{25}$ as well as, for obtaining the internal pressure. ${ }^{25,27,114}$

The acoustic method, which has found wide acceptance as a precise tool for the determination of thermodynamic properties of compressed liquids is an attractive alternative to the direct determination of the $p \rho T$ data of liquids.,8,29,40 These data obtained from the experimental speeds of sound belong to the most reliable ones because the speed of sound can be measured accurately over wide ranges of temperature and pressure. High pressure speed of sound data were reported only in seven pure ILs, namely $\left[\mathrm{C}_{2} \mathrm{C}_{1} \mathrm{im}\right]\left[\mathrm{NTf}_{2}\right], \quad\left[\mathrm{C}_{3} \mathrm{C}_{1} \mathrm{im}\right]\left[\mathrm{NTf}_{2}\right]$, $\left[\mathrm{C}_{4} \mathrm{C}_{1} \mathrm{im}\right]\left[\mathrm{NTf}_{2}\right], \quad\left[\mathrm{C}_{5} \mathrm{C}_{1} \mathrm{im}\right]\left[\mathrm{NTf}_{2}\right], \quad\left[\mathrm{C}_{6} \mathrm{C}_{1} \mathrm{im}\right]\left[\mathrm{NTf}_{2}\right], \quad\left[\mathrm{C}_{4} \mathrm{C}_{1} \mathrm{im}\right]\left[\mathrm{PF}_{6}\right], \quad\left[\mathrm{C}_{4} \mathrm{C}_{1} \mathrm{im}\right]\left[\mathrm{BF}_{4}\right] .{ }^{14,15,29,17,214}$ Additionally, $p \rho T$ data of $\left[\mathrm{C}_{4} \mathrm{C}_{1} \mathrm{im}\right]\left[\mathrm{NTf}_{2}\right],{ }^{218}\left[\mathrm{C}_{6} \mathrm{C}_{1} \mathrm{im}\right]\left[\mathrm{NTf}_{2}\right],{ }^{207}$ and $\left[\mathrm{C}_{4} \mathrm{C}_{1} \mathrm{im}\right][\mathrm{Ac}]^{196}$ have been used for the further calculations of the $u(p, T)$ data. Some $u(p, T)$ data were also estimated using SAFT-BACK equation of state for $\left[\mathrm{C}_{4} \mathrm{C}_{1} \mathrm{im}\right]\left[\mathrm{NTf}_{2}\right]^{199,200}$ and for all $\operatorname{ILs}^{199}$ for which $u(p, T)$ experimental data were published before $2013,{ }^{14,15,17}$ as well as, for the $\left[\mathrm{C}_{3} \mathrm{C}_{1}\right.$ im] $]\left[\mathrm{NTf}_{2}\right]$, $\left[\mathrm{C}_{4} \mathrm{C}_{1} \mathrm{im}\right]\left[\mathrm{NTf}_{2}\right],\left[\mathrm{C}_{5} \mathrm{C}_{1} \mathrm{im}\right]\left[\mathrm{NTf}_{2}\right],\left[\mathrm{C}_{4} \mathrm{C}_{1} \mathrm{im}\right]\left[\mathrm{PF}_{6}\right] .{ }^{198}$ There are two main reasons which may explain the lack of $u(p, T)$ data. First, the instruments for that purpose are not purchased from commercial supplier. Usually, they are designed and constructed in research laboratories. Second, the interpretation of the speed of sound data and their use for the further determination of related thermodynamic properties is only possible with the prior knowledge of the relaxation regions (see also paragraph 2.2.2). Observed ultrasound absorption spectra of some ILs suggest that under high pressure and/or low temperature, the dependence of speed of sound on frequency could appear at frequencies of transducers operating in conventional ultrasound devices. In that case, the speed of sound cannot be regarded as the thermodynamic quantity; thus it is not possible to use the Newton-Laplace equation and to determine then related thermodynamic properties. As 
a result of IUPAC Project 2002-005-1-100 [ $\left.\mathrm{C}_{6} \mathrm{C}_{1} \mathrm{im}\right]\left[\mathrm{NTf}_{2}\right]$ was selected as a IUPAC reference sample for thermodynamic, transport, and phase equilibrium properties. ${ }^{45,285}$ However the speed of sound under high pressure was not included. Gomes de Azevedo et al. ${ }^{14}$ reported high pressure thermodynamic properties of two ILs namely the $\left[\mathrm{C}_{4} \mathrm{C}_{1} \mathrm{im}\right]\left[\mathrm{NTf}_{2}\right]$ as well as the IUPAC reference sample $\left[\mathrm{C}_{6} \mathrm{C}_{1} \mathrm{im}\right]\left[\mathrm{NTf}_{2}\right]$. However, these authors did not report the high pressure speed of sound in $\left[\mathrm{C}_{6} \mathrm{C}_{1} \mathrm{im}\right]\left[\mathrm{NTf}_{2}\right]$. Unfortunately, authors did not explain why high pressure speed of sound experiment was not performed for $\left[\mathrm{C}_{6} \mathrm{C}_{1} \mathrm{im}\right]\left[\mathrm{NTf}_{2}\right]$. However, recent investigation has proven that the absorption spectra of $\left[\mathrm{C}_{6} \mathrm{C}_{1} \mathrm{im}\right]\left[\mathrm{NTf}_{2}\right]$ show dependence on frequency. ${ }^{34}$ In consequence speed of sound dispersion is observed (Figure 3). Therefore $p \rho T$ data of $\left[\mathrm{C}_{6} \mathrm{C}_{1} \mathrm{im}\right]\left[\mathrm{NTf}_{2}\right]$ should not be calculated from $u(p, T)$ data without additional analyzes of temperature and pressure speed of sound dispersion. Thus, Dzida et al. ${ }^{214}$ measured speed of sound in $\left[\mathrm{C}_{6} \mathrm{C}_{1} \mathrm{im}\right]\left[\mathrm{NTf}_{2}\right]$ at pressures up to $100 \mathrm{MPa}$ in the temperature range from $303.15 \mathrm{~K}$ to $323.15 \mathrm{~K}$.

The pressure dependencies of the density and heat capacity, isentropic compressibility, the isothermal compressibility, isobaric expansibility, isochoric thermal-pressure coefficient, isochoric heat capacity are calculated by acoustic method using the well-known thermodynamic relationships..$^{8,14,15,29}$ The density of $\left[\mathrm{C}_{3} \mathrm{C}_{1} \mathrm{im}\right]\left[\mathrm{NTf}_{2}\right],\left[\mathrm{C}_{4} \mathrm{C}_{1} \mathrm{im}\right]\left[\mathrm{NTf}_{2}\right],\left[\mathrm{C}_{5} \mathrm{C}_{1} \mathrm{im}\right]\left[\mathrm{NTf}_{2}\right]$ and $\left[\mathrm{C}_{6} \mathrm{C}_{1} \mathrm{im}\right]\left[\mathrm{NTf}_{2}\right]$ under high pressure obtained by the acoustic method by Dzida et al. ${ }^{214}$ are in a very good agreement with data obtained by high pressure densimeter $14,17,207,218,286$, while a bad agreement with the high-pressure specific volumes obtained using dilatometer ${ }^{287}$ is observed. The maximum deviation is $-1.96 \mathrm{~kg} \cdot \mathrm{m}^{-3}$ at $1.83 \mathrm{MPa}$ and $313.15 \mathrm{~K}$ for $\left[\mathrm{C}_{3} \mathrm{C}_{1} \mathrm{im}\right]\left[\mathrm{NTf}_{2}\right],-0.95 \mathrm{~kg} \cdot \mathrm{m}^{-3}$ at $5 \mathrm{MPa}$ and $308.09 \mathrm{~K}$ for $\left[\mathrm{C}_{4} \mathrm{C}_{1} \mathrm{im}\right]\left[\mathrm{NTf}_{2}\right]$ reported by Gomes de Azevedo et al. ${ }^{14},-1.17 \mathrm{~kg} \cdot \mathrm{m}^{-3}$ at 59.1 $\mathrm{MPa}$ and $323.15 \mathrm{~K}$ for $\left[\mathrm{C}_{4} \mathrm{C}_{1} \mathrm{im}\right]\left[\mathrm{NTf}_{2}\right]$ reported by Hamidova et al. ${ }^{218},+1.1 \mathrm{~kg} \cdot \mathrm{m}^{-3}$ at 40 $\mathrm{MPa}$ and $313.15 \mathrm{~K}$ for $\left[\mathrm{C}_{4} \mathrm{C}_{1} \mathrm{im}\right]\left[\mathrm{NTf}_{2}\right]$ reported by Currás et al. ${ }^{286},-22 \mathrm{~kg} \cdot \mathrm{m}^{-3}$ at $40 \mathrm{MPa}$ and 
$314.78 \mathrm{~K}$ for $\left[\mathrm{C}_{4} \mathrm{C}_{1} \mathrm{im}\right]\left[\mathrm{NTf}_{2}\right]$ reported by Wojnarowska et $\mathrm{al}^{287},-2.48 \mathrm{~kg} \cdot \mathrm{m}^{-3}$ at $31.48 \mathrm{MPa}$ and $298.15 \mathrm{~K}$ for $\left[\mathrm{C}_{5} \mathrm{C}_{1} \mathrm{im}\right]\left[\mathrm{NTf}_{2}\right], 2.2 \mathrm{~kg} \cdot \mathrm{m}^{-3}$ at $44.17 \mathrm{MPa}$ and $323.15 \mathrm{~K}$ for $\left[\mathrm{C}_{6} \mathrm{C}_{1} \mathrm{im}\right]\left[\mathrm{NTf}_{2}\right]$ reported by Gomes de Azevedo et al. ${ }^{14},-0.96 \mathrm{~kg} \cdot \mathrm{m}^{-3}$ at $19.342 \mathrm{MPa}$ and $313.16 \mathrm{~K}$ for $\left[\mathrm{C}_{6} \mathrm{C}_{1} \mathrm{im}\right]\left[\mathrm{NTf}_{2}\right]$ reported by Safarov et al. ${ }^{207}$ While $u(p, T)$ data for $\left[\mathrm{C}_{6} \mathrm{C}_{1}\right.$ im $]\left[\mathrm{NTf}_{2}\right]$ calculated by Safarov et al. ${ }^{207}$ and for $\left[\mathrm{C}_{4} \mathrm{C}_{1} \mathrm{im}\right]\left[\mathrm{NTf}_{2}\right]$ calculated by Hamidova et al. ${ }^{218}$ from high pressure densities are in bad agreement with experimental ones reported by Dzida et al. ${ }^{214}$, the maximum deviation is $-45.45 \mathrm{~m} \cdot \mathrm{s}^{-1}$ at $99.55 \mathrm{MPa}$ and $313.15 \mathrm{~K}$ for $\left[\mathrm{C}_{6} \mathrm{C}_{1} \mathrm{im}\right]\left[\mathrm{NTf}_{2}\right]$ and $-20.07 \mathrm{~m} \cdot \mathrm{s}^{-1}$ at 69.996 $\mathrm{MPa}$ and $293.15 \mathrm{~K}$ for $\left[\mathrm{C}_{4} \mathrm{C}_{1} \mathrm{im}\right]\left[\mathrm{NTf}_{2}\right]$. Isentropic compressibility obtained by the acoustic method by Dzida et al. is also in a very good agreement with experimental ones for $\left[\mathrm{C}_{3} \mathrm{C}_{1} \mathrm{im}\right]\left[\mathrm{NTf}_{2}\right]$ (the maximum deviation is $0.0055 \mathrm{GPa}^{-1}$ at $59.59 \mathrm{MPa}$ and $313.15 \mathrm{~K}$ ) and $\left[\mathrm{C}_{5} \mathrm{C}_{1} \mathrm{im}\right]\left[\mathrm{NTf}_{2}\right]$ (the maximum deviation is $0.0053 \mathrm{GPa}^{-1}$ at $59.59 \mathrm{MPa}$ and $313.15 \mathrm{~K}^{17}$ and with excellent agreement with calculated by the acoustic method by Gomes de Azevedo et al. ${ }^{14}$ (the maximum deviation is $0.0013 \mathrm{GPa}^{-1}$ at $10 \mathrm{MPa}$ and $303.15 \mathrm{~K}$ ). Herein, a statistical analysis is presented in Table 5. As illustration, we presented the comparison of density calculated by an indirect acoustic method as a function of pressure to ones measured directly by high pressure densimeter, as well as, speeds of sound and isentropic compressibilities reported in literature (Figures 25 and 26). ${ }^{14,17,214,218}$

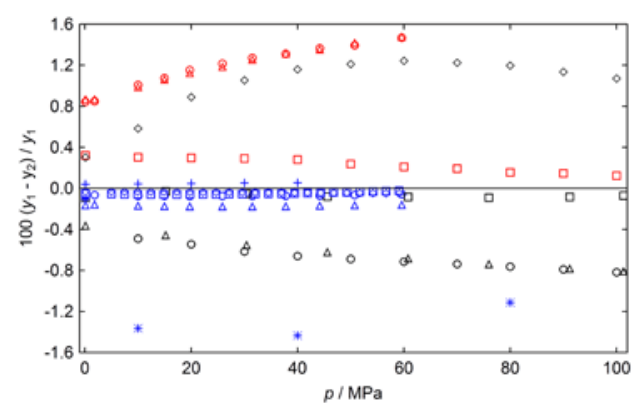


Figure 25. Relative deviations of the speed of sound (open black points), densities (open blue points) and isentropic compressibilities (open red points) between results obtained for $\left[\mathrm{C}_{3} \mathrm{C}_{1} \mathrm{im}\right]\left[\mathrm{NTf}_{2}\right]$ (circles), $\left[\mathrm{C}_{4} \mathrm{C}_{1} \mathrm{im}\right]\left[\mathrm{NTf}_{2}\right]$ (squares $^{14}$, diamonds $^{218}$, pluses ${ }^{286}$, stars $^{287}$ ), $\left[\mathrm{C}_{5} \mathrm{C}_{1} \mathrm{im}\right]\left[\mathrm{NTf}_{2}\right]$ (triangles) at $298.15 \mathrm{~K}$ reported by Dzida et al. ${ }^{214}\left(y_{1}\right)$ and by Esperança et al. ${ }^{17}$ for $\left[\mathrm{C}_{3} \mathrm{C}_{1} \mathrm{im}\right]\left[\mathrm{NTf}_{2}\right]$ and $\left[\mathrm{C}_{5} \mathrm{C}_{1} \mathrm{im}\right]\left[\mathrm{NTf}_{2}\right]$ and by Gomes de Azevedo et al. ${ }^{14}$ and Hamidova et al. ${ }^{218}$ for $\left[\mathrm{C}_{4} \mathrm{C}_{1} \mathrm{im}\right]\left[\mathrm{NTf}_{2}\right],\left(y_{2}\right)$.

Figure 25 presents that the leading systematic error contribution to the calculated isentropic compressibilities arises mainly from the speed of sound measurement errors, which became more significant in the area of high pressure.

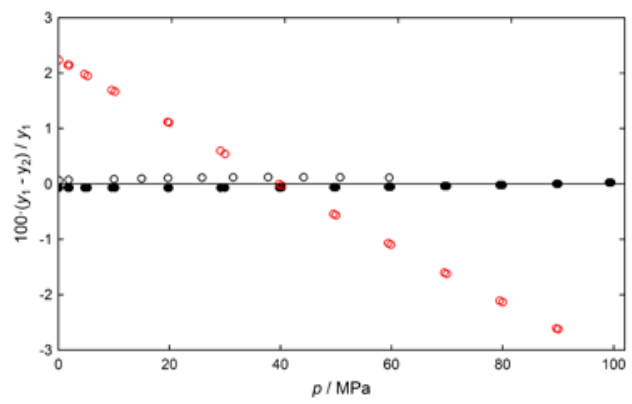

Figure 26. Relative deviations of the speed of sound and density between results obtained for $\left[\mathrm{C}_{6} \mathrm{C}_{1} \mathrm{im}\right]\left[\mathrm{NTf}_{2}\right]$ at $313.15 \mathrm{~K}$ reported by Dzida et al. ${ }^{214}\left(y_{1}\right)$ and Gomes de Azevedo et al. ${ }^{14}$ for density (open black circle) and Safarov et al. ${ }^{207}$ for density (filled black circle) and Safarov et al. ${ }^{207}$ for speed of sound (open red circle) $\left(y_{2}\right)$.

Figure 26 shows that the largest deviation is observed for speed of sound data calculated by Safarov et al., ${ }^{207}$ indicating that this procedure is subject to enormous errors, and difficulty in interpretation due to influence of numerical methods on the calculated values of speed of sound. 
The results underscore previous warnings as to the enormous errors incurred by using the Safarov’s approximation for calculation of high-pressure speed of sound data.

Table 5. Comparison of the Data Reported by Dzida et al. ${ }^{214}$ with Data Reported by Esperança et al. ${ }^{17}$, Gomes de Azevedo et al. ${ }^{14}$, Hamidova et al. ${ }^{218}$, Currás et al. ${ }^{286}$, Wojnarowska et al. ${ }^{287}$, and Safarov et al. ${ }^{207}$

\begin{tabular}{|c|c|c|c|}
\hline ionic liquid & speed of sound & density & $\begin{array}{c}\text { isentropic } \\
\text { compressibility }\end{array}$ \\
\hline \multicolumn{4}{|c|}{$A A R D \%^{a}$} \\
\hline$\left[\mathrm{C}_{3} \mathrm{C}_{1} \mathrm{im}\right]\left[\mathrm{NTf}_{2}\right]^{b}$ & 0.62 & 0.08 & 1.2 \\
\hline$\left[\mathrm{C}_{4} \mathrm{C}_{1} \mathrm{im}\right]\left[\mathrm{NTf}_{2}\right]^{c}$ & 0.08 & 0.03 & 0.2 \\
\hline$\left[\mathrm{C}_{4} \mathrm{C}_{1} \mathrm{im}\right]\left[\mathrm{NTf}_{2}\right]^{d}$ & 0.90 & 0.06 & - \\
\hline$\left[\mathrm{C}_{4} \mathrm{C}_{1} \mathrm{im}\right]\left[\mathrm{NTf}_{2}\right]^{e}$ & - & 0.05 & - \\
\hline$\left[\mathrm{C}_{4} \mathrm{C}_{1} \mathrm{im}\right]\left[\mathrm{NTf}_{2}\right]^{f}$ & - & 1.03 & - \\
\hline$\left[\mathrm{C}_{5} \mathrm{C}_{1} \mathrm{im}\right]\left[\mathrm{NTf}_{2}\right]^{b}$ & 0.61 & 0.15 & 1.1 \\
\hline$\left[\mathrm{C}_{6} \mathrm{C}_{1} \mathrm{im}\right]\left[\mathrm{NTf}_{2}\right]^{c}$ & - & 0.09 & - \\
\hline$\left[\mathrm{C}_{6} \mathrm{C}_{1} \mathrm{im}\right]\left[\mathrm{NTf}_{2}\right]^{g}$ & 1.57 & 0.05 & - \\
\hline \multicolumn{4}{|c|}{$\begin{array}{l}\text { considered. } y_{1} \text { - data reported by Dzida et al. }{ }^{214}, y_{2} \text { - data reported by }{ }^{b} \text { Esperança et al. }{ }^{17} \text {, } \\
{ }^{c} \text { Gomes de Azevedo et al. }{ }^{14},{ }^{d} \text { Hamidova et al. }{ }^{218},{ }^{e} \text { Currás et al. }{ }^{286},{ }^{f} \text { Wojnarowska et al. }{ }^{287} \\
\text { and }{ }^{g} \text { Safarov et al. }{ }^{207}\end{array}$} \\
\hline
\end{tabular}




\section{Existing correlations and evaluative methods}

Since the last two decades, ILs have received significant interest from various research groups and industry for a wide range of novel applications ${ }^{288}$ including separation, ${ }^{289}$ catalysis $^{290}$ and energy storage systems, ${ }^{291}$ for example. Many of these applications require a prior knowledge and understanding of the thermophysical properties of the pure ILs and their mixtures with other fluids. To drive a better understanding of their structure-property relationships, it is in fact necessary to collect accurate experimental data for many properties under a wide range of temperature and pressure. ${ }^{5,292}$ By looking at the NIST-ILs database available online, ${ }^{5}$ data assessed by the NIST to date are often inconsistent among the various sources of datasets. However, by using accurate data, correlative and, more importantly, predictive models can be developed which are highly valuable and some would consider crucial to further truly appreciate and recognize the full potential of ILs. The development of predictive methods is particularly important if one can use them to design new ILs with tailored properties. This section will review some of the exiting correlations and predictive methods described in the literature for the determination of the pure ILs speed of sound property.

\subsection{Empirical Models}

To date, the more frequently used relationship to calculate speed of sound data of pure ILs at $0.1 \mathrm{MPa}$ is undoubtedly the Auerbach's model, ${ }^{293}$ which relates the speed of sound (in $\left.\mathrm{m} \cdot \mathrm{s}^{-1}\right)$ to the surface tension $\gamma\left(\right.$ in $\mathrm{N} \cdot \mathrm{m}^{-1}$ ) and density (in $\mathrm{kg} \cdot \mathrm{m}^{-3}$ ) of a given fluid. In the popular form it can be expresses as follows:

$u=\left(\frac{\gamma}{6.33 \cdot 10^{-10} \cdot \rho}\right)^{a}$ 
where $a=2 / 3$ according to the original paper. ${ }^{293}$

In other words, using the original Auerbach's model (i.e., with $a=2 / 3$ ), it is $a$ priori possible to evaluate the speed of sound of an IL within the prior knowledge of its density and surface tension at a given temperature at $0.1 \mathrm{MPa}$. In fact, several authors explored this possibility especially for novel ILs, ${ }^{124,194,195,197,201-203,206,209,210}$ as in the case of the [C ${ }_{n}$-3CNpy][NTf 2 series published by Domańska et al., ${ }^{194}$ for example. Nevertheless, in this later case, authors simply calculated speed of sound data in these ILs without further experimental verification. However, according to the data analysis reported by Bandrés et al., ${ }^{124}$ it appears that an error close to $2.5 \%$ is observed between the original Auerbach's model (i.e. with $a=2 / 3$ ) and experimental data in the case of the $\left[\mathrm{C}_{4}-3-\mathrm{C}_{1} \mathrm{py}\right]\left[\mathrm{BF}_{4}\right]$ and $\left[\mathrm{C}_{4}-4-\mathrm{C}_{1} \mathrm{py}\right]\left[\mathrm{BF}_{4}\right]$ for a temperature range from $278.15 \mathrm{~K}$ to $328.15 \mathrm{~K}$ at $0.1 \mathrm{MPa}$. By using 133 data points from the literature for 14 different ILs structure, Gardas and Coutinho proved that the original form of the Auerbach's model (i.e., with $a=2 / 3$ ) could not describe accurately the selected experimental speed of sound data of ILs. ${ }^{211}$ According to these authors, using Eq. 7 as is for the dataset investigated, a coefficient of determination $R^{2}$ close to 0.9717 at $95 \%$ confidence level is observed from 278.15 $\mathrm{K}$ to $343.15 \mathrm{~K}$ and speed of sound data from 1129.0 to $1851.0 \mathrm{~m} \cdot \mathrm{s}^{-1}$ at $0.1 \mathrm{MPa}$. However, a better correlation of selected experimental data may be obtained by using the regression proposed by Gardas and Coutinho where $a=0.6714 \pm 0.0002$ in Eq. 7.211 This modified Auerbach's equation is able to improve the capability to calculate the speed of sound data within a mean percent deviation close to $1.96 \%$ with a maximum deviation inferior to $5 \% .{ }^{211}$ This was in fact claimed by others, for example by following a similar approach, Singh and Singh ${ }^{193}$ modified the Auerbach's equation ( $a=0.8511$ ) by regressing speed of sound data in the case of the $\left[\mathrm{C}_{4} \mathrm{C}_{1} \mathrm{im}\right]\left[\mathrm{PF}_{6}\right],\left[\mathrm{C}_{4} \mathrm{C}_{1} \mathrm{im}\right]\left[\mathrm{C}_{8} \mathrm{SO}_{4}\right]$ and $\left[\mathrm{C}_{2} \mathrm{C}_{1} \mathrm{im}\right]\left[\mathrm{C}_{1} \mathrm{SO}_{3}\right]$ from $303 \mathrm{~K}$ to $333 \mathrm{~K}$ at $0.1 \mathrm{MPa}$. 
More interestingly, to drive this correlation Gardas and Coutinho proposed an original approach by optimizing the Auerbach's equation a parameter using various models like the extension of the Ye and Shreeve method (Eq. 8), ${ }^{294,295}$ and the parachor equation (Eq. 9) ${ }^{296}$ to estimate the density and the surface tension, respectively;

$\rho=\frac{M}{N_{A} \cdot V \cdot(a+b \cdot T+c \cdot p)}$

where $N_{\mathrm{A}}$ is the Avogadro constant, $V$ is the molecular volume in $\AA^{3}, p$ is the pressure in MPa. $a$, $b$ and $c$ are correlative parameters described by Gardas and Coutinho. ${ }^{295}$

$\gamma=\left(\frac{P_{c h} \cdot \rho}{M}\right)^{4}$

where $P_{c h}$ is the parachor of the investigated IL. During their work, parachors of ILs were determined using the neutral parachor contribution values originally proposed by Knotts et al. ${ }^{297}$

Using this approach authors clearly develop the first Computer Aided Molecular Design $(C A M D)$ approach to describe the speed of sound in ILs. ${ }^{211}$ In other words, according to the Eq. 10, the speed of sound correlation approach developed by Gardas and Coutinho could be used to evaluate a priory the speed of sound of novel ILs in wide ranges of temperature at $0.1 \mathrm{MPa}$ $u=\left(\frac{P_{c h}{ }^{4}}{6.33 \cdot 10^{-10} \cdot M \cdot\left(N_{A} \cdot V \cdot(a+b \cdot T+c \cdot p)\right)^{3}}\right)^{a}$.

It is also very important to highlight that to date, the group of Guan developed ionic parachors (see for example ref. 298 and references therein) which may be then used to refine the approach described by Gardas and Coutinho. ${ }^{211}$ Additionally several novel models ${ }^{199,295,299-308}$ are also available in the literature to evaluate the volumetric properties of several ILs as the function of 
temperature and pressure. To sum up, using the various density models and ionic parachor available in the literature such approach may be refined to describe a better correlation of speed of sound of ILs.

More recently, the evaluation of the speed of sound in pure ILs as a function of the IL structure and temperature at $0.1 \mathrm{MPa}$ was investigated by several other authors within the development of original Group Contribution Methods (GCMs). ${ }^{4,212,213}$ Sattari et al. ${ }^{213}$ developed a GCM based on least squares support vector machine (LSSVM) algorithm to correlate and then evaluate the speed of sound of 41 ILs from $293.15 \mathrm{~K}$ to $328.15 \mathrm{~K}$ at atmospheric pressure. This GCM was created and tested using 446 data points for 41 different ILs structure based on 29 cations and 11 anions within an average absolute relative deviation close to $0.36 \%$ and a root mean square error of $8.47 \mathrm{~m} \cdot \mathrm{s}^{-1}$ for speeds of sound range from $1128 \mathrm{~m} \cdot \mathrm{s}^{-1}$ to $1851 \mathrm{~m} \cdot \mathrm{s}^{-1}$. The LSSVM algorithm was based on an 8-variable model using the temperature, as well as seven chemical structural descriptors to define selected anion and cation. Only two fitting parameters, such as the weight of the regression error $(\lambda=104.183)$ and the RBF Kernel parameter $\left(\sigma^{2}=\right.$ 14.755), must be regressed. Sattari et al. ${ }^{213}$ then proved using 446 speed of sound data from 293.15 K to 328.15 K at atmospheric pressure for 41 different ILs that their LSSVM-based GCM is more accurate $(A A R D=0.51 \%)$ than those reported by Gardas and Coutinho ${ }^{211}(26 \%)$ and by Singh and Singh (113\% - the model fails and is in practice not acceptable). ${ }^{193}$

The same group has then proposed another quantitative structure-property relationship (QSPR) model to correlate and then evaluate the speed of sound in ILs. ${ }^{212}$ In their paper, Sattari et al. ${ }^{212}$ used this time a methodology based on a nine-variable multivariate linear model using the same database as that used in their LSSVM-based GCM, ${ }^{213}$ which is based on 41 different ILs. Interestingly, authors selected and then evaluated within the genetic function approximation 
(GFA) technique different fine-tuned molecular descriptors to determine the speed of sound data of ILs. Originally, the authors preselected 15 classes of descriptors such as: "constitutional descriptors; topological indices; walk and path counts; connectivity indices; information indices; $2 D$ autocorrelations; burden Eigen values; edge-adjacency indices; functional group counts; atom-centered fragments; molecular properties; topological charge indices; Eigen value-based indices; $2 D$ binary finger print; $2 D$ frequency finger print; and $3 D$ conformational descriptors". ${ }^{212}$ More than 2000 molecular descriptors were calculated based on the SMILES (simplified molecular input line entry specification) structure of ILs. During their work, authors finally achieved the convergence of their training set, which was based on 370 speed of sound data, with an average absolute relative deviation close to $0.76 \%$ by using the following equation: 212

$u=u_{\text {cation }}+u_{\text {anion }}+$ intercept $-2.7271 \cdot T$,

where $u, \quad u_{\text {cation }}$ and $u_{\text {anion }}$ are in $\mathrm{m} \cdot \mathrm{s}^{-1}$ and intercept $=3000.68056 \mathrm{~m} \cdot \mathrm{s}^{-1}$, $u_{\text {cation }}=98.66368 \cdot M o r 03 u-88.27463 \cdot A T S 5 m-638.70715 \cdot X 2 A-49.4333 \cdot R \cdots C R \cdots R, \quad$ and $u_{\text {anion }}=-30.37573 \cdot n C-47.8716 \cdot n F-104.91867 \cdot M A T S 3 p-510.95776 \cdot J G I 2$. Variables $n C$ and $n F$ are the number of carbon and fluorine atoms in the anion structure, respectively. While the atom centered fragment descriptor $R \cdots C R \cdots R$, which is the number of carbon atoms on an aromatic ring that has three carbon neighbors on the same aromatic ring, has been described for the cation. Speeds of sound of the cations were also described using various 3D descriptors like, the 3D molecule representation of structures based on electron diffraction descriptors: Mor03u; or the average connectivity index chi-2: $X 2 A$; as well as the Broto-Moreau autocorrelation of a topological structure - lag 5 weighted by atomic masses: ATS5m. ${ }^{212}$ While other 3D descriptors 
were used to compute speeds of sound of the anions, such as the Moran autocorrelation - lag 3 weighted by atomic polarizabilities: MATS3p and the mean topological charge index of order 2 descriptor: JGI2. ${ }^{212}$ In other words, this QSPR method is based only on eight molecular descriptors, a constant (intercept) and the temperature.

More interestingly, according to Sattari et al. convergence calculations, ${ }^{212}$ it appears that the $X 2 A$ and JGI2 descriptors affect strongly and mostly the determination of the speed of sound parameters for both the cation and anion, respectively. In other words, speeds of sound in ILs seem to be mainly affected by the intramolecular bonding in the cations and by the charge transfer on the anion structure. To further validate their methodology, 76 data points were then used to test their GFA-based QSPR model. Based on this test evaluation an accuracy close to $1.66 \%$ was reported by Sattari et al. ${ }^{212}$ However, based on its definition, this QSPR approach seems to be unable to evaluate, to date, a non-linear temperature dependence on speed of sound in ILs. This later limitation may explain the large deviation observed with some datasets like in the case of the $\left[\mathrm{C}_{8} \mathrm{C}_{1} \mathrm{im}\right][\mathrm{Cl}]$, for example. ${ }^{212}$ However, the overall accuracy $(0.92 \%)$ claimed by the authors highlight that this GFA-based QSPR model is a simple and robust empirical method able to evaluate accurately the speed of sound in ILs as a function of temperature from $293.15 \mathrm{~K}$ to $328.15 \mathrm{~K}$ at $0.1 \mathrm{MPa}$.

Wu et al. ${ }^{4}$ have also proposed another GCM to determine the speed of sound in ILs as a function of temperature at 0.1 MPa. In this paper, the authors collected 4478 speed of sound data points for 96 different ILs based on 51 cations and 23 anions. Based on their database, authors then developed a second-order corresponding states group contribution (CSGC) method to determine the speed of sound in ILs. This method, which is driven by molecular structure descriptors, is based on the combination of two types of groups called the first-order and second 
order groups. The first-order groups are used to describe the basic structure of ILs which basically mimics description reported in the Joback and Reid method, ${ }^{309}$ whereas the secondorder groups fine-tunes this description especially to highlight isomers like the substituted pyridinium series. ${ }^{4}$ To describe the temperature dependence on the speed of sound in ILs a corresponding states group contribution method was then applied according to the Eq. 12.

$u=u_{0}\left(1-\frac{T}{T_{C}}\right)^{\mathrm{m}}$

where $u_{0}$ is a temperature-independent constant calculated thanks to the ILs molecular structure and $m$ is a correlated coefficient. $T_{\mathrm{C}}$ is the critical temperature of a given IL directly calculated using the Valderrama group contribution method. ${ }^{310}$ By rearranging the Eq.12 using molecular descriptors, authors defined an equation (Eq.13) which reflects the second-order CSGC method used.

$u=\sum_{i=0}^{3} a_{i}\left(\sum_{j=1}^{k} n_{j} \Delta u_{0, j}\right)^{i}\left(1-\frac{T}{T_{C}}\right)^{m}$

where $n_{j}$ is the number of groups of type $j, k$ is the total number of different groups defining the $\mathrm{IL}, a_{i}$ and $\Delta u_{0, j}$ are two set of fitting parameters determined by Wu et al. ${ }^{4}$ by minimizing the average square deviations between experimental and calculated speed of sound trial sets based on 86 different ILs, e.g. 3875 data points. Based on their minimization, fitting parameters were then determined as follows: $m=0.653586 ; a_{0}=4462.199 ; a_{1}=1009.572808 ; a_{2}=114.8067 ; a_{3}=$ 4.283299; furthermore 30 values of $\Delta u_{0, j}$ were also calculated accordingly to first-order and second order groups defined by the authors. Then, by using these parameters an average absolute relative deviation close to $2.34 \%$ was then determined for the 4478 speed of sound data points 
collected for 96 different ILs from $278.14 \mathrm{~K}$ to $343.15 \mathrm{~K}$ at $0.1 \mathrm{MPa}$. This deviation may be regarded as the accuracy of the proposed model, which is not based only on the current accuracy of experimental data available in the literature but also on the accuracy of the critical temperature determined by the Valderrama group contribution method. ${ }^{310}$ The main advantage of this model is based on the simplicity and the diversity of molecular groups described by the authors $a$ contrario of the LSSVM-based GCM described by Sattari et al. ${ }^{213}$ However, the main disadvantage of this model is the poor description of the speed of sound in protic ILs, which are mainly driven by proton-donor and proton-acceptor sites, in contrast to the QSPR method proposed by Sattari et al. ${ }^{212}$, for example. Even if these GCMs ${ }^{4,211-213}$ seem to be able to determine accurately the speed of sound in different ILs as the function of temperature, each model is not, yet, able to evaluate this property as the function of pressure. Classically, the first datasets of speeds of sound in ILs as the function of temperature and pressure published in the literature, ${ }^{14,15,17,311}$ were described using classical thermodynamic formalism only, even if relaxation properties of selected ILs were neither investigated nor commented (see paragraph $2.2 .2)$

\subsection{Theoretical Models}

To solve this lack of correlation/prediction tools for the speed of sound in ILs as the function of the pressure, several groups then used/developed various Equations of State (EoS) based on the thermodynamic formalism, which relate $p \rho T$ data to speeds of sound. $196,198,200,204,207,312$ The first example of EoS used to determine the speed of sound data for ILs was reported by the group of Safarov et al. ${ }^{204}$ During their work, authors proposed the following empirical EoS (Eq. 14): 
$p(\rho, T)=\sum_{i=1}^{4} a_{i} T^{i}(\rho)^{2}+\sum_{i=0}^{3} b_{i} T^{i}(\rho)^{8}+\sum_{i=0}^{3} c_{i} T^{i}(\rho)^{12}$,

where $p$ and $\rho$ are the pressure in MPa and the density in $\mathrm{g} \cdot \mathrm{cm}^{-3} \cdot a_{i}, b_{i}$ and $c_{i}$ are temperature Commented [J 1]: Units here could be deleted as dependent fitting parameters determined by last-square method.

In their paper, authors used the Eq. 14, along with experimental data of isobaric heat capacity at atmospheric pressure to determine then the speed of sound of the $\left[\mathrm{C}_{2} \mathrm{C}_{1} \mathrm{im}\right]\left[\mathrm{C}_{2} \mathrm{SO}_{4}\right]$ from 283.15 $\mathrm{K}$ to $373.15 \mathrm{~K}$ at $0.1 \mathrm{MPa}$ within an accuracy close to $1.2 \%$. More interestingly, by following the methodology, Safarov et al. ${ }^{196,207}$ then calculated various properties including the speed of sounds in ILs as a function of temperature and pressure. In their papers, these authors defined EoS parameters of Eq. 14 in the case of the $\left[\mathrm{C}_{6} \mathrm{C}_{1} \mathrm{im}\right]\left[\mathrm{NTf}_{2}\right]^{196}$ and $\left[\mathrm{C}_{4} \mathrm{C}_{1} \mathrm{im}\right][\mathrm{Ac}]^{207}$ from $273.15 \mathrm{~K}$ to 413.15 K for pressure up to $140 \mathrm{MPa}$. Accuracy of calculated speed of sound data was then estimated using available data in the literature as close as $2.4 \% .{ }^{196}$ Even if the group of Safarov was the first to use an EoS to calculate the speed of sound in ILs, the first example of highpressure prediction of the speeds of sound in ILs was described by Polishuk. ${ }^{198}$ In this paper, the author used three EoS: i.e., the perturbed-chain statistical association fluid theory (PC-SAFT), the generalized for heavy compounds version of SAFT+Cubic (GSAFT+Cubic), and the cubic-plusassociation EoS (CPA) to predict various properties of ILs and particularly the speed of sound in $\left[\mathrm{C}_{n} \mathrm{C}_{1} \mathrm{im}\right]\left[\mathrm{NTf}_{2}\right]$ (with $n=3$, 4, or 5) as a function of temperature from $288.15 \mathrm{~K}$ to $338.15 \mathrm{~K}$ and pressure up to $200 \mathrm{MPa}$. During this work, Polishuk clearly showed that speeds of sound in selected ILs are accurately determined by using the GSAFT+Cubic with a maximum deviation with literature data close to $2 \%$, while deviations up to $4.4 \%$ and to $21 \%$ were observed using the PC-SAFT and the CPA EoS, respectively. ${ }^{198}$ Similarly, Maghari et al. ${ }^{199,200}$ proposed the utilization of the extended SAFT-BACK equation of state to predict the $p \rho T$ data and related 
thermodynamic properties of various pure ILs. To test the validity of their approach, authors investigated several ILs for which density data as the function of temperature and pressure were reported in the literature. The data set included $\left[\mathrm{C}_{n} \mathrm{C}_{1} \mathrm{im}\right]\left[\mathrm{PF}_{6}\right]$ with $n=2,4,6$ or $8 ;{ }^{199,200}$ $\left[\mathrm{C}_{n} \mathrm{C}_{1} \mathrm{im}\right]\left[\mathrm{BF}_{4}\right]$ with $n=2,4,6$ or $8 ;{ }^{199,200}\left[\mathrm{C}_{n} \mathrm{C}_{1} \mathrm{im}\right]\left[\mathrm{NTf}_{2}\right]$ with $n=3,4,5$ or $6 .{ }^{199}$ Good agreement between experimental and predicted values of speed of sound was then reported including highpressure data up to $100 \mathrm{MPa}$ in the case of the $\left[\mathrm{C}_{4} \mathrm{C}_{1} \mathrm{im}\right]\left[\mathrm{PF}_{6}\right]$ and $\left[\mathrm{C}_{4} \mathrm{C}_{1} \mathrm{im}\right]\left[\mathrm{BF}_{4}\right] .{ }^{199,200}$ For example a deviation up to $2.2 \%$ between literature and calculated speed of sound of the $\left[\mathrm{C}_{4} \mathrm{C}_{1} \mathrm{im}\right]\left[\mathrm{BF}_{4}\right]$ at $323.15 \mathrm{~K}$ and $150 \mathrm{MPa}$ is reported. ${ }^{199}$ Furthermore, it appears that this model is also able to predict very well the temperature dependence on the speed of sound in ILs as an average deviation close to $1.8 \%$ was reported between predicted and experimental data in the case of the $\left[\mathrm{C}_{6} \mathrm{C}_{1} \mathrm{im}\right]\left[\mathrm{BF}_{4}\right]$ from $293.15 \mathrm{~K}$ to $318.15 \mathrm{~K}$ at $0.1 \mathrm{MPa}$, for example. ${ }^{200}$ More interestingly, it appears that this EoS is able to predict correctly the trend of the speed of sound as the function of the ILs structure. ${ }^{199}$ This is in fact related to the good accuracy of the SAFTBACK EoS for the determination of the speed of sound in ILs as a function of temperature from $283 \mathrm{~K}$ to $338 \mathrm{~K}$ for pressures up to $200 \mathrm{MPa}$, which is better than $2.2 \%, 1.5 \%, 1.8 \%, 2.0 \%$ or $2.1 \%$ in the case of $\left[\mathrm{C}_{4} \mathrm{C}_{1} \mathrm{im}\right]\left[\mathrm{BF}_{4}\right],\left[\mathrm{C}_{4} \mathrm{C}_{1} \mathrm{im}\right]\left[\mathrm{PF}_{6}\right], \quad\left[\mathrm{C}_{3} \mathrm{C}_{1} \mathrm{im}\right]\left[\mathrm{NTf}_{2}\right],\left[\mathrm{C}_{4} \mathrm{C}_{1} \mathrm{im}\right]\left[\mathrm{NTf}_{2}\right]$, or $\left[\mathrm{C}_{5} \mathrm{C}_{1} \mathrm{im}\right]\left[\mathrm{NTf}_{2}\right]$, respectively. ${ }^{199}$

More recently, by following the same methodology Shen et al. ${ }^{312}$ used the ePC-SAFT to predict the speed of sound data of $\left[\mathrm{C}_{4} \mathrm{C}_{1} \mathrm{im}\right]\left[\mathrm{PF}_{6}\right]$ (accuracy $\left.=3.6 \%\right),\left[\mathrm{C}_{3} \mathrm{C}_{1} \mathrm{im}\right]\left[\mathrm{NTf}_{2}\right](7.8 \%)$, $\left[\mathrm{C}_{4} \mathrm{C}_{1} \mathrm{im}\right]\left[\mathrm{NTf}_{2}\right](7.4 \%),\left[\mathrm{C}_{5} \mathrm{C}_{1} \mathrm{im}\right]\left[\mathrm{NTf}_{2}\right](7.1 \%)$ and $\left[\mathrm{C}_{6} \mathrm{C}_{1} \mathrm{im}\right]\left[\mathrm{NTf}_{2}\right](7.6 \%)$ from $273.15 \mathrm{~K}$ to 413.15 K for pressure up to $150 \mathrm{MPa}$.

Even if several EoS have been defined and then used to determine quite accurately, based on the thermodynamic relationships, the speed of sound in ILs as the function of temperature and 
pressure, the relaxation properties of selected ILs were not investigated nor commented into their modeling approach. This is, in fact, not the case of the model based on MD-simulation published by Ribiero in the case of the $\left[\mathrm{C}_{6} \mathrm{C}_{1} \mathrm{im}\right][\mathrm{Br}]{ }^{208}$ During this work, Ribiero investigated the highfrequency acoustic modes in the $\left[\mathrm{C}_{6} \mathrm{C}_{1} \mathrm{im}\right][\mathrm{Br}]$ by determining, using in silico MD calculations, the time correlation functions of mass current fluctuations for several wavevectors and the dispersion curves of excitations for longitudinal and transverse acoustic sound modes at different temperatures and pressures. From these calculations, high-frequency sound velocity data has been determined (e.g. $2460 \mathrm{~m} \cdot \mathrm{s}^{-1}$ at $400 \mathrm{~K}$ and $0.1 \mathrm{MPa}$ ) but more importantly structural information like the impact of the heterogeneous structure of the $\left[\mathrm{C}_{6} \mathrm{C}_{1} \mathrm{im}\right][\mathrm{Br}]$, driven by the presence of polar and non-polar domains, on the high-frequency acoustic modes are depicted. ${ }^{208}$

\section{Importance of speed of sound knowledge for the chemical engineering design of industrial applications based on ionic liquids}

ILs are the most promising class of compounds that has ever been synthesized in the laboratory. A perception remains that ILs may revolutionize the chemical industry and engineering applications in the years to come. However, we require basic knowledge of their thermodynamic, fluid mechanic and heat transfer properties to assess their suitability in countless engineering applications. In 2010, this problem was aptly defined by Aparicio et al. ${ }^{313}$ : (...) one of the main barriers for the development of ionic liquids for industrial applications is the scarce knowledge of their thermo-physical properties, both for pure and mixed fluids, in the wide

pressure and temperature ranges (...). The authors of this paper ${ }^{313}$ provided some examples: "PVT data can be considered as fundamental data for developing equations of state, which are the main tool used for thermo-physical properties prediction for process design purposes, and solution theories for ionic liquids. It is also required for many relevant industrial problems such 
as liquid metering applications or for the design of different types of equipment such as condensers, reboilers, separation trains, or even storage vessels.” The $p \rho T$ data of ILs usually came from vibrating tube densimeters, and the authors indicated that the density results strongly depended on the viscosity correction factor. ${ }^{313}$ An excellent alternative to the densimeter technique is speed of sound measurements under elevated pressures followed by acoustic method, which is a commonly accepted computational procedure to quantitatively determine relevant thermodynamic quantities such as the heat capacity, expansibility and compressibility of compressed liquids. ${ }^{4,14,15,314,315} \mathrm{Wu}$ et al. ${ }^{4}$ noted the usefulness of acoustic method to estimate the thermodynamic properties of ILs. An additional valuable aspect of their work is a mathematical relationship among the thermal conductivity, speed of sound and density, and the authors established a generalized model for the thermal conductivity of ILs. Knowledge of these thermophysical properties over a sufficiently wide range of temperatures and pressures for a maximum group of ILs will undoubtedly facilitate the extraction of the properties that have the greatest potential and are best suited for industrial and large-scale engineering applications.

A number of excellent reviews, although recently published, ${ }^{4,316-324}$ describe some engineering and industrial applications of ILs; unfortunately, practical applications for knowledge regarding when the above high-pressure properties could be used during design are still lacking. So far, the only exceptions are high-pressure hydraulic fluids and heat transfer fluids.

Because fluids are compressible, the appropriate thermodynamic properties should be considered when designing pumps and compressors. The bulk modulus is a measure of a fluid's resistance to compression that describes the power level, response time, and stability of the high pressure system and can be experimentally obtained from the speed of sound measurements. ${ }^{325}$ Predel et al. ${ }^{326}$ showed that ILs should have a low compressibility, an adjustable gas solubility 
and superior lubricating abilities for high pressure applications. Hydraulic ILs with low compressibility permit higher frequencies because of the shorter piston strokes that are required and increase the efficiency factor of pumps and compressors. Previous research compared six ILs (authors did not provide the chemical names of ILs and their abbreviated/commercial names) with standard hydraulic oil and concluded that measurements in a high-pressure pulser (up to 400 MPa) showed an efficiency improvement of up to $30 \%$. $^{326}$

Schlücker et al. ${ }^{327}$ observed an increase in the volumetric efficiency from approximately $10 \%$ to $30 \%$ in hydraulically driven diaphragm commercial pumps by using the low compressibility of $\left[\mathrm{C}_{2} \mathrm{C}_{1} \mathrm{im}\right]\left[\mathrm{C}_{2} \mathrm{SO}_{4}\right]$ instead of standard mineral oils. An IL piston compressor has already been used for pure hydrogen; an initial technical application was reported by Linde AG in 2006. ${ }^{328}$ Because the number of moving internal parts in the compressor decreased dramatically, the system is much more efficient than standard compressors. The compressibility of ILs plays a crucial role in the design and selection of the operating conditions of oxygen screw compressors. ${ }^{329}$ The same $\left[\mathrm{C}_{2} \mathrm{C}_{1} \mathrm{im}\right]\left[\mathrm{C}_{2} \mathrm{SO}_{4}\right]$ has recently been investigated ${ }^{325}$ as a potential hydraulic fluid that could replace the classical hydraulic mineral oil ISO VG 46 and the HFDtype hydraulic fluid Quintolubric 888-68. Kambic et al. ${ }^{325}$ described three types of experimental methods (based on measuring of the speed of sound) in compression and decompression modes (up to $40 \mathrm{MPa}$ ) to determine the bulk modulus of ILs. In the authors ${ }^{325}$ opinion, the lower compressibility (high bulk modulus) of $\left[\mathrm{C}_{2} \mathrm{C}_{1} \mathrm{im}\right]\left[\mathrm{C}_{2} \mathrm{SO}_{4}\right]$ compared to both hydraulic fluids and water opens up new possibilities regarding its usage within hydraulic systems with increased dynamics. Other ILs were investigated with acoustic techniques by Dzida et al. ${ }^{330}$ as potential replacements for mineral oils in hydraulic systems. The isothermal compressibilities and isobaric thermal expansibilities of $\left[\mathrm{C}_{2} \mathrm{C}_{1} \mathrm{im}\right]\left[\mathrm{NTf}_{2}\right]$ and $\left[\mathrm{C}_{4} \mathrm{C}_{1} \mathrm{pyr}\right]\left[\mathrm{NTf}_{2}\right]$ were studied under high- 
pressure, whereas of $\left[\mathrm{C}_{2} \mathrm{C}_{1} \mathrm{im}\right]_{2}\left[\mathrm{Co}(\mathrm{NCS})_{4}\right]$ and $\left[\mathrm{C}_{4} \mathrm{C}_{1} \mathrm{im}\right]_{2}\left[\mathrm{Co}(\mathrm{NCS})_{4}\right]$ only at atmospheric pressure. The results were compared to reference mineral oil and biodegradable oil. The lowest compressibilities were exhibited by $\left[\mathrm{C}_{2} \mathrm{C}_{1} \mathrm{im}\right]_{2}\left[\mathrm{Co}(\mathrm{NCS})_{4}\right]$ and $\left[\mathrm{C}_{4} \mathrm{C}_{1} \mathrm{im}\right]_{2}\left[\mathrm{Co}(\mathrm{NCS})_{4}\right]$, thereby confirming their usefulness as potential working hydraulic fluids. Regueira et al. ${ }^{331}$ compared the

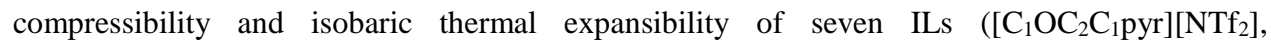
$\left[\mathrm{C}_{4} \mathrm{C}_{1} \mathrm{pyr}\right]\left[\mathrm{NTf}_{2}\right], \quad\left[\mathrm{C}_{1} \mathrm{OC}_{2} \mathrm{C}_{1} \mathrm{pyr}\right][\mathrm{FAP}], \quad\left[\mathrm{C}_{2} \mathrm{C}_{1} \mathrm{im}\right]\left[\mathrm{C}_{2} \mathrm{SO}_{4}\right], \quad\left[\mathrm{C}_{4} \mathrm{C}_{1} \mathrm{pyr}\right][\mathrm{FAP}], \quad\left[\mathrm{C}_{2} \mathrm{C}_{1} \mathrm{im}\right]\left[\mathrm{C}_{6} \mathrm{SO}_{4}\right]$, $\left.\left[\mathrm{P}_{66614}\right][\mathrm{FAP}]\right)$ to synthetic, mineral and vegetable oils and water and discovered that the lowest compressibility was exhibited by alkylimidazolium alkylsulfates. The authors confirmed that compressibility is a key parameter in the use of new ILs as hydraulic fluids. ${ }^{331}$ Thus, all these works demonstrate that high-pressure thermodynamic properties play an important role in assessing the suitability of ILs as hydraulic fluids.

The most important thermophysical properties for the design of heat exchange thermal equipment are the viscosity, thermal conductivity, density, and heat capacity. ${ }^{320}$ As demonstrated by $\mathrm{Wu}$ et al., ${ }^{4}$ the last three directly correlate to the propagation of the speed of sound in ILs. Wu et al. ${ }^{4}$ also noted that the thermal conductivity and thermal diffusivity are essential, particularly in designing and optimizing any process or device that involves heat transfer. Knowledge of these parameters can facilitate the search for answers to whether classes of ILs can be used as practical heat transfer fluids. ${ }^{323}$ Additional research ${ }^{320}$ analyzed how the sensitivity of the design parameters in heat exchange processes are affected by the uncertainty of the thermodynamic properties, which are used as input values for simulation. Precisely determined thermodynamic properties translate into the final economic costs of heat transfer equipment. The significance of this problem has also been noted by França et al. ${ }^{333}$ 
The unique characteristics of ILs makes these materials promising candidates for use as industrial lubricants, especially under hydrodynamic and elastohydrodynamic regimes. ${ }^{320,334,335}$ Kumar et al. ${ }^{335}$ observed that not enough attention is paid to the importance of high-pressure lubricant properties, such as the density and thermal expansibility. Pensado et al. ${ }^{336}$ also proved that the pressure profile of viscosity should consider the pressure-temperature path of thermal expansibilities and the isothermal compressibilities of IL lubricants to model ILs.

ILs have shown excellent performance in many industrial areas, including organic synthesis, catalysis, separations, biomass conversion and so on. ${ }^{337}$ However, many chemical processes and separation operations are performed under elevated pressures. The influence of elevated pressures on chemical processes and on the design of engineering devices and machine processes, for which ILs could be used for handling on a commercial scale, is still a central issue. Providing the basic high-pressure thermodynamic properties of ILs to support the industrial design of high-pressure technology. In this respect, measurements of the speed of sound under wide temperature and pressure intervals followed by an acoustic method may play a huge role in determining the number of relevant thermophysical properties.

\section{Conclusions}

According to Nieto de Castro 215 "Do we know enough about the molecular constitution and properties of these fluids, to measure correctly their properties? And if we think we know, which types of care have we take a priori?”, two aspects regarding speed of sound measurements should be consided before performing any acoustic studies of ILs. The first aspect, knowledge of

the purity (water. metal and halide contents) and hygroscopy of the sample and properties such as the viscosity and absorption, bridges towards the second aspect, namely, the careful choice of experimental methods and conditions. Accordingly, an analysis of available literature data did not 
provide sufficient information regarding the influence of halide content on the speed of sound in ILs. Skowronek et al. ${ }^{225}$ showed that, an amount of water up to a mass fraction of $2.0 \cdot 10^{-3}$ affected change of speed of sound for selected ILs lower than declared $u$ uncertainty of $\pm 0.5 \mathrm{~m} \cdot \mathrm{s}^{-}$ ${ }^{1}$. Widegren and Magee $^{31}$ claimed that a change of the amount of water at the level of mass fraction of $8.6 \cdot 10^{-4}$ gives much more significant change on the speed of sound, namely $\pm 0.7 \mathrm{~m} \cdot \mathrm{s}^{-}$ ${ }^{1}$. However, properties of a liquid such as the viscosity and absorption are especially important for acoustic investigations because these factors can affect the proper choice of the measuring method and temperature-pressure conditions. ILs are generally much more viscous than conventional molecular organic liquids, i.e., the viscosity values of most ILs at room temperatures are from 2 to 3 orders of magnitude larger than almost all molecular organic liquids. Thus, the propagation terms in most ILs are rather similar to those in highly associated viscous polyhydroxyl liquids compared to those in low-viscous conventional molecular organic liquids. Under such conditions, ultrasound wave propagation is not purely compressional, and a shear component also appears. Thus, the ultrasound propagation conditions in viscoelastic materials, such as many ILs, cannot be ignored. Knowledge of the viscosity-temperature dependence allows one to estimate a classical absorption coefficient and roughly estimation of presumable absorption in the low frequency range to properly interpretation or planning of the experiment and choose a measuring method based on the group or phase velocity. Analyses of the experimental speeds of sound from the literature revealed that till $81.5 \%$ of data sets have been obtained from device measured group velocity based on the time of flight and sing-around methods. The time of flight and sing-around speed of sound measurement methods are only appropriate when the distinction between the group and phase velocity is not significant. Because all currently measured ILs can be classified as intermediately and highly ultrasound absorbing 
media with negative temperature absorption coefficients, care must be taken when speed of sound measurements are recorded by these methods at temperatures below $298.15 \mathrm{~K}$ and/or at high pressure. As long as no high pressure absorption data exist for ILs, quantitatively defining the pressure value above which relaxation phenomena are observed is impossible. In addition to viscosity temperature characteristics, the second criterion that indicates whether the obtained speed of sound values are thermodynamically correct is a rate of $(\partial u / \partial T)_{p}$. Taking into consideration these conditions allows to obtain the speed of sound which is thermodynamic speed, and can be subsequently used to determine relevant quantities and to study the relation to IL structures. The structure of the anion seems to have more significant impact on the value of $u$ than that of the cations. Generally, elongated alkyl chains in $\left[\mathrm{C}_{n} \mathrm{C}_{1} \text { im }\right]^{+}$cations decrease the speed of sound for many ILs. One of the most striking exceptions is the non-monotonic behavior of the speed of sound with elongated alkyl chains in imidazolium cations in the $\left[\mathrm{C}_{n} \mathrm{C}_{1} \mathrm{im}^{\mathrm{m}}\right]\left[\mathrm{NTf}_{2}\right]$ ILs. Because of their molecular and ionic structures, ILs do not resemble conventional molecular solvents; thus, the influence of constitution of the ILs on the speed of sound is also different. This observation reflects how the upper limit for the speed of sound in ILs is slightly higher than that observed for molecular liquids, while the lower limit is considerably different (about $700 \mathrm{~m} \cdot \mathrm{s}^{-1}$ ). Concluding still is actual observations made by França et al. ${ }^{333}$ “....ionic liquids are innovative fluids for chemical and materials processing, and the recent explosion on their measurement, molecular interpretation, and property prediction, allied to the first industrial processes that started to use them as environmentally friendly solvents and reaction fluids, raises very important points to the scientific and industrial community. These points are related with all the available knowledge on the properties of these fluids and its relation with the chemical structure, its quality, and our capacity of using this knowledge for the benefit of society. These liquids possess 
a unique array of physicochemical properties that make them suitable in numerous task-specific applications in which conventional solvents are nonapplicable or insufficiently effective." As long as we cannot properly determine the speed of sound, related thermophysical quantities and another physicochemical properties, and establish their relationships to the ILs' structures, we cannot implement these data into the design proceses or any industrial applications.

At the same time, although the ultrasound absorption spectroscopy of ILs may look like the Cinderella in comparison to other spectroscopic techniques (e.g., dielectric, viscoelastic, neutron spin echo, and NMR) used in the investigations of ILs, the ultrasound absorption spectroscopy seems indispensable for the better understanding of structure, dynamics and possible correlations between various properties (e.g., mechanical and dielectric one) of ILs. Without doubt, however, an extending the number of absorption measurements for ILs by simultaneous broadening of the frequency range is necessary.

\section{Outlook}

The number of speed of sound investigations will be growing. In addition to the broadening of the available database, which is important for chemical engineering, a fundamental understanding of the relationship between the speed of sound and ionic structure is necessary, among others to more rationally design and synthesize an IL with a desired speed of sound. However, measurements of the phase speed of sound should be recorded for highly viscous IL samples to obtain more consistent and reliable data in the future. In other words, measurements in such samples by commercial apparatuses that are designed and appropriated for non-dispersive materials (i.e. which measure the group velocity) should be avoided or the existence of dispersion phenomena should be excluded. 


\section{ABBREVIATIONS}

\section{List of ionic liquids regarded in this work}

\begin{tabular}{|c|c|c|c|c|c|c|c|}
\hline No. & ionic liquid & cation & c-acronym & anion & a-acronym & CASRN & molecular formula \\
\hline 1. & 1,2-diethylpyridinium ethyl sulfate & 1,2-diethylpyridinium & $\mathrm{C}_{2}-2-\mathrm{C}_{2} \mathrm{py} / 1,2-\mathrm{dC}_{2} \mathrm{py}$ & ethyl sulfate & $\mathrm{C}_{2} \mathrm{SO}_{4}$ & - & C11H19NO4S \\
\hline 2. & $\begin{array}{l}\text { 1,3-dimethylimidazolium methyl } \\
\text { sulfate }\end{array}$ & 1,3-dimethylimidazolium & $\mathrm{C}_{1} \mathrm{C}_{1} \mathrm{im}$ & methyl sulfate & $\mathrm{C}_{1} \mathrm{SO}_{4}$ & 97345-90-9 & $\mathrm{C} 6 \mathrm{H} 12 \mathrm{~N} 2 \mathrm{O} 4 \mathrm{~S}$ \\
\hline 3. & $\begin{array}{l}\text { 1,3-dimethylpyridinium methyl } \\
\text { sulfate }\end{array}$ & 1,3-dimethylpyridinium & $\mathrm{C}_{1}-3-\mathrm{C}_{1} \mathrm{py} / 1,3-\mathrm{dC}_{1} \mathrm{py}$ & methyl sulfate & $\mathrm{C}_{1} \mathrm{SO}_{4}$ & $929518-07-0$ & C8H13NO3S \\
\hline 4. & $\begin{array}{l}\text { bis(1-butyl-3-methylimidazolium) } \\
\text { tetraisocyanatocobaltate(II) }\end{array}$ & $\begin{array}{l}\text { bis(1-butyl-3- } \\
\text { methylimidazolium) }\end{array}$ & $\left(\mathrm{C}_{4} \mathrm{C}_{1} \mathrm{im}\right)_{2}$ & tetraisocyanatocobaltate(II) & $\mathrm{Co}(\mathrm{NCS})_{4}$ & $1245942-47-5$ & C20H30CoN8S4 \\
\hline 5. & $\begin{array}{l}\text { bis(1-ethyl-3-methylimidazolium) } \\
\text { tetraisocyanatocobaltate(II) }\end{array}$ & $\begin{array}{l}\text { bis(1-ethyl-3- } \\
\text { methylimidazolium) }\end{array}$ & $\left(\mathrm{C}_{2} \mathrm{C}_{1} \mathrm{im}\right)_{2}$ & tetraisocyanatocobaltate(II) & $\mathrm{Co}(\mathrm{NCS})_{4}$ & $1255925-80-4$ & C16H22CoN8S4 \\
\hline 6. & $\begin{array}{l}\text { 1-benzyl-3-methylimidazolium } \\
\text { chloride }\end{array}$ & $\begin{array}{l}\text { 1-benzyl-3- } \\
\text { methylimidazolium }\end{array}$ & $\mathrm{Benz}_{1} \mathrm{im}$ & chloride & $\mathrm{Cl}$ & $36443-80-8$ & C11H13CIN2 \\
\hline 7. & $\begin{array}{l}\text { 1-butyl-1-ethylpyrrolidinium ethyl } \\
\text { sulfate }\end{array}$ & $\begin{array}{l}\text { 1-butyl-1- } \\
\text { ethylpyrrolidinium }\end{array}$ & $\mathrm{C}_{4} \mathrm{C}_{1} \mathrm{pyr}$ & ethyl sulfate & $\mathrm{C}_{2} \mathrm{SO}_{4}$ & - & $\mathrm{C} 12 \mathrm{H} 27 \mathrm{NO} 4 \mathrm{~S}$ \\
\hline 8. & $\begin{array}{l}\text { 1-butyl-1-methylpyrrolidinium } \\
\text { bis(trifluoromethylsulfonyl)imide }\end{array}$ & $\begin{array}{l}\text { 1-butyl-1- } \\
\text { methylpyrrolidinium }\end{array}$ & $\mathrm{C}_{4} \mathrm{C}_{1} \mathrm{pyr}$ & $\begin{array}{l}\text { bis(trifluoromethylsulfonyl)i } \\
\text { mide }\end{array}$ & $\mathrm{NTf}_{2}$ & 223437-11-4 & $\mathrm{C} 11 \mathrm{H} 20 \mathrm{~F} 6 \mathrm{~N} 2 \mathrm{O} 4 \mathrm{~S} 2$ \\
\hline 9. & $\begin{array}{l}\text { 1-butyl-1-methylpyrrolidinium } \\
\text { dicyanamide }\end{array}$ & $\begin{array}{l}\text { 1-butyl-1- } \\
\text { methylpyrrolidinium }\end{array}$ & $\mathrm{C}_{4} \mathrm{C}_{1} \mathrm{pyr}$ & dicyanamide & $\mathrm{N}(\mathrm{CN})_{2}$ & $370865-80-8$ & $\mathrm{C} 11 \mathrm{H} 20 \mathrm{~N} 4$ \\
\hline 10. & $\begin{array}{l}\text { 1-butyl-1-methylpyrrolidinium } \\
\text { methyl sulfate }\end{array}$ & $\begin{array}{l}\text { 1-butyl-1- } \\
\text { methylpyrrolidinium }\end{array}$ & $\mathrm{C}_{4} \mathrm{C}_{1} \mathrm{pyr}$ & methyl sulfate & $\mathrm{C}_{1} \mathrm{SO}_{4}$ & - & $\mathrm{C} 10 \mathrm{H} 23 \mathrm{NO} 4 \mathrm{~S}$ \\
\hline 11. & 1-butyl-1-methylpyrrolidinium & 1-butyl-1- & $\mathrm{C}_{4} \mathrm{C}_{1} \mathrm{pyr}$ & trifluoromethanesulfonate & TFO & 367522-96-1 & C10H20F3NO3S \\
\hline
\end{tabular}


12. 1-butyl-1-methylpyrrolidinium

tris(pentafluoroethyl)trifluorophosp

1-butyl-1-

methylpyrrolidinium

$\mathrm{C}_{4} \mathrm{C}_{1} \mathrm{pyr}$

13. 1-butyl-2,3-dimethylimidazolium tetrafluoroborate

1-butyl-2,3-

dimethylimidazolium

$\mathrm{C}_{4}-2,3-\mathrm{dC}_{1} \mathrm{im}$

1-butyl-2-

methylpyridinium

$\mathrm{C}_{4}-2-\mathrm{C}_{1} \mathrm{py}$

tetrafluoroborate

15. 1-butyl-3,5-dimethyl-2-

pentylpyridinium

bis(trifluoromethylsulfonyl)imide

16. 1-butyl-3-cyanopyridinium bis(trifluoromethylsulfonyl)imide

17. 1-butyl-3-methylimidazolium 4,5

dicyano-2-

(trifluoromethyl)imidazolide

18. 1-butyl-3-methylimidazolium

acetate

1-butyl-3,5-dimethyl-2-

pentylpyridinium

$\mathrm{C}_{4}-3,5-\mathrm{dC}_{1}-2-\mathrm{C}_{5} \mathrm{py}$

1-butyl-3-cyanopyridinium $\quad \mathrm{C}_{4}-3-\mathrm{CNpy}$

1-butyl-3-

methylimidazolium

$\mathrm{C}_{4} \mathrm{C}_{1} \mathrm{im}$

1-butyl-3-

methylimidazolium

$\mathrm{C}_{4} \mathrm{C}_{1} \mathrm{im}$

1-butyl-3-

methylimidazolium

$\mathrm{C}_{4} \mathrm{C}_{1} \mathrm{im}$ aspartate

1-butyl-3-

methylimidazolium

$\mathrm{C}_{4} \mathrm{C}_{1} \mathrm{im}$

bis(trifluoromethylsulfonyl)imide

1-butyl-3-

methylimidazolium

1-butyl-3-

$\mathrm{C}_{4} \mathrm{C}_{1} \mathrm{im}$

$\mathrm{C}_{4} \mathrm{C}_{1} \mathrm{im}$ tris(pentafluoroethyl)trifluoro

phosphate

tetrafluoroborate

$\mathrm{BF}_{4}$

tetrafluoroborate

bis(trifluoromethylsulfonyl)

mide

bis(trifluoromethylsulfonyl)i

mide

4,5-dicyano-2-

(trifluoromethyl)imidazolide

acetate

Ac

aspartate

As

bis(trifluoromethylsulfonyl)i

mide

$\mathrm{NTf}_{2}$

bromide

chloride
402846-78-0

286453-46-1

851856-47-8

C15H20F18NP

C9H17BF4N2

C10H16BF4N

C18H28F6N2O4S2

C12H21F6N3O4S2

C14H15F3N6

284049-75-8 C10H18N2O2

C12H21N3O4

C10H15F6N3O4S2

C8H15BrN2

79917-90-1 C8H15ClN2 
chloride

23. 1-butyl-3-methylimidazolium

dicyanamide

24. 1-butyl-3-methylimidazolium hexafluorophosphate

25. 1-butyl-3-methylimidazoliun hydrogen sulfate

26. 1-butyl-3-methylimidazolium methyl sulfate

methylimidazolium

methylimidazolium

1-butyl-3-

methylimidazolium

1-butyl-3-

methylimidazolium

1-butyl-3-

methylimidazolium

1-butyl-3-methylimidazolium octyl

sulfate

1-butyl-3-

methylimidazolium

1-butyl-3-

methylimidazolium

1-butyl-3-

methylimidazolium

1-butyl-3-

methylimidazolium

1-butyl-3-

methylpyridinium

1-butyl-3-

methylpyridinium

1-butyl-3-

methylpyridinium

1-butyl-3-

(trifluoromethyl)imidazolide

bis(trifluoromethylsulfonyl)imide

chloride

34. 1-butyl-3-methylpyridinium

C $4-3-\mathrm{C}_{1}$ py

$\mathrm{C}_{4} \mathrm{C}_{1} \mathrm{im}$

$\mathrm{C}_{4} \mathrm{C}_{1} \mathrm{im}$

$\mathrm{C}_{4} \mathrm{C}_{1} \mathrm{im}$

$\mathrm{C}_{4} \mathrm{C}_{1} \mathrm{im}$

$\mathrm{C}_{4} \mathrm{C}_{1} \mathrm{im}$

$\mathrm{C}_{4} \mathrm{C}_{1} \mathrm{im}$

$\mathrm{C}_{4} \mathrm{C}_{1} \mathrm{im}$

$\mathrm{C}_{4} \mathrm{C}_{1} \mathrm{im}$

$\mathrm{C}_{4}-3-\mathrm{C}_{1} \mathrm{py}$

\section{dicyanamide}

hexafluorophosphate

hydrogen sulfate

methyl sulfate

octyl sulfate

tetrafluoroborate

thiocyanate

trifluoromethanesulfonate

4,5-dicyano-2-

(trifluoromethyl)imidazolide

bis(trifluoromethylsulfonyl)

$\mathrm{C}_{4}-3-\mathrm{C}_{1} \mathrm{py}$

$\mathrm{C}_{4}-3-\mathrm{C}_{1} \mathrm{py}$

$\mathrm{C}_{4}-3-\mathrm{C}_{1} \mathrm{py}$

mide

chloride

dicyanamide
$\mathrm{N}(\mathrm{CN})_{2}$

448245-52-1

C10H15N5

174501-64-5

C8H15F6N2P

297-13-2

C8H16N2O4S

C9H18N2O4S

445473-58-5 C16H32N2O4S

174501-65-6 C8H15BF4N2

344790-87-0 C9H15N3S

174899-66-2 C9H15F3N2O3S

$\mathrm{Cl}$

$\mathrm{N}(\mathrm{CN})_{2}$

125652-55-3

C10H16ClN

712355-12-9

C12H16N4 
dicyanamide

35. 1-butyl-3-methylpyridinium

tetrafluoroborate

36. 1-butyl-3-methylpyridinium trifluoromethanesulfonate

37. 1-butyl-4-methylpyridinium tetrafluoroborate

38. 1-butylpyridinium bis(trifluoromethylsulfonyl)imide

39. 1-butylpyridinium tetrafluoroborate 1-butylpyridinium

40. 1-butylpyridinium trifluoromethanesulfonate

41. ethylammonium nitrate

42. 1-ethyl-1-methylpyrrolidinium ethyl sulfate ethylammonium

1-ethyl-1-

43. 1-ethyl-2-methylpyridinium bis(trifluoromethylsulfonyl)imide

methylpyrrolidinium

1-ethyl-2

methylpyridinium

1-ethyl-3,5-dimethyl-2pentylpyridinium

1-ethyl-3-

methylimidazolium

lactate

1-ethyl-3-

methylimidazolium

1-ethyl-3-
$\mathrm{C}_{2} \mathrm{C}_{1} \mathrm{im}$

C $\mathrm{C}_{4}-3-\mathrm{C}_{1} \mathrm{py}$

C-3-C 1 py

$\mathrm{C}_{4}-4-\mathrm{C}_{1} \mathrm{py}$

$\mathrm{C}_{4} \mathrm{py}$

$\mathrm{C}_{4} \mathrm{py}$

C4py

$\mathrm{N}_{2000}$

$\mathrm{C}_{2} \mathrm{C}_{1} \mathrm{pyr}$

C $2-2-C_{1} p y$

$\mathrm{C}_{2}-3,5-\mathrm{dC}_{1}-2-\mathrm{C}_{5} \mathrm{py}$

$\mathrm{C}_{2} \mathrm{C}_{1} \mathrm{im}$

$\mathrm{C}_{2} \mathrm{C}_{1} \mathrm{im}$ tetrafluoroborate

$\mathrm{BF}_{4}$

trifluoromethanesulfonate

TFO

tetrafluoroborate

bis(trifluoromethylsulfonyl)

mide

tetrafluoroborate

trifluoromethanesulfonate

nitrate

ethyl sulfate

bis(trifluoromethylsulfonyl)

mide

bis(trifluoromethylsulfonyl)i

mide

lactate

acetate

bis(trifluoromethylsulfonyl)
$\mathrm{BF}_{4}$

$\mathrm{NTf}_{2}$

$\mathrm{BF}_{4}$

TFO

$\mathrm{NO}_{3}$

$\mathrm{C}_{2} \mathrm{SO}_{4}$

$\mathrm{NTf}_{2}$

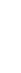

$\mathrm{NTf}_{2}$

Lact

Ac

$\mathrm{NTF}_{2}$
597581-48-1

C10H16BF4N

857841-32-8 C11H16F3NO3S

343952-33-0 C10H16BF4N

187863-42-9 C11H14F6N2O4S2

203389-28-0 C9H14BF4N

390423-43-5

C10H14F3NO3S

22113-86-6

C2NH8NO3

C9H21NO4S

712354-99-9

C16H24F6N2O4S2

878132-19-5 C9H16N2O3

143314-17-4 C8H14N2O2

174899-82-2 C8H11F6N3O4S2 
$48 . \quad$ 1-ethyl-3-methylimidazolium

1-ethyl-3-

chloride

methylimidazolium

$\mathrm{C}_{2} \mathrm{C}_{1} \mathrm{im}$

1-ethyl-3-

49. 1-ethyl-3-methylimidazolium

methylimidazolium

$\mathrm{C}_{2} \mathrm{C}_{1} \mathrm{im}$

dicyanamide

1-ethyl-3-

sulfate

methylimidazolium

$\mathrm{C}_{2} \mathrm{C}_{1} \mathrm{im}$

1-ethyl-3-

sulfate

methylimidazolium

$\mathrm{C}_{2} \mathrm{C}_{1} \mathrm{im}$

1-ethyl-3-

1-ethyl-3-methylimidazolium

methylimidazolium

$\mathrm{C}_{2} \mathrm{C}_{1} \mathrm{im}$

methanesulfonate

1-ethyl-3-

methylimidazolium

$\mathrm{C}_{2} \mathrm{C}_{1} \mathrm{im}$ methyl sulfate

1-ethyl-3-

$\mathrm{C}_{2} \mathrm{C}_{1} \mathrm{im}$

tetrafluoroborate

methylimidazolium

$\mathrm{C}_{2}$

$\mathrm{C}_{2} \mathrm{C}_{1}$ im

tricyanomethanide

methylimidazoliun

$\mathrm{C}_{2} \mathrm{C}_{1} \mathrm{im}$

methylimidazolium

1-ethyl-3-

trifluoromethanesulfonate

1-ethyl-3-methylpyridinium

bis(trifluoromethylsulfonyl)imide

methylpyridinium

$\mathrm{C}_{2}-3-\mathrm{C}_{1} \mathrm{py}$

58. 1-ethylpyridinium

bis(trifluoromethylsulfonyl)imide

1-ethylpyridinium

$\mathrm{C}_{2} \mathrm{py}$

59. 1-ethylpyridinium ethyl sulfate

1-ethylpyridinium

1-hexyl-2,3,5-trimethylpyridinium

1-hexyl-2,3,5-

$\mathrm{C}_{2} \mathrm{py}$

$\mathrm{C}_{6}-2,3,5-\mathrm{tC}_{1} \mathrm{py}$

chloride

dicyanamide

hexyl sulfate

ethyl sulfate

methanesulfonate

methyl sulfate

tetrafluoroborate

$\mathrm{BF}_{4}$

tricyanomethanide

trifluoromethanesulfonat

TFO

bis(trifluoromethylsulfonyl)i

mide

bis(trifluoromethylsulfonyl)i mide

$\begin{array}{ll}\text { ethyl sulfate } & \mathrm{C}_{2} \mathrm{SO}_{4} \\ \text { bis(trifluoromethylsulfonyl)i } & \mathrm{NTf}_{2}\end{array}$

$\mathrm{C}_{6} \mathrm{SO}_{4}$

65039-09-0

C6H11CIN2

$\mathrm{N}(\mathrm{CN})_{2}$

370865-89-7

C8H11N5

942916-86-1

C12H24N2O4S

$\mathrm{C}_{2} \mathrm{SO}_{4}$

$\mathrm{C}_{1} \mathrm{SO}_{3}$

342573-75-5

C8H16N2O4S

145022-45-3 C7H14N2O3S

516474-01-4 C7H14N2O4S

143314-16-3 C6H11BF4N2

C10H11N5

145022-44-2 C7H11F3N2O3S

841251-37-4 C10H12F6N2O4

712354-97-7 C9H10F6N2O4

2073-48-5 C9H15NO4S

C16H24F6N2O4S2 
bis(trifluoromethylsulfonyl)imide

61. 1-hexyl-3,5-dimethyl-2

pentylpyridinium

bis(trifluoromethylsulfonyl)imide

62. 1-hexyl-3-cyanopyridinium bis(trifluoromethylsulfonyl)imide

63. 1-hexyl-3-methylimidazolium

bis(trifluoromethylsulfonyl)imide

64. 1-hexyl-3-methylimidazolium

bromide

65. 1-hexyl-3-methylimidazolium dicyanamide

66

\section{1-hexyl-3-methylimidazolium}

hexafluorophosphate

67. 1-hexyl-3-methylimidazolium tetrafluoroborate

68. 1-hexyl-3-methylimidazolium trifluoromethanesulfonate

69. 1-hexyl-4-cyanopyridinium bis(trifluoromethylsulfonyl)imide

70. 1-hexylpyridinium bis(trifluoromethylsulfonyl)imide

71. 1-(2-methoxyethyl)-1-

methylpyrrolidinium

bis(trifluoromethylsulfonyl)imide trimethylpyridinium

1-hexyl-3,5-dimethyl-2-

pentylpyridinium

$\mathrm{C}_{6}-3,5-\mathrm{dC}_{1}-2-\mathrm{C}_{5} \mathrm{py}$

1-hexyl-3-

cyanopyridinium

1-hexyl-3-

methylimidazolium

1-hexyl-3-

methylimidazolium

1-hexyl-3-

methylimidazolium

1-hexyl-3-

methylimidazolium

1-hexyl-3-

methylimidazolium

1-hexyl-3-

methylimidazolium

1-hexyl-4-

cyanopyridinium

1-hexylpyridinium

1-(2-methoxyethyl)-1-

methylpyrrolidinium mide

bis(trifluoromethylsulfonyl)i

mide

bis(trifluoromethylsulfonyl)

mide

NTf $_{2}$

14H17F6N3O4S2

bis(trifluoromethylsulfonyl)i

mide

$\mathrm{NTf}_{2}$

382150-50-7

C12H19F6N3O4S2

bromide

85100-78-3

C10H19BrN2

dicyanamide

$\mathrm{N}(\mathrm{CN})_{2}$

448245-52-

C10H15N5

hexafluorophosphate

$\mathrm{PF}_{6}$

304680-35-1

C10H19F6N2P

tetrafluoroborate

$\mathrm{BF}_{4}$

244193-50-8

C10H19BF4N2

trifluoromethanesulfonate

TFO

460345-16-8

C11H19F3N2O3S

bis(trifluoromethylsulfonyl)

mide

bis(trifluoromethylsulfonyl)

mide

bis(trifluoromethylsulfonyl)i

mide

$\mathrm{NTf}_{2}$

757240-24- 
72. 1-(2-methoxyethyl)-1-

methylpyrrolidiniun

1-(2-methoxyethyl)-1-

tris(pentafluoroethyl)trifluoro

1195983-48-2

C14H18F18NOP

hate
73. bis(trifluoromethylsulfonyl)imide

1-methyl-1-

propylpyrrolidinium

74. 1-methylpyridinium methyl sulfate

1-methylpyridinium

1-octyl-3-cyanopyridinium

$\mathrm{C}_{3} \mathrm{C}_{1} \mathrm{pyr}$

$\mathrm{C}_{1} \mathrm{py}$

75. 1-octyl-3-cyanopyridinium bis(trifluoromethylsulfonyl)imide bis(trifluoromethylsulfonyl)imide

1-octyl-3-

methylimidazolium

1-octyl-3-

methylimidazolium

1-octyl-3-

methylimidazolium

1-octyl-3-

methylimidazolium

1-octyl-3-

methylpyridinium

1-octylisoquinolinium

1-pentyl-3-

methylimidazolium

1-pentyl-3-

methylimidazolium

$\mathrm{C}_{8} \mathrm{C}_{1} \mathrm{im}$

$\mathrm{C}_{8} \mathrm{C}_{1} \mathrm{im}$

$\mathrm{C}_{8} \mathrm{C}_{1} \mathrm{im}$

1- 1-octylisoquinolinium

bis(trifluoromethylsulfonyl)imid

CoiQuin

1-pentyl-3-methylimidazolium bis(trifluoromethylsulfonyl)imide

$\mathrm{C}_{5} \mathrm{C}_{1} \mathrm{im}$

83. 1-pentyl-3-methylimidazolium

bromide
76. 1-octyl-3-methylimidazolium

phosphate

bis(trifluoromethylsulfonyl)i

mide

methyl sulfate

bis(trifluoromethylsulfonyl)

mide

bis(trifluoromethylsulfonyl)i

mide

chloride

$\mathrm{C}_{8}-3-\mathrm{C}_{1} \mathrm{py}$

hexafluorophosphate

tetrafluoroborate

tetrafluoroborate

bis(trifluoromethylsulfonyl)i

mide

bis(trifluoromethylsulfonyl)i

mide

bromide

37943-43-4

C7H11NO4S

C16H21F6N3O4S2

178631-04-4

C14H23F6N3O4S2

64697-40-1

C12H23CIN2

$\mathrm{PF}_{6}$

304680-36-2

C12H23N2·PF6

$\mathrm{BF}_{4}$

244193-52-0

C12H23BF4N2

$\mathrm{BF}_{4}$

C14H24BF4N

$\mathrm{NTf}_{2}$

C19H24F6N2O4S2

C9H17BrN2 


\begin{tabular}{|c|c|c|c|c|c|c|c|}
\hline 84. & $\begin{array}{l}\text { 1-pentyl-3-methylimidazolium } \\
\text { tetrafluoroborate }\end{array}$ & $\begin{array}{l}\text { 1-pentyl-3- } \\
\text { methylimidazolium }\end{array}$ & $\mathrm{C}_{5} \mathrm{C}_{1} \mathrm{im}$ & tetrafluoroborate & $\mathrm{BF}_{4}$ & - & C9H17BF4N2 \\
\hline 85. & $\begin{array}{l}\text { 1-pentylpyridinium } \\
\text { bis(trifluoromethylsulfonyl)imide }\end{array}$ & 1-pentylpyridinium & Сspy & $\begin{array}{l}\text { bis(trifluoromethylsulfonyl)i } \\
\text { mide }\end{array}$ & $\mathrm{NTf}_{2}$ & - & C8H8F6N2O4S2 \\
\hline 86. & $\begin{array}{l}\text { 1-propyl-2-methylpyridinium } \\
\text { bis(trifluoromethylsulfonyl)imide }\end{array}$ & $\begin{array}{l}\text { 1-propyl-2- } \\
\text { methylpyridinium }\end{array}$ & $\mathrm{C}_{3}-2-\mathrm{C}_{1} \mathrm{py}$ & $\begin{array}{l}\text { bis(trifluoromethylsulfonyl)i } \\
\text { mide }\end{array}$ & $\mathrm{NTf}_{2}$ & 817575-06-7 & C11H14F6N2O4S2 \\
\hline 87. & $\begin{array}{l}\text { 1-propyl-3-methylimidazolium } \\
\text { bis(trifluoromethylsulfonyl)imide }\end{array}$ & $\begin{array}{l}\text { 1-propyl-3- } \\
\text { methylimidazolium }\end{array}$ & $\mathrm{C}_{3} \mathrm{C}_{1} \mathrm{im}$ & $\begin{array}{l}\text { bis(trifluoromethylsulfonyl)i } \\
\text { mide }\end{array}$ & $\mathrm{NTf}_{2}$ & 216299-72-8 & C9H13F6N3O4S2 \\
\hline 88. & $\begin{array}{l}\text { 1-propyl-3-methylimidazolium } \\
\text { bromide }\end{array}$ & $\begin{array}{l}\text { 1-propyl-3- } \\
\text { methylimidazolium }\end{array}$ & $\mathrm{C}_{3} \mathrm{C}_{1} \mathrm{im}$ & bromide & $\mathrm{Br}$ & 85100-76-1 & C7H13BrN2 \\
\hline 89. & $\begin{array}{l}\text { 1-propyl-3-methylpyridinium } \\
\text { bis(trifluoromethylsulfonyl)imide }\end{array}$ & $\begin{array}{l}\text { 1-propyl-3- } \\
\text { methylpyridinium }\end{array}$ & Сз-3-С & $\begin{array}{l}\text { bis(trifluoromethylsulfonyl)i } \\
\text { mide }\end{array}$ & $\mathrm{NTf}_{2}$ & 817575-06-7 & C11H14F6N2O4S2 \\
\hline 90. & $\begin{array}{l}\text { 1-propylpyridinium } \\
\text { bis(trifluoromethylsulfonyl)imide }\end{array}$ & 1-propylpyridinium & $\mathrm{C}_{3} \mathrm{py}$ & $\begin{array}{l}\text { bis(trifluoromethylsulfonyl)i } \\
\text { mide }\end{array}$ & $\mathrm{NTf}_{2}$ & - & C10H12F6N2O4S2 \\
\hline 91. & $\begin{array}{l}\text { 1-propylpyridinium } \\
\text { tetrafluoroborate }\end{array}$ & 1-propylpyridinium & $\mathrm{C}_{3} \mathrm{py}$ & tetrafluoroborate & $\mathrm{BF}_{4}$ & 239084-00-5 & C8H12BF4N \\
\hline 92. & $\begin{array}{l}\text { 2-ethyl-1-hexyl-3,5- } \\
\text { dimethylpyridinium } \\
\text { bis(trifluoromethylsulfonyl)imide }\end{array}$ & $\begin{array}{l}\text { 2-ethyl-1-hexyl-3,5- } \\
\text { dimethylpyridinium }\end{array}$ & $\mathrm{C}_{6}-2-\mathrm{C}_{2}-3,5-\mathrm{dC}_{1} \mathrm{py}$ & $\begin{array}{l}\text { bis(trifluoromethylsulfonyl)i } \\
\text { mide }\end{array}$ & $\mathrm{NTf}_{2}$ & - & C17H26F6N2O4S2 \\
\hline 93. & $\begin{array}{l}\text { 2-ethyl-1-methylpyridinium methyl } \\
\text { sulfate }\end{array}$ & $\begin{array}{l}\text { 2-ethyl-1- } \\
\text { methylpyridinium }\end{array}$ & $\mathrm{C}_{1}-2-\mathrm{C}_{2} \mathrm{py}$ & methyl sulfate & $\mathrm{C}_{1} \mathrm{SO}_{4}$ & - & C9H15NO3S \\
\hline 94. & $\begin{array}{l}\text { 2-hydroxy diethylammonium } \\
\text { formate }\end{array}$ & $\begin{array}{l}\text { 2-hydroxy } \\
\text { diethylammonium }\end{array}$ & $\mathrm{N}\left(2(\mathrm{OH}) \mathrm{C}_{2}\right) 200$ & formate & $\mathrm{HCOO}$ & - & C5H13NO4 \\
\hline 95. & $\begin{array}{l}\text { 2-hydroxy diethylammonium } \\
\text { pentanoate }\end{array}$ & $\begin{array}{l}\text { 2-hydroxy } \\
\text { diethylammonium }\end{array}$ & $\mathrm{N}\left(2(\mathrm{OH}) \mathrm{C}_{2}\right) 2_{00}$ & pentanoate & $\mathrm{C}_{4} \mathrm{COO}$ & - & C9H21NO4 \\
\hline
\end{tabular}




\begin{tabular}{|c|c|c|c|c|c|c|c|}
\hline 96. & 2-hydroxy ethylammonium acetate & 2-hydroxy ethylammonium & $\mathrm{N} 2(\mathrm{OH}) \mathrm{C}_{2000}$ & acetate & Ac & $54300-24-2$ & C4H11NO3 \\
\hline 97. & 2-hydroxy ethylammonium formate & 2-hydroxy ethylammonium & $\mathrm{N} 2(\mathrm{OH}) \mathrm{C}_{2000}$ & formate & $\mathrm{HCOO}$ & 213619-93-3 & C3H9NO3 \\
\hline 98. & 2-hydroxy ethylammonium oleate & 2-hydroxy ethylammonium & $\mathrm{N} 2(\mathrm{OH}) \mathrm{C}_{2000}$ & oleate & $\mathrm{O}$ & 2272-11-09 & $\mathrm{C} 20 \mathrm{H} 41 \mathrm{NO} 3$ \\
\hline 99. & $\begin{array}{l}\text { 2-hydroxy ethylammonium } \\
\text { pentanoate }\end{array}$ & 2-hydroxy ethylammonium & $\mathrm{N} 2(\mathrm{OH}) \mathrm{C}_{2000}$ & pentanoate & $\mathrm{C}_{4} \mathrm{COO}$ & - & C7H17O2N \\
\hline 100. & $\begin{array}{l}\text { 2-hydroxy triethylammonium } \\
\text { formate }\end{array}$ & $\begin{array}{l}\text { 2-hydroxy } \\
\text { triethylammonium }\end{array}$ & $\mathrm{N}\left(2(\mathrm{OH}) \mathrm{C}_{2}\right) 3_{0}$ & formate & $\mathrm{HCOO}$ & - & C7H17O5N \\
\hline 101. & $\begin{array}{l}\text { 2-hydroxy triethylammonium } \\
\text { pentanoate }\end{array}$ & $\begin{array}{l}\text { 2-hydroxy } \\
\text { triethylammonium }\end{array}$ & $\mathrm{N}\left(2(\mathrm{OH}) \mathrm{C}_{2}\right) 3_{0}$ & pentanoate & $\mathrm{C}_{4} \mathrm{COO}$ & - & C11H27O5N \\
\hline 102. & $\begin{array}{l}\text { 2-hydroxyethyltrimethylammonium } \\
\text { L-lactate }\end{array}$ & $\begin{array}{l}\text { 2-hydroxy } \\
\text { ethyltrimethylammonium }\end{array}$ & $\mathrm{N} 2(\mathrm{OH}) \mathrm{C}_{2111}$ & L-lactate & Lact & 888724-51-4 & C8H19NO4 \\
\hline 103. & $\begin{array}{l}\text { 3-butyl-1-ethylimidazolium } \\
\text { trifluoromethanesulfonate }\end{array}$ & $\begin{array}{l}\text { 3-butyl-1- } \\
\text { ethylimidazolium }\end{array}$ & $\mathrm{C}_{4} \mathrm{C}_{2} \mathrm{im} / \mathrm{C}_{2} \mathrm{C}_{4} \mathrm{im}$ & trifluoromethanesulfonate & TFO & $174899-66-2$ & C9H15F3N2O3S \\
\hline 104. & 3-hydroxypropylammonium acetate & $\begin{array}{l}\text { 3- } \\
\text { hydroxypropylammonium }\end{array}$ & $\mathrm{N} 3(\mathrm{OH}) \mathrm{C}_{3000}$ & acetate & Ac & - & C5H13NO3 \\
\hline 105. & $\begin{array}{l}\text { 3-hydroxypropylammonium } \\
\text { formate }\end{array}$ & $\begin{array}{l}\text { 3- } \\
\text { hydroxypropylammonium }\end{array}$ & $\mathrm{N} 3(\mathrm{OH}) \mathrm{C}_{3} 000$ & formate & $\mathrm{HCOO}$ & - & C4H11NO3 \\
\hline 106. & $\begin{array}{l}\text { 3-hydroxypropylammonium } \\
\text { trifluoroacetate }\end{array}$ & $\begin{array}{l}\text { 3- } \\
\text { hydroxypropylammonium }\end{array}$ & $\mathrm{N} 3(\mathrm{OH}) \mathrm{C}_{3000}$ & trifluoroacetate & $\mathrm{CF}_{3} \mathrm{COO}$ & - & C11H21F3O5N \\
\hline 107. & $\begin{array}{l}\text { bis(2-hydroxyethyl)ammonium } \\
\text { oleate }\end{array}$ & $\begin{array}{l}\text { bis(2- } \\
\text { hydroxyethyl)ammonium }\end{array}$ & $\mathrm{N}\left(2(\mathrm{OH}) \mathrm{C}_{2}\right) 2_{00}$ & oleate & $\mathrm{O}$ & - & $\mathrm{C} 22 \mathrm{H} 45 \mathrm{NO} 4$ \\
\hline 108. & butyrolactam acetate & butyrolactam & BT & acetate & Ac & - & C6H11O3N \\
\hline 109. & butyrolactam formate & butyrolactam & BT & formate & HCOO & - & C5H9O3N \\
\hline 110. & butyrolactam hexanoate & butyrolactam & BT & hexanoate & $\mathrm{C}_{5} \mathrm{COO}$ & - & C10H19O3N \\
\hline 111. & caprolactam acetate & caprolactam & $\mathrm{CP}$ & acetate & Ac & - & C8H15O3N \\
\hline
\end{tabular}




\begin{tabular}{|c|c|c|c|c|c|c|c|}
\hline 112. & caprolactam formate & caprolactam & СР & formate & $\mathrm{HCOO}$ & - & C7H13O3N \\
\hline 113. & caprolactam hexanoate & caprolactam & СР & hexanoate & $\mathrm{C}_{5} \mathrm{COO}$ & - & C12H23O3N \\
\hline 114. & diethylammonium acetate & diethylammonium & $\mathrm{N}_{2200}$ & acetate & Ac & 20726-63-0 & C6H15NO2 \\
\hline 115. & diethylammonium hydrogen sulfate & diethylammonium & $\mathrm{N}_{2200}$ & hydrogen sulfate & $\mathrm{HSO}_{4}$ & - & C4H13NO4S \\
\hline 116. & $\begin{array}{l}\text { L-alanine isobutylester lauryl } \\
\text { sulfate }\end{array}$ & L-alanine isobutylester & $\mathrm{AlaC}_{4}$ & lauryl sulfate & LS & - & C19H41NO6S \\
\hline 117. & $\begin{array}{l}\text { L-alanine isopropylester lauryl } \\
\text { sulfate }\end{array}$ & L-alanine isopropylester & $\mathrm{AlaC}_{3}$ & lauryl sulfate & LS & - & C18H39NO6S \\
\hline 118. & $\begin{array}{l}\text { L-glutamic acid diisobutylester } \\
\text { lauryl sulfate }\end{array}$ & $\begin{array}{l}\text { L-glutamic acid } \\
\text { diisobutylester }\end{array}$ & $\mathrm{GluC}_{4}$ & lauryl sulfate & LS & - & C25H51NO8S \\
\hline 119. & $\begin{array}{l}\text { L-glutamic acid diisopropylester } \\
\text { lauryl sulfate }\end{array}$ & $\begin{array}{l}\text { L-glutamic acid } \\
\text { diisopropylester }\end{array}$ & $\mathrm{GluC}_{3}$ & lauryl sulfate & LS & - & C23H47NO8S \\
\hline 120. & $\begin{array}{l}\text { L-glycine isobutylester lauryl } \\
\text { sulfate }\end{array}$ & L-glycine isobutylester & $\mathrm{GlyC}_{4}$ & lauryl sulfate & LS & - & C18H39NO6S \\
\hline 121. & $\begin{array}{l}\text { L-glycine isopropylester lauryl } \\
\text { sulfate }\end{array}$ & L-glycine isopropylester & $\mathrm{GlyC}_{3}$ & lauryl sulfate & LS & - & C17H37NO6S \\
\hline 122. & $\begin{array}{l}\text { L-proline isobutylester lauryl } \\
\text { sulfate }\end{array}$ & L-proline isobutylester & $\mathrm{ProC}_{4}$ & lauryl sulfate & LS & - & C21H45NO6S \\
\hline 123. & $\begin{array}{l}\text { L-proline isopropylester lauryl } \\
\text { sulfate }\end{array}$ & L-proline isopropylester & $\mathrm{ProC}_{3}$ & lauryl sulfate & LS & - & C20H41NO6S \\
\hline 124. & L-valine isobutylester lauryl sulfate & L-valine isobutylester & $\mathrm{ValC}_{4}$ & lauryl sulfate & LS & - & $\mathrm{C} 21 \mathrm{H} 45 \mathrm{NO} 6 \mathrm{~S}$ \\
\hline 125. & $\begin{array}{l}\text { L-valine isopropylester lauryl } \\
\text { sulfate }\end{array}$ & L-valine isopropylester & $\mathrm{ValC}_{3}$ & lauryl sulfate & LS & - & C20H43NO6S \\
\hline 126. & $\begin{array}{l}\text { methyltrioctylammonium } \\
\text { bis(trifluoromethylsulfonyl)imide }\end{array}$ & methyltrioctylammonium & $\mathrm{N}_{1888}$ & $\begin{array}{l}\text { bis(trifluoromethylsulfonyl)i } \\
\text { mide }\end{array}$ & $\mathrm{NTf}_{2}$ & 375395-33-8 & $\mathrm{C} 27 \mathrm{H} 54 \mathrm{~F} 6 \mathrm{~N} 2 \mathrm{O} 4 \mathrm{~S} 2$ \\
\hline
\end{tabular}


127. N, N, N-trimethyl-N-

propylammonium

bis(trifluoromethylsulfonyl)imide

128. N-ethyl-N- (2-hydroxyethyl)-N,N-

dimethylammonium

butanesulfonate

129.

N-ethyl-N-(2-hydroxyethyl)-N,N-

dimethylammonium ethyl sulfate

130. N-ethyl-N,N-

dimethylbutylammonium ethyl

sulfate

131. N-methyl- 2-

hydroxyethylammonium acetate

132. N-methyl- 2-

hydroxyethylammonium butyrate

133. N-methyl-2-

hydroxyethylammonium pentanoate

134. N-methyl- 2-

hydroxyethylammonium propionate

135. N-methyl-2-

hydroxyethylammonium isobutyrate

136. N-methyl-2-

hydroxyethylammonium formate

137. PEG-5 cocomonium methyl sulfate
$\mathrm{N}, \mathrm{N}, \mathrm{N}$-trimethyl-N-

propylammonium

$\mathrm{N}_{111}$

N-ethyl-N-(2-

hydroxyethyl)-N,N-

dimethylammonium

N-ethyl-N-(2-

hydroxyethyl)-N,N-

dimethylammonium

N-ethyl-N,N-

dimethylbutylammoniun

N-methyl-2-

hydroxyethylammonium

N-methyl-2

hydroxyethylammonium

N-methyl-2-

hydroxyethylammonium

N-methyl-2-

hydroxyethylammonium

N-methyl-2-

N-methyl-2

hydroxyethylammonium

PEG-5 cocomonium
$\mathrm{N}_{2114}$

$\mathrm{N}_{2} 2(\mathrm{OH}) \mathrm{C}_{21}$

$\mathrm{N}_{2} 2(\mathrm{OH}) \mathrm{C}_{21}$

ethyl sulfate

ethyl sulfate

acetate

butyrate

$\mathrm{N}_{1} 2(\mathrm{OH}) \mathrm{C}_{200}$

$\mathrm{N}_{1} 2(\mathrm{OH}) \mathrm{C}_{20}$

$\mathrm{N}_{1} 2(\mathrm{OH}) \mathrm{C}_{200}$

$\mathrm{N}_{1} 2(\mathrm{OH}) \mathrm{C}_{200}$

$\mathrm{N}_{1} 2(\mathrm{OH}) \mathrm{C}_{200}$

PEG5cocom

pentanoate

propionate

isobutyrate

formate bis(trifluoromethylsulfonyl)i

mide

C8H16F6N2O4S2

C10H25NO3S

C8H21NO4S

$\mathrm{C}_{2} \mathrm{SO}_{4}$

C6H11NO4S

Ac

C5H13NO3

$\mathrm{C}_{3} \mathrm{COO}$

C7H17NO3

$\mathrm{C}_{4} \mathrm{COO}$

C8H19NO3

$\mathrm{C}_{2} \mathrm{COO}$

C6H15NO3

$\mathrm{iC}_{3} \mathrm{COO}$

C7H17NO3

HCOO

C4H11NO3

methyl sulfate 


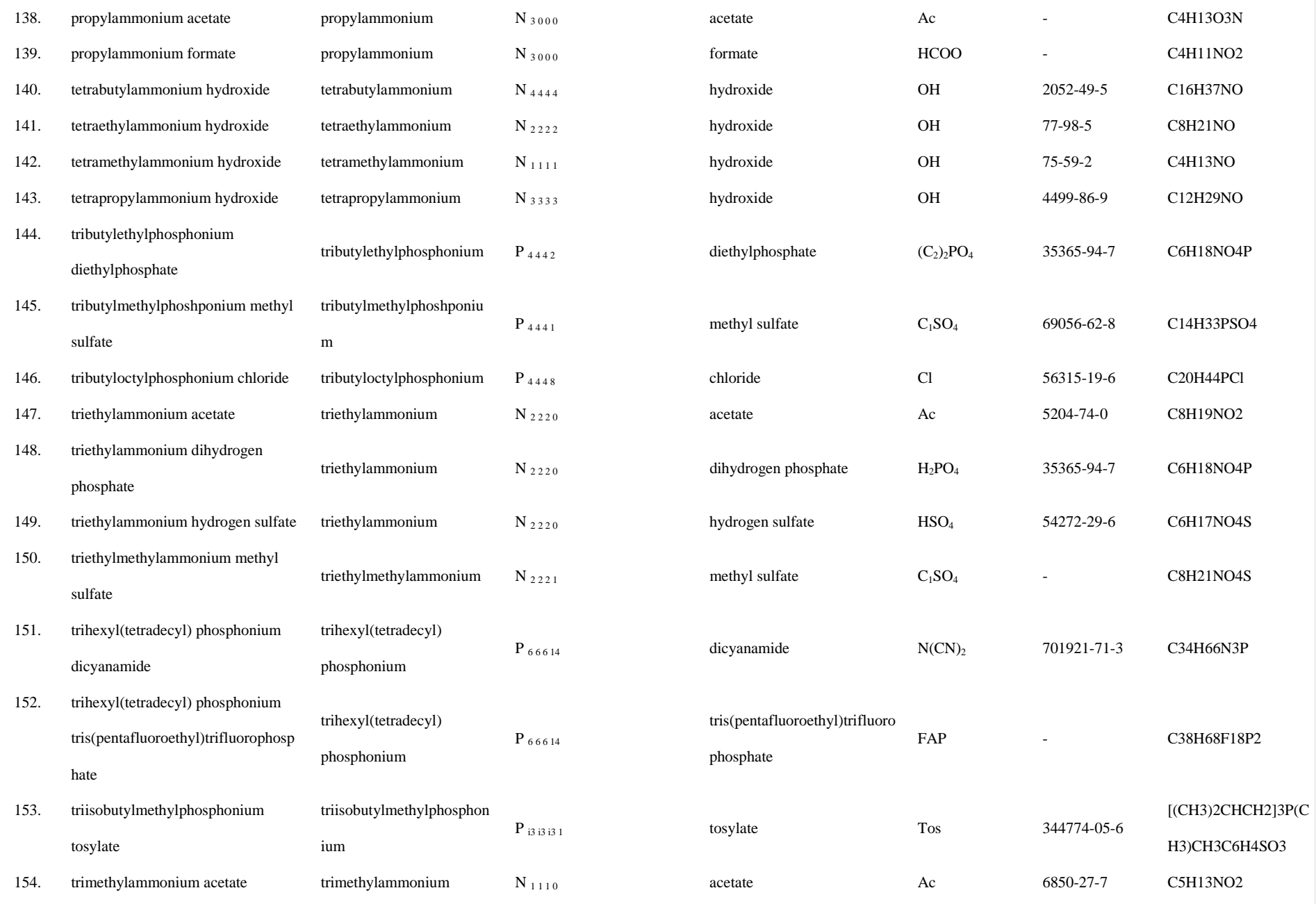


155. trimethylammonium dihydrogen

phosphate

trimethylammonium $\quad \mathrm{N}_{1110}$

$\mathrm{H}_{2} \mathrm{PO}_{4}$

C3H12PO4

156. trimethylammonium hydrogen

sulfate

trimethylammonium

$\mathrm{N}_{1110}$

hydrogen sulfate

$\mathrm{HSO}_{4}$

C3H11NO4S

157. $\operatorname{tris}(2$

tris(2

hydroxyethyl)methylammonium

hydroxyethyl)methylammo $\quad \mathrm{N}\left(2(\mathrm{OH}) \mathrm{C}_{2}\right) 3_{1}$

methyl sulfate

$\mathrm{C}_{1} \mathrm{SO}_{4}$

$5204-74-0$

C8H19NO2

methyl sulfate

nium

description

tetraammonium-based IL - tetraalkylammonium sulfate, acyclic

Ammoeng 102

choline chloride : ethylene glycol (molar ratio 1:2)

\section{ethaline}

choline chloride : fructose (molar ratio 2:1)

fructoline

glucoline

choline chloride : glucose (molar ratio 2:1)

glyceline

choline chloride : glycerol (molar ratio 1:2)

choline chloride : urea (molar ratio 1:2)

reline

${ }^{a}$ there are given: acronyms of cations and anions, CASRN numbers, if exists, and molecular formulas (for some less popular, synthesized ILs acronyms proposed by authors were used). 


\section{ACKNOWLEDGMENTS}

The authors are profoundly indebted to Ms. Katarzyna Bartoszek for her participation in the database compilation.

\section{SUPPORTING INFORMATION}

Table S1 contains the full names of anions and cations, the purity (the purity of IL, water content, and halide content), the number of experimental points and frequency if is not typical, the measurement method, the temperature and pressure range, the title of the publication, the authors, the year and listed references.

\section{REFERENCES}

(1) Arce, A.; Rodríguez, O.; Soto, A. Experimental Determination of Liquid-Liquid Equilibrium Using Ionic Liquids: tert-Amyl Ethyl Ether + Ethanol + 1-Octyl-3-methylimidazolium Chloride System at 298.15 K. J. Chem. Eng. Data 2004, 49, 514-517.

(2) Arce, A.; Rodríguez, O.; Soto, A. tert-Amyl Ethyl Ether Separation from its Mixtures with Ethanol Using the 1-Butyl-3-methylimidazolium Trifluoromethanesulfonate Ionic Liquid: Liquid-Liquid Equilibrium. Ind. Eng. Chem. Res. 2004, 43, 8323-8327.

(3) Gabriel, S.; Weiner, J. Ueber einige Abkömmlinge des Propylamins. Chem. Ber. 1888, 21 (2), 2669-2679. 
(4) Wu, K-J.; Chen, Q-L.; He, Ch-H. Speed of Sound of Ionic Liquids: Database, Estimation, and its Application for Thermal Conductivity Prediction. AIChE Journal 2014, 60, $1120-1131$

(5) Kazakov, A.; Magee, J. W.; Chirico, R. D.; Paulechka, E.; Diky, V.; Muzny, C. D.; Kroenlein, K.; Frenkel, M. NIST Standard Reference Database 147: NIST Ionic Liquids Database - (ILThermo), Version 2.0; National Institute of Standards and Technology: Gaithersburg MD, 20899.

(6) Povey, M. J. W. Ultrasonic Techniques for Fluids Characterization; Academic Press: San Diego, 1997.

(7) Herzfeld, K. F.; Litovitz, T. A. Absorption and Dispersion of Ultrasonic Waves; Academic Press: New York and London, 1959.

(8) Wilhelm, E. What You Always Wanted to Know About Heat Capacities, But Were Afraid to Ask. J. Solution Chem. 2010, 39, 1777-1818.

(9) Riazi, M. R.; Mansoori, G. A. Use of the Velocity of Sound in Predicting the PVT Relations. Fluid Phase Equilibria 1993, 90, 251-264.

(10)Span, R.; Wagner, W. Equations of State for Technical Applications. I. Simultaneously Optimized Functional Forms for Nonpolar and Polar Fluids. Int. J. Thermophys. 2003, 24, $1-39$.

(11)Lemmon, E. W.; Span, R. Short Fundamental Equations of State for 20 Industrial Fluids. J. Chem. Eng. Data 2006, 51, 785-850.

(12)Frez, C.; Diebold, G. J.; Tran, C. D.; Yu, S. Determination of Thermal Diffusivities, Thermal Conductivities, and Sound Speeds of Room-Temperature Ionic Liquids by the Transient Grating Technique. J. Chem. Eng. Data 2006, 51, 1250-1255. 
(13)Zafarani-Moattar, M. T.; Shekaari, H. Volumetric and Speed of Sound of Ionic Liquid, 1-Butyl-3-methylimidazolium Hexafluorophosphate with Acetonitrile and Methanol at T = (298.15 to 318.15). K J. Chem. Eng. Data 2005, 50, 1694-1699.

(14)Gomes de Azevedo, R. G.; Esperança, J. M. S. S.; Szydlowski, J.; Visak, Z. P.; Pires, P. F.; Guedes, H. J. R.; Rebelo, L. P. N. Thermophysical and Thermodynamic Properties of Ionic Liquids Over an Extended Pressure Range: [Bmim][NTf2] and [Hmim][NTf2]. J. Chem. Thermodyn. 2005, 37, 888-899.

(15)Gomes de Azevedo, R.; Esperança, J. M. S. S.; Najdanovic-Visak, V.; Visak, Z. P.; Guedes, H. J. R.; Nunes da Ponte, M.; Rebelo, L. P. N. Thermophysical and Thermodynamic Properties of 1-Butyl-3-methylimidazolium Tetrafluoroborate and 1-Butyl-3-methylimidazoliuin Hexafluorophosphate Over an Extended Pressure Range. J. Chem. Eng. Data 2005, 50, 997-1008.

(16)Gomes de Azevedo, R.; Szydlowski, J.; Pires, P. F.; Esperança, J. M. S. S.; Guedes, H. J. R.; Rebelo, L. P. N. A Novel Non-Intrusive Microcell for Sound-Speed Measurements in Liquids. Speed of Sound and Thermodynamic Properties of 2-Propanone at Pressures up to 160 MPa. J. Chem. Thermodyn. 2004, 36, 211-222.

(17)Esperança, J. M. S. S.; Visak, Z. P.; Plechkova, N. V.; Seddon, K. R.; Guedes, H. J. R.; Rebelo, L. P. N. Density, Speed of Sound, and Derived Thermodynamic Properties of Ionic Liquids Over an Extended Pressure Range. 4. [C3mim][NTf2] and [C5mim][NTf2]. J. Chem. Eng. Data 2006, 51, 2009-2015.

(18)Makino, W.; Kishikawa, R.; Mizoshiri, M.; Takeda, S; Yao, M. Viscoelastic Properties of Room Temperature Ionic Liquids. J. Chem. Phys. 2008, 129, 104510. 
(19)Fukuda, M.; Kajimoto, O.; Terazima, M.; Kimura, Y. Application of the Transient Grating Method to the Investigation of the Photo-Thermalization Process of Malachite Green in Room Temperature Ionic Liquids. J. Mol. Liq. 2007, 134, 49-54.

(20)Kozlov, D. N.; Kiefer, J.; Seeger, T.; Fröba, A. P.; Leipertz, A. Simultaneous Measurement of Speed of Sound, Thermal Diffusivity, and Bulk Viscosity of 1-Ethyl-3-methylimidazolium-Based Ionic Liquids Using Laser-Induced Gratings. J. Phys. Chem. B 2014, 118, 14493-14501.

(21)Demizu, M.; Terazima, M.; Kimura, Y. Transport Properties of Binary Mixtures of Carbon Dioxide and 1-Butyl-3-methylimidazolium Hexafluorophosphate Studied by Transient Grating Spectroscopy. Anal. Sci. 2008, 24, $1329-1334$.

(22)Fukuda, M.; Terazima, M.; Kimura, Y. Sound Velocity Dispersion in Room Temperature Ionic Liquids Studied Using the Transient Grating Method. J. Chem. Phys. 2008, 128, 114508.

(23)Demizu, M.; Harada, M.; Saijo, K.; Terazima, M.; Kimura, Y. Transport Properties and Solvation Structure of Mixtures of Carbon Dioxide and Room-Temperature Ionic Liquids. Bull. Chem. Soc. Jpn. 2011, 84, 70-78.

(24)Kozlov, D. N.; Kiefer, J.; Seeger, T.; Fröba, A. P.; Leipertz, A. Determination of Physicochemical Parameters of Ionic Liquids and Their Mixtures with Solvents Using Laser-Induced Gratings. J. Phys. Chem. B 2011, 115, 8528-8533.

(25)Zorębski, E.; Geppert-Rybczyńska, M.; Zorębski, M. Acoustics as a Tool for Better Characterization of Ionic Liquids: A Comparative Study of 1-Alkyl-3-methylimidazolium Bis[(trifluoromethyl)sulfonyl] Imide Room-Temperature Ionic Liquids. J. Phys. Chem. B 2013, 117, 3867-3876. 
(26)Geppert-Rybczyńska, M.; Lehmann, J. K.; Heintz, A. Physicochemical Properties of Two 1-Alkyl-1-methylpyrrolidinium Bis[(trifluoromethyl)sulfonyl]imide Ionic Liquids and of Binary Mixtures of 1-Butyl-1-methylpyrrolidinium Bis[(trifluoromethyl)sulfonyl]imide with Methanol or Acetonitrile. J. Chem. Thermodyn. 2014, 71, 171-181.

(27)Kumar, A. Estimates of Internal Pressure and Molar Refraction of Imidazolium Based Ionic Liquids as a Function of Temperature. J. Sol. Chem. 2008, 37, 203-214.

(28)Singh, T.; Kumar, A. Self-Aggregation of Ionic Liquids in Aqueous Media: A Thermodynamic Study. Colloid. Surface A 2008, 318, 263-268.

(29)Dzida, M.; Chorążewski, M.; Geppert-Rybczyńska, M.; Zorębski, E.; Zorębski, M.; Żarska, M.; Czech, B. Speed of Sound and Adiabatic Compressibility of 1Ethyl-3-methylimidazolium Bis(trifluoro methyl sulfonyl)imide Under Pressures up to 100 MPa. J. Chem. Eng. Data 2013, 58, 1571-1576.

(30)Geppert-Rybczyńska, M.; Sitarek, M. Acoustic and Volumetric Properties of Binary Mixtures of Ionic Liquid 1-Butyl-3-methylimidazolium Bis(trifluoromethylsulfonyl)imide with Acetonitrile and Tetrahydrofuran. J. Chem. Eng. Data 2014, 59, 1213-1224.

(31)Widegren, J. A.; Magee, J. W. Density, Viscosity, Speed of Sound, and Electrolytic Conductivity for the Ionic Liquid 1-Hexyl-3-methylimidazolium Bis(trifluoromethylsulfonyl)imide and its Mixtures with Water. J. Chem. Eng. Data 2007, 52, 2331-2338.

(32)Fortin, J. T.; Laesecke, A.; Freund, M.; Outcalt, S. Advanced Calibration, Adjustment, and Operation of a Density and Sound Speed Analyzer. J. Chem. Thermodyn. 2013, 57, 276285. 
(33)Singh, M. P.; Mandal, S. K.; Verma, Y. L.; Gupta, A. K.; Singh, R. K.; Chandra, S. Viscoelastic, Surface, and Volumetric Properties of Ionic Liquids [BMIM][OcSO4], [BMIM][PF6], and [EMIM][MeSO3]. J. Chem. Eng. Data 2014, 59, 2349-2359.

(34)Zorębski, M.; Zorębski, E.; Dzida, M.; Skowronek, J.; Jężak, S.; Goodrich P.; Jacquemin, J. Ultrasonic Relaxation Study of 1-Alkyl-3-methylimidazolium-Based Room-Temperature Ionic Liquids: Probing the Role of Alkyl Chain Length in the Cation. J. Phys. Chem. B 2016, 120, 3569-3581.

(35) Attri, P.; Reddy, P. M.; Venkatesu, P. Density and Ultrasonic Sound Speed Measurements for N,N-Dimethylformamide with Ionic Liquids. Indian J. Chem. 2010, 49A, 736-742.

(36)Kavitha, T.; Attri, P.; Venkatesu, P.; Rama Devi, R. S.; Hofman, T. Temperature Dependence Measurements and Molecular Interactions for Ammonium Ionic Liquid with N-Methyl-2-pyrrolidone. J. Chem. Thermodyn. 2012, 54, 223-237.

(37)Ernst, S.; Marczak, W.; Manikowski, R.; Zorębski, E.; Zorębski, M. A Sing-Around Apparatus for Group Velocity Measurements in Liquids. Testing by Standard Liquids and Discussion of the Errors. Acoust. Letters 1992, 15, 123-130.

(38)Zorębski, E.; Zorębski, M.; Ernst, S. Speed of Ultrasound in Liquids Measured at a Constant Acoustic Pathlength. Comparison and Discussion of Errors. J. Phys. IV 2005, 129, 79-82.

(39)Żak, A.; Dzida, M.; Zorębski, M.; Ernst, S. A High Pressure Device for Measurements of the Sound velocity in Liquids. Rev. Sci. Instrum. 2000, 71, $1756-1765$.

(40)Trusler, J. P. M. Physical Acoustics and Metrology of Fluids; Adam Hilger: Bristol, Philadelphia and New York, 1991. 
(41)Pires P. F.; Guedes, H. J. R. The Speed of Sound and Isentropic Compressibility of Liquid Difluoromethane (HFC32) from $T=(248$ to 343) K and Pressures up to $65 \mathrm{MPa}$. J. Chem. Thermodyn. 1999, 31, 55-69.

(42)Papadakis E. P. Ultrasonic Phase Velocity by the Pulse-Echo-Overlap Method Incorporating Diffraction Phase Corrections. J. Acoust. Soc. Am. 1967, 42, 1045-1051.

(43)Dzida, M. Chorążewski M.; Zorębski, M.; Mańka R. Modifications of a High Pressure Device for Speed of Sound Measurements in Liquids. J. Phys. IV 2006, 130, 203-207.

(44)Eichler, H. J.; Gunter, P.; Pohl, D. W. Laser-Induced Dynamic Gratings; Springer-Verlag: Berlin, 1986.

(45)Chirico, R. D.; Diky, V.; Magee, J. W.; Frenkel, M.; Marsh, K. N. Thermodynamic and Thermophysical Properties of the Reference Ionic Liquid: 1-Hexyl-3-methylimidazolium Bis[(trifluoromethyl)Sulfonyl]amide (Including Mixtures). Part 2. Critical Evaluation and Recommended Property Values (IUPAC Technical Report). Pure Appl. Chem. 2009, 81, 791-828.

(46)Kaatze, U.; Eggers, F.; Lautscham, K. Ultrasonic Velocity Measurements in Liquids with High Resolution-Techniques, Selected Applications and Perspectives. Meas. Sci. Technol. 2008, 19, 062001-21.

(47)Klieber, C.; Hecksher, T.; Pezeril, T.; Torchinsky, D. H.; Dyre, J. C.; Nelson, K. A. Mechanical Spectra of Glass-Forming Liquids. II. Gigahertz-Frequency Longitudinal and Shear Acoustic Dynamics in Glycerol and DC704 Studied by Time-Domain Brillouin Scattering. J. Chem. Phys. 2013, 138, 12A544-1-12.

(48)Khelladi, H.; Plantier, F; Daridon, J. L. A Phase Comparison Technique for Sound Velocity Measurement in Strongly Dissipative Liquids Under Pressure. J. Acoust. Soc. Am. 2010, $128,672-678$. 
(49)Labhardt, A.; Schwarz, G. A High Resolution and Low Volume Ultrasonic Resonator Methodfor Fast Chemical Relaxation Measurements. Ber. Bunsen. Phys. Chem. 1976, 80, 83-92.

(50) Voleišienè, B.; Voleišis, A. Investigation of Relaxation Process in Aqueous Gadolinium Sulphate Solutions. Ultragarsas 1985, 17, 60-65 (in Russian).

(51) Voleišienè, B.; Voleišis, A. Ultrasound Velocity Measurements in Liquid Media. Ultragarsas 2008, 63, 7-19.

(52)Bauer, H. J. Properties of Gases, Liquids and Solutions, in: Physical Acoustics, Vol. 2a Mason, W. P., Ed.; Academic Press: New York, 1965.

(53)Wald, E.; Kaatze, U. Chain Dynamics of Ethylene Oxide Oligomer Melts. An Ultrasonic Spectroscopy Study. J. Phys. Chem. B 2014, 118, 13300-13311.

(54)Hensel-Bielówka, S.; Wojnarowska, Ż.; Dzida, M.; Zorębski, E.; Zorębski, M.; Geppert-Rybczyńska, M.; Peppel, T.; Grzybowska, K.; Wang, Y.; Sokolov, A. P.; Paluch, M. Heterogeneous Nature of Relaxation Dynamics of Room-Temperature Ionic Liquids $(\mathrm{EMIm})_{2}\left[\mathrm{Co}(\mathrm{NCS})_{4}\right]$ and $(\mathrm{BMIm})_{2}\left[\mathrm{Co}(\mathrm{NCS})_{4}\right]$. J. Phys. Chem. C 2015, 119 (35), 20363-20368.

(55) Mirzaev, S. Z.; Kaatze, U. Critical Concentration Fluctuations in the Ionic Binary Mixture Ethylammonium Nitrate-n-Octanol: An Ultrasonic Spectrometry Study. Phys. Rev. E 2002, 65, 021509.

(56)Eggers, F.; Kaatze, U. Broad-Band Ultrasonic Measurement Techniques for Liquids. Meas. Sci. Technol. 1996, 7, 1-19.

(57)Zorebski, E.; Zorębski, M.; Gepert, M. Ultrasonic Absorption Measurements by Means of a Megahertz-Range Measuring Set. J. Phys. IV 2006, 137, 231-236. 
(58)Cao, Y. N.; Diebold, G. J.; Zimmt, M. B. Transient Grating Studies of Micellar Solutions. Chem. Phys. Lett. 1997, 276, 388-392.

(59)Kaatze, U.; Hushcha, T. O.; Eggers, F. Ultrasonic Broadband Spectrometry of Liquids: A Research Tool in Pure and Applied Chemistry and Chemical Physics. J. Solution Chem. 2000, 29(4), 299-367.

(60)Kaatze, U. Non-Critical Fluctuations in Liquids: Cinderella of Ultrasonic Spectroscopy? Int. J. Thermophys. 2014, 35, 1976-1989.

(61) Cobb, W.N. Finite-Amplitude Method for the Determination of the Acoustic Nonlinearity Parameter B/A. J. Acoust. Soc. Am. 1983, 73(5), 1525-1531.

(62) Kujawska, T.; Nowicki, A.; Lewin, P.A. Determination of Nonlinear Medium Parameter B/A Using Model Assisted Variable-Length Measurement Approach. Ultrasonics 2011, 51, $997-1005$.

(63) Zorebski, E.; Zorębski, M. A Comparative Ultrasonic Relaxation Study of Lower Vicinal and Terminal Alkanediols at $298.15 \mathrm{~K}$ in Relation to Their Molecular Structure and Hydrogen Bonding. J. Phys. Chem. B 2014, 118, 5934-5942.

(64) Litovitz, T. A.; Carnevale, E. H. Effects of Pressure on Ultrasonic Relaxation in Liquids. II. J. Chem. Phys. 1958, 30, 134-136.

(65) Litovitz, T. A.; Carnevale, E. H.; Kendall, P. A. Effects of Pressure on Ultrasonic Relaxation in Liquids. J. Chem. Phys. 1957, 26, 465-468.

(66) Linde, B. B. J.; Esanov, U. M. Pressure Acoustic Spectroscopy of Cyclic Compounds. J. Phys. IV France 2005, 129, 55-59.

(67) Matheson, A. J. Molecular Acoustics; Wiley: New York, 1971. 
(68) Zorębski, E.; Dzida, M. The Effect of Temperature and Pressure on Acoustic and Thermodynamic Properties of 1,4-Butanediol. The Comparison with 1,2- and 1,3-Butanediols. J. Chem. Thermodyn. 2012, 54, 100-107.

(69) Kofu, M.; Nagao, M.; Ueki, T.; Kitazawa, Y.; Nakamura, Y.; Sawamura, S.; Watanabe, M.; Yamamuro, O. Heterogeneous Slow Dynamics of Imidazolium-Based Ionic Liquids Studied by Neutron Spin Echo. J. Phys. Chem. B 2013, 117, 2773-2781.

(70) Yamaguchi, T.; Mikawa, K.; Koda, S.; Fujii, K.; Endo, H.; Shibayama, M.; Hamano, H.; Umebayashi, Y. Relationship Between Mesoscale Dynamics and Shear Relaxation of Ionic Liquids with Long Alkyl Chain. J. Chem. Phys. 2012, 137, 104511.

(71) Weingärtner, H.; Sasisanker, P.; Daguenet,C.; Dyson, P.J.; Krossing, I.; Slattery, J.M.; Schubert, T. The Dielectric Response of Room-Temperature Ionic Liquids: Effect of Cation Variation. J. Phys. Chem. B 2007, 111, 4775-477

(72) Wuensch, B. J.; Hueter, T. F.; Cohen, M. S. Ultrasonic Absorption in Castor Oil: Deviations from Classical Behaviour. J. Acoust. Soc. Am. 1956, 28, 311-312.

(73) Zinovew, O. I.; Tachirbzanow, Kh. Acoustic Spectroscopy - Investigation Method for Hydrogen Bonds. Liquids n-Amids. Akust. Zhur. 1979, 25, 81-86.

(74) Yamaguchi, T.; Miyake, S.; Koda, S. Shear Relaxation of Imidazolium-Based Room-Temperature Ionic Liquids. J. Phys. Chem.B, 2010, 114, 8126-8133.

(75) Pereiro, A. B.; Legido, J. L.; Rodríguez, A. Physical Properties of Ionic Liquids Based on 1-Alkyl-3-methylimidazolium Cation and Hexafluorophosphate as Anion and Temperature Dependence. J. Chem. Thermodyn. 2007, 39, 1168-1175.

(76) Pal, A.; Kumar, B. Densities, Speeds of Sound and 1H NMR Spectroscopic Studies for Binary Mixtures of 1-Hexyl-3-methylimidazolium Based Ionic Liquids with Ethylene 
Glycol Monomethyl Ether at Temperature from T=(288.15-318.15)K. Fluid Phase Equilib. 2012, 334, 157-165.

(77) Deive, F. J.; Rivas, M. A.; Rodríguez, A.Study of Thermodynamic and Transport Properties of Phosphonium-Based Ionic Liquids. J. Chem.Thermodyn. 2013, 62, 98-103.

(78) Álvarez, V. H.; Mattedi, S.; Martin-Pastor, M.; Aznar, M.; Iglesias, M. Synthesis and Thermophysical Properties of Two New Protic Long-Chain Ionic Liquids with the Oleate Anion. Fluid Phase Equilib. 2010, 299, 42-50.

(79) Seoane, R. G.; Corderí, S.; Gómez, E.; Calvar, N.; González, E. J.; Macedo, E. A.; Domínguez, Á. Temperature Dependence and Structural Influence on the Thermophysical Properties of Eleven Commercial Ionic Liquids. Ind. Eng. Chem. Res. 2012, 51, $2492-2504$

(80) Govinda, V.; Attri, P.; Venkatesu, P.; Venkateswarlu, P. Temperature Effect on the Molecular Interactions Between Two Ammonium Ionic Liquids and Dimethylsulfoxide. J. Mol. Liq. 2011, 164, 218-225.

(81) Kavitha, T.; Attri, P.; Venkatesu, P.; Rama Devi, R. S.; Hofman, T. Influence of Temperature on Thermophysical Properties of Ammonium Ionic Liquids with N-Methyl-2-pyrrolidone. Thermochim. Acta 2012, 545, 131-140.

(82) Bahadur, I.; Deenadayalu, N. Apparent Molar Volume and Apparent Molar Isentropic $\begin{array}{llll}\text { Compressibility for } & \text { Binary }\end{array}$ \{Methyltrioctylammoniumbis(trifluoromethylsulfonyl) imide + Ethyl Acetate or Ethanol\} at Different Temperatures Under Atmospheric Pressure. Thermochim. Acta 2013, 566, 7783. 
(83) Govinda, V.; Attri, P.; Venkatesu, P.; Venkateswarlu, P. Evaluation of Thermophysical Properties of Ionic Liquids with Polar Solvent: A Comparable Study of Two Families of Ionic Liquids with Various Ions. J. Phys. Chem. B 2013, 117, 12535-12548.

(84) Gómez, E.; Calvar, N.; Domínguez, Á.; Macedo, E. A. Synthesis and Temperature Dependence of Physical Properties of Four Pyridinium-Based Ionic Liquids: Influence of the Size of the Cation. J. Chem. Thermodyn. 2010, 42, 1324-1329.

(85) González, E. J.; Domínguez, Á.; Macedo, E. A. Physical and Excess Properties of Eight Binary Mixtures Containing Water and Ionic Liquids. J. Chem. Eng. Data 2012, 57, $2165-2176$.

(86) Pereiro, A. B.; Santamarta, F.; Tojo, E.; Rodríguez, A.; Tojo, J. Temperature Dependence of Physical Properties of Ionic Liquid 1,3-Dimethylimidazolium Methyl Sulfate. J. Chem. Eng. Data 2006, 51, 952-954.

(87) Pereiro, A. B.; Rodríguez, A. Study on the Phase Behaviour and Thermodynamic Properties of Ionic Liquids Containing Imidazolium Cation with Ethanol at Several Temperatures. J. Chem. Thermodyn. 2007, 39, 978-989.

(88) Pereiro, A. B.; Rodríguez, A. Thermodynamic Properties of Ionic Liquids in Organic Solvents from (293.15 to 303.15) K. J. Chem. Eng. Data 2007, 52, 600-608.

(89) AlTuwaim, M. S.; Alkhaldi, K. H. A. E.; Al-Jimaz, A. S.; Mohammad, A. A. Temperature Dependence of Physicochemical Properties of Imidazolium-, Pyroldinium-, and Phosphonium-Based Ionic Liquids. J. Chem. Eng. Data 2014, 59, 1955-1963.

(90) Attri, P.; Reddy, P.M.; Venkatesu, P.; Kumar, A.; Hofman, T. Measurements and Molecular Interactions for N, N-Dimethylformamide with Ionic Liquid Mixed Solvents. $J$. Phys. Chem. B 2010, 114, 6126-6133. 
(91) González, B.; Gómez, E.; Domínguez, Á.; Vilas, M.; Tojo, E. Physicochemical Characterization of New Sulfate Ionic Liquids. J. Chem. Eng. Data 2011, 56, 14-20.

(92) Pereiro, A. B.; Veiga, H. I. M.; Esperança, J. M. S. S.; Rodríguez, A. Effect of Temperature on the Physical Properties of Two Ionic Liquids. J. Chem. Thermodyn. 2009, 41, 1419-1423.

(93) González, E. J.; Requejo, P. F.; Domínguez, Á.; Macedo, E. A. Physical Properties of Binary Alcohol + Ionic Liquid Mixtures at Several Temperatures and Atmospheric Pressure. J. Sol. Chem. 2013, 42, 746-763.

(94) González, E. J.; González, B.; Macedo, E. A. Thermophysical Properties of the Pure Ionic Liquid 1-Butyl-1-methylpyrrolidinium Dicyanamide and its Binary Mixtures with Alcohols. J. Chem. Eng. Data 2013, 58, 1440-1448.

(95) Vercher, E.; Miguel, P.J.; Llopis, F.J.; Orchillés, A.V.; Martínez-Andreu, A. Volumetric and Acoustic Properties of Aqueous Solutions of Trifluoromethanesulfonate-Based Ionic Liquids at Several Temperatures. J. Chem. Eng. Data 2012, 57, 1953-1963.

(96) Pal, A.; Kumar, B.; Kang, T. S. Effect of Structural Alteration of Ionic Liquid on Their Bulk and Molecular Level Interactions with Ethylene Glycol. Fluid Phase Equilib. 2013, 358, 241-249.

(97) Bandrés, I.; Meler, S.; Giner, B.; Cea, P.; Lafuente, C. Aggregation Behavior of Pyridinium-Based Ionic Liquids in Aqueous Solution. J. Sol. Chem. 2009, 38, 1622-1634.

(98) Bandrés, I.; Pera, G.; Martín, S.; Castro, M.; Lafuente, C. Thermophysical Study of 1-Butyl-2-methylpyridinium Tetrafluoroborate Ionic Liquid. J. Phys. Chem. B 2009, 113, 11936-11942. 
(99) Verdía, P.; Hernaiz, M.; González, E. J.; Macedo, E. A.; Salgado, J.; Tojo, E. Effect of the Number, Position and Length of Alkyl Chains on the Physical Properties of Polysubstituted Pyridinium Ionic Liquids. J. Chem. Thermodyn. 2014, 69, 19-26.

(100) Araújo, J. M. M.; Pereiro, A. B.; Alves, F.; Marrucho, I. M.; Rebelo, L. P. N. Nucleic Acid Bases in 1-Alkyl-3-methylimidazolium Acetate Ionic Liquids: A Thermophysical and Ionic Conductivity Analysis. J. Chem. Thermodyn. 2013, 57, 1-8.

(101) Teodorescu, M. Isothermal Vapor + Liquid Equilibrium and Thermophysical Properties for 1-Butyl-3-methylimidazolium Bromide + 1-Butanol Binary System. Ind. Eng. Chem. Res. 2014, 53, 13522-13528.

(102) Govinda, V.; Attri, P.; Venkatesu, P.; Venkateswarlu, P. Thermophysical Properties of Dimethylsulfoxide with Ionic Liquids at Various Temperatures. Fluid Phase Equilib. 2011, 304, 35-43.

(103) Kavitha, T.; Vasantha, T.; Venkatesu, P.; Rama Devi, R. S.; Hofman, T. Thermophysical Properties for the Mixed Solvents of N-Methyl-2-pyrrolidone with Some of the Imidazolium-Based Ionic Liquids. J. Mol. Liq. 2014, 198, 11-20.

(104) Calvar, N.; González, E. J.; Domínguez, Á.; Macedo, E. A. Acoustic, Volumetric and Osmotic Properties of Binary Mixtures Containing the Ionic Liquid 1-Butyl-3-methylimidazolium Dicyanamide Mixed with Primary and Secondary Alcohols. J. Chem. Thermodyn. 2012, 50, 19-29.

(105) Zafarani-Moattar, M. T.; Shekaari, H. Volumetric and Compressibility Behaviour of Ionic Liquid, 1-n-Butyl-3-methylimidazolium Hexafluorophosphate and Tetrabutylammonium Hexafluorophosphate in Organic Solvents at T = 298.15 K. J. Chem. Thermodyn. 2006, 38, 624-633. 
(106) Zafarani-Moattar, M. T.; Shekaari, H. Application of Prigogine-Flory-Patterson Theory to Excess Molar Volume and Speed of Sound of 1-n-Butyl-3-methylimidazolium Hexafluorophosphate or 1-n-Butyl-3-methylimidazolium Tetrafluoroborate in Methanol and Acetonitrile. J. Chem. Thermodyn. 2006, 38, 1377-1384.

(107) Zafarani-Moattar, M. T.; Majdan-Cegincara, R. Viscosity, Density, Speed of Sound, and Refractive Index of Binary Mixtures of Organic Solvent + Ionic Liquid, 1-Butyl-3-methylimidazolium Hexafluorophosphate at 298.15 K. J. Chem. Eng. Data 2007, 52, 2359-2364.

(108) Pal, A.; Gaba, R.; Singh, T.; Kumar, A. Excess Thermodynamic Properties of Binary Mixtures of Ionic Liquid (1-Butyl-3-methylimidazolium Hexafluorophosphate) with Alkoxyalkanols at Several Temperatures. J. Mol. Liq. 2010, 154, 41-46.

(109) Pal, A.; Kumar, B. Volumetric, Acoustic and Spectroscopic Studies for Binary Mixtures of Ionic Liquid (1-Butyl-3-methylimidazolium Hexafluorophosphate) with Alkoxyalkanols at T $=(288.15$ to 318.15$)$ K. J. Mol. Liq. 2011, 163, 128-134.

(110) Chaudhary, G. R.; Bansal, S.; Mehta, S. K.; Ahluwalia, A. S. Thermophysical and Spectroscopic Studies of Room Temperature Ionic Liquid, 1-Butyl-3-methylimidazolium Hexafluorophosphate in Tritons. J. Chem. Thermodyn. 2012, 50, 63-70.

(111) Pereiro, A. B.; Verdía, P.; Tojo, E.; Rodríguez, A. Physical Properties of 1-Butyl-3-methylimidazolium Methyl Sulfate as a Function of Temperature. J. Chem. Eng. Data 2007, 52, 377-380.

(112) García-Miaja, G.; Troncoso, J.; Romaní, L. Excess Properties for Binary Systems Ionic Liquid + Ethanol: Experimental Results and Theoretical Description Using the ERAS Model. Fluid Phase Equilib. 2008, 274, 59-67. 
(113) García-Miaja, G.; Troncoso, J.; Romaní, L. Excess Molar Properties for Binary Systems of Alkylimidazolium-Based Ionic Liquids + Nitromethane. Experimental Results and ERAS-Model Calculations. J. Chem. Thermodyn. 2009, 41, 334-341.

(114) Singh, T.; Kumar, A. Temperature Dependence of Physical Properties of Imidazolium Based Ionic Liquids: Internal Pressure and Molar Refraction. J. Sol. Chem. 2009, 38, 10431053.

(115) Singh, S.; Aznar, M.; Deenadayalu, N. Densities, Speeds of Sound, and Refractive Indices for Binary Mixtures of 1-Butyl-3-methylimidazolium Methyl Sulphate Ionic Liquid with Alcohols at $\mathrm{T}=(298.15,303.15,308.15$, and 313.15) K. J. Chem. Thermodyn. 2013, 57, 238-247.

(116) Dávila, M. J.; Aparicio, S.; Alcalde, R.; García, B.; Leal, J. M. On the Properties of 1-Butyl-3-methylimidazolium Octylsulfate Ionic Liquid. Green Chem. 2007, 9, 221-232.

(117) Shekaari, H.; Zafarani-Moattar, M. T. Volumetric Properties of the Ionic Liquid, 1-Butyl-3-methylimidazolium Tetrafluoroborate, in Organic Solvents at T =298.15K. Int. J. Thermophys. 2008, 29, 534-545.

(118) Pal, A.; Kumar, B. Volumetric and Acoustic Properties of Binary Mixtures of the Ionic Liquid 1-Butyl-3-methylimidazolium Tetrafluoroborate $\quad[$ Bmim $][\mathrm{BF} 4]$ with Alkoxyalkanols at Different Temperatures. J. Chem. Eng. Data 2012, 57, 688-695.

(119) Chaudhary, G. R.; Bansal, S.; Mehta, S. K.; Ahluwalia, A. S. Thermophysical and Spectroscopic Studies of Pure 1-Butyl-3-methylimidazolium Tetrafluoroborate and its Aqueous Mixtures. J. Sol. Chem. 2014, 43, 340-359.

(120) Singh, S.; Bahadur, I.; Redhi, G. G.; Ramjugernath, D.; Ebenso, E. E. Density and Speed of Sound Measurements of Imidazolium-Based Ionic Liquids with Acetonitrile at Various Temperatures. J. Mol. Liq. 2014, 200, 160-167. 
(121) González, E. J.; Calvar, N.; Domínguez, Á.; Macedo, E. A. Osmotic and Apparent Molar Properties of Binary Mixtures Alcohol + 1-Butyl-3-methylimidazolium Trifluoromethanesulfonate Ionic Liquid. J. Chem. Thermodyn. 2013, 61, 64-73.

(122) Bandrés, I.; Giner, B.; Gascón, I.; Castro, M.; Lafuente, C. Physicochemical Characterization of n-Butyl-3-methylpyridinium Dicyanamide Ionic Liquid. J. Phys. Chem. B 2008, 112, 12461-12467.

(123) García-Mardones, M.; Barrós, A.; Bandrés, I.; Artigas, H.; Lafuente, C. Thermodynamic Properties of Binary Mixtures Combining Two Pyridinium-Based Ionic Liquids and Two Alkanols. J. Chem. Thermodyn. 2012, 51, 17-24.

(124) Bandrés, I.; Giner, B.; Artigas, H.; Royo, F. M.; Lafuente, C. Thermophysic Comparative Study of Two Isomeric Pyridinium-Based Ionic Liquids. J. Phys. Chem. B 2008, 112, 3077-3084.

(125) García-Mardones, M.; Pérez-Gregorio, V.; Guerrero, H.; Bandrés, I.; Lafuente, C. Thermodynamic Study of Binary Mixtures Containing 1-Butylpyridinium Tetrafluoroborate and Methanol or Ethanol. J. Chem. Thermodyn. 2010, 42, 1500-1505.

(126) Bandrés, I.; Royo, F. M.; Gascón, I.; Castro, M.; Lafuente, C. Anion Influence on Thermophysical Properties of Ionic Liquids: 1-Butylpyridinium Tetrafluoroborate and 1-Butylpyridinium Triflate. J. Phys. Chem. B 2010, 114, 3601-3607.

(127) García-Mardones, M.; Bandrés, I.; López, M. C.; Gascón, I.; Lafuente, C. Experimental and Theoretical Study of Two Pyridinium-Based Ionic Liquids. J. Sol. Chem. 2012, 41, $1836-1852$.

(128) Aparicio, S.; Alcalde, R.; Atilhan, M. Experimental and Computational Study on the Properties of Pure and Water Mixed 1-Ethyl-3-methylimidazolium L-(+)-Lactate Ionic Liquid. J. Phys. Chem. B 2010, 114, 5795-5809. 
(129) Bansal, S.; Kaur, N.; Chaudhary, G. R.; Mehta, S. K.; Ahluwalia, A. S. Physiochemical Properties of New Formulations of 1-Ethyl-3-methylimidazolium Bis(trifluoromethylsulfonyl)imide with Tritons. J. Chem. Eng. Data 2014, 59, 3988-3999.

(130) Gómez, E.; González, B.; Calvar, N.; Tojo, E.; Domínguez, Á. Physical Properties of Pure 1-Ethyl-3-methylimidazolium Ethylsulfate and its Binary Mixtures with Ethanol and Water at Several Temperatures. J. Chem. Eng. Data 2006, 51, 2096-2102.

(131) Arce, A.; Rodil, E.; Soto, A. Volumetric and Viscosity Study for the Mixtures of 2-Ethoxy-2-methylpropane, Ethanol, and 1-Ethyl-3-methylimidazolium Ethyl Sulfate Ionic Liquid. J. Chem. Eng. Data 2006, 51, 1453-1457.

(132) González, E. J.; González, B.; Calvar, N.; Domínguez, Á. Physical Properties of Binary Mixtures of the Ionic Liquid 1-Ethyl-3-methylimidazolium Ethyl Sulfate with Several Alcohols at $\mathrm{T}=(298.15,313.15$, and 328.15) $\mathrm{K}$ and Atmospheric Pressure. J. Chem. Eng. Data 2007, 52, 1641-1648.

(133) Singh, S.; Bahadur, I.; Redhi, G. G.; Ebenso, E. E.; Ramjugernath, D. Density and Speed of Sound of 1-Ethyl-3-methylimidazolium Ethyl Sulphate with Acetic or Propionic Acid at Different Temperatures. J. Mol. Liq. 2014, 199, 518-523.

(134) Requejo, P. F.; González, E. J.; Macedo, E. A.; Domínguez, Á. Effect of the Temperature on the Physical Properties of the Pure Ionic Liquid 1-Ethyl-3-methylimidazolium Methylsulfate and Characterization of its Binary Mixtures with Alcohols. J. Chem. Thermodyn. 2014, 74, 193-200.

(135) Sharma, V. K.; Solanki, S.; Bhagour, S.; Sharma, D. Topological Investigations of Thermodynamic Properties of Ionic Liquid Mixtures: Excess Molar Volumes and Excess Isentropic Compressibilities. J. Mol. Liq. 2013, 188, 258-271. 
(136) Sharma, D.; Bhagour, S.; Sharma, V. K. Thermodynamic and Topological Studies of 1-Ethyl-3-methylimidazolium Tetrafluoroborate $\quad+\quad$ Pyrrolidin-2-one and 1-Methyl-pyrrolidin-2-one Mixtures. J. Chem. Eng. Data 2012, 57, 3488-3497.

(137) Sharma, V. K.; Bhagour, S.; Solanki, S.; Rohilla, A. Thermodynamic Properties of Ternary Mixtures Containing Ionic Liquids and Organic Solvents. J. Chem. Eng. Data 2013, 58, 1939-1954.

(138) Sharma, V. K.; Solanki, S. Topological Investigations of Binary Mixtures Containing 1-Ethyl-3-methylimidazolium Tetrafluoroborate and Anilines. J. Mol. Liq. 2013, 177, $133-144$.

(139) Sharma, V. K.; Bhagour, S.; Sharma, D.; Solanki, S. Thermodynamic Properties of Ternary Mixtures of 1-Ethyl-3-methylimidazolium Tetrafluoroborate with 1-Methyl Pyrrolidin-2-one or Pyrrolidin-2-one + Water. Thermochim. Acta 2013, 563, 72-81.

(140) Solanki, S.; Hooda, N.; Sharma, V. K. Topological Investigations of Binary Mixtures Containing Ionic Liquid 1-Ethyl-3-methylimidazolium Tetrafluoroborate and Pyridine or Isomeric Picolines. J. Chem. Thermodyn. 2013, 56, 123-135.

(141) Bhagour, S.; Solanki, S.; Hooda, N.; Sharma D.; Sharma, V. K. Thermodynamic Properties of Binary Mixtures of the Ionic Liquid [Emim][BF4] with Acetone and Dimethylsulphoxide. J. Chem. Thermodyn. 2013, 60, 76-86.

(142) Sharma, V. K.; Bhagour, S. Molecular Interactions in 1-Ethyl-3-methylimidazolim Tetrafluoroborate + Amide Mixtures: Excess Molar Volumes, Excess Isentropic Compressibilities and Excess Molar Enthalpies. J. Sol. Chem. 2013, 42, 800-822.

(143) Sharma, V. K.; Solanki, S.; Bhagour, S. Thermodynamic Properties of Ternary Mixtures Containing Ionic Liquid and Organic Liquids: Excess Molar Volume and Excess Isentropic Compressibility. J. Chem. Eng. Data 2014, 59, 1140-1157. 
(144) Sharma, V. K.; Solanki, S.; Bhagour, S. Excess Heat Capacities of Binary and Ternary Mixtures Containing 1-Ethyl-3-methylimidazolium Tetrafluoroborate and Anilines. J. Chem. Eng. Data 2014, 59, 1852-1864.

(145) Sharma, V. K.; Bhagour, S.; Solanki, S.; Sheetal; Jangra, S.K. Excess Molar Enthalpies for $[$ Emim $][$ BF4 $]+$ Pyrrolidin-2-one or 1-Methyl-Pyrrolidin-2-one + Pyridine or Water Mixtures. J. Chem. Thermodyn. 2014, 68, 235-243.

(146) Sharma, V. K.; Kataria, J.; Bhagour, S. Thermodynamic Investigations of 1-Ethyl-3-methylimidazolium Tetrafluoroborate and Cycloalkanone Mixtures. J. Therm. Anal. Calorim. 2014, 118, 431-447.

(147) Vercher, E.; Orchillés, A. V.; Miguel, P. J.; Martínez-Andreu, A. Volumetric and Ultrasonic Studies of 1-Ethyl-3-methylimidazolium Trifluoromethanesulfonate Ionic Liquid with Methanol, Ethanol, 1-Propanol, and Water at Several Temperatures. J. Chem. Eng. Data 2007, 52, 1468-1482.

(148) Vercher, E.; Llopis, F. J.; González-Alfaro, M. V.; Martínez-Andreu, A. Density, Speed of Sound, and Refractive Index of 1-Ethyl-3-methylimidazolium Trifluoromethanesulfonate with Acetone, Methyl Acetate, and Ethyl Acetate at Temperatures from (278.15 to 328.15) K. J. Chem. Eng. Data 2010, 55, 1377-1388.

(149) Vercher, E.; Orchillés A.V.; Llopis, F. J.; González-Alfaro, V.; Martínez-Andreu, A. Ultrasonic and Volumetric Properties of 1-Ethyl-3-methylimidazolium Trifluoromethanesulfonate Ionic Liquid with 2-Propanol or Tetrahydrofuran at Several Temperatures. J. Chem. Eng. Data 2011, 56, 4633-4642.

(150) Benito, J.; García-Mardones, M.; Pérez-Gregorio, V.; Gascón, I.; Lafuente, C. Physicochemical Study of $\mathrm{n}$-Ethylpyridinium Bis(trifluoromethylsulfonyl) Imide Ionic Liquid. J. Sol. Chem. 2014, 43, 696-710. 
(151) González, B.; Calvar, N.; Gómez, E.; Domínguez, I.; Domínguez, Á. Synthesis and Physical Properties of 1-Ethylpyridinium Ethylsulfate and its Binary Mixtures with Ethanol and 1-Propanol at Several Temperatures. J. Chem. Eng. Data 2009, 54, 13531358.

(152) González, E. J.; Domínguez, Á.; Macedo, E. A. Excess Properties of Binary Mixtures Containing 1-Hexyl-3-methylimidazolium Bis(trifluoromethylsulfonyl)imide Ionic Liquid and Polar Organic Compounds. J. Chem. Thermodyn. 2012, 47, 300-311.

(153) Sadeghi, R.; Shekaari, H.; Hosseini, R. Effect of Alkyl Chain Length and Temperature on the Thermodynamic Properties of Ionic Liquids 1-Alkyl-3-methylimidazolium Bromide in Aqueous and Non-Aqueous Solutions at Different Temperatures. J. Chem. Thermodyn. 2009, 41, 273-289.

(154) Pereiro, A. B.; Rodríguez, A. Phase Equilibria of the Azeotropic Mixture Hexane + Ethyl Acetate with Ionic Liquids at 298.15 K. J. Chem. Eng. Data 2008, 53, 1360-1366.

(155) Malek, N. I.; Singh, A.; Surati, R.; Ijardar, S. P. Study on Thermo Physical and Excess Molar Properties of Binary Systems of Ionic Liquids. I: $\left[\mathrm{C}_{n} \mathrm{mim}\right]\left[\mathrm{PF}_{6}\right](n=6,8)$ and Alkyl Acetates. J. Chem. Thermodyn. 2014, 74, 103-118.

(156) Malek, N. I.; Ijardar, S. P.; Oswal, S. B. Excess Molar Properties for Binary Systems of CnMIM-BF 4 Ionic Liquids with Alkylamines in the Temperature Range (298.15 to 318.15) K. Experimental Results and Theoretical Model Calculations. J. Chem. Eng. Data 2014, 59, 540-553.

(157) Ijardar, S. P.; Malek, N. I. Experimental and Theoretical Excess Molar Properties of Imidazolium Based Ionic Liquids with Molecular Organic Solvents - I. 1-Hexyl-3-methylimidazlouim Tetraflouroborate and 1-Octyl-3-methylimidazlouim Tetraflouroborate with Cyclic Ethers. J. Chem. Thermodyn. 2014, 71, 236-248. 
(158) González, E.J.; Calvar, N.; Macedo, E. A. Osmotic Coefficients and Apparent Molar Volumes of 1-Hexyl-3-methylimidazolium trifluoromethanesulfonate Ionic Liquid in Alcohols. J. Chem. Thermodyn. 2014, 69, 93-100.

(159) González, B.; González, E. J. Physical Properties of the Pure 1-Methyl-1-propylpyrrolidinium bis(trifluoromethylsulfonyl)imide Ionic Liquid and its Binary Mixtures with Alcohols. J. Chem. Thermodyn. 2014, 68, 109-116.

(160) González, E. J.; Alonso, L.; Domínguez, Á. Physical Properties of Binary Mixtures of the Ionic Liquid 1-Methyl-3-octylimidazolium Chloride with Methanol, Ethanol, and 1-Propanol at $\mathrm{T}=(298.15,313.15$, and 328.15) $\mathrm{K}$ and at $\mathrm{P}=0.1 \mathrm{MPa}$. J. Chem. Eng. Data 2006, 51, 1446-1452.

(161) Calvar, N.; Gómez, E.; González, B.; Domínguez, Á. Experimental Determination, Correlation, and Prediction of Physical Properties of the Ternary Mixtures Ethanol + Water with 1-Octyl-3-methylimidazolium Chloride and 1-Ethyl-3-methylimidazolium Ethylsulfate J. Chem. Eng. Data 2007, 52, 2529-2535.

(162) Pereiro, A. B.; Rodríguez, A. Binary Mixtures Containing OMIM PF6: Density, Speed of Sound, Refractive Index and LLE with Hexane, Heptane and 2-Propanol at Several Temperatures. Phys. Chem. Liq. 2008, 46 (2), 172-184.

(163) Pereiro, A. B.; Rodríguez, A. Measurement and Correlation of (Liquid + Liquid) Equilibrium of the Azeotrope (Cyclohexane + 2-Butanone) with Different Ionic Liquids at T = 298.15 K. J. Chem. Thermodyn. 2008, 40, 1282-1289.

(164) Arce, A.; Rodil, E.; Soto, A. Physical and Excess Properties for Binary Mixtures of 1-Methyl-3-octylimidazolium Tetrafluoroborate, [Omim][BF4], Ionic Liquid with Different Alcohols. J. Sol. Chem. 2006, 35, 63-78. 
(165) Bandrés, I.; Giner, B.; Artigas, H.; Lafuente, C.; Royo, F. M. Thermophysical Properties of N-Octyl-3-methylpyridinium Tetrafluoroborate. J. Chem. Eng. Data 2009, 54, 236240.

(166) Bandrés, I.; López, M. C.; Castro, M.; Barberá, J.; Lafuente, C. Thermophysical Properties of 1-Propylpyridinium Tetrafluoroborate. J. Chem. Thermodyn. 2012, 44, 148153.

(167) García-Mardones, M.; Martín, S.; Gascón, I.; Lafuente C. Thermophysical Properties of the Binary Mixture 1-Propylpyridinium Tetrafluoroborate with Methanol. J. Chem. Eng. Data 2014, 59, 1564-1573.

(168) Gómez, E.; Calvar, N.; Macedo, E. A.; Domínguez, Á. Effect of the Temperature on the Physical Properties of $\quad$ Pure Propyl-3-methylimidazolium Bis(trifluoromethylsulfonyl)imide and Characterization of its Binary Mixtures with Alcohols. J. Chem. Thermodyn. 2012, 45, 9-15.

(169) Sadeghi, R.; Shekaari, H.; Hosseini, R. Volumetric and Isentropic Compressibility Behavior of Ionic Liquid, 1-Propyl-3-methylimidazolium Bromide in Acetonitrile, Dimethylformamide, and Dimethylsulfoxide at $\mathrm{T}=(288.15$ to 308.15$) \mathrm{K}$. Int. J. Thermophys. 2009, 30, 1491-1509.

(170) Cota, I.; Gonzalez-Olmos, R.; Iglesias, M.; Medina, F. New Short Aliphatic Chain Ionic Liquids: Synthesis, Physical Properties, and Catalytic Activity in Aldol Condensations. The J. Phys. Chem. B 2007, 111, 12468-12477.

(171) Iglesias, M; Gonzalez-Olmos, R.; Cota, I.; Medina F. Brønsted Ionic Liquids: Study of Physico-Chemical Properties and Catalytic Activity in Aldol Condensations. Chem. Eng. J. 2010, 162, 802-808. 
(172) Álvarez, V. H.; Mattedi, S.; Martin-Pastor, M.; Aznar, M.; Iglesias, M. Thermophysical Properties of Binary Mixtures of \{Ionic Liquid 2-Hydroxy Ethylammonium Acetate + (Water, Methanol, or Ethanol)\}. J. Chem. Thermodyn. 2011, 43, 997-1010.

(173) Iglesias, M.; Torres, A.; Gonzalez-Olmos, R.; Salvatierra, D. Effect of Temperature on Mixing Thermodynamics of a New Ionic Liquid: $\{2-$ Hydroxy Ethylammonium Formate (2-HEAF) + Short Hydroxylic Solvents \}. J. Chem. Thermodyn. 2008, 40, 119-133.

(174) Aparicio, $\quad$ S.; Atilhan, M.; Khraisheh, M.; Alcalde, R. Study on Hydroxylammonium-Based Ionic Liquids. I. Characterization. J. Phys. Chem. B 2011, 115, 12473-12486.

(175) Chaudhary, G. R.; Bansal, S.; Mehta, S. K.; Ahluwalia, A. S. Structural and Interactional Behaviour of Aqueous Mixture of Room Temperature Ionic Liquid; 2-Hydroxyethyl-trimethylammonium 1-Lactate. J. Chem. Thermodyn. 2014, 76, 134-144.

(176) Chhotaray, P. K.; Gardas, R. L. Thermophysical Properties of Ammonium and Hydroxylammonium Protic Ionic Liquids. J. Chem. Thermodyn. 2014, 72, 117-124.

(177) Chhotaray, P. K.; Jella, S.; Gardas, R. L. Physicochemical Properties of Low Viscous Lactam Based Ionic Liquids. J. Chem. Thermodyn. 2014, 74, 255-262.

(178) Umapathi, R.; Attri, P.; Venkatesu, P. Thermophysical Properties of Aqueous Solution of Ammonium-Based Ionic Liquids. J. Phys. Chem. B 2014, 118, 5971-5982.

(179) Trivedi, T. J.; Bharmoria, P.; Singh, T.; Kumar, A. Temperature Dependence of Physical Properties of Amino Acid Ionic Liquid Surfactants. J. Chem. Eng. Data 2012, 57, 317-323.

(180) Bahadur, I.; Deenadayalu, N. Apparent Molar Volume and Isentropic Compressibility for the Binary Systems \{Methyltrioctylammonium Bis(trifluoromethylsulfonyl)imide + Methyl Acetate or Methanol $\}$ and (Methanol + Methyl Acetate) at T=298.15, 303.15, 308.15 and 313.15 K and Atmospheric Pressure. J. Sol. Chem. 2011, 40, 1528-1543. 
(181) Mahrova, M.; Vilas, M.; Domínguez, Á.; Gómez, E.; Calvar, N.; Tojo, E.

Physicochemical Characterization of New Sulfonate and Sulfate Ammonium Ionic Liquids.

J. Chem. Eng. Data 2012, 57, 241-248.

(182) Álvarez, V. H.; Dosil, N.; Gonzalez-Cabaleiro, R.; Mattedi, S.; Martin-Pastor, M.; Iglesias, M.; Navaza, J. M. Brønsted Ionic Liquids for Sustainable Processes: Synthesis and Physical Properties. J. Chem. Eng. Data 2010, 55, 625-632.

(183) Reddy, P.; Siddiqi, M. A.; Atakan, B.; Diedenhofen, M.; Ramjugernath, D. Activity Coefficients at Infinite Dilution of Organic Solutes in the Ionic Liquid PEG-5 Cocomonium Methylsulfate at $\mathrm{T}=(313.15,323.15,333.15$, and 343.15) K: Experimental Results and COSMO-RS Predictions. J. Chem. Thermodyn. 2013, 58, 322-329.

(184) Pereiro, A. B.; Rodríguez, A. Application of the Ionic Liquid Ammoeng 102 for Aromatic/Aliphatic Hydrocarbon Separation. J. Chem. Thermodyn. 2009, 41, 951-956.

(185) Kavitha, T.; Attri, P.; Venkatesu, P.; Rama Devi, R. S.; Hofman, T. Influence of Alkyl Chain Length and Temperature on Thermophysical Properties of Ammonium-Based Ionic Liquids with Molecular Solvent. J. Phys. Chem. B 2012, 116, 4561-4574.

(186) Attri, P.; Baik, K.Y.; Venkatesu, P.; Kim, I. T.; Choi, E. H. Influence of Hydroxyl Group Position and Temperature on Thermophysical Properties of Tetraalkylammonium Hydroxide Ionic Liquids with Alcohols. PLoS ONE 2014, 9, e86530.

(187) Attri, P.; Venkatesu, P.; Kumar, A. Temperature Effect on the Molecular Interactions Between Ammonium Ionic Liquids and N, N-Dimethylformamide. J. Phys. Chem. B 2010, 114, 13415-13425.

(188) Govinda, V.; Reddy, P. M.; Attri, P.; Venkatesu, P.; Venkateswarlu, P. Effect of Anion Variation on the Thermophysical Properties of Triethylammonium Based Protic Ionic Liquids with Polar Solvent. Thermochim. Acta 2013, 556, 75-88. 
(189) Attri, P.; Venkatesu, P.; Hofman, T. Temperature Dependence Measurements and Structural Characterization of Trimethyl Ammonium Ionic Liquids with a Highly Polar Solvent. J. Phys. Chem. B 2011, 115, 10086-10097.

(190) Govinda, V.; Reddy, P. M.; Attri, P.; Venkatesu, P.; Venkateswarlu, P. Influence of Anion on Thermophysical Properties of Ionic Liquids with Polar Solvent. J. Chem. Thermodyn. 2013, 58, 269-278.

(191) Mjalli, F. S.; Jabbar, N. M. A. Acoustic Investigation of Choline Chloride Based Ionic Liquids Analogs. Fluid Phase Equilib. 2014, 381, 71-76.

(192) Shah, D.; Mjalli, F.S. Effect of Water on the Thermo-Physical Properties of Reline: An Experimental and Molecular Simulation Based Approach. Phys. Chem. Chem. Phys. 2014, 16, 23900-23907.

(193) Singh, M. P.; Singh, R. K. Correlation Between Ultrasonic Velocity, Surface Tension, Density and Viscosity of Ionic Liquids. Fluid Phase Equilib. 2011, 304, 1-6.

(194) Domańska, U.; Skiba, K.; Zawadzki, M.; Paduszyński, K.; Królikowski M. Synthesis, Physical, and Thermodynamic Properties of 1-Alkyl-cyanopyridinium Bis $\{$ (trifluoromethyl)sulfonyl $\}$ imide Ionic Liquids. J. Chem. Thermodyn. 2013, 56, 153161.

(195) Zawadzki, M.; Niedzicki, L.; Wieczorek, W.; Domańska, U. Estimation of Extraction Properties of New Imidazolide Anion Based Ionic Liquids on the Basis of Activity Coefficient at Infinite Dilution Measurements. Sep. Purif. Technol. 2013, 118, 242-254.

(196) Safarov, J.; Geppert-Rybczyńska, M.; Kul, I.; Hassel, E. Thermophysical Properties of 1-Butyl-3-methylimidazolium Acetate Over a Wide Range of Temperatures and Pressures. Fluid Phase Equilib. 2014, 383, 144-155. 
(197) Wei, Y.; Jin, Y.; Wu, Z.-J.; Yang, Y.; Zhang, Q.-G.; Kang, Z.-H. Synthesis and Physicochemical Properties of Amino Acid Ionic Liquid 1-Butyl-3-methylimidazolium Aspartate and Binary Mixture with Methanol. J. Chem. Eng. Data 2013, 58, 349-356.

(198) Polishuk, I. Implementation of Perturbed-Chain Statistical Associating Fluid Theory (PC-SAFT), Generalized (G) SAFT+Cubic, and Cubic-Plus-Association (CPA) for Modeling Thermophysical Properties of Selected 1-Alkyl-3-methylimidazolium Ionic Liquids in a Wide Pressure Range. J. Phys. Chem. A 2013, 117, 2223 -2232.

(199) Maghari, A.; ZiaMajidi, F., Pashaei, E. Thermophysical Properties of Alkyl-Imidazolium Based Ionic Liquids Through the Heterosegmented SAFT-BACK Equation of State. J. Mol. Liq. 2014, 191, 59-67.

(200) Maghari, A.; ZiaMajidi, F. Prediction of Thermodynamic Properties of Pure Ionic Liquids Through Extended SAFT-BACK Equation of State. Fluid Phase Equilib. 2013, 356, 109116.

(201) Domańska, U.; Królikowska, M. Effect of Temperature and Composition on the Surface Tension and Thermodynamic Properties of Binary Mixtures of 1-Butyl-3-methylimidazolium Thiocyanate with Alcohols. J. Colloid Interf. Sci. 2010, 348, 661-667.

(202) Liu, Q.-S.; Yang, M.; Yan, P.-F.; Liu, X.-M.; Tan, Z.-C.; Welz-Biermann, U. Density and Surface Tension of Ionic Liquids [Cnpy][NTf2] (n ) 2, 4, 5). J. Chem. Eng. Data 2010, 55, 4928-4930.

(203) Zaitsau, . H.; Yermalayeu, A. V.; Emel'yanenko, V. N.; Verevkin, S. P.; Welz-Biermann, U.; Schubert, T. Structure-Property Relationships in ILs: A study of the Alkyl Chain Length Dependence in Vaporisation Enthalpies of Pyridinium Based Ionic Liquids. Sci. China Chem. 2012, 55, 1525-1531. 
(204) Schmidt, H.; Stephan, M.; Safarov, J.; Kul, I.; Nocke, J.; Abdulagatov, I. M.; Hassel, E.

Experimental Study of the Density and Viscosity of 1-Ethyl-3-methylimidazolium Ethyl Sulfate. J. Chem. Thermodyn. 2012, 47, 68-75.

(205) Golzar, K.; Amjad-Iranagh, S.; Modarress, H. Prediction of Thermophysical Properties for Binary Mixtures of Common Ionic Liquids with Water or Alcohol at Several Temperatures and Atmospheric Pressure by Means of Artificial Neural Network. Ind. Eng. Chem. Res. 2014, 53, 7247-7262.

(206) Domańska, U.; Królikowska, M.; Walczak, K. Effect of Temperature and Composition on the Density, Viscosity Surface Tension and Excess Quantities of Binary Mixtures of 1-Ethyl-3-methylimidazolium Tricyanomethanide with Thiophene. Colloids Surf. A 2013, 436, 504-511.

(207) Safarov, J.; Hamidova, R.; Zepik, S.; Schmidt, H.; Kul, I.; Shahverdiyev, A.; Hassel, E. Thermophysical Properties of 1-Hexyl-3-methylimidazolium Bis(trifluoromethylsulfonyl)imide at High Temperatures and Pressures. J. Mol. Liq. 2013, $187,137-156$.

(208) Ribeiro, M. C. C. High-Frequency Acoustic Modes in an Ionic Liquid. J. Chem. Phys. 2013, 139, 114505.

(209) Liu, Q.-S.; Yang, M.; Li, P.-P.; Sun, S.-S.; Welz-Biermann, U.; Tan, Z.-C.; Zhang, Q.-G. Physicochemical Properties of Ionic Liquids $\left[\mathrm{C}_{3} \mathrm{py}\right]\left[\mathrm{NTf}_{2}\right]$ and $\left[\mathrm{C}_{6} \mathrm{py}\right]\left[\mathrm{NTf}_{2}\right] . J$. Chem. Eng. Data 2011, 56, 4094-4101.

(210) Domańska, U.; Zawadzki, M.; Lewandrowska, A. Effect of Temperature and Composition on the Density, Viscosity, Surface Tension, and Thermodynamic Properties of Binary Mixtures of N-Octylisoquinolinium Bis $\{$ (trifluoromethyl)sulfonyl $\}$ imide with Alcohols. $J$. Chem. Thermodyn. 2012, 48, 101-111. 
(211) Gardas, R. L.; Coutinho, J. A. P. Estimation of Speed of Sound of Ionic Liquids Using Surface Tensions and Densities: A Volume Based Approach. Fluid Phase Equilib. 2008, 267, 188-192.

(212) Sattari, M.; Gharagheizi, F.; Ilani-Kashkouli, P.; Mohammadi, A. H.; Ramjugernath, D. A chemical Structure Based Model for the Determination of Speed of Sound in Ionic Liquids. J. Mol. Liq. 2014, 196, 7-13.

(213) Sattari, M.; Gharagheizi, F.; Ilani-Kashkouli, P.; Mohammadi, A. H.; Ramjugernath, D. Determination of the Speed of Sound in Ionic Liquids Using a Least Squares Support Vector Machine Group Contribution Method. Fluid Phase Equilib. 2014, 367, 188-193.

(214) Dzida, M.; Skowronek, J.; Jężak, S.; Chorążewski, M.; Żarska, M.; Zorębski, M.; Zorębski, E.; Jaquemin, J.; Goodrich, P.; 1-Ethyl-3-methylimidazolium Bis[(trifluoromethyl)sulfonyl]imide as a Reference Ionic Liquid for Speed of Sound Measurements Under High Pressure. A More Formal Approach Based on Occuring Relaxation. J. Chem. Eng. Data 2016 (submitted)

(215) Nieto de Castro, C. A. Thermophysical Properties of Ionic Liquids: Do we Know How to Measure them Accurately? J. Mol. Liq. 2010, 156, 10-17.

(216) Ribeiro, M. C. C. Intermolecular Vibrations and Fast Relaxations in Supercooled Ionic Liquids. J. Chem. Phys. 2011, 134, 244507.

(217) Gómez, E.; González, B.; Domínguez, A.; Tojo, E.; Tojo, J. Dynamic Viscosities of a Series of 1-Alkyl-3-methylimidazolium Chloride Ionic Liquids and Their Binary Mixtures with Water at Several Temperatures. J. Chem. Eng. Data 2006, 51, 696-701.

(218) Hamidova, R.; Kul, I.; Safarov, J.; Shahverdiyev, A.; Hassel, E. Thermophysical Properties of 1-Butyl-3-methylimidazolium Bis(trifluoromethylsulfonyl)imide at High Temperatures and Pressures. Braz. J. Chem. Eng. 2015, 32, 303-316. 
(219) Sun, T.; Biswas, S. N.; Trappeniers, N. J.; Ten Seldam, C. A. Acoustic and Thermodynamic Properties of Methanol from 273 to $333 \mathrm{~K}$ and at Pressures to $280 \mathrm{MPa}$. $J$. Chem. Eng. Data 1988, 33, 395-398.

(220) Dzida, M. Speeds of Sound, Densities, Isobaric Thermal Expansion, Compressibilities and Internal Pressures of Heptan-1-ol, Octan-1-ol, Nonan-1-ol and Decan-1-ol at Temperatures from (293 to 318) K and Pressures up to 100 MPa. J. Chem. Eng. Data 2007, $52,521-531$

(221) Zorębski, E.; Zorębski, M.; Dzida, M. Acoustic Nonlinearity Parameter B/A, Internal Pressure, and Acoustic Impedance Determined at Pressures up to $100 \mathrm{MPa}$ for 1-Ethyl-3-methylimidazolium Bis[(trifluoromethyl)sulfonyl] Imide. Arch. Acoust. 2016, 41, 59-66.

(222) Seddon, K. R.; Stark, A.; Torres, M.-J. Influence of Chloride, Water, and Organic Solvents on the Physical Properties of Ionic Liquids. Pure Appl. Chem. 2000, 72, 22752287.

(223) Ionic Liquids in Synthesis; Wasserscheid, P., Welton, T., Eds.; Wiley: Weinheim, 2008. (224) Ionic Liquids in Synthesis; Kirchner, B., Ed.; Springer-Verlag: Berlin, Heidelberg, 2009. (225) Skowronek, J.; Geppert-Rybczyńska, M.; Jacquemin, J.; Goodrich, P.; Alvarez Vicente, J.; Chorążewski, M.; Jężak, S.; Zorębski, M.; Zorębski, E.; Żarska, M.; Kaca, W.; Berdyczko, P.; Dzida, M. Acoustic and Volumetric Properties of Diluted Solutions of Water in Ionic Liquids. J. Sol. Chem. 2015, 44, 824-837.

(226) Del Grosso, V. A.; Mader, C. W. Speed of Sound in Pure Water. J. Acoust. Soc. Am. 1972, 52, 1442-1446.

(227) Hayes, R.; Warr, G. G.; Atkin, R. Structure and Nanostructure Ionic Liquids. Chem. Rev. 2015, 115, 6357-6426. 
(228) Gutel, T.; Santini, C. C.; Philippot, K.; Padua, A.; Pelzer, K.; Chaudret, B.; Chauvin, Y.; Basset, Y.-M. Organized 3D-alkyl Imidazolium Ionic Liquids Could be Used to Control the Size of in situ Generated Ruthenium Nanoparticles? J. Mater. Chem. 2009, 19, 3624-3631.

(229) Canongia Lopes, J. N. A.; Pádua, A. A. H. Nanostructural Organization in Ionic Liquids.

J. Phys. Chem. B 2006, 110, 3330-3335.

(230) Johansson, P.; Gejji, S. P.; Tegensfeldt, J.; Lindgren, J. The Imide Ion: Potential Energy Surface and Geometries. Electrochim. Acta 1998, 43, 1375-1379.

(231) Fuji, K.; Fujimori, T.; Takamuku, T.; Kanzaki, R.; Umebayashi, Y.; Ishigaro, S. Conformational Equilibrium of Bis[(trifluoromethane)sulfonyl]imide Anion of a RoomTemperature Ionic Liquid: Raman Spectroscopic Study and DFT Calculations. J. Phys. Chem. B 2006, 110, 8179-8183.

(232) Ramya, K. R.; Kumar, P.; Venkatnathan, A. Molecular Simulations of Anion and Temperature Dependence on Structure and Dynamics of 1-Hexyl-3-methylimidazolium Ionic Liquids. J. Phys. Chem. B 2015, 119, 14800-14806.

(233) Gálan Sánchez, L.; Ribé Espel, J.; Onink, F.; Wytze Meindersma, G.; de Haan A. B. Density, Viscosity, and Surface Tension of Synthesis Grade Imidazolium, Pyridinium, and Pyrrolidinium Based Room Temperature Ionic Liquids. J. Chem. Eng. Data 2009, 54, 2803-2812.

(234) Chen, S.; Zhang, S.; Liu, X.; Wang, J.; Wang, J.; Dong, K.; Sun, J.; Xu, B. Ionic Liquid Clusters: Structure, Formation Mechanism, and Effect on the Behavior of Ionic Liquids. Phys. Chem. Chem. Phys. 2014, 16, 5893-5906.

(235) Narayana, K. L.; Swamy, K. M. Temperature Variation of Ultrasonic Velocity in Some Low Velocity Fluorocarbon Liquids. Acoust. Lett. 1986, 9, 137-143. 
(236) Cusco, L.; Trusler, J. P. M. Identification of Environmentally Acceptable Low-Sound Speed Liquids. Int. J. Thermophys. 1995, 16(3), 675-685.

(237) Marsh, J. N.; Hall, C. S.; Wickline, S. A.; Lanza, G. M. Temperature Dependence of Acoustic Impedance for Specific Fluorocarbon Liquids. J. Acoust. Soc. Am., 2002, 112 (6), 2858-2862.

(238) Zorębski, E.; Zorębski, M.; Nurek, J. Densities, Speed of Ultrasound, Ultrasonic Absorption and Viscosities of 1-Butanol+1,3-Butanediol System at 298.15 K. Z. Phys.Chem. 2002, 216, 895-904.

(239) Aminabhavi, T. M.; Patil, V. B. Density, Viscosity, Refractive Index, and Speed of Sound in Binary Mixtures of Ethenylbenzene with N,N-Dimethylacetamide, Tetrahydrofuran, N,N-Dimethylformamide, 1,4-Dioxane, Dimethyl Sulfoxide, Chloroform, Bromoform, and 1-Chloronaphthalene in the Temperature Interval (298.15-308.15) K. J. Chem. Eng. Data 1998, 43, 497-503.

(240) Nath, J. Speeds of Sound in and Isentropic Compressibilities of ( $n-$ Butanol $+n-$ Pentane) at $T=298.15 \mathrm{~K}$, and (n-Butanol $+\mathrm{n}$-Hexane, or $\mathrm{n}$-Heptane, or $\mathrm{n}$-Octane, or 2,2,4-Trimethylpentane) at T=303.15 K. J. Chem. Thermodyn. 1998, 30, 885-895.

(241) Zorębski, E.; Deć, E. Speeds od Sound and Isentropic Compressibilities for Binary Mixtures of 1,2-Ethanediol with 1-Butanol, 1-Hexanol, or 1-Octanol in the Temperature Range from 293.15 to 313.15 K. J. Mol. Liq. 2012, 168, 61-68.

(242) Parthasarathy, S. Sound Velocity and Chemical Constitution. Curent Sci. 1938, 7, $322-323$.

(243) Parthasarathy, S.; Bakhshi, N. N. Relation Between Velocity of Sound and Viscosity in Liquids. P. Phys. Soc. Lond. B 1953, 66, 368-370. 
(244) Parthasarathy, S.; Bakhshi, N. N. Velocity of Sound in Liquids and Molecular Weight. J.

Phys. Chem. 1953, 57, 453-454.

(245) Rao, R. M. A Relation Between Velocity of Sounds in Liquids and Molecular Volume. Indian J. Physics, 1940, 23, 109-116.

(246) Janz, G. J. Molten Salts Handbook, Academic Press: New York, London, 1967.

(247) Crocker, M. J. Handbook of Acoustics, John Wiley \& Sons: New York, 1998.

(248) Tardajos, G.; Diaz Pena, M.; Aicart, E. Speed of Sound in Pure Liquids by a Pulse-Echo-Overlap Method. J. Chem. Thermodyn. 1986, 18, 683-689.

(249) Dymond, J. H.; Oye, H. A. Viscosity of Selected Liquid n-Alkanes. J. Phys. Chem. Ref. Data 1994, 23, 41-53.

(250) Matos, J. S.; Trenzado, J. L.; Santana, S. Viscometric Study of (an Aliphatic Methyl Ester

+ Heptane or Nonane) at the Temperature 298.15 K. J. Chem. Eng. Data 1996, 41, 825-830.

(251) Wu, J.; Nhaesi, A. H.; Asfour, A.-F. A. Viscosities of Eight Binary Liquid n-Alkane Systems at 293.15 K and 298.15 K. J. Chem. Eng. Data 1999, 44, 990-993.

(252) Fermeglia, M.; Torriano, G. Density, Viscosity, and Refractive Index for Binary Systems of n-C16 and Four Nonlinear Alkanes at 298.15 K. J. Chem. Eng. Data 1999, 44, 965-969.

(253) Mehta, S. K.; Chauhan, R. K. Ultrasonic Velocity and Apparent Isentropic Compressibilities in Mixtures of Nonelectrolytes. J. Sol. Chem. 1977, 26, 295-308.

(254) Aminabhavi, T. M.; Aralaguppi, M. I.; Harogoppad, S. B.; Balundgi, R. H. Densities, Viscosities, Refractive Indices and Speeds of Sound for Methyl Acetoacetate + Aliphatic Alcohols (C1-C8). J. Chem. Eng. Data 1993, 38, 31-39.

(255) Shan, Z.; Asfour, A.-F. A. Viscosities and Densities of Nine Binary 1-Alkanol Systems at 293.15 K and 298.15 K. J. Chem. Eng. Data 1999, 44, 118-123. 
(256) Żarska, M.; Bartoszek, K.; Dzida, M. High Pressure Physicochemical Properties of Biodiesel Components Derived from Coconut Oil or Babassu Oil. Fuel 2014, 125, 144 151.

(257) Pratas, M. J; Freitas, S.; Oliveira, M. B.; Monteiro, S. C.; Lima, A. S.; Coutinho, J. A. P. Densities and Viscosities of Fatty Acid Methyl and Ethyl Esters. J. Chem. Eng. Data 2010, 55, 3983-90.

(258) Dzida, M.; Jężak, S.; Sumara, J.; Żarska, M.; Góralski, P. High Pressure Physicochemical Properties of Biodiesel Components Used for Spray Characteristics in Diesel Injection Systems. Fuel 2013, 111, 165-171.

(259) Dzida, M.; Jężak, S.; Sumara, J.; Żarska, M.; Góralski, P. High Pressure Physicochemical Properties of Ethyl Caprylate and Ethyl Caprate. J. Chem. Eng. Data 2013, 58, 1955-1962. (260) Zorębski, E.; Lubowiecka-Kostka, B. Thermodynamic and Transport Properties of (1,2-Ethanediol + 1-Nonanol) at Temperatures from (298.15 to 313.15) K. J. Chem. Thermodyn. 2009, 41, 197-204.

(261)Zorębski, E.; Dzida, M.; Piotrowska, M. Study of the Acoustic and Thermodynamic Properties of 1,2- and 1,3-Propanediol by Means of High-Pressure Speed of Sound Measurements at Temperatures from (293 to 318) K and Pressures up to $101 \mathrm{MPa}$. J. Chem. Eng. Data 2008, 53, 136-144.

(262) George, J.; Sastry, N. V. Densities, Dynamic Viscosities, Speeds of Sound, and Relative Permittivities for Water + Alkanediols (Propane-1,2- and -1,3-diol and Butane-1,2-, -1,3-, -1,4-, and -2,3-Diol) at Different Temperatures. J. Chem. Eng. Data 2003, 48, $1529-1539$. 
(263) Zorębski, E.; Geppert-Rybczyńska, M. Thermodynamic and Transport Properties of (1-Butanol + 1,4-Butanediol) at Temperatures from (298.15 to 318.15) K. J. Chem. Thermodyn. 2010, 42, 409-418.

(264) Zorębski, E.; Żak, A. Acoustic and Volumetric Investigations of 1,5-Pentanediol Plus Glycerol at $298.15 \mathrm{~K}$; Comparison with Recalculated Data for: 1,3-Butanediol Plus Glycerol and 2-Methyl-2,4-pentanediol Plus Glycerol. Z. Phys. Chem. 1999, 210, 223-233.

(265) Marks, G. W. Acoustic Velocity with Relation to Chemical Constitution in Alcohols. J. Acoust. Soc. Am. 1967, 41, 103-107.

(266) Zorębski, E.; Dzida, M. Study of the Acoustic and Thermodynamic Properties of 1,2- and 1,3-Butanediol by Means of High-Pressure Speed of Sound Measurements at Temperatures from (293 to 318) K and Pressures up to 101 MPa. J. Chem. Eng. Data 2007, $52,1010-1017$.

(267) Tokuda, H.; Tsuzuki, S.; Susan, M. A. B. H.; Hayamizu, K.; Watanabe, M. How Ionic are Room-Temperature Ionic Liquids? An Indicator of the Physicochemical Properties. J. Phys. Chem. B 2006, 110, 19593-19600.

(268) McHale, G.; Hardacre, C.; Ge, R.; Doy, N.; Allen, R. W. K.; MacInnes, J. M.; Bown, M. R.; Newton, M. Density-Viscosity Product of Small-Volume Ionic Liquid Samples Using Quartz Crystal Impedance Analysis. Anal. Chem. 2008, 80, 5806-5811.

(269) Andreatta, A.; Arce, A.; Rodil, E.; Soto, A. Physical and Excess Properties of (Methyl Acetate + Methanol $+1-$ Octyl-3-methylimidazolium Bis(trifluoromethylsulfonyl)imide) and its Binary Mixtures at T=298.15 K and Atmospheric Pressure. J. Chem. Thermodyn. 2009, 41, 1317-1323. 
(270) Abbo, A. P.; McKenzie, K. J. Application of Ionic Liquids to the Electrodeposition of Metals. Phys. Chem. Chem. Phys. 2006, 8, 4265-4279.

(271) Vercher, E.; Llopis, F. J.; González-Alfaro, V.; Miguel, P. J.; Orchillés, V.; Martínez-Andreu, A. Volumetric Properties, Viscosities and Refractive Indices of Binary Liquid Mixtures of Tetrafluoroborate-Based Ionic Liquids with Methanol at Several Temperatures. J. Chem. Thermodyn. 2015, 90, 174-184.

(272) Sanmamed, Y. A.; Gonzalez-Salgado, D.; Troncoso, J.; Cerdeirina, C. A.; Roman, L. Viscosity-Induced Errors in the Density Determination of Room Temperature Ionic Liquids Using Vibrating Tube Densitometry. Fliuid Phase Equilib. 2007, 252, 96-102.

(273) Kermanpour, F.; Niakan, H. Z. Measurement and Modeling the Excess Molar Properties of Binary Mixtures of $\{[\mathrm{C} 6 \mathrm{mim}][\mathrm{BF} 4]+3-\mathrm{Amino}-1-$ propanol $\}$ and $\{\mathrm{C} 6 \mathrm{mim}\}[\mathrm{BF} 4]+$ Isobutanol\}: Application of Prigogine-Flory-Patterson Theory. J. Chem. Thermodyn. 2012, 48, 129-139.

(274) Harris, K. R.; Kanakubo, M.; Woolf, L. A. Temperature and Pressure Dependence of the Viscosity of the Ionic Liquids 1-Methyl-3-octylimidazolium Hexafluorophosphate and 1-Methyl-3-octylimidazolium Tetrafluoroborate. J. Chem. Eng. Data 2006, 51, $1161-1167$.

(275) Wang, J. J.; Zhu, A. L.; Zhao, Y.; Zhuo, K. L. Excess Molar Volumes and Excess Logarithm Viscosities for Binary Mixtures of the Ionic Liquid 1-Butyl-3-methylimidazolium Hexaflurophosphate with Some Organic Compounds. J. Sol. Chem. 2005, 34, 585-590.

(276) Ahosseini, A.; Scurto, A. M. Viscosity of Imidazolium-Based Ionic Liquids at Elevated Pressures: Cation and Anion Effects. Int. J. Thermophys. 2008, 29, 1222-1243. 
(277) Reis, J. C. R.; Blandamer, M. J.; Davis, M. I.; Douhéret, G. The Concept of Non-Gibbsian and Non-Lewisian Properties in Chemical Thermodynamics. Chem. Phys. Chem. 2001, 3, 1465-1470.

(278) Douhéret, G.; Davis, M. I.; Reis, J. C. R.; Blandamer, M. J. Isentropic Compressibilities-Experimental Origin and the Quest for their Rigorous Estimation in Thermodynamically Ideal Liquid Mixtures. Chem. Phys. Chem. 2001, 2, 148-161.

(279) Wagner, W.; Kleinrahm, R.; Losch, H. W.; Watson, J. T. R.; Majer, V.; Pádua, A. A. H.; Woolf, L.; Holste, J. C.; De Figueiredo Palavra, A. M.; Fujii, K.; Stansfeld, J. W. Experimental Thermodynamics, Vol. VI : Measurement of the Thermodynamic Properties of Single Phases, Goodwin, A. R. H., Marsh, K. N., Wakeham, W. A., Eds.; IUPAC/ Elsevier: Amsterdam, Chapter 5, 2003, 125-236.

(280) Zhang, S.; Sun. N.; He, X.; Lu, X.; Zhang, X. Physical Properties of Ionic Liquids: Database and Evaluation. J. Phys. Chem. Ref. Data 2006, 35, 1475-1517.

(281) Anton Paar Instruction Manual - Genaration M, Anton Paar GmbH: Graz, Austria, 2014.

(282) Guerrero, H.; García-Mardones, M.; Cea, P.; Lafuente, C.; Bandrés, I. Correlation of the Volumetric Behaviour of Pyridinium-Based Ionic Liquids with Two Different Equations. Thermochim. Acta 2012, 531, 21-27.

(283) Regueira, T.; Lugo, L.; Fernández, J. Influence of the Pressure, Temperature, Cation and Anion on the Volumetric Properties of Ionic Liquids: New Experimental Values for Two Salts. J. Chem. Thermodyn. 2013, 58, 440-448.

(284) Machida, H.; Sato, Y.; Smith Jr., R. L. Pressure-Volume-Temperature (PVT) Measurements of Ionic Liquids ([bmim $\left.{ }^{+}\right]\left[\mathrm{PF}_{6}^{-}\right],\left[\mathrm{bmim}^{+}\right]\left[\mathrm{BF}_{4}^{-}\right],\left[\mathrm{bmim}^{+}\right]\left[\mathrm{OcSO}_{4}^{-}\right]$) and Analysis with the Sanchez-Lacombe Equation of State. Fluid Phase Equilib. 2008, 264, $147-155$. 
(285) Marsh, K. N.; Brennecke, J. F.; Chirico, R. D.; Frenkel, M.; Heintz, A.; Magee, J. W.;

Peters, C. J.; Rebelo, L. P. N.; Seddon, K. R. Thermodynamic and Thermophysical Properties of the Reference Ionic Liquid: 1-Hexyl-3-methylimidazolium Bis[(Trifluoromethyl)Sulfonyl]amide (Including Mixtures) Part 1. Experimental Methods and Results (IUPAC Technical Report). Pure Appl. Chem. 2009, 81, 781-790.

(286) Currás, M. R.; Husson, P.; Pádua, A. A. H.; Costa Gomes, M. F.; García, J. High-Pressure Densities of 2,2,2-Trifluoroethanol + Ionic Liquid Mixtures Useful for Possible Applications in Absorption Cycles. Ind. Eng. Chem. Res. 2014, 53, 10791-10802.

(287) Wojnarowska, Z.; Jarosz, G.; Grzybowski, A.; Pionteck, J.; Jacquemin, J.; Paluch, M. On the scaling behavior of electric conductivity in $\left[\mathrm{C}_{4} \mathrm{mim}\right]\left[\mathrm{NTf}_{2}\right]$. Phys. Chem. Chem. Phys. 2014, 16, 20444-20450

(288) Plechkova, N. V.; Seddon, K. R. Applications of Ionic Liquids in the Chemical Industry. Chem. Soc. Rev. 2008, 37, 123-150.

(289) Han, X.; Armstrong, D. W. Ionic Liquids in Separations. Acc. Chem. Res. 2007, 40, 1079-1086

(290) Hallett, J. P.; Welton, T. Room-Temperature Ionic Liquids: Solvents for Synthesis and Catalysis. 2. Chem. Rev. 2011, 111, 3508-3576.

(291) Fedorov, M. V.; Kornyshev, A. A. Ionic Liquids at Electrified Interfaces. Chem. Rev. 2014, 114, 2978-3036.

(292) Dong, Q.; Muzny, C. D.; Kazakov, A.; Diky, V.; Magee, J. W.; Widegren, J. A.; Chirico, R. D.; Marsh, K. N.; Frenkel, M. ILThermo: A Free-Access Web Database for Thermodynamic Properties of Ionic Liquids. J. Chem. Eng. Data 2007, 52, 1151-1159.

(293) Auerbach, N. Oberflächenspannung und Schallgeschwindigkeit. Experientia 1948, 4, 473-474. 
(294) Ye, C.; Shreeve, J. M. Rapid and Accurate Estimation of Densities of Room-Temperature Ionic Liquids and Salts. J. Phys. Chem. A 2007, 111, 1456-1461.

(295) Gardas, R.; Coutinho, J. A. P. Extension of the Ye and Shreeve Group Contribution Method for Density Estimation of Ionic Liquids in a Wide Range of Temperatures and Pressures. Fluid Phase Equilib. 2008, 263, 26-32.

(296) Gardas, R.; Coutinho, J. A. P. Applying a QSPR Correlation to the Prediction of Surface Tensions of Ionic Liquids. Fluid Phase Equilib. 2008, 265, 57-65.

(297) Knotts, T. A.; Wilding, W. V.; Oscarson, J. L.; Rowley, R. L. Use of the DIPPR Database for Development of QSPR Correlations: Surface Tension. J. Chem. Eng. Data 2001, 46, $1007-1012$.

(298) Ma, X.-X.; Wei, J.; Guan, W.; Pan, Y.; Zheng, L.; Wu, Y.; Yang, J.-Z. Ionic Parachor and its Application to Pyridinium-Based Ionic Liquids of $\left\{\left[C_{n} p y\right][D C A](n=2,3,4,5\right.$, 6)\}. J. Chem. Thermodyn. 2015, 89, 51-59.

(299) Jacquemin, J.; Ge, R.; Nancarrow, P.; Rooney, D. W.; Costa Gomes, M. F.; Pádua, A. A. H.; Hardacre, C. Prediction of Ionic Liquid Properties. I. Volumetric Properties as a Function of Temperature at 0.1 MPa. J. Chem. Eng. Data 2008, 53, 716-726.

(300) Jacquemin, J.; Nancarrow, P.; Rooney, D. W.; Costa Gomes, M. F.; Husson, P.; Majer, V.; Pádua, A. A. H.; Hardacre, C. Prediction of Ionic Liquid Properties. II. Volumetric Properties as a Function of Temperature and Pressure. J. Chem. Eng. Data 2008, 53, 2133-2143.

(301) Valderrama, J. O.; Reátegui, A.; Rojas, R. E. Density of Ionic Liquids Using Group Contribution and Artificial Neural Networks. Ind. Eng. Chem. Res. 2009, 48, 3254-3259.

(302) Lazzús, J. A. A Group Contribution Method to Predict $\rho-T-P$ of Ionic Liquids. Chem. Eng. Commun. 2010, 197, 974-1015. 
(303) Qiao, Y.; Ma, Y.; Huo, Y.; Ma, P.; Xia, S. A Group Contribution Method to Estimate the Densities of Ionic Liquids. J. Chem. Thermodyn. 2010, 42, 852-855.

(304) Shen, C.; Li, C.-X.; Li, X.-M.; Lu, Y.-Z.; Muhammad, Y. Estimation of Densities of Ionic Liquids Using Patel-Teja Equation of State and Critical Properties Determined from Group Contribution Method. Chem. Eng. Sci. 2011, 66, 2690-2698.

(305) Xiong, Y.; Ding, J.; Yu, D.; Peng, C.; Liu, H.; Hu, Y. Volumetric Connectivity Index: A New Approach for Estimation of Density of Ionic Liquids. Ind. Eng. Chem. Res. 2011, $50,14155-14161$.

(306) Paduszyński, K.; Domańska, U. A New Group Contribution Method for Prediction of Density of Pure Ionic Liquids over a Wide Range of Temperature and Pressure. Ind. Eng. Chem. Res. 2012, 51, 591-604.

(307) Evangelista, N. S.; Do Carmo, F. R.; De Santiago-Aguiar, R. S.; De Sant'Ana, H. B. Development of a New Group Contribution Method Based on GCVOL Model for the Estimation of Pure Ionic Liquid Density Over a Wide Range of Temperature and Pressure. Ind. Eng. Chem. Res. 2014, 53, 9506-9512.

(308) Mozaffari, F. Volumetric Properties of Imidazolium-Based Ionic Liquids Using Song and Mason Equation of State. J. Mol. Liq. 2015, 209, 657-661.

(309) Joback, K. G.; Reid, R. C. Estimation of Pure-Component Properties from Group-Contributions. Chem. Eng. Commun. 1987, 57, 233-243.

(310) Valderrama, J. O.; Forero, L. A.; Rojas, R. E. Critical Properties and Normal Boiling Temperature of Ionic Liquids. Update and a New Consistency Test. Ind. Eng. Chem. Res. 2012, 51, 7838-7844. 
(311) Esperança, J. M. S. S.; Guedes, H. J. R.; Blesic, M.; Rebelo, L. P. N. Densities and Derived Thermodynamic Properties of Ionic Liquids. 3. Phosphonium-Based Ionic Liquids Over an Extended Pressure Range. J. Chem. Eng. Data 2006, 51, 237-242.

(312) Shen, G.; Held, C.; Lu, X.; Ji, X. Modeling Thermodynamic Derivative Properties of Ionic Liquids with ePC-SAFT. Fluid Phase Equilib. 2015, 405, 73-82.

(313) Aparicio, S.; Atilhan, M.; Karadas, F. Thermophysical Properties of Pure Ionic Liquids: Reviev of Present Situation. Ind. Eng. Chem. Res. 2010, 49, 9580-9595.

(314) Daridon, J. L.; Lagourette, B.; Grolier, J.-P. E. Experimental Measurements of the Speed of Sound in n-Hexane from 293 to $373 \mathrm{~K}$ and up to $150 \mathrm{MPa}$. Int. J. Thermophys. 1998, $19,145-160$.

(315) Goodwin, A. R. H.; Marsh, K. N.; Wakeham, W. A. Measurement of the Thermodynamic Properties of Single Phase. In Experimental Thermodynamics; Volume VI, Elsevier: Amsterdam, 2003.

(316) Weyershausen, B.; Lehmann, K. Industrial application of ionic liquids as performance additives. Green Chem. 2005, 7, 15-19.

(317) Weyershausen, B.; Hell, K.; Hesse, U. Industrial application of ionic liquids as process aid. Green Chem. 2005, 7, 283-287.

(318) Handy, S. Applications of Ionic Liquids in Science and Technology, InTech: Rijeka, 2011.

(319) Visser, A. E.; Bridges, N. J.; Rogers, R. D. Ionic Liquids: Science and Applications, ACS Symposium Series, Volume 1117, Oxford University Press: Washington, 2012.

(320) Kadokawa, J. Ionic Liquids - New Aspects for the Future, InTech: Rijeka, 2013.

(321) Seddon, K. R.; Plechkova, N. V. Ionic Liquids UnCOILed: Critical Expert Overviews, John Wiley \& Sons: Hoboken, New Jersey, 2013. 
(322) Plechkova, N. V.; Seddon, K. R. Ionic Liquids further UnCOILed: Critical Expert Overviews, John Wiley \& Sons: Hoboken, New Jersey, 2014.

(323) Fang, Z.; Smith, Jr., R. L.; Qi, X. Production of Biofuels and Chemicals with Ionic Liquids, Springer: Netherlands, 2014.

(324) Mecerreyes, D. Applications of Ionic Liquids in Polymer Science and Technology, Springer-Verlag: Berlin, Heidelberg, 2015.

(325) Kambic, M.; Kalb, R.; Tasner, T.; Lovrec, D. High Bulk Modulus of Ionic Liquid and Effects on Performance of Hydraulic System. Sci. World J. 2014, 504762.

(326) Predel, T.; Schlücker, E.; Wasserscheid, P.; Gerhard, D.; Arlt, W. Ionic Liquids as Operating Fluids in High Pressure Applications. Chem. Eng. Technol. 2007, 30, $1475-1480$.

(327) Schlücker, E.; Szarvas, L.; Uerdingen, E. New Developments in Pumps and Compressors Using Ionic Liquids. Achema Worldwide News 2008, 1, 5-7.

(328) Linde Reports on Science and Technology, Linde AG: Wiesbaden, January 2006.

(329) Predel, T.; Schlücker, E. Ionic liquids in Oxygen Compression. Chem. Eng. Technol. 2009, 32, 1183-1188.

(330) Dzida, M.; Zorębski, E.; Chorążewski, M.; Heintz, A. Compressibility of Ionic Liquids as a Hydraulic Fluids. Przem. Chem. 2013, 92, 1595-1597 (in Polish).

(331) Regueira, T.; Lugo, L.; Fernández, J. Ionic Liquids as Hydraulic Fluids: Comparison of Several Properties with those of Conventional Oils. Lubr. Sci. 2014, 26, 488-499.

(332) Jacquemin, J.; Feder-Kubis, J.; Zorębski, M.; Grzybowska, K.; Chorążewski, M.; Hensel-Bielówka, S.; Zorębski, E.; Paluch, M.; Dzida, M. Structure and Thermal Properties of Salicylate-Based Protic Ionic Liquids as New Heat Storage Media. 
COSMO-RS Structure Characterization and Modeling of Heat Capacities. Phys. Chem. Chem. Phys. 2014, 16, 3549-3557.

(333) França, J. M. P.; Nieto de Castro, C. A. ; Lopes, M. M. ; Nunes, V. M. B. Influence of Thermophysical Properties of Ionic Liquids in Chemical Process Design. J. Chem. Eng. Data 2009, 54, 2569-2575.

(334) Zhou, F.; Liang, Y.; Liu, W. Ionic Liquid Lubricants: Designed Chemistry for Engineering Appliactions. Chem. Soc. Rev. 2009, 38, 2590-2599.

(335) Kumar, P.; Anuradha, P.; Khonsari, M. M. Some Important Aspects of Thermal Elastohydrodynamic Lubrication. P. I. Mech. Eng. C- J. Mec. 2010, 224, 2588-2598.

(336) Pensado, A. S.; Pádua, A. A. H.; Comuñas, M. J. P.; Fernández, J. Relationship Between Viscosity Coefficients and Volumetric Properties Using a Scaling Concept for Molecular and Ionic Liquids. J. Phys. Chem. B 2008, 112, 5563-5574.

(337) Werner, S.; Haumann, M.; Wasserscheid, P. Ionic Liquids in Chemical Engineering. Annu. Rev. Chem. Biomol. Eng. 2010, 1, 203-230.

\section{AUTHOR INFORMATION}

Marzena Dzida received her Ph.D. degree in Physical Chemistry from University of Silesia in 2000, Habilitation in Physical and Theoretical Chemistry from University of Wrocław in 2010. Since December 2012 she is a head of Department of Physical Chemistry of University of Silesia in Katowice. She is interested mainly in application of the acoustic methods in determining thermodynamic properties of the liquids, especially ionic liquids and biofuels, under high pressure, description relationships between chemical structure of the liquid state and 
physicochemical properties, development of the apparatuses for the speed of sound measurements.

Edward Zorębski completed his M.Sc. (1983) and Ph.D (1991) in Physical Chemistry at the University of Silesia in Katowice (Poland), where he is currently assistant professor at the Institute of Chemistry. Fellowship of DAAD in years 1991-1992 at the University of Karlsruhe, now Karlsruher Institute of Technology (Germany). Habilitation (2014) in Physical Chemistry at the University of Wrocław (Poland). His research focuses on: physicochemical properties of the associating molecular liquids and ionic liquids as well as development of the apparatuses for the speed of sound and ultrasound absorption measurements. He has published over 55 per-reviewed journal articles.

Michał Zorębski (born in 1960) is an engineer with extensive experience in a field of molecular acoustics and particularly ultrasound measurements in liquids. After having graduated from AGH University of Science and Technology in Cracow with a M.Sc. in electronic systems, he began work from 1986 as a senior technical and research specialist in Institute of Chemistry at Silesian University in Katowice. He constructs and develops measuring sets for determining the structure of liquids by means acoustic methods and is coauthor of a several papers concerning the physicochemical properties of liquids.

Monika Żarska was born in Sosnowiec, Poland, in 1978. She received her M.Sc. degree in chemistry in 2003 from the University of Silesia and started to work in the Department of Physical Chemistry at the same University. In 2002, she studied at the University of Rostock in the Socrates/Erasmus program. She is a member of the Polish Chemical Society. Her research activities include the high pressure physicochemical studies of molecular and ionic liquids. 
Monika Geppert-Rybczyńska received the Ph.D. degree in physical chemistry from University of Silesia in Katowice, Poland, in 2002. Since then, she has been an Adjunct Assistant Professor with Department of Physical Chemistry in her home University. She worked as a post-doctoral researcher in the laboratory of Professor Andreas Heintz at University of Rostock in Germany (2008-2011). She published 18 papers in the field of physicochemical properties of pure ionic liquids and their binary mixtures with molecular solvents. Her research interests currently cover the surface properties of chiral ionic liquids containing natural and/or pharmaceutical components.

Mirosław Chorążewski received his Ph.D. degree in Physical Chemistry (2003) from the University of Silesia, Poland. He is now an adjunct professor in the Institute of Chemistry at the University of Silesia. In 2009 he was postdoctoral research fellow at the E. Hala Laboratory of Thermodynamics Academy of Sciences of the Czech Republic, where he was working under the guidance of Professor Ivan Wichterle. In 2006 and 2009-2011 he was postdoctoral research fellow at the University of Blaise Pascal, France, where he was working on thermodynamic modeling of high-pressure biofuels under the guidance of Professor Jean-Pierre Grolier. He is interested mainly in application of the transitiometry technique and acoustic methods in determining thermodynamic properties of substances under high pressure.

Johan Jacquemin received a Ph.D. in Physical Chemistry from the Blaise Pascal University of Clermont-Ferrand, France in 2006. He is currently senior lecturer in Chemical Engineering at the Queen’s University Belfast, in order to apply his physical chemistry science, and more precisely his knowledge in thermodynamic and in chemical engineering, for the study of novel materials, including electrolytes, solar cell materials, from the determination and the modeling of their fundamental properties through to the development of novel applications. He is interested in 
physical chemistry of pure components and their mixtures with other fluids and in particular on relationships between chemical structure and physical properties. More precisely his research area is focused on the development of original experimental apparatuses and physical models able to predict measured properties.

Ivan Cibulka received the graduation (Ing.) and Ph.D. degree in Physical Chemistry from the Institute of Chemical Technology, Prague in 1973, 1977, respectively. He has held a postdoctoral position at University College, London, Great Britain in 1981, and at Kanazawa University, Japan (1985-1987). In 1997 he worked as a visiting professor at Kanazawa University, Japan. Currently, he is a member of the Editorial Advisory Board of the Journal of Chemical and Engineering Data. His research interests cover experimental study of the state behavior of liquids, particularly mixtures (nonelectrolyte mixtures, aqueous solutions of organic solutes at extreme ranges of temperature and pressure), as well as data compilation, correlations and critical evaluation. 
TOC

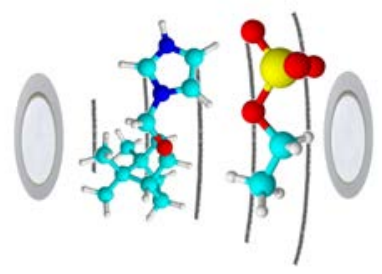

